Award Number: W81XWH-11-1-0376

TITLE: Comprehensive Population-Specific Marker Panel for Early Prostate Cancer Diagnostics and Risk Assessment

PRINCIPAL INVESTIGATOR: Ganna Chornokur

CONTRACTING ORGANIZATION: H. Lee Moffitt Cancer Center \& Research Institute Tampa, FL 33612

REPORT DATE: August 2014

TYPE OF REPORT: Final Annual Summary

PREPARED FOR: U.S. Army Medical Research and Materiel Command Fort Detrick, Maryland 21702-5012

DISTRIBUTION STATEMENT: Approved for Public Release; Distribution Unlimited

The views, opinions and/or findings contained in this report are those of the author(s) and should not be construed as an official Department of the Army position, policy or decision unless so designated by other documentation. 


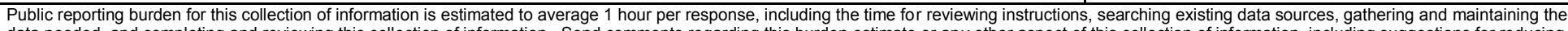

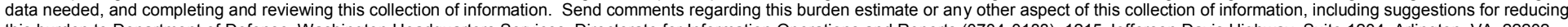

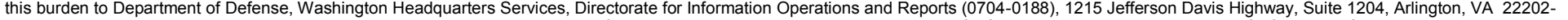

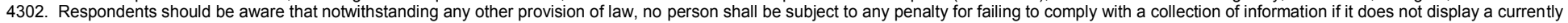
valid OMB control number. PLEASE DO NOT RETURN YOUR FORM TO THE ABOVE ADDRESS.

\begin{tabular}{|l|l|l|}
\hline 1. REPORT DATE & 2. REPORT TYPE & 3. DATES COVERED
\end{tabular}

\begin{tabular}{l}
\multicolumn{1}{c}{ August 2014} \\
4. TITLE AND SUBTITLE \\
Comprehensive Population-Specific Marker Panel for Early Prostate Cancer \\
Diagnostics and Risk Assessment
\end{tabular}

Diagnostics and Risk Assessment

1 June $2011-31$ May 2014

5a. CONTRACT NUMBER

5b. GRANT NUMBER

W81XWH-11-1-0376

5c. PROGRAM ELEMENT NUMBER

5d. PROJECT NUMBER

6. AUTHOR(S)

Ganna Chornokur

email: ganna.chornokur@moffitt.org

7. PERFORMING ORGANIZATION NAME(S) AND ADDRESS(ES)

H. Lee Moffitt Cancer Center \& Research Institute

Tampa, FL 33612

9. SPONSORING / MONITORING AGENCY NAME(S) AND ADDRESS(ES)

10. SPONSOR/MONITOR'S ACRONYM(S)

U.S. Army Medical Research and Materiel Command

Fort Detrick, Maryland 21702-5012

11. SPONSOR/MONITOR'S REPORT

NUMBER(S)

12. DISTRIBUTION / AVAILABILITY STATEMENT

Approved for Public Release; Distribution Unlimited

\section{SUPPLEMENTARY NOTES}

\section{ABSTRACT}

The overall scope of the proposed postdoctoral training project is to provide protected time for the primary investigator ( $\mathrm{PI}$ ) to obtain a comprehensive training in the field of prostate cancer health disparity. Within the scope of this grant, a comprehensive training consists of the two main parts; a training part and a research part. For the training part, PI attended relevant seminars, conferences, classes, and wrote manuscripts and grants. For the research part, we hypothesized that a combination panel (DETECT) of genetic biomechanical, socio-cultural and lifestyle population specific biomarkers and factors will provided a valuable PCa screening and risk assessment tool. The PI genotyped 528 DNA samples obtained from African American and European American men with prostate cancer controls. It was found that two SNPs were statistically significantly associated with prostate cancer risk associated with one of the SNPs in African American men was found in obese men only; if was not seen in either non-obese African American men or European American men regardless of their body mass. The PI has proposed a concept of the increased risk in obese AAM for which the NIH R21 was submitted on $11 / 2012$. The grant was scored in the $30^{\text {th }}$ percentile and will be resubmitted on $07 / 2013$. In addition, the PI has genotyped the samples for the androgen receptor gene CAG repeat length, and found the connection with obesity of African American men. Investigations of these topics are on going

15. SUBJECT TERMS- African American, prostate cancer, risk factors, biomarkers, health disparity, obesity

\begin{tabular}{|c|c|c|c|c|c|}
\hline \multicolumn{3}{|c|}{ 16. SECURITY CLASSIFICATION OF: } & \multirow{2}{*}{$\begin{array}{c}\text { 17. LIMITATION } \\
\text { OF ABSTRACT } \\
\text { UU }\end{array}$} & \multirow{2}{*}{$\begin{array}{l}\text { 18. NUMBER } \\
\text { OF PAGES } \\
164\end{array}$} & \multirow{2}{*}{$\begin{array}{l}\text { 19a. NAME OF RESPONSIBLE PERSON } \\
\text { USAMRMC } \\
\text { 19b. TELEPHONE NUMBER (include area } \\
\text { code) }\end{array}$} \\
\hline $\begin{array}{r}\text { a. REPORT } \\
U\end{array}$ & $\begin{array}{c}\text { b. ABSTRACT } \\
U\end{array}$ & $\begin{array}{c}\text { c. THIS PAGE } \\
U\end{array}$ & & & \\
\hline
\end{tabular}


Table of Contents

Page

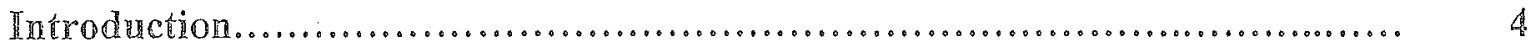

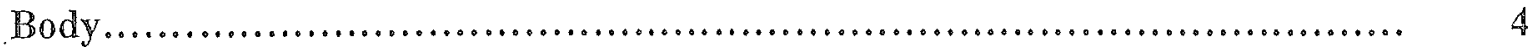

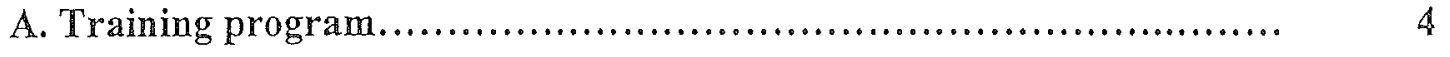

B. Research project................................................. 10

Key Research Accomplishments........................................... 21

Reportable Outcomes.................................................... 22

Conclusions................................................................ 24

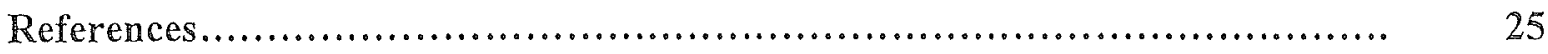

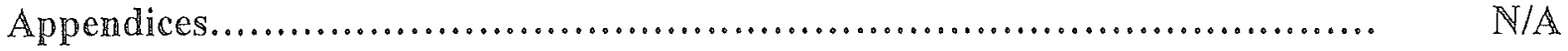




\section{Introduction}

The overall scope of the proposed 2-year postdoctoral training project (plus a year of a no-cost extension $[\mathrm{NCE}]$ ) is to provide protected time for the Primary Investigator (PI) to obtain a comprehensive training in the field of prostate cancer health disparity. The PI is a postdoctoral scientist / young investigator whose long-term career goal is to contribute to the resolution of cancer-related health disparities by conducting innovative, highimpact research as an independent investigator with competitive, peer-reviewed funding. PI aims to achieve her long-term career goal through an integrated 2-year research and training program in the comprehensive $H$. Lee Moffitt Cancer Center and Research Institute, with appropriate guidance of an experienced Mentor, Dr. Nagi Kumar, who is a nationally recognized expert in the chemoprevention of cancer and is a leader in health disparities research, and the team of Co-mentors (Drs. Park and Phelan). Within the scope of this grant, a comprehensive training agenda has been proposed; it consists of the two main parts: a training part and a research part (supplemental project). Specific progress on each of those parts is outlined in the body of this annual report. It is resumed with the "Key Research Accomplishments" and "Reportable Outcomes" sections that briefly summarize the main reportable outcomes emanating from this work.

\section{$\mathrm{BODY}$}

A. Training Program. The specific activities of the PY's career development plan are provided below.

1. Structured mentoring program coordinated by PUprimary mentor and co-mentor(s).

For the duration of this award (years 1,2 and no-cost extension [NCE]), Dr. Chornokur has been maintaining weekly and/or bi-weekly one hour meetings with her primary mentor, Dr. Nagi Kumar, and co-mentors, Drs. Catherine Phelan and Jong Park.

2. Gain proficiency and a better understanding of science used to develop and implement primary prevention intervention in minority populations.

- During the years 1,2 and NCE of award, this task is being accomplished by: 1. regular meetings with the Mentoring team as described above; 2. conducting extensive bi-annual literature searches on the topics of chemoprevention of prostate cancer, prostate cancer racial health disparity, and other relevant literature (community outreach programs, for example); 3. being involved in the relevant research projects at the Moffitt Cancer Center (please see Table 1); 4 . attending the relevant talks, ground rounds and seminars at Moffitt and USF (please see task 7); and 5. extensive networking (please see task 9). This comprehensive systematic approach has allowed Dr Chomokur to develop and submit three peer-reviewed grants (please see the task 6) and publish 6 peer-reviewed manuscripts with additional one currently undergoing peer-review (please see the task 8 ), and one being in preparation.

3. Gain hands-on research experience in the implementation and conduct of research studies.

These activities has been going on during both the years 1,2 and NCE of award.

- Under the mentorship of Dr Phelan, the PI is currently involved in the three NIH and DoD funded projects (aside from her own research study): 1. PC050873 (Phelan PI): Prostate Cancer in African-American Men: Serum Biomarkers for Early Detection Using Nanoparticles; 2. 1R01 CA149429-01 (Phelan PI): The Mitochondrial Genome and Ovarian Cancer Risk; and 3. 5 U19 CA148112-02 (Sellers PI): Follow-up of Ovarian Cancer Genetic Association and Interaction Studies (FOCI). The PI is also involved in the following NHA funded clinical trial under the mentorship of Dr. Kumar: R01 CA12060-01A1 (Kumar PI): Phase II, Randomized, Double-blind, Multi-centered Study of Polyphenon E in Men with High-grade Prostatic Intraepithelial Neoplasia (HGPIN) and Atypical Small Acinar Proliferation (ASAP). The summary of these projects, along with specific PI's activities, are shown in the Table 1.

Table 1. Research projects that the PI is currently involved with through her Mentors. 


\begin{tabular}{|c|c|c|}
\hline Project & $\begin{array}{l}\text { Primary hypothesis, } \\
\text { goals and/or objectives }\end{array}$ & PI's involvement, tasks etc \\
\hline $\begin{array}{l}\text { PC050873 Prostate } \\
\text { Cancer in African- } \\
\text { American Men: } \\
\text { Serum Biomarkers } \\
\text { for Early Detection } \\
\text { Using Nanoparticles }\end{array}$ & 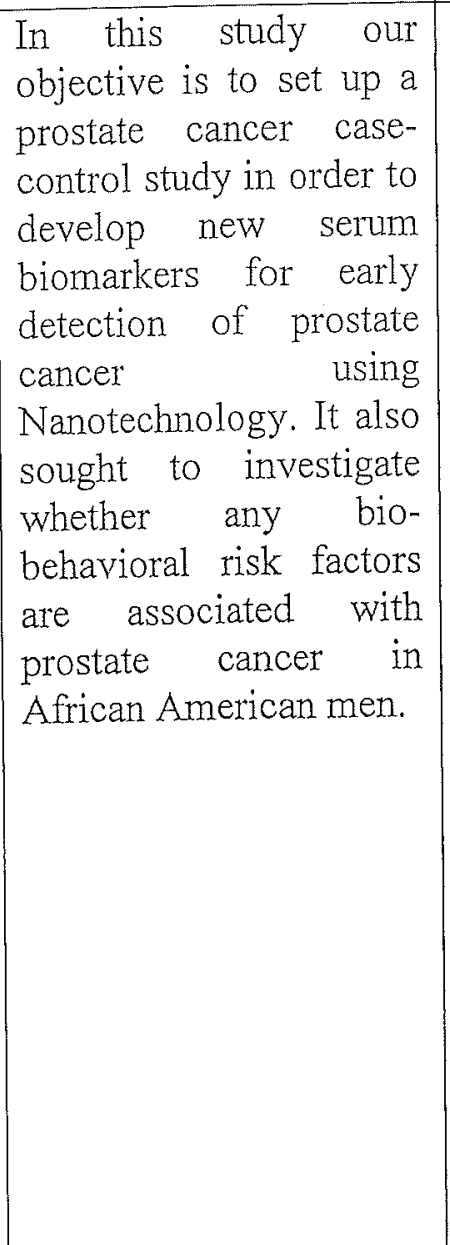 & $\begin{array}{l}\text { The PI was involved in this study while doing her PhD work } \\
\text { in Biomedical Engineering at the University of South } \\
\text { Florida. The study is now closed for accrual, however, the } \\
\text { data analysis and research dissemination continue. } \\
\text { Specifically, under the mentorship of Dr Phelan, the PI } \\
\text { collaborated with a statistician to investigated known bio- } \\
\text { behavioral risk factors of prostate cancer, along with PSA } \\
\text { levels, and risk of prostate cancer in African American / } \\
\text { Black men. This work has generated intriguing pilot results } \\
\text { that were presented by the PI as a poster at several relevant } \\
\text { high-impact scientific meetings. The PI has also prepared a } \\
\text { manuscript entitled "Risk Factors for Prostate Cancer in } \\
\text { African American Men" that is now undergoing final } \\
\text { revisions. This project, that is highly relevant to the PIs } \\
\text { training and her own research work, provides plethora of } \\
\text { vital skills needed to conduct an interdisciplinary health } \\
\text { disparity research in prostate cancer. The latter includes } \\
\text { review and understanding of the most up-to-date literature in } \\
\text { the field, skills necessary to perform epidemiological and } \\
\text { statistical analyses, and - the most importantly - } \\
\text { understanding and interpretation of the findings. These skills } \\
\text { will lay the foundation for the PI to start developing her own } \\
\text { intervention and independent research in prostate cancer } \\
\text { health disparity in the year } 2 \text { (as outlined in the task } 5 \text { of this } \\
\text { award). }\end{array}$ \\
\hline $\begin{array}{l}\text { 1R01 CA149429-01 } \\
\text { The Mitochondrial } \\
\text { Genome r and } \\
\text { Ovarian } \\
\text { Risk }\end{array}$ & $\begin{array}{l}\text { It was hypothesized that } \\
\text { that inherited variation } \\
\text { in mitochondrial-related } \\
\text { genes is associated with } \\
\text { ovarian cancer risk. The } \\
\text { objective is to more } \\
\text { comprehensively } \\
\text { investigater the } \\
\text { contribution of } \\
\text { mitochondrial genome } \\
\text { variation to ovarian } \\
\text { cancer risk. }\end{array}$ & $\begin{array}{l}\text { In this award, the PI is actively involved in the pathways and } \\
\text { genes/SNPs selection, as well as analysis interpretation and } \\
\text { dissemination. This includes extensive literature search on } \\
\text { the topic, review of the molecular and biochemical } \\
\text { mechanisms that may play a role in the development of } \\
\text { ovarian cancer, and understanding the statistical analyses } \\
\text { involved in the data management. Importantly, the PI is } \\
\text { exposed to the opportunities and challenges of the } \\
\text { multicenter, multi-institution, collaborative work that } \\
\text { involves extraordinary big sample size. These experiences } \\
\text { are vital for an independent health disparity researcher. In } \\
\text { addition, the PI obtains basic understanding of ovarian } \\
\text { cancer research through this project. While not explicitly } \\
\text { health disparity related, this project may serve as a } \\
\text { foundation for the PI's own future work in ovarian cancer } \\
\text { health disparity. }\end{array}$ \\
\hline $\begin{array}{l}5 \text { U19 CA148112- } \\
\text { 02 Follow-up of } \\
\text { Ovarian Cancer } \\
\text { Genetic Association } \\
\text { and Interaction }\end{array}$ & $\begin{array}{l}\text { Specific aims of this } \\
\text { project } \\
\text { evaluating the role of } \\
\text { candidate genes at } \\
\text { susceptibility loci in }\end{array}$ & $\begin{array}{l}\text { PI's involvement into this multicenter, multi-institution high- } \\
\text { impact study is similar to the one described above } \\
\text { (CA149429-01). However, it allows for an even broader } \\
\text { understanding of all ovarian cancer research, mitochondria } \\
\text { related or not. PI attends the regular monthly-scheduled }\end{array}$ \\
\hline
\end{tabular}




\begin{tabular}{|c|c|c|}
\hline Studies (FOCI) & $\begin{array}{l}\text { ovarian cancer; } \\
\text { determining the } \\
\text { functional significance } \\
\text { of top candidate SNPS; } \\
\text { and performing detailed } \\
\text { functional } \\
\text { characterization } \\
\text { candidate genes and } \\
\text { SNPs. }\end{array}$ & $\begin{array}{l}\text { conference calls where the findings, challenges, manuscripts } \\
\text { and cofrenence presentations, future funding opportunities } \\
\text { and current progress are being systematically discussed. } \\
\text { Similarly to CA149429-01, this work is not disparity-related, } \\
\text { however, it exposes the PI to a unique research experience } \\
\text { that is vital to a transdisciplinary health disparity researcher } \\
\text { and would have been hard to impossible to obtain elsewhere. }\end{array}$ \\
\hline $\begin{array}{l}\text { R01 CA12060- } \\
\text { 01A1 Phase II, } \\
\text { Randomized, } \\
\text { Double-blind, } \\
\text { Multi-centered } \\
\text { Study } \\
\text { Polyphenon E in } \\
\text { Men with High- } \\
\text { grade Prostatic } \\
\text { Intraepithelial } \\
\text { Neoplasia (HGPIN) } \\
\text { and Atypical Small } \\
\text { Acinar Proliferation } \\
\text { (ASAP) }\end{array}$ & $\begin{array}{l}\text { Men with HGPIN who } \\
\text { receive Polyphenon E } \\
\text { containing } 400 \mathrm{mg} \text { of } \\
\text { EGCG per day for } 12 \\
\text { months } \\
\text { significantly decrease } \\
\text { progression to CaP } \\
\text { compared with men } \\
\text { with HGPIN who take } \\
\text { placebo. }\end{array}$ & $\begin{array}{l}\text { PI attends the monthly research meetings where specific } \\
\text { research-related progress is being discussed. PI is aware of } \\
\text { the recruitment challenges and is involved in the } \\
\text { interventions aimed at increasing the recruitment rates. In } \\
\text { addition, the PI will shadow the project coordinator when } \\
\text { she recruits and/or follows up new or existing patients. The } \\
\text { PI is using this trial as an opportunity to learn how to } \\
\text { conceive and implement a chemopreventive intervention in } \\
\text { prostate cancer. }\end{array}$ \\
\hline
\end{tabular}

4. Initiate and complete a research supplement project.

- The Institutional Review Board (IRB) and Scientific Review Committee (SRC) approvals have been obtained by the PI. The copies of both approvals are attached in the appendices 1 and 2, respectively. At the end of year \#1, specific aim 1 has been completed. At the end of year \#2, specific aims 2 and 3 have been partially completed. During the NCE, data analysis continued, resulting in the submission and subsequent award of the competitive R21 proposal (Chomokur PI).

5. To develop interventions and independent research questions based on the results from research study completed.

- Based on the data obtained within the scope of this training grant, we hypothesized that select genetic variation, when combined with the environment of obesity, influences PCa risk by impacting key cellular processes relevant to the tumor biology. In the year 2 of this award, the PI, with the guidance of her Mentors, has developed a methodological pilot high-risk high-gain project to test that hypothesis. During the NCE, the PI successfully competed for the NIH R21 project, entitled "Obesity and prostate cancer risk in Black and White men: a functional approach."

6. Gain extensive grant writing experience.

- As a part of her grant writing training, the PI has attended an NIH-organized grant writing workshop that was held during the annual AACR meeting (May 31, 2012, Chicago IL). She has also attended several scientific writing/grant writing seminars (please see task 7 , items $B, J, K, L$ ).

- During the year 1, PI has submitted the following two extramural peer-reviewed research grants: an NIH R03 on 02/2012 (1R03CA172753-01: Comparative race-specific chemopreventive effects of curcumin in prostate cancer), and a DoD hypothesis development award on 06/2012 (PC120156: Comparative race-specific chemopreventive effects of curcumin in prostate cancer). Specific aims page for the aforementioned grants is 
shown in the appendix 3. Although those grants were not funded, they nonetheless provided useful grant writing experience.

- During the year 2, PI has submitted an NIH R21 grant on 11/2012 in response to PAR12-094 (1R21CA179659-01: Obesity and prostate cancer risk in Black and White men: a functional approach). The proposal was scored in the $30^{\text {th }}$ percentile with the priority score of 3.9 . The PI is currently preparing a resubmission due 07/16//2013. Specific aims page for the aforementioned grant, as well as the summary statement, are shown in the appendix 4.

- During the NCE, the R21 project (Appendix 17) has been awarded, approvals obtained and the work is about to start.

\section{To attend research and educational meetings.}

- PI is an associate member at the American Association for Cancer Research (AACR).

- During the year 1, PI has attended (and presented her work, where indicated) at the following relevant research and educational meetings.

1. Joining FORCEs Against Hereditary Cancer Conference (June 2011, Orlando FL). The poster presentation entitled "Risk of Gastrointestinal Cancers in Female BRCA1 and BRCA2 Mutation Carriers".

2. Center for Equal Health Strategic Planning Retreat Meeting (September 2011).

3. Annual AACR meeting (March-April 2012, Chicago IL). The poster presentation entitled "The Risk Factors for Prostate Cancer in African American Men".

4. The First Florida Prostate Cancer Research Symposium (May 4-5 2012, Orlando FL). The poster presentation entitled "The Risk Factors for Prostate Cancer in African American Men".

5. Moffitt's 2012 Scientific Symposium (May 10 2012, Tampa FL). The poster presentation entitled "The Risk Factors for Prostate Cancer in African American Men".

During the year 2, PI has attended (and presented her work, where indicated) at the following relevant research and educational meetings.

6. The Second Florida Prostate Cancer Research Symposium (March 2013, Orlando FL). The poster presentation entitled "Androgen Receptor CAG Repeat Length and Association with Prostate Cancer Risk in Obese and Non-Obese African American men".

7. AACR Annual Meeting $(04,2013)$ : Variation in transmembrane transport genes influence epithelial ovarian cancer risk and histopathologic subtype (poster presentation). Authors: Chornokur G; Tyrer J; Lin H-Y; Han G; Qu X; Chen Z; Tsai Y-Y; Goode EL; Cunningham JM; Iversen E; Ramus S; Berchuck A; Schildkraut JM; Monteiro A; Gayther S; Narod SA; Pharoah P; Sellers TA; Phelan CM.

8. NIH "2012 Science of Eliminating Health Disparities Summit" (12, 2012): Polymorphisms in the metabolism related genes and obesity may explain prostate cancer disparity in African American men (poster presentation). Authors: Chornokur G; Amankwah EK; Park JY; Phelan CM; Kumar NB.

9. AACR "The Science of Health Disparities" Conference (10, 2012): Polymorphisms in the metabolism related genes and obesity may explain prostate cancer disparity in African American men (poster presentation). Authors: Chornokur G; Amankwah EK; Park JY; Phelan CM; Kumar NB.

The PI has received a competitive Scholar-in-training Award to cover the travel/attendance cost for this meeting.

PI is also attending relevant scientific talks, ground rounds and seminars that occur at Moffitt and/or USF. Select, the most relevant presentations are showin below.

A. Why Culture Matter in. Eliminating Health Disparities, Collins Airhihenbuwa, PhD, June 3, 2011.

B. American Cancer Society-Funding Opportunities for Research and Training. Charles L. Saxe, PhD. Moffitt

Cancer Center. August 1, 2011.

C. Fishers of Med: Evaluating a Digital Training Curriculum, Brian Rivers, PhD, MPH. August 31, 2011. 
D. The Skin You're In: Making Progress in Eliminating Health Inequalities, Thomas LaVeist, PhD. November 4, 2011.

E. Medically Underserved Areas and Patient Navigation, Elizabeth Calhoun, Med, PhD. January 19, 2012.

F. A Biocultural Approach to Racial Disparities in Health: Genetics, Epigenetics, and the Biological

Embedding of Psychosocial Stress, Amy Non, PhD. Candidate for Faculty Position in Biological Anthropology

Seminar. January 23, 2012.

G. Minority Enrollment in Clinical Trials: Challenges and Best Practices, Mona N. Fouad, MD, MPH. February 13, 2012.

H. Participatory Research and Evaluation: Case for Building Practice-Based Evidence, Joseph Telfair, DrPH, MSW, MPH. Center for Equal Health External Advisory Board Meeting, February 16, 2012.

I. Planning and Implementing Lay Health Worker Interventions for Cancer Control: a Systematic Process to Increase Program Outcomes, Maria Fernandez, PhD. March 9, 2012.

J. Elements of Basic Science Grant Writing: A physician-scientist View, Eduardo Sotomayor, MD. MPDA Grant Writing Seminar. January 12, 2012.

K. Manuscript writing workshop: The Introduction, Methods, Results, and Discussion (IMRaD) Format, Jane

D. Carver, PhD, MS, MPH. MPDA Career Development Seminar. February 21, 2012.

L. Enhancing Your Success as a Published Author, Jane D. Carver, PhD, MS, MPH. Cancer Epidemiology

Career Development Seminar. March 21, 2012.

M. Socioeconomic Status and Tobacco Related Disparities. David Wetter, PhD, MS. May 11, 2012

N. Ethical Cancer Research \& Uninformed Consent: The Henrietta Lacks Story. Organized by Moffitt

Diversity Department. May 23, 2012.

O. Past Experiences - Lessons Learned (SELECT, CARET, Retinoids vs. Statins, COX-2 inhibitors): What Went Wrong? Where Do We Go From Here? Ernest Hawk, MD, PhD. May 29, 2012.

Additionally, as required by her work, the PI maintains the Human Subjects (certification updated on 04/2012), Biosafety (04/2012) and Mandatory Moffitt education (05/2012) tests and trainings up to date.

\section{Scientific writing and research dissemination.}

- The following peer-reviewed research articles have been published or accepted for publication during the year 1 of this award (06/2011-06/2012):

1. Shahnjayla Connors, Ganna Chornokur, Nagi Kumar. New Insights to the Mechanisms of Green Tea Catechins in the Chemoprevention of Prostate Cancer. Nutrition and cancer. 11/2011; 64(1):4-22; PMID: 22098273

2. Kumar NB, Crocker, T, Smith T, Pow-Sang, J, Spiess, PE, Connors, SK, Chornokur, G, Iravani Dickinson, S, Williams, CR, Salup, R, Bai, W. Prostate Cancer Chemoprevention targeting High Risk Populations: Model for trial design and outcome measures. J Cancer Sci Ther. 2012; PMID: 22422102

3. T.G. Kryshtab L.V. Borkovska O. Kolomys N.O. Korsunska V.V. Strelchuk, L.P. Germash, K.Yu. Pechers'ka, G. Chornokur, S.S. Ostapenko, C.M. Phelan, O.L. Stroyuk. The effect of bio-conjugation on aging of the photoluminescence in CdSeTe-ZnS core-shell quantum dots. Superlattices and Microstructures 51(3) 2012, 353-62

4. Manju Venugopal, Sunil K. Arya, Ganna Chornokur, Shekhar Bhansali. A Realtime and Continuous Assessment of Cortisol in ISF Using Electrochemical Impedance Spectroscopy // Sens Actuators A Phys. 2011 1;172(1):154-160. PMID: 22163154

- The following peer-reviewed research articles have been published or accepted for publication during the year 2 of this award (07/2012-06/2013):

5. Chornokur G., Kumar NB. Prostate cancer chemoprevention in men of African descent: current state of the art and opportunities for future research. Cancer Causes and Control 2013 [in press]. DOI: 10.1007/s10552-013-0241-x. PMID: 23737026 
6. Kumar N, Chornokur G (2012) Molecular Targeted Therapies Using Botanicals for Prostate Cancer Chemoprevention. Transl Med S2: 005. doi:10.4172/2161-1025.S2-005

7. Chornokur G; Han G; Tanner R; Lin H-Y; Green LB, Pow-Sang J; Phelan CM. High Grade Prostate Intraepithelial Neoplasia (PIN) is a PSA-independent risk factor for prostate cancer in African American men: results from a pilot study. Cancer Letters 331(2): 154-7, 2013. PMID: 23268329

8. Chornokur G, Amankwah EK, Schildkraut JM, Phelan CM. Global ovarian cancer health disparities. Gyn Oncol 121(1): 358-64, 2013. PMID: 23266352

- The following research articles are currently being peer-reviewed:

9. Chornokur G, Amankwah EK, Davis SN, Phelan CM, Park JY, Pow-Sang J, Kumar NB. Variation in $H N F 1 B$ and obesity may influence prostate cancer risk in African American men: a pilot study. Submitted to "Cancer Prevention research", 06/2013. [included in the appendix 10]

10. Phelan CM, Iqbal J, Lubinski J, Ragone A, Cybulski C, Lynch HT, Moller P, Ghadirian P, Foulkes WD, Armel S, Neuhausen SL, Senter L, Singer CF, Kim-Sing C, Tung N, Llacuachaqui M, Chornokur G, Ping S, Narod SA and the Hereditary Breast Cancer Study Group. Incidence of colorectal cancer in BRCA1 and BRCA2 mutation carriers: Results from a follow-up study. Submitted to Br. J. Cancer, 05/2013. [included in the appendix 11]

- The following research article was accepted with minor revisions to the PLOS One during the NCE:

10. Chornokur G, Phelan CM et al on behalf of OCAC. Cellular Transport Gene Variants Are Associated With Susceptibility to Epithelial Ovarian Cancer Risk and Histopathologic Subtypes. [included in the appendix 12]

Please see the section 7 for the list of attended meetings and poster presentations.

\section{Interactions with established scientists, networking, and peer linkages.}

During the years 1,2 and NCE of award, this training activity is being achieved through: 1 . working with collaborators (inside and outside of the mentoring team) to write joint grant submissions; 2 . contributing to manuscripts written by other scientists; 3 . networking and learning from peers and colleagues at the research meetings; 4 . participating in the USF/Moffitt Center for Equal Health; and $\mathbf{5}$. attending the "networking with experts" lunches that follow bi-monthly ground rounds at Moffitt.

10. Additionally, as requested by the peer-review committee, Dr. Chornokur has audited the "Cancer epidemiology" course at USF that was taught by two Moffitt Cancer Epidemiology Assistant Members. She has also completed the 5-weeks "Biostatistics 101" course (certificate awarded), designed and taught by the Moffitt Biostatistical core (both courses during the year 1 of award). During the year 2 of award, she has audited the "Cancer genetics" course (Spring 2013) taught by Dr. Alvaro Monteiro who is a Senior Member at Moffitt, as well as other Moffitt faculty.

11. Deliverables and Evaluation. PI will be evaluated annually by Mentor, co-Mentor and other faculty. Annual evaluations will assist the Mentor in refining this training program.

Successful annual evaluation is a part of this training grant, as well as a requirement a Moffitt Cancer Center sets for every postdoctoral scientist. This extensive evaluation process includes a rating of the postdoc's behavioral criteria (teamwork, responsibility, adaptability etc), as well as professional accomplishments and progress within the past year. It also includes an outline of the major professional 
goals and career targets set for the next year. These goals are set up by a postdoc herself, and approved (with modifications, if needed) by her Mentor(s). To comply with this requirement, PI was evaluated by the team of her mentors during the year 1 in December-January 2011/2012 (the PI's anniversary date at Moffitt). Based on this evaluation, PI has gotten an overall score of 4.2 out of 5 that corresponds to the "Surpasses" mark on the evaluation scale used. A list of professional goals for the next year was also set and approved. These goals either meet or exceed the goals set up within the scope of this training grant. The copy of a complete evaluation is included in the appendix 13.

In the year 2 , the PI was also evaluated following the same process described above (in DecemberJanuary 2012/2013). Based on this evaluation, PI has gotten an overall score of 4.4 out of 5 that corresponds to the "Surpasses" mark on the evaluation scale used. A list of professional goals for the next year was also set and approved. The copy of a complete evaluation is included in the appendix 14.

Table 2. Career Development Experiences and Timeline (training SOW).

\begin{tabular}{|l|l|l|l|l|l|l|}
\hline Career Development Experiences / Timeline in Months & $\begin{array}{l}\mathbf{1 -} \\
\mathbf{5}-\end{array}$ & $\begin{array}{l}\mathbf{9 -} \\
\mathbf{1 2}\end{array}$ & $\begin{array}{l}\mathbf{1 3 -} \\
\mathbf{1 6}\end{array}$ & $\begin{array}{l}\mathbf{1 7 -} \\
\mathbf{2 0}\end{array}$ & $\begin{array}{l}\mathbf{2 1 -} \\
\mathbf{2 4}\end{array}$ \\
\hline $\begin{array}{l}\text { 1. Structured mentoring program coordinated by the primary mentor through } \\
\text { regularly scheduled weekly one-hour face-to-face meetings }\end{array}$ & $\mathrm{x}$ & $\mathrm{x}$ & $\mathrm{x}$ & $\mathrm{x}$ & $\mathrm{x}$ & $\mathrm{x}$ \\
\hline $\begin{array}{l}\text { 2. Gain an understanding of the scientific paradigm used to develop, propose and } \\
\text { implement bio-behavioral studies in minority populations }\end{array}$ & $\mathrm{x}$ & $\mathrm{x}$ & & & \\
\hline 3. Hands-on research experiences in scientific studies & & $\mathrm{x}$ & $\mathrm{x}$ & $\mathrm{x}$ & $\mathrm{x}$ & $\mathrm{x}$ \\
\hline 4. Initiate and complete the research project & $\mathrm{x}$ & $\mathrm{x}$ & $\mathrm{x}$ & $\mathrm{x}$ & $\mathrm{x}$ & $\mathrm{x}$ \\
\hline $\begin{array}{l}\text { 5. Begin developing bio-behavioral interventions and initiate her independent } \\
\text { research plan for an independent position }\end{array}$ & & & & $\mathrm{x}$ \\
\hline 6. Hands-on grant writing experiences & & & $\mathrm{x}$ & $\mathrm{x}$ & $\mathrm{x}$ & $\mathrm{x}$ \\
\hline 7. Research and educational meetings/journal club/grand rounds(1 per week) & $\mathrm{x}$ & $\mathrm{x}$ & $\mathrm{x}$ & $\mathrm{x}$ & $\mathrm{x}$ & $\mathrm{x}$ \\
\hline 8. Scientific writing and research dissemination & & $\mathrm{x}$ & $\mathrm{x}$ & $\mathrm{x}$ & $\mathrm{x}$ \\
\hline 9. Interactions with established scientists, networking, and peer linkages & $\mathrm{x}$ & $\mathrm{x}$ & $\mathrm{x}$ & $\mathrm{x}$ & $\mathrm{x}$ & $\mathrm{x}$ \\
\hline
\end{tabular}

Summary of the training program progress: all tasks up to date or completed as proposed in the training SOW.

B. Research Project. Specific progress to date is outlined below.

12. Specific Aim \#1. Evaluate different role(s) of genetic variations between AAM and EAM using the panel of select genetic markers. This will be achieved by an analysis of 600 germline DNA samples ( $300 \mathrm{AA}$ and $300 \mathrm{EA}$ ), with each racial group containing 180 cases and 120 controls.

13. Specific Aim \#2. Assess the genotype/phenotype correlations using the total of 120 AA samples (60 cases and 60 controls). This will be achieved by plasma analysis for expression of the most significant gene(s)/SNP(s), identified within the specific aim \#1.

14. Specific Aim \#3. To evaluate the feasibility of using the comprehensive DETECT approach in AAM as a PCa screening and risk assessment tool. Statistical measures to analyze the data obtained in the Aims $\# 1-2$, in addition to the medical charts and bio-behavioral questionnaire data, will be used. This will be achieved by: 3a. Estimating the associations between the individual DETECT markers and PCa risk. 3b. Establishing combined associations of elected (in sub-aim 2a.) markers and PCa. 3c. Building and evaluating a prediction model of $\mathrm{PCa}$ risk based on results in Aim $2 \mathrm{a}$ and $2 \mathrm{~b}$.

$\underline{\text { YEAR 1 }}$ 
Specific progress. Aim \#1: Evaluate different role(s) of genetic variations between AAM and EAM using the panel of select genetic markers. This will be achieved by an analysis of 600 germline DNA samples (300 $A A$ and 300 EA), with each racial group containing 180 cases and 120 controls.

SNP selection. PI has performed extensive literature search, that allowed her to select 10 short nucleotide polymorphisms (SNPs) that were: 1. reported positively associated with prostate cancer (increased risk) in African American (desirable) and/or White men; 2. functional (i.e. possibly having an influence on the gene expression); 3. reported Minor allele frequency (MAF) at least 15\% in both African / Black and European / White men. Based on these criteria, the following SNPs were selected (Table 3).

Table 3. Short description of the SNPs selected for the Aim \#1 of this study. W: White men; AA: African American men; OR: odds ratio;

\begin{tabular}{|c|c|c|c|}
\hline SNP & Functional $(\mathrm{Y} / \mathrm{N})$ and gene & notes & ref \\
\hline $\begin{array}{l}\text { Rs4430796 } \\
\text { G/A, Transition Substitution } \\
\text { W:0.47(A) } \\
\text { AA:0.34(A) }\end{array}$ & $\begin{array}{l}\text { Possibly Y. TCF } 2 \text { gene } \\
\text { intronic region, possible } \\
\text { effect on transcription }\end{array}$ & $\mathrm{OR}=1.4$ & 1 \\
\hline $\begin{array}{l}\text { Rs7501939 } \\
\text { T/C, Transition Substitution } \\
\text { W:0.49(T) } \\
\text { AA:0.48(C) }\end{array}$ & & $\mathrm{OR}=1.44$ & \\
\hline $\begin{array}{l}\text { Rs1859962 } \\
\text { G/T, Transversion Substitution } \\
\text { W:0.5(G) } \\
\text { AA:0.2(G) }\end{array}$ & & $\begin{array}{l}\mathrm{OR}=1.21 \\
\text { Associated with both overall, and } \\
\text { familial/aggressive } \mathrm{PCa} \text { in white men }\end{array}$ & \\
\hline $\begin{array}{l}\text { Rs10993994 } \\
\text { C/T, Transition Substitution } \\
\text { W:0.34(T) } \\
\text { AA:0.2(C) }\end{array}$ & $\begin{array}{l}\text { Y; MSMB gene encodes } \\
\text { PSP94; reduced promoter } \\
\text { activity }\end{array}$ & $\mathrm{OR}=1.3$ & $\begin{array}{l}2, \\
3\end{array}$ \\
\hline $\begin{array}{l}\text { rs822396 } \\
\text { A/G, Transition Substitution } \\
\text { W:0.15(G) } \\
\text { AA:0.2(G) }\end{array}$ & Y; ADIPOQ & $\mathrm{OR}=3$ & 4 \\
\hline $\begin{array}{l}\text { Rs4263970 } \\
\text { C/T, Transition Substitution } \\
\text { W:0.45(C) } \\
\text { AA: } 0.47(T)\end{array}$ & Y: EPHB2 & $\mathrm{OR}=1.31$ & 5 \\
\hline $\begin{array}{l}\text { Rs4612601 } \\
\text { A/G, Transition Substitution } \\
\text { W:0.45(A) } \\
\text { AA:0.5(G) }\end{array}$ & & $\begin{array}{l}\mathrm{OR}=1.35 \\
\text { Sporadic PCa in AAM only }\end{array}$ & \\
\hline $\begin{array}{l}\text { rs4962416 } \\
\text { C/T, Transition Substitution } \\
W: 0.23(\mathrm{C})\end{array}$ & Y: CTBP2 gene & $\mathrm{OR}=1.17-1.63$ in $\mathrm{AAM}$ & 6 \\
\hline
\end{tabular}




\begin{tabular}{|l|l|l|l|}
\hline AA:0.23(C) & & & \\
\hline Rs627839 & Y: RNASEL & $\begin{array}{l}\text { OR=3.98 in White men (PCa specific } \\
\text { G/T, transversion substitution }\end{array}$ & 7 \\
W:0.45(T) & & & \\
AA:0.46(T) & & OR=2.16 in White men (PCa specific & 7 \\
\hline Rs2070874 & Y: IL4 & death) & \\
G/T, transition substitution & & & \\
W:0.2(T) & & & \\
AA:0.45(T) & & \\
\hline
\end{tabular}

- Merging of the databases and creating the data dictionary. Because the samples came from two different and independent studies (Drs. Phelan and Park PIs), the PI had to create a merged data dictionary to be used in her study. This task was successfully accomplished. The data dictionary can be found in the appendix 15.

- The Institutional Review Board (IRB) and Scientific Review Committee (SRC) approvals were successfully obtained by the PI. The copies of both approvals are attached in the appendices 1 and 2, respectively.

- Sample selection. The PI has selected the samples for her study on the basis of matching. She has performed a pair wise extensive matching of cases and controls by race and ethnicity, age ( $+/-2$ years in most cases), Gleason score, TNM stage (cases), and PSA (where available).

- Genotyping was carried out by the PI in the Dr. Park's molecular biology laboratory. Applied Biosystems primer and PCR supplies were used to genotype the individual SNPs in all the samples.

- Data analysis was carried out using the SAS software.

Results. 528 germline DNA samples were successfully genotyped. That includes 259 samples obtained from African American men (136 cases and 123 controls), and 269 samples obtained from Non-Hispanic White men (147 cases and 142 controls). Each genotyping plate included 5-10\% of duplicate samples, and concordance rates for all the genotyping experiments were $99 \%$ or more. Once the genotyping was completed, the dominant, recessive and additive age-adjusted models were fitted to explore the associations of individual SNPs with prostate cancer. We have presented the results for all men combined (cases vs controls), as well as African American (AAM) and European American (EAM) men separately. Please see table 4 for detailed genotyping results. Significant associations are shown in bold.

Table 4. Age-adjusted genotyping models for prostate cancer.

\begin{tabular}{|c|c|c|c|}
\hline SNP & $\begin{array}{l}\text { Dominant Model } \\
\text { OR (CI); p-value }\end{array}$ & $\begin{array}{l}\text { Recessive Model } \\
\text { OR(CI); p-value }\end{array}$ & $\begin{array}{l}\text { Additive Model } \\
\text { OR(CI); p-value }\end{array}$ \\
\hline \multirow{3}{*}{ 1. rs4612601 } & AAM: $1.09(0.63-1.9) ; 0.749$ & $0.86(0.46-1.61) ; 0.638$ & $0.99(0.69-1.41) ; 0.951$ \\
\hline & EAM: $1.18(0.67-2.10) ; 0.564$ & $0.9(0.52-1.56) ; 0.709$ & $1.02(0.73-1.43) ; 0.912$ \\
\hline & All: $1.13(0.76-1.69) ; 0.537$ & $0.89(0.59-1.34) ; 0.565$ & $1.00(0.79-1.28) ; 0.969$ \\
\hline \multirow[t]{3}{*}{ 2. rs4263970 } & AAM: $0.98(0.57-1.68) ; 0.932$ & $0.88(0.44-1.75) ; 0.711$ & $0.95(0.66-1.38) ; 0.797$ \\
\hline & EAM: $1.08(0.61-1.9) ; 0.795$ & $0.76(0.44-1.33) ; 0.334$ & $0.93(0.66-1.30) ; 0.665$ \\
\hline & All: $1.02(0.69-1.5) ; 0.918$ & $0.81(0.53-1.25) ; 0.343$ & $0.94(0.73-1.21) ; 0.630$ \\
\hline \multirow[t]{3}{*}{ 3. rs822396 } & AAM: $0.89(0.52-1.52) ; 0.671$ & $1.64(0.37-7.21) ; 0.511$ & $0.96(0.6-1.54) ; 0.878$ \\
\hline & EAM: $0.75(0.44-1.27) ; 0.288$ & $1.1(0.29-4.09) ; 0.094$ & $0.82(0.53-1.29) ; 0.392$ \\
\hline & All: $0.82(0.56-1.19) ; 0.285$ & $1.29(0.49-3.48) ; 0.601$ & $0.88(0.64-1.22) ; 0.456$ \\
\hline \multirow[t]{3}{*}{ 4. rs10993994 } & AAM: $0.82(0.48-1.4) ; 0.472$ & $1.04(0.51-2.10) ; 0.919$ & $0.92(0.63-1.33) ; 0.657$ \\
\hline & EAM: $1.04(0.54-2.00) ; 0.899$ & $0.61(0.36-1.05) ; 0.077$ & $0.81(0.56-1.17) ; 0.258$ \\
\hline & All: $0.9(0.6-1.35) ; 0.611$ & $0.75(0.49-1.14) ; 0.177$ & $0.87(0.67-1.11) ; 0.261$ \\
\hline \multirow[t]{3}{*}{ 5. rs1859962 } & AAM: $1.03(0.61-1.74) ; 0.905$ & $1.23(0.54-2.81) ; 0.626$ & $1.06(0.72-1.56) ; 0.752$ \\
\hline & EAM: $1.38(0.77-2.45) ; 0.278$ & $1.00(0.57-1.76) ; 0.997$ & $1.13(0.79-1.6) ; 0.508$ \\
\hline & All: $1.16(0.8-1.69) ; 0.431$ & $1.06(0.67-1.69) ; 0.790$ & $1.09(0.85-1.4) ; 0.503$ \\
\hline
\end{tabular}




\begin{tabular}{|c|c|c|c|}
\hline \multirow[t]{3}{*}{ 6. rs7501939 } & AAM: $1.34(0.73-2.47) ; 0.343$ & $2.42(1.31-4.47) ; 0.0046$ & $1.56(1.08-2.27) ; 0.0193$ \\
\hline & EAM: $0.82(0.5-1.35) ; 0.439$ & $1.13(0.54-2.38) ; 0.742$ & $0.93(0.65-1.33) ; 0.692$ \\
\hline & All: $0.99(0.68-1.45) ; 0.981$ & $1.76(1.11-2.79) ; 0.0167$ & $1.18(0.92-1.52) ; 0.187$ \\
\hline \multirow[t]{3}{*}{ 7. rs4430796 } & AAM: $0.57(0.34-0.97) ; 0.0383$ & $0.64(0.29-1.42) ; 0.272$ & $0.67(0.46-0.99) ; 0.0431$ \\
\hline & EAM: $1.27(0.7-2.3) ; 0.439$ & $0.98(0.57-1.68) ; 0.946$ & $1.07(0.76-1.51) ; 0.689$ \\
\hline & All: $0.81(0.55-1.18) ; 0.273$ & $0.86(0.59-1.33) ; 0.500$ & $0.87(0.69-1.12) ; 0.279$ \\
\hline \multirow[t]{3}{*}{ 8. rs2070874 } & AAM: $0.94(0.54-1.64) ; 0.824$ & $1.45(0.7-3.0) ; 0.314$ & $1.08(0.73-1.59) ; 0.700$ \\
\hline & EAM: $0.65(0.38-1.11) ; 0.115$ & $0.92(0.22-3.93) ; 0.916$ & $0.72(0.45-1.14) ; 0.161$ \\
\hline & All: $0.82(0.57-1.17) ; 0.275$ & $1.32(0.7-2.49) ; 0.386$ & $0.94(0.71-1.24) ; 0.649$ \\
\hline \multirow[t]{3}{*}{ 9. rs627839 } & AAM: $1.2(0.7-2.06) ; 0.511$ & $1.63(0.78-3.42) ; 0.192$ & $1.24(0.85-1.83) ; 0.252$ \\
\hline & EAM: $0.86(0.5-1.47) ; 0.571$ & $0.99(0.55-1.8) ; 0.986$ & $0.94(0.67-1.32) ; 0.710$ \\
\hline & All: $1.01(0.69-1.48) ; 0.952$ & $1.21(0.76-1.91) ; 0.427$ & $1.06(0.83-1.37) ; 0.632$ \\
\hline \multirow[t]{3}{*}{ 10. rs4962416 } & AAM: $0.9(0.5-1.59) ; 0.709$ & $5.65(0.62-51.7) ; 0.125$ & $1.05(0.63-1.74) ; 0.861$ \\
\hline & EAM: $1.69(1.02-2.8) ; 0.0415$ & $1.72(0.68-4.31) ; 0.251$ & $1.52(1.02-2.26) ; 0.0384$ \\
\hline & All: $1.28(0.88-1.85) ; 0.198$ & $2.12(0.92-4.9) ; 0.0784$ & $1.31(0.97-1.78) ; 0.083$ \\
\hline
\end{tabular}

The main findings from the Table 4 can be summarized as follows:

1. African American men carrying two copies of the rs7501939 SNP (homozygous for the C-allele) have more than twofold increase in prostate cancer risk (2.42 (1.31-4.47); 0.0046), and this increase in risk appears to be highly statistically significant. The minor allele frequency (MAF) in African American men is high ( $47.7 \%$ calculated in our study, $48 \%$ reported previously), and $24 \%$ of men are homozygous for the $\mathrm{C}$-allele in our study. However, heterozygous men also appear to be at the statistically significantly increased risk $(1.56(1.08-2.27) ; 0.0193)$, albeit to a lesser extent. About $47 \%$ of men were heterozygous in our study. Hence, the C-allele of the rs7501939 SNP appears to be a risk factor for prostate cancer in African American men.

2. African American men carrying two copies of the wild allele of rs4430796 SNP (homozygous for the Gallele) have decreased prostate cancer risk $(0.57(0.34-0.97) ; 0.0383)$. MAF (A-allele) in African American men is $31 \%$ calculated in our study, and 34\% reported previously. However, heterozygous men also appear to be at the statistically significantly reduced risk $(0.67(0.46-0.99) ; 0.0431)$. About $50 \%$ of men were homozygous of the wild allele, and $37 \%$ of men were heterozygous in our study. Hence, the wild allele of the rs4430796 SNP (G-allele) appears to be protective of prostate cancer in African American men.

3. European American men carrying two copies of the wild allele of rs4962416 (homozygous for the Tallele) have increased prostate cancer risk $(1.69$ (1.02-2.8); 0.0415). MAF (C-allele) in White men is $29 \%$ calculated in our study, and $23 \%$ reported previously. However, heterozygous men also appear to be at the statistically significantly increased risk $(1.52(1.02-2.26) ; 0.0384)$. About $50 \%$ of men were homozygous of the wild allele, and $40 \%$ of men were heterozygous in our study. Hence, the wild allele of the rs4962416 SNP (T-allele) appears to be a risk factor of prostate cancer in White men.

4. Since rs7501939 and rs4430796 are located in the same region of chromosome 17, we used the SNAP software to determine if they are in a linkage disequilibrium (LD). In White men, the SNPs were in a relatively strong linkage disequilibrium $\left(\mathrm{r}^{2}=0.76\right)$; however, this did not appear to be the case in Black men $\left(r^{2}=0.145\right)$. Hence, we conclude that in African American men, the effects of those SNPs are independent of each other.

5. We have used the SNAP software to further look for SNPs that are in a strong $\left(r^{2} \geq 0.8\right)$ and/or moderate LD $\left(\mathrm{r}^{2} \geq 0.5\right)$ with $\mathrm{rs} 7501939$ and $\mathrm{rs} 4430796$ in African American men, and rs4962416 in European American men. The results are shown in the Table 5. From these results, we conclude that the effects of our SNPs of interest, if indeed real, are coming from the SNPs itself and not from any other SNPS in the LD region.

Table 5. SNPs reported being in LD regions with our SNPs of interest. 


\begin{tabular}{|l|l|l|l|}
\hline SNP of interest & $\mathrm{r}^{2} \geq 0.8$ & $\mathrm{r}^{2} \geq 0.5$ & Disease and comments \\
\hline rs7501939 in AAM & none & $\begin{array}{l}\mathrm{rs} 11657964\left(\mathrm{r}^{2}=0.61\right) \\
\mathrm{rs} 8064454\left(\mathrm{r}^{2}=0.549\right)\end{array}$ & $\begin{array}{l}\text { None reported being associated } \\
\text { with prostate cancer or any other } \\
\text { disease. }\end{array}$ \\
\hline rs4430796 in AAM & none & none & NA \\
\hline rs4962416 in EAM & $\begin{array}{l}\text { rs4962720 }\left(\mathrm{r}^{2}=1.00\right) \\
\text { rs4962419 }\left(\mathrm{r}^{2}=1.00\right) \\
\left.\text { rs12771627( } \mathrm{r}^{2}=1.00\right) \\
\text { rs12769019 }\left(\mathrm{r}^{2}=0.92\right) \\
\mathrm{rs} 11598549\left(\mathrm{r}^{2}=0.92\right) \\
\mathrm{rs} 12782469\left(\mathrm{r}^{2}=0.83\right)\end{array}$ & 14 additional SNPs & $\begin{array}{l}\text { rs12769019: slightly increased } \\
\text { risk for prostate cancer in EAM } \\
(\mathrm{OR}=1.1)[8] ;\end{array}$ \\
\end{tabular}

We have also started looking at the bio-behavioral risk factors that were previously reported being associated with prostate cancer. The results are shown in the Table 6 . Additional variables will be analyzed in the year \#2 of this award.

Table 6. Age-adjusted association between select anthropometric and behavioral variables and prostate cancer in men stratifying by race and combined. Bold denotes statistically significant associations; italics denotes statistically marginally significant associations.

\begin{tabular}{|l|l|l|l|}
\hline & AAM & EAM & All \\
\hline $\begin{array}{l}\text { Height: OR (95\% CI); p- } \\
\text { value }\end{array}$ & $0.98(0.9-1.05) ; 0.544$ & $\mathbf{0 . 9 2}(\mathbf{0 . 8 5 - 0 . 9 9 ) ; 0 . 0 4 3 4}$ & $\begin{array}{l}0.95 \\
0.0549\end{array}$ \\
\hline $\begin{array}{l}\text { BMI: OR (95\% CI); p- } \\
\text { value }\end{array}$ & $\mathbf{1 . 0 6 ( 1 . 0 0 8 - 1 . 1 1 4 ) ; 0 . 0 2 2}$ & $0.98(0.93-1.023) ; 0.332$ & $1.02(0.98-1.05) ; 0.374$ \\
\hline $\begin{array}{l}\text { Smoking: OR (95\% CI); } \\
\text { p-value }\end{array}$ & $1.01(0.99-1.03) ; 0.118$ & $1.00(0.99-1.01) ; 0.959$ & $1.002(0.99-1.01) ; 0.565$ \\
\hline
\end{tabular}

Since our results indicated that BMI might be positively associated with prostate cancer in African American men, we decided to look for possible associations between BMI and significant SNPs: rs7501939 and rs4430796. Although our numbers were small, the results are shown in Table 7.

Table 7. rs7501939 and rs4430796 as risk factors for prostate cancer in African American men stratified by the body weight/BMI. Statistically significant associations are shown in bold.

\begin{tabular}{|l|l|l|l|}
\hline & $\begin{array}{l}\text { Non-obese AAM: BMI }<30 ; 55 \\
\text { cases and 69 controls }\end{array}$ & $\begin{array}{l}\text { Obese AAM: BMI } \geq 30 ; 79 \\
\text { cases and 49 controls }\end{array}$ & All AAM (data from table 4) \\
\hline rs7501939 & $1.09(0.64-1.83) ; 0.763$ & $\mathbf{2 . 1 4}(\mathbf{1 . 2 - 3 . 8}) ; \mathbf{0 . 0 1 0 3}$ & $\mathbf{2 . 4 2} \mathbf{( 1 . 3 1 - 4 . 4 7 ) ; 0 . 0 0 4 6}$ \\
\hline rs4430796 & $0.84(0.49-1.43) ; 0.513$ & $0.67(0.37-1.2) ; 0.181$ & $\mathbf{0 . 5 7}(\mathbf{0 . 3 4 - 0 . 9 7 )} \mathbf{0 . 0 3 8 3}$ \\
\hline
\end{tabular}

Similarly, we have also tested the association of rs7501939 and prostate cancer in White men by obesity status. No statistically significant association was seen in either non-obese $(p=0.3)$ or obese $(p=0.8)$ men of European descent.

As could be seen from data shown in Table 7, we were either underpowered to detect the effect of obesity in the rs4430796 carriers, or there's no apparent association. Interestingly, the ORs (point estimates) were still in the protective range (less than 1.0) in both groups; however that observation did not attain statistical significance perhaps due to decreased sample size in both groups.

Interestingly, the rs7501939 remained a significant risk factor for prostate cancer in obese AAM even considering a small sample size, and the excessive risk was still more than twice. However, rs7501939 no longer appeared to be a risk factor for prostate cancer in the non-obese AAM. 
Hypothesis to be tested in the specific aim \#2: in obese (diabetic?) AAM, there may be active obesity-related mechanisms that alone do not lead to increased PCa risk; however, the presence of the rs7501939 C-allele may either cause additional risk-increasing mechanisms, or enhance the ones related to obesity, leading to more than twofold increased PCa risk. In the non-obese (non-diabetic?) men, the rs7501939 C-allele alone may not be sufficient to increase the PCa risk. Please see schematic illustration of this hypothesis (Figure 1).

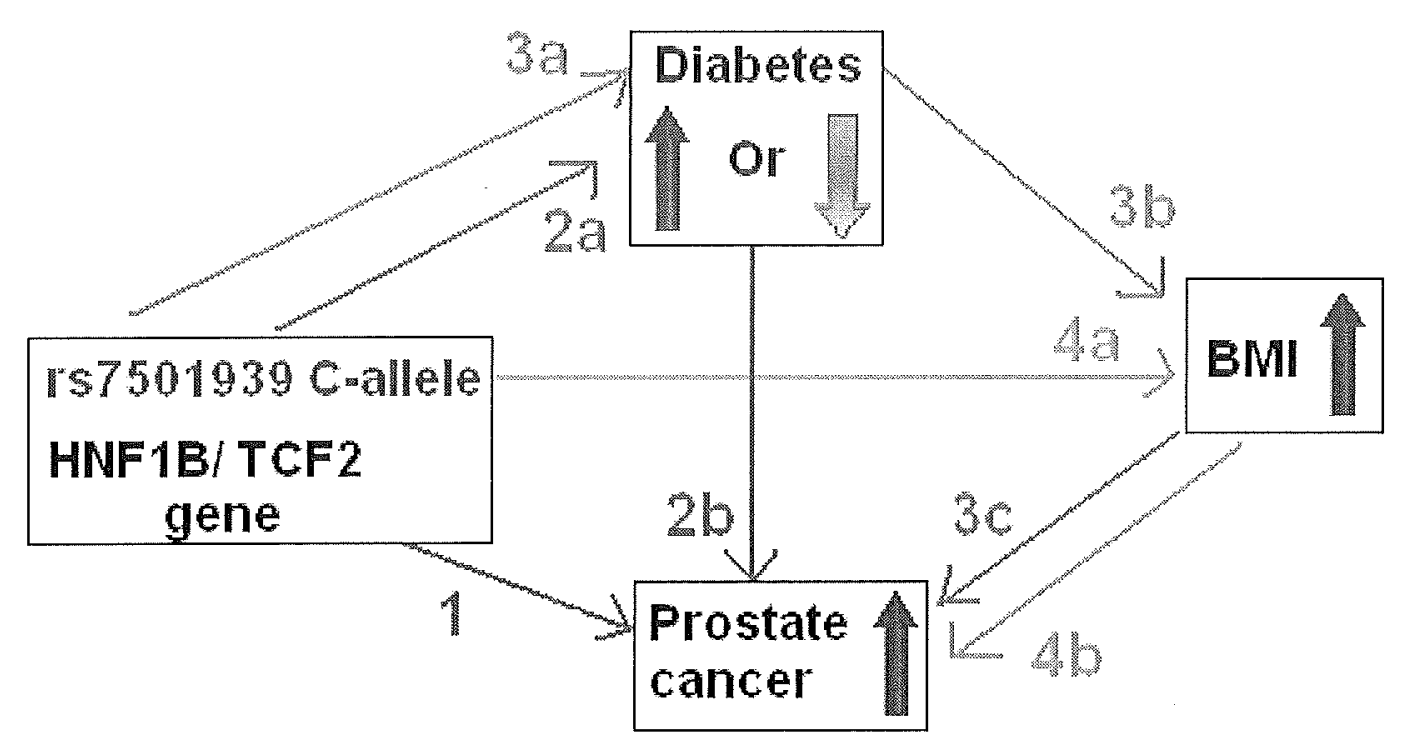

Figure 1. Possible pathways involved in the increased prostate cancer risk in rs7501939 C-allele African American carriers. 1 (blue line): direct association; $2 \mathrm{a}$ and $2 \mathrm{~b}$ (magenta lines): association mediated through increased or decreased diabetes risk; $3 a, 3 b$ and $3 c$ (grey lines): association mediated through increased or decreased diabetes risk and associated BMI increase; $4 \mathrm{a}$ and $4 \mathrm{~b}$ (green line): association mediated through increased BMI.

\section{YEAR 2}

Specific progress. Specific Aim \#2. Assess the genotype/phenotype correlations using the total of $120 \mathrm{AA}$ samples ( 60 cases and 60 controls). This will be achieved by plasma analysis for expression of the most significant gene(s)/SNP(s), identified within the specific aim \#1.

Rationale. The need for an effective diagnostic and/or screening test, with higher sensitivity and specificity towards malignant prostate tumors in African American men, has been recognized [8]. This need drives the search for diagnostic biomarkers, specific to the high risk population of African Americans. Among the nonspecific markers, OPG [9] and p53 [10] are recognized as indirect markers for prostate cancer progression and prognosis, however, their utility as serum detection and screening biomarkers was not explored in a high risk cohort of African American men. In the present study, we hypothesized that accuracy of the Serum Prostate Specific Antigen (PSA) prostate cancer screening test can be improved by serum p53 and OPG, which are established non-specific biomarkers for prostate cancer progression and prognosis.

Methods. The study is approved by the University of South Florida Institutional Review Board (IRB\#104213). Cases are African American men with biopsy-proven prostate cancer. Controls are African American men with low PSA and no other evidence of biopsy by prostate cancer. The cases and controls have come from screening at Lifetime Cancer Screening and prevention Center at the H. Lee Moffitt Cancer Center and Research Institute, the Moffitt Cancer Center Hospital, Tampa Bay Radiation Oncology centers, and $30^{\text {th }}$ Street Medical Associates. 
Written informed consent is obtained from each of the men in this study in accordance with local institutional review board approval. Human subjects in this study are asked to complete a questionnaire about general health risk factors, and family history, and provide blood samples.

Data were obtained from medical records by study personnel. Operative and pathology reports are obtained by study personnel from the office of the diagnosing physician. From these reports, we verified prostate cancer stage, grade, histological type, size of tumor and extent of surgical treatment. Data abstracted from these reports was reviewed in conjunction with review of pathology slides from the surgical specimen by a single pathologist, who verified disease grade and histological type. The results from the operative and pathology results determined whether a study volunteer is classified as 'case' if cancer is present or 'control' if cancer is not present.

Two vials of blood will be collected from each subject, Ten $\mathrm{ml}$ of blood was drawn (by the phlebotomist or nurse) into each tube prior to intervention or treatment (which may affect the serum and plasma proteins). Both tubes will be brought to Tissue Procurement at the Moffitt Cancer Center.

The $10 \mathrm{ml}$ purple top EDTA tubes will be centrifuged within 24 to 72 hours of blood drawing at $2500 \mathrm{~g}$ for 15 minutes for plasma separation and buffy coat extraction for DNA. Plasma will be transferred and stored in microtubes at $-70^{\circ} \mathrm{C}$. The buffy coat in the EDTA-tube will be placed in a $50 \mathrm{ml}$ falcon tube, and RBC lysis buffer added and the tube incubated for 30 minutes. The tube is then vortexed, and cell lysis buffer added and the tube incubated at room temperature overnight. Then the sample is treated to remove RNA and proteins, prior to and isopropanol ethanol wash and the DNA is resuspensed in Tris-EDTA buffer, as per manufacturers" instructions (Puregene, Gentra systems, MN, USA). The DNA is stored at $4^{\circ} \mathrm{C}$. The red tiger topped tube will be spun down as soon as possible to remove the sera. The sera will also be stored at $-70{ }^{\circ} \mathrm{C}$. Sera, Plasma and DNA samples will be stored indefinitely for this and other studies as long as the integrity of the sample is maintained.

Commercially available ELISA kits were purchased from Abnova (product numbers: PSA - KA0208; OPG KA0030; p53 - KA0155) and were stored and used according to manufacturer's instructions. Phosphate buffered saline (PBS) tablets were purchased from Sigma Aldrich. PBS solution (10 mM, pH 7.4) was prepared by dissolving 1 tablet in $200 \mathrm{ml}$ of deionized water. Synergy HT microplate reader was purchased from Biotek.

Statistical analyses. Frequency and percentages of the discrete variables were computed. Pearson's Chi-square test and Fisher's exact test were used to test the independence between discrete variables and cancer status as being positive (case) or negative (control). Wilcoxon rank-sum test was used to compare the distributions of each continuous variable between the case and control groups. Univariable and multivariable logistic regression models were built to test the marginal and joint effects of the variables when predicting the cancer status. Point and interval estimates of the odds ratio as well as the p-value of each of the variables were reported. All pvalues less than 0.05 were considered significant. Statistical analyses were conducted using Statistical Analysis System (SAS) software, version 9.2 (SAS Institute, Cary, NC).

Results. Total of 29 cases and 32 controls were tested. Age and stage characteristics are shown in Table 8. Despite the best effort to perform a close age matching, cases were, on average, older than controls; however, an average age of cases in our cohort was still 7 years younger than an average nationwide age at the time of PCa diagnosis (69 years). This reflects the general trend that African American males are on average 3-5 years younger than men of other racial groups at the time of initial prostate cancer diagnosis [11]. All the cases in our study carried a moderately differentiated $\mathrm{PCa}$ at time of diagnosis. There were no patients with advanced or very initial stages of $\mathrm{PCa}$. One case and four controls were below the recommended starting age for $\mathrm{PCa}$ screenings (50 years [12]) which also reflects the nationwide trend observed in African American men.

Table 8. Patients' characteristics.

\begin{tabular}{|l|l|l|l|}
\hline $\begin{array}{l}\mathrm{PCa} \\
\text { status/characteristic }\end{array}$ & $\begin{array}{l}\text { Age range } \\
\text { (average), years }\end{array}$ & $\begin{array}{l}\text { Gleason score } \\
\text { range }\end{array}$ & T stage range \\
\hline Cases $(+)$ & $44-74(62)$ & $6-8$ & T1 - T2 \\
\hline Controls $(-)$ & $38-73(56.5)$ & N/A & N/A \\
\hline
\end{tabular}


As expected, all the samples tested, including the cases and controls, expressed PSA. Average PSA for cases is $6.1 \mathrm{ng} / \mathrm{ml}$, and $1.3 \mathrm{ng} / \mathrm{ml}$ for controls. In addition, all samples tested had detectable OPG expression. The average expression for cases was $328 \mathrm{pg} / \mathrm{ml}$, and $289 \mathrm{pg} / \mathrm{ml}$ for controls. However, only $25 \%$ of samples had detectable p53 expression, including 8 cases and 7 controls. The average expression for cases was $6.12 \mathrm{u} / \mathrm{ml}$, and $25.99 \mathrm{u} / \mathrm{ml}$ for controls. The summary of each biomarker expression is shown in Table 9.

Table 9. Expression of biomarkers

\begin{tabular}{|c|c|c|c|}
\hline & PSA & P53 & OPG \\
\hline Total tested & 61 & 60 & 60 \\
\hline Cases (+) & 29 & 28 & 28 \\
\hline Controls (-) & 32 & 32 & 32 \\
\hline $\begin{array}{l}\text { Expression } \\
\text { detected (ED) total }\end{array}$ & $61(100 \%)$ & $15(25 \%)$ & $60(100 \%)$ \\
\hline ED cases & $29(100 \%)$ & $8(29 \%)$ & $28(100 \%)$ \\
\hline ED controls & $32(100 \%)$ & $7(22 \%)$ & $32(100 \%)$ \\
\hline Average cases & $6.1 \mathrm{ng} / \mathrm{ml}$ & $6.12 \mathrm{u} / \mathrm{ml}$ & $328 \mathrm{pg} / \mathrm{ml}$ \\
\hline Average controls & $1.3 \mathrm{ng} / \mathrm{ml}$ & $25.99 \mathrm{u} / \mathrm{ml}$ & $289 \mathrm{pg} / \mathrm{ml}$ \\
\hline
\end{tabular}

As expected, PSA expression was significantly correlated with $\mathrm{PCa}$ status: $\mathrm{OR}=2.85$ (95\% $\mathrm{CI}$ : 1.72-4.73). The strong association is clearly illustrated by the ROC curve (Figure 2).

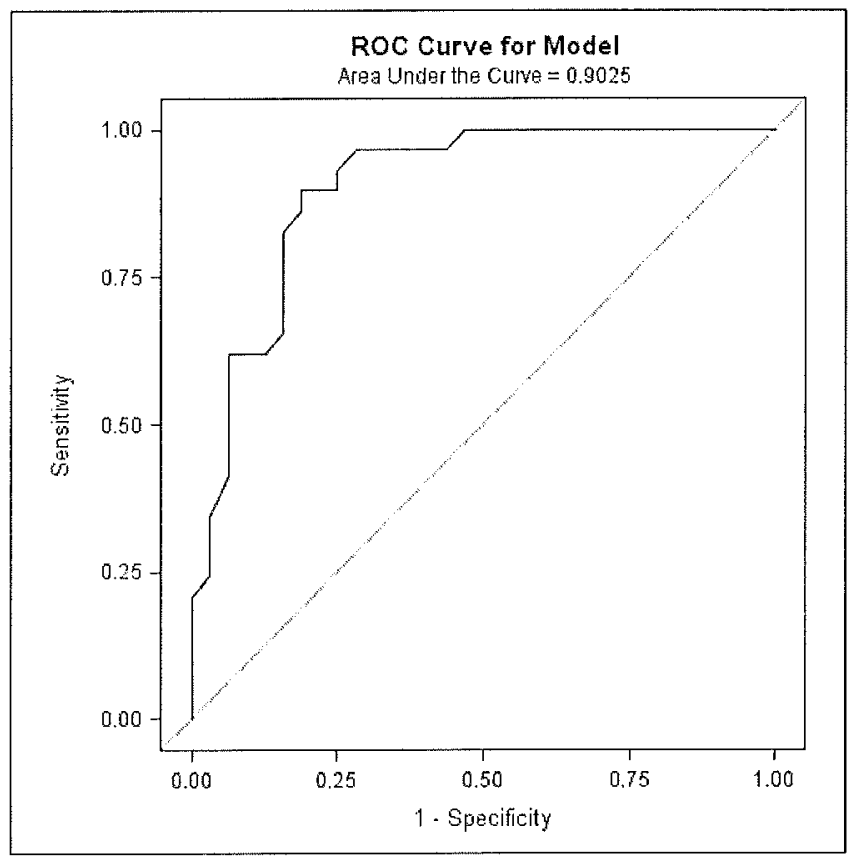

Figure 2. ROC curve for PSA

In contrast, neither OPG [OR=1.003 (95\%CI: 0.998 1.007)], nor p53 [OR=0.936 (95\%: 0.79-1.11)] expression was statistically significantly correlated with PCa status. Figure 3 depicts the absence of correlationg by illustrating the ROC curve for OPG. Due to the limited number of samples with detectable p53 expression, no ROC was generated. 


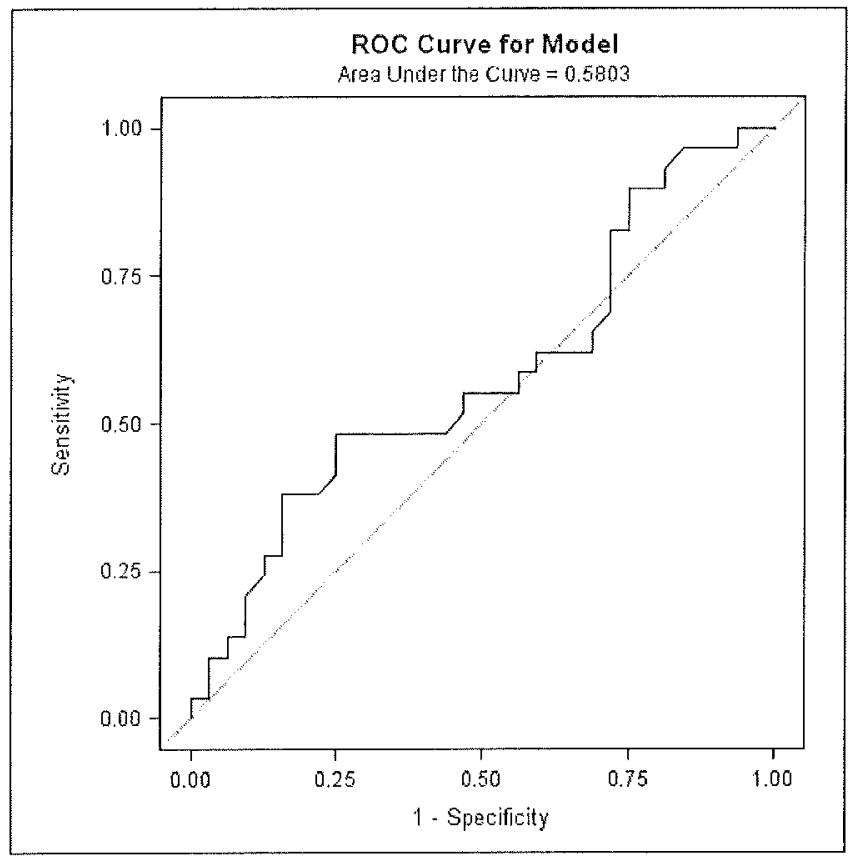

Figure 3. ROC curve for OPG.

In addition, no significant association was found between the 3 biomarkers which are illustrated in Table 10.

Table 10. Pearson coefficient ( $\mathrm{p}$ value) for the three biomarkers studied

\begin{tabular}{|l|l|l|l|}
\hline & PSA & OPG & P53 \\
\hline PSA & N/A & $0.15(0.25)$ & $0.19(0.46)$ \\
\hline OPG & & N/A & $0.11(0.67)$ \\
\hline P53 & & & N/A \\
\hline
\end{tabular}

\section{NCE}

During the NCE, Dr Chornokur and colleagues have analyzed a total of 220 tumors (200 White and 20 Black men) were profiled for expression of $\sim 1200$ genes implicated in carcinogenesis. Prostate tumors were collected from patients treated at the Moffitt Cancer Center or affiliated hospital network. Tumor RNA was extracted using the commercial kits, and gene expression was performed using the Affymetrix U133A human arrays. Descriptive statistics and paired t-tests were performed. Of those, a total of 15 genes showed statistically significant $(\mathrm{p}<0.05)$ differences in expression (Table 11). The top hit was PSPHP1 upregulated in Black men $(\mathrm{FC}=4.7 ; \mathrm{p}=1.99 * 10-3)$ and associated with Falconi anemia. Other top hits all upregulated in White men included PDXDC2P (FC=2.7; $\left.\mathrm{p}=1.99^{*} 10-3\right)$, ACTN2 (FC=1.8; $\left.\mathrm{p}=1.99^{*} 10-3\right)$ and PRN3P1 (FC=1.6; $\mathrm{p}=1.99 * 10-3)$. The differentially expressed genes are mainly implicated in the invasion and migration and angiogenesis.

Conclusions. Prostate tumors derived from Black and White men demonstrate differential gene expression profiles. The genes appear to be implicated in the invasion and migration, and angiogenesis. Further research is needed to determine the impact of the observed differences on prostate cancer health disparity.

Table 11. Genes differentially expressed in PCa tumors of $A A$ and EA men, sorted by the p-value (p-values $<$ 0.005 listed). FC: fold change; Upr: upregulated in; AA: African American; W: White. AA tumors $=20 ; E A$ tumors $=200$. Total number of genes analyzed $\sim 1200$. Although AA sample size was low, we will attempt to stratify by BMI (data analysis in process). [Chornokur, Qu, Phelan et al; unpublished data]

\begin{tabular}{|l|l|l|l|l|l|l|l|l|l|l|l|l|l|l|l|}
\hline Gen & PS & PDX & LO & RR & AC & LO & SERP & CRY & GO & OR & MAR & AN & RA & PCD & RP \\
$\mathrm{e}$ & PH & DC2 & C10 & N3P & TN & C10 & NE1 & BB2P & LIM & 2L1 & K2P1 & PE & B6 & H17 & S23 \\
& P1 & P & 050 & 1 & 2 & 050 & & 1 & 4 & 3 & 5 & P & A & & \\
\hline
\end{tabular}




\begin{tabular}{|l|l|l|l|l|l|l|l|l|l|l|l|l|l|l|l|}
\hline & & & 5 & & & 0 & & & & & & & & & \\
\hline $\begin{array}{l}\text { p- } \\
\text { val } \\
* \\
10^{-3}\end{array}$ & $\begin{array}{l}1.9 \\
9\end{array}$ & 1.99 & 1.99 & 1.99 & $\begin{array}{l}1.9 \\
9\end{array}$ & 1.99 & 1.99 & 1.99 & 1.99 & 1.99 & 1.99 & $\begin{array}{l}3.9 \\
9\end{array}$ & $\begin{array}{l}3.9 \\
9\end{array}$ & 3.99 & $\begin{array}{l}3.9 \\
9\end{array}$ \\
\hline FC & 4.7 & 2.7 & 1.2 & 1.6 & 1.8 & 1.02 & 1.19 & 1.9 & 1.03 & 1.05 & 1.2 & 1.1 & 1.2 & 1 & 1.1 \\
\hline Upr & $\begin{array}{l}\text { A } \\
\text { A }\end{array}$ & W & W & W & W & W & AA & W & AA & AA & AA & AA & W & AA & W \\
\hline
\end{tabular}

Discussion. In this work, we thought to evaluate the utility of serum OPG and p53 as independent or joint with serum PSA screening or diagnostic biomarkers of prostate cancer in African American men. The rationale behind our work was that, in addition to higher prostate cancer incidence and mortality in African American population, there is no reliable screening or early detection tools that will allow sensitive and specific detection of prostate cancer. The rationale behind selecting OPG and p53 was that, increased serum OPG and p53 levels are also associated with increased tumor stage, tumor grade and early recurrence in myelomas, lung, bladder, breast, colorectal and, most importantly, prostate cancers [13]. In prostate cancer, increased OPG serum levels were linked to the disease progression [9], and thus OPG was declared to be a promising potential candidate for prostate cancer detection and progression in a pilot experiment with comparable sample sizes [14]. It was proposed that $\mathrm{OPG}$ may protect the tumor cells from apoptosis [15]. The need for additional experiments to further investigate the role of serum OPG in prostate cancer was therefore warranted.

P53 is an important tumor suppressor gene and it's product - p53 protein - is often either down-regulated or mutated and up-regulated during malignant transformation and progression [10]. Although well studied, the role of $\mathrm{p} 53$ in cancer is elusive: the wild-type p53 may possess pro-apoptotic properties and be down regulated in the process of tumorigenesis [16], while mutated p53 may be up regulated because it suppress apoptosis and induces proliferation [17]. We aimed to explore, if any of these scenarios can be detected in serum of African American patients with moderately differentiated prostate cancer, and if this data can be used to improve the diagnostic or prognostic tools for this type of malignancy. It is notable, however, that no information on the levels of either OPG or p53 in circulation of African American males with any type of cancer, including carcinoma of the prostate, exists to date, which makes our work highly innovative with a potential to yield novel, important results which may not only drive the field of prostate cancer diagnostics forward, but also contribute to the resolution of cancer related disparities.

Based on the results presented earlier, the main outcome of our study can be formulated as such: no significant association between OPG or p53 and prostate cancer was found in our pilot cohorts of African American men with moderately differentiated prostate cancer, neither the levels of OPG and/or p53 were found useful to improve the detection value of PSA. This finding is in concordance with [14], who found significant association only between the serum OPG levels and advanced, untreated PCa. No difference in OPG levels was found in sera from patients with low to moderate grade prostate cancer, and healthy males of similar ages. The authors concluded that serum OPG may hold promise as a marker of progression and metastatic spread, but not the marker of early detection or screening.

Specific progress. Specific Aim \#3. To evaluate the feasibility of using the comprehensive DETECT approach in AAM as a PCa screening and risk assessment tool. Statistical measures to analyze the data obtained in the Aims \#1-2, in addition to the medical charts and bio-behavioral questionnaire data, will be used. This will be achieved by: $3 a$. Estimating the associations between the individual DETECT markers and PCa risk. $3 b$. Establishing combined associations of elected (in sub-aim 2a.) markers and PCa. 3c. Building and evaluating a prediction model of $P$ Ca risk based on results in Aim $2 a$ and $2 b$.

Rationale. The trinucleotide (CAG)(n) repeat polymorphism in exon 1 of the androgen receptor (AR) gene regulates AR activity, with longer alleles conferring reduced activity (Figure 4 [18]). Significant interethnic 
variations in the allele length frequencies of the $A R(C A G)(n)$ polymorphism repeat have been reported [19]. We investigated the association between the $A R C A G(n)$ repeat length and prostate cancer risk in AAM and EAM. We further explored if this association varied by body mass index (BMI) in the two races.

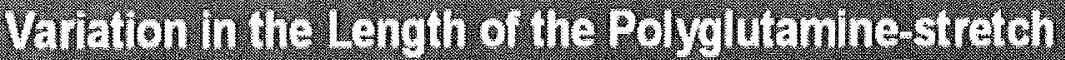 in lie Homan andogen Regertor}

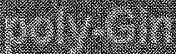
15010
$15 \mathrm{~b}$
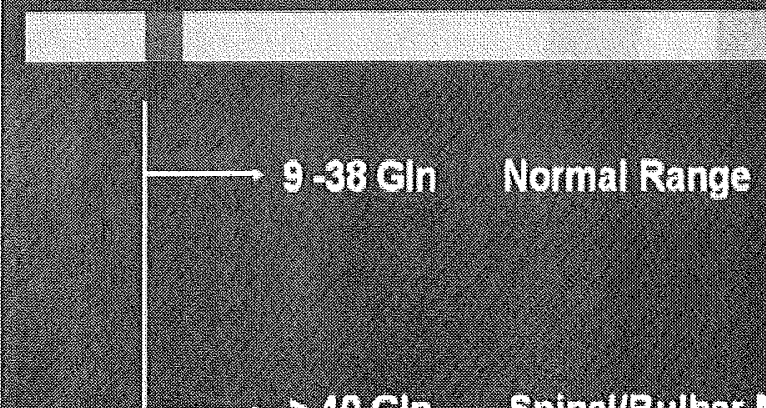

Figure 4. Schematic of the human androgen receptor. $\mathrm{DBD}=$ DNA binding domain; $\mathrm{LBD}=$ ligand binding domain; poly-GLN = polyglutamine repeats (CAG) [18].

Methods. Study participants were recruited from various hospitals in Tampa Bay. Eligible subjects selfclassified as either AAM or EAM and were 30-80 years old. Cases had biopsy-confirmed prostate cancer and had no prior treatment at the time of enrollment. Controls were defined as men having no evidence of prostate cancer on biopsy and/or low PSA levels. All men signed an informed consent form and provided a blood or saliva sample for DNA. We tested DNA samples from 259 (136 cases and 123 controls) AA and 269 (147 cases and 142 controls) NHW men, matched by age, Gleason score and PSA. The CAG repeat region was PCR amplified, and the PCR fragments were analyzed using the Beckman Coulter CEQ8000 DNA sequencer to establish the repeat length.

Statistical analyses. Descriptive statistics was performed for discrete and continuous variables. Associations between repeats and prostate cancer risk were evaluated using unconditional logistic regression to estimate odds ratios (OR) and 95\% confidence intervals $(95 \% \mathrm{CI})$ for each race. Repeats were categorized using the median (22 repeats) as a cutpoint. Significance was defined as the p-value $<0.05$.

Results. DNA samples from 259 (136 cases and 123 controls) AAM and 269 (147 cases and 142 controls) EAM were analyzed, yielding a total sample size of 528 men. EAM were matched to AAM by case status, age, and Gleason score. Select characteristics of the study participants by case/control status are shown in the Table 11 . For both ethnic groups, men were likely to be between 50 to 64 years of age and between 68 and 72 inches tall. Within ethnic groups, AAM cases were more likely to be obese than AAM controls. In contrast, EAM controls were more likely to be obese than EAM cases. AAM were more likely to be obese and taller than EAM. However, these differences were not statistically significant $(p>0.05)$.

Table 11. Select characteristics of the study participants by case/control status.

\begin{tabular}{|c|c|c|c|c|c|}
\hline & \multicolumn{2}{|c|}{ AAM: 259 total } & \multicolumn{2}{|c|}{ EAM: 269 total } \\
\hline & & $\begin{array}{l}\text { \# Cases (\%) } \\
136(52.5)\end{array}$ & $\begin{array}{l}\text { \# Controls (\%) } \\
123(47.5)\end{array}$ & $\begin{array}{l}\text { \# Cases (\%) } \\
147(54.6)\end{array}$ & $\begin{array}{l}\text { \# Controls (\%) } \\
122(45.4)\end{array}$ \\
\hline \multirow[t]{4}{*}{ Age } & $<50$ & $11(8)$ & $30(24)$ & $12(8)$ & $19(16)$ \\
\hline & $50-64$ & $74(54)$ & $73(59)$ & $80(54)$ & $85(70)$ \\
\hline & 865 & $51(38)$ & $17(14)$ & $55(38)$ & T18(14) \\
\hline & missing & $\overline{\mathrm{NA}}$ & $\overline{3(3)}$ & $\overline{\mathrm{NA}}$ & $\overline{\mathrm{NA}}$ \\
\hline
\end{tabular}




\begin{tabular}{|c|c|c|c|c|c|}
\hline \multirow[t]{4}{*}{ BMI } & $\begin{array}{l}\leq 24.9 \\
\text { normal weight }\end{array}$ & $9(7)$ & $26(21)$ & $25(17)$ & $28(23)$ \\
\hline & $\begin{array}{l}25.0-29.9 \\
\text { overweight }\end{array}$ & $44(34.5)$ & $46(37)$ & $70(48)$ & $47(38)$ \\
\hline & $\begin{array}{l}30.0 \\
\text { obese }\end{array}$ & $71(52)$ & $\sqrt{51(42)}$ & $48(33)$ & $46(38)$ \\
\hline & missing & $9(6.5)$ & $\sqrt{\mathrm{NA}}$ & $4(2)$ & $1(1)$ \\
\hline \multirow[t]{4}{*}{ Height } & $\leq 67$ in & $30(22)$ & $21(17)$ & $\sqrt{26(17.5)}$ & $22(18)$ \\
\hline & $\overline{68-72 \text { in }}$ & $65(48)$ & $74(60)$ & $98(66.5)$ & $79(65)$ \\
\hline & 873 in & $32(23.5)$ & $28(23)$ & $19(13)$ & $21(17)$ \\
\hline & missing & $9(6.5)$ & NA & $\longdiv { 4 ( 3 ) }$ & NA \\
\hline
\end{tabular}

Results for the CAG repeat analysis and prostate cancer status are shown in the Table 12. No statistically significant associations were noted when the repeat length was treated as a continuous variable. However, when a binary cutpoint was used (a median repeat length in our study, $C A G=22)$, AAM with longer repeats $(\geq 22)$ demonstrated increased prostate cancer risk. Interestingly, the increased risk was only evident in obese $(\mathrm{BMI} \geq 30)$, but not in the non-obese $(\mathrm{BMI}<30)$ AAM. No associations were noted in EAM regardless of the BMI.

We have analyzed the CAG repeat distribution using other categories commonly used in other studies $(<19 ; 12$ 25 ; and $\geq 26$ repeats). None of the analyses were significant using these categories $(p>0.05)$.

Table 12. AR CAG-repeat length and prostate cancer status. "+" denotes a case; "-" denotes a control.

\begin{tabular}{|c|c|c|c|c|c|c|c|c|c|c|c|c|}
\hline & \multicolumn{4}{|c|}{ AAM } & \multicolumn{4}{|c|}{ EAM } & \multicolumn{4}{|c|}{ Combined } \\
\hline & + & |- & $\overline{\mathrm{OR}(95 \% \mathrm{CI})}$ & $\bar{P}$ & + & - & $\overline{\mathrm{OR}(95 \% \mathrm{CI})}$ & $\sqrt{\mathrm{P}}$ & $\sqrt{1+}$ & - & OR $(95 \% \mathrm{CI})$ & $\mathrm{P}$ \\
\hline Continuous & 147 & $\sqrt{122}$ & $1.00(0.94-1.07)$ & 0.94 & $\mid 136$ & $\sqrt{123}$ & $\sqrt{1.08(1.00-1.17)}$ & 0.06 & 283 & 245 & $1.04(0.99-1.09)$ & 0.17 \\
\hline Binary all & & & & & & & & & & & & \\
\hline$<22$ & 40 & 49 & Reference & & $\sqrt{66}$ & 66 & Reference & & 106 & 115 & Reference & \\
\hline$\geq 22$ & 86 & 63 & $1.81(1.05-3.13)$ & 0.034 & 53 & $\sqrt{50}$ & $\longdiv { 0 . 9 6 ( 0 . 5 6 - 1 . 6 5 ) }$ & 0.87 & 136 & 116 & $1.37(0.90-1.92)$ & 0.15 \\
\hline Non-obese & & & & & & & & & & & & \\
\hline$\overline{<22}$ & 30 & 31 & Reference & & $\sqrt{28}$ & 38 & Reference & & 58 & 69 & Reference & \\
\hline$\overline{822}$ & 54 & 39 & $1.43(0.73-2.77)$ & 0.30 & 19 & 33 & $0.80(0.35-1.83)$ & 0.60 & 73 & 72 & $1.22(0.73-2.01)$ & 0.45 \\
\hline Obese & & & & & & & & & & & & \\
\hline$<22$ & 9 & 18 & Reference & & 34 & 28 & Reference & & 43 & 46 & Reference & \\
\hline$\geq 22$ & $\sqrt{29}$ & $\sqrt{23}$ & $\mid 3.12(1.12-8.73)$ & 0.03 & 27 & 20 & $\sqrt{1.11(0.51-2.41)}$ & 0.79 & 56 & 43 & $1.45(0.18-2.60)$ & 0.21 \\
\hline
\end{tabular}

Discussion. Obesity (BMI $\geq 30$ ) alters individual's hormonal profile; specifically, estrogens are increased, and androgens are decreased in obese compared to normal weight men [20]. While the majority of early prostate cancers rely on androgens, depletion of androgens (castration) eventually leads to an androgen independent malignancy [21]. Our provocative, very preliminary findings may indicate that obese AAM with altered androgen/estrogen profile (androgen $\downarrow$, estrogen $\uparrow$ ) and reduced activity AR receptors may be more susceptible to develop prostate cancers (Table 13). Further, we are tempted to hypothesize that obese AAM with longer $\mathrm{CAG}$ repeats are prone to develop an androgen-independent malignancy that may be more aggressive and/or resistant to conventional treatments. Additional research is needed to test this hypothesis as well as establish possible reasons why this effect is observed in AAM but not in EAM. 
Table 13. Androgen receptor (AR) activity, androgen/estrogen balances and prostate cancer in AAM

\begin{tabular}{|l||l|l|}
\hline AR activity & Androgen/estrogen & Low/High $(\mathrm{BMI} \geq \mathbf{3 0})$ \\
\cline { 2 - 3 } & $\begin{array}{l}\text { Normal/normal }(\mathrm{BMI}<30) \\
\text { Normal }(\mathrm{CAG}<22)\end{array}$ & $\begin{array}{l}\text { Conventional slow-growing prostate cancer } \\
\text { ? Still conventional slow-growing cancer }\end{array}$ \\
\hline $\begin{array}{l}\text { Reduced } \\
(\mathrm{CAG} \geq 22)\end{array}$ & $\begin{array}{l}\text { ? Still conventional slow-growing prostate } \\
\text { cancer? }\end{array}$ & $\begin{array}{l}\text { Androgen-independent, } \\
\text { cancer }\end{array}$ \\
\hline
\end{tabular}

Conclusions. Our results suggest that prostate cancer risk may be increased in AAM with longer AR CAG repeats $(\geq 22)$, especially obese (BMI $\geq 30)$ AAM. The data provide evidence for ethnic differences in androgenic pathway activity and androgen sensitivity which may contribute to prostate cancer disparity.

\section{Future directions}

We plan to continue the work proposed in the funded R21 (Chornokur PI) shown in the Appendix ... . This project was written using the preliminary data obtained within the scope of this training grant. The R21 is directly relevant to the issue of prostate cancer health disparity.

\section{Summary of the research progress: Aim \#1,2 and 3: completed.}

Year 1:

\section{$\underline{\text { Key Research Accomplishments }}$}

1. 528 germline DNA samples were successfully genotyped for selected functional SNPs. That includes 259 samples obtained from African American men (136 cases and 123 controls), and 269 samples obtained from Non-Hispanic White men (147 cases and 142 controls).

2. Based on the genotyping results, three SNPs showed statistically significant associations with prostate cancer. In African American men: rs7501939 C-allele (OR 2.42; CI 1.31-4.47; p=0.0046) and rs4430796 G-allele (OR 0.57; CI 0.34-0.97; p=0.0383). In European American men: rs4962416 T-allele (OR 1.52; CI 1.02-2.26; $\mathrm{p}=0.0384$ ).

3. Select anthropometric variables were statistically significantly associated with prostate cancer in our cohort of men. In African American men: BMI (OR 1.06; CI 1.008-1.114; $\mathrm{p}=0.022$ ). In European American men: height (OR 0.92; CI 0.85-0.99; $\mathrm{p}=0.0434$ ).

4. Interestingly, rs7501939 $\mathrm{C}$-allele appeared to be a risk factor for prostate cancer in obese (BMI $\geq 30$ ) African American men only (OR 2.14; CI 1.2-3.8; p=0.0103). It was no longer a risk factor in the nonobese African American men.

5. Neither rs 4430796 nor rs 4962416 showed statistically significant associations with BMI and/or height.

Year 2:

6. No significant association between OPG or p53 and prostate cancer was found in our pilot cohorts of African American men with moderately differentiated prostate cancer, neither the levels of OPG and/or p53 were found useful to improve the detection value of PSA.

7. No difference in OPG levels was found in sera from patients with low to moderate grade prostate cancer, and healthy males of similar ages. 
8. 528 germline DNA samples were successfully genotyped for the CAG repeat length in the androgen receptor gene. That includes 259 samples obtained from African American men (136 cases and 123 controls), and 269 samples obtained from Non-Hispanic White men (147 cases and 142 controls).

9. Based on the genotyping results, no statistically significant associations were noted when the repeat length was treated as a continuous variable. However, when a binary cutpoint was used (a median repeat length in our study, $\mathrm{CAG}=22$ ), AAM with longer repeats $(\geq 22)$ demonstrated increased prostate cancer risk.

10. Interestingly, the increased risk was only evident in obese (BMI $\geq 30)$, but not in the non-obese $(\mathrm{BMI}<30)$ AAM. No associations were noted in EAM regardless of the BMI.

11. We have analyzed the $C A G$ repeat distribution using other categories commonly used in other studies $(<19 ; 12-25$; and $\geq 26$ repeats). None of the analyses were significant using these categories $(p>0.05)$.

12. On the basis of our data, we are tempted to hypothesize that obese AAM with longer CAG repeats are prone to develop an androgen-independent malignancy that may be more aggressive and/or resistant to conventional treatments. Additional research is needed to test this hypothesis as well as establish possible reasons why this effect is observed in AAM but not in EAM.

\section{NCE:}

13. Prostate tumors were collected from patients treated at the Moffitt Cancer Center or affiliated hospital network. Tumor RNA was extracted using the commercial kits, and gene expression was performed using the Affymetrix U133A human arrays. Descriptive statistics and paired t-tests were performed.

14. A total of 220 tumors ( 200 White and 20 Black men) were profiled for expression of $\sim 1200$ genes implicated in carcinogenesis. Of those, a total of 15 genes showed statistically significant $(\mathrm{p}<0.05)$ differences in expression. The top hit was PSPHP1 upregulated in Black men $(\mathrm{FC}=4.7 ; \mathrm{p}=1.99 * 10-3)$ and associated with Falconi anemia. Other top hits all upregulated in White men included PDXDC2P $(\mathrm{FC}=2.7 ; \mathrm{p}=1.99 * 10-3)$, ACTN2 ( $\mathrm{FC}=1.8 ; \mathrm{p}=1.99 * 10-3)$ and PRN3P1 ( $\mathrm{FC}=1.6 ; \mathrm{p}=1.99 * 10-3)$. The differentially expressed genes are mainly implicated in the invasion and migration and angiogenesis.

\section{$\underline{\text { Reportable Outcomes }}$}

\section{Grants submitted:}

$1^{\text {st }}$ year:

- NIH R03 1R03CA172753-01: Comparative race-specific chemopreventive effects of curcumin in prostate cancer; submitted on 02/2012; [not funded]

- DoD hypothesis development PC120156: Comparative race-specific chemopreventive effects of curcumin in prostate cancer; submitted on 06/2012. [not funded]

$2^{\text {nd }}$ year:

- NIH R21 1R21CA179659-01: Obesity and prostate cancer risk in Black and White men: a functional approach; submitted on $11 / 2012$; scored 3.9 ( $30^{\text {th }}$ percentile).

- NIH R21 1R21CA179659-01-Resubmission: Obesity and prostate cancer risk in Black and White men: a functional approach; will be submitted 07/2013.

NCE:

- NIH R21 1R21CA179659-01- Obesity and prostate cancer risk in Black and White men: a functional approach; resubmitted 11/2013. Scored 13\%-tile and funded on September 19, 2014. 


\section{Posters presented:}

$1^{\text {st }}$ year:

- Joining FORCEs Against Hereditary Cancer Conference (June 2011, Orlando FL). The poster presentation entitled "Risk of Gastrointestinal Cancers in Female BRCA1 and BRCA2 Mutation Carriers".

- Center for Equal Health Strategic Planning Retreat Meeting (September 2011).

- Annual AACR meeting (March-April 2012, Chicago IL). The poster presentation entitled "The Risk Factors for Prostate Cancer in African American Men".

- The First Florida Prostate Cancer Research Symposium (May 4-5 2012, Orlando FL). The poster presentation entitled "The Risk Factors for Prostate Cancer in African American Men".

- Moffitt's 2012 Scientific Symposium (May 10 2012, Tampa FL). The poster presentation entitled "The Risk Factors for Prostate Cancer in African American Men".

$2^{\text {nd }}$ year:

- The Second Florida Prostate Cancer Research Symposium (March 2013, Orlando FL). The poster presentation entitled "Androgen Receptor CAG Repeat Length and Association with Prostate Cancer Risk in Obese and Non-Obese African American men".

- AACR Annual Meeting (04, 2013): Variation in transmembrane transport genes influence epithelial ovarian cancer risk and histopathologic subtype (poster presentation). Authors: Chornokur G; Tyrer J; Lin H-Y; Han G; Qu X; Chen Z; Tsai Y-Y; Goode EL; Cunningham JM; Iversen E; Ramus S; Berchuck A; Schildkraut JM; Monteiro A; Gayther S; Narod SA; Pharoah P; Sellers TA; Phelan CM.

- NIH "2012 Science of Eliminating Health Disparities Summit" (12, 2012): Polymorphisms in the metabolism related genes and obesity may explain prostate cancer disparity in African American men (poster presentation). Authors: Chornokur G; Amankwah EK; Park JY; Phelan CM; Kumar NB.

- AACR "The Science of Health Disparities" Conference $(10,2012)$ : Polymorphisms in the metabolism related genes and obesity may explain prostate cancer disparity in African American men (poster presentation). Authors: Chornokur G; Amankwah EK; Park JY; Phelan CM; Kumar NB.

The PI has received a competitive Scholar-in-training Award to cover the travel/attendance cost for this meeting.

NCE:

- AACR "The Science of Health Disparities" Conference $(11,2014)$ : Differential gene expression profiles in prostate tumors of Black and White men (poster presentation). Authors: Chornokur G; Hui-Yi Lin, Jong Y Park, Nagi B Kumar and Catherine M Phelan

- AACR "The Science of Health Disparities" Conference (11, 2014): Effect of Polyphenon E on Progression to Prostate Cancer after Diagnosis of High Grade Prostatic Intraepithelial Neoplasia or Atypical Small Acinar Proliferation in African American Men" (poster presentation). Authors: Kumar NB [senior author], Chornokur G [presenting author] et al.

The PI has received a competitive Scholar-in-training Award to cover the travel/attendance cost for this meeting.

\section{Manuscripts (published, accepted for publication or submitted):}


$11^{\text {st }}$ year:

- Shahnjayla Connors, Ganna Chornokur, Nagi Kumar. New Insights to the Mechanisms of Green Tea Catechins in the Chemoprevention of Prostate Cancer. Nutrition and cancer. 11/2011; 64(1):4-22; PMID: 22098273

- Kumar NB, Crocker, T, Smith T, Pow-Sang, J, Spiess, PE, Connors, SK, Chornokur, G, Iravani Dickinson, S, Williams, CR, Salup, R, Bai, W. Prostate Cancer Chemoprevention targeting High Risk Populations: Model for trial design and outcome measures. J Cancer Sci Ther. 2012; PMID: 22422102

- T.G. Kryshtab L.V. Borkovska O. Kolomys N.O. Korsunska V.V. Strelchuk, L.P. Germash, K.Yu. Pechers'ka, G. Chornokur, S.S. Ostapenko, C.M. Phelan, O.L. Stroyuk. The effect of bio-conjugation on aging of the photoluminescence in CdSeTe-ZnS core-shell quantum dots. Superlattices and Microstructures 51(3) 2012, 353-62

- Manju Venugopal, Sunil K. Arya, Ganna Chornokur, Shekhar Bhansali. A Realtime and Continuous Assessment of Cortisol in ISF Using Electrochemical Impedance Spectroscopy // Sens Actuators A Phys. 2011 1;172(1):154-160. PMID: 22163154

$2^{\text {nd }}$ year:

- Chornokur G., Kumar NB. Prostate cancer chemoprevention in men of African descent: current state of the art and opportunities for future research. Cancer Causes and Control 2013 [in press]. DOI: 10.1007/s10552-013-0241-x. PMID: 23737026

- Kumar N, Chornokur G (2012) Molecular Targeted Therapies Using Botanicals for Prostate Cancer Chemoprevention. Transl Med S2: 005. doi:10.4172/2161-1025.S2-005

- Chornokur G; Han G; Tanner R; Lin H-Y; Green LB, Pow-Sang J; Phelan CM. High Grade Prostate Intraepithelial Neoplasia (PIN) is a PSA-independent risk factor for prostate cancer in African American men: results from a pilot study. Cancer Letters 331(2): 154-7, 2013. PMID: 23268329

- Chornokur G, Amankwah EK, Schildkraut JM, Phelan CM. Global ovarian cancer health disparities. Gyn Oncol 121(1): 358-64, 2013. PMID: 23266352

- Chornokur G, Amankwah EK, Davis SN, Phelan CM, Park JY, Pow-Sang J, Kumar NB. Variation in $H N F 1 B$ and obesity may influence prostate cancer risk in African American men: a pilot study. Submitted to "Cancer Prevention Research", 06/2013.

- Phelan CM, Iqbal J, Lubinski J, Ragone A, Cybulski C, Lynch HT, Moller P, Ghadirian P, Foulkes WD, Armel S, Neuhausen SL, Senter L, Singer CF, Kim-Sing C, Tung N, Llacuachaqui M, Chornokur G, Ping $\mathrm{S}$, Narod SA and the Hereditary Breast Cancer Study Group. Incidence of colorectal cancer in BRCAI and BRCA2 mutation carriers: Results from a follow-up study. Submitted to Br. J. Cancer, 05/2013.

- Chornokur G, Amankwah EK, Lin HY .... and Phelan CM on behalf of OCAC. Cellular Transport Gene Variants Are Associated With Susceptibility to Epithelial Ovarian Cancer Risk and Histopathologic Subtypes. In preparation. Targeted timeline for submission 08/2013.

NCE:

- Chornokur G, Amankwah EK, Lin HY ... and Phelan CM on behalf of OCAC. Cellular Transport Gene Variants Are Associated With Susceptibility to Epithelial Ovarian Cancer Risk and Histopathologic Subtypes. Accepted to PLOS One with minor revisions. 
- Kim SJ, Amankwah E, Connors S, Park HY, Rincon M, Cornnell H, Chornokur G, Hashim AI, Choi J, Tsai Y-Y, Engelman RW, Kumar N, Park JY. Safety and chemopreventive effect of polyphenon E in preventing early and metastatic progression of prostate cancer in TRAMP mice. Cancer Prev Res 2014; 7(4); 435-44. DOI: 10.1158/1940-6207.CAPR-13-0427-T. PMID: 24501325

- Borysova M, Sultan D, Troutman A, Chornokur G, Dalton K. Prostate Cancer Disparities throughout the Cancer Control Continuum. Soc. Sci. 2013, 2, 247-269; doi:10.3390/socsci2040247.

\section{Classes / courses taken or audited:}

$1^{\text {st }}$ year:

- Cancer Epidemiology (Moffitt Cancer Center and University of South Florida);

- Biostatistics 101 (Moffitt);

- NIH grant writing workshop (AACR Annual Meeting);

- Human Subjects Protection refresher course (Moffitt Cancer Center and University of South Florida);

- Biosafety refresher course (Moffitt Cancer Center and University of South Florida);

- Moffitt annual Mandatory education test (Moffitt);

$2^{\text {nd }}$ year:

- Cancer Genetics (Moffitt);

- Moffitt annual Mandatory education test (Moffitt);

\section{Awards received by the PI:}

\section{$2^{\text {nd }}$ year and NCE:}

Scholar-in-training Award to attend the Fifth AACR Conference on The Science of Cancer Health Disparities in Racial/Ethnic Minorities and the Medically Underserved, 10, 2012

\section{Conclusions}

Both the training program and the research supplemental project are up to date, as described in the SOW in the original proposal.

On the training part, the PI advanced her knowledge and expertise in prostate cancer health disparity. The main training activities include, but are not limited to, regular meetings with the Mentoring team; gain hands-on research experience in the implementation and conduct of research studies; writing and submitting grants and manuscripts; attending relevant high-impact scientific meetings and conferences; making presentations; taking relevant courses and classes; and attending local seminars, ground rounds, and/or workshops focused on the topics of cancer (including prostate cancer), health disparities, community outreach and molecular biology/genetics.

On the research part, in the year 1, the PI has successfully genotyped 528 germline DNA samples obtained from AAM and EAM with prostate cancer and controls. For the genotyping experiments, she has selected 10 functional SNPs previously reported being associated with increased prostate cancer risk. It was found that two SNPs were statistically significantly associated with prostate cancer risk in AA, and one SNP - in EA men. Going further, the excessive prostate cancer risk associated with one of the SNPs in AA men was found in obese men only; it was not seen in either non-obese AAM, or EAM of any body mass.

In the year 2, the PI has proposed a concept of the increased risk in obese AAM based on the results of her year 1 results. Simultaneously, the PI has genotyped the same 528 AA/EA germline samples for CAG repeat in the androgen receptor gene. Data analysis revealed that no statistically significant associations were noted when the repeat length was treated as a continuous variable. However, when a binary cutpoint was used (a median repeat 
length in our study, $\mathrm{CAG}=22$ ), $\mathrm{AAM}$ with longer repeats $(\geq 22)$ demonstrated increased prostate cancer risk. Interestingly, the increased risk was only evident in obese (BMI $\geq 30)$, but not in the non-obese (BMI $<30) A A M$. No associations were noted in EAM regardless of the BMI. On the basis of these data, we are tempted to hypothesize that obese AAM with longer CAG repeats are prone to develop an androgen-independent malignancy that may be more aggressive and/or resistant to conventional treatments. Additional research is needed to test this hypothesis as well as establish possible reasons why this effect is observed in AAM but not in EAM.

In the NCE, the PI has analyzed the gene expression in the large subset of tumors of Black and White men with prostate cancer who undergo radical prostatectomy at the Moffitt Cancer Center. She has found a subset of genes which are differentially expressed in the tumors of Black and White men. She plans to combine these gene expression data with the genotyping data obtained earlier to try to unravel the biological and genetic determinants in $\mathrm{PCa}$ health disparity.

In summary, during the duration of this award, the PI has submitted 4 peer-reviewed grants (including one resubmission); received one competitive peer-reviewed research R21 grant (Chornokur PI) to continue her work on prostate cancer health disparity; presented her work at 10 relevant national meetings and conferences; published 10 peer-reviewed manuscripts (including 4 first-author); has taken/audited 8 relevant classes and/or workshops; and received 2 competitive travel awards. Most importantly, the PI has used this protected time and training to secure her own, independent research funds to continue her work in prostate cancer health disparities.

A "so what section": prostate cancer health disparity has a recognized genetic basis. It may, however, be challenging to translate the genetic data from bench to bedside due to the inherent complexity of the gene-gene, as well as gene-environment interactions. In this study, we have identified the functional SNPs that are significantly associated with prostate cancer risk in Black and White men. Further, we determined that the effect of these SNPs, as well as the length of CAG repeat polymorphism, on prostate cancer risk appears to correlate with obesity status and race. Our preliminary, hypothesis generating data has important public health implications for the US population, as $35-40 \%$ of people are obese and 1 in 5 AAM will be diagnosed with prostate cancer. Dr. Chornokur and her research team have developed a systematic project to attempt to tease out the biological basis for the observed associations between obesity, prostate cancer, race and androgen metabolism. While our data is preliminary, we strongly believe that our comprehensive approach will allow to shed light on the important question of the individual's genetic variance, obesity and its connection to prostate cancer risk in the susceptible population of AAM.

\section{References}

1. Levin AM, Machiela MJ, Zuhlke KA, et al. Chromosome 17q12 Variants Contribute to Risk of EarlyOnset Prostate Cancer // Cancer Res 2008;68:6492-6495.

2. Chang B-L, Cramer SD, Wiklund F, et al. Fine mapping association study and functional analysis implicate a SNP in MSMB at 10q11 as a causal variant for prostate cancer risk // Human Molecular Genetics, 2009, Vol. 18, No. 7

3. Ahn J, Kibel AS, Park JY, et al. Prostate Cancer Predisposition Loci and Risk of Metastatic Disease and Prostate Cancer Recurrence // Clin Cancer Res 2011;17:1075-1081

4. Kaklamania V, Yib N, Zhang K, et al. Polymorphisms of ADIPOQ and ADIPOR1 and prostate cancer risk // Metabolism 2011; 60(9): 1234-43.

5. Robbins CM, Hooker S, Kittles RA, Carpten JD. EphB2 SNPs and Sporadic Prostate Cancer Risk in African American Men // PLOS one May 2011 | Volume 6 | Issue 5 | e19494.

6. Thomas G, Jacobs KB, Yeager M, et al. Multiple loci identified in a genome-wide association study of prostate cancer // Nat Genetics 2008 40(3).

7. Lin DW, FitzGerald LM, Fu R, et al. Genetic Variants in the LEPR, CRY1, RNASEL, IL4, and ARVCF Genes Are Prognostic Markers of Prostate Cancer-Specific Mortality. Cancer Epidemiol Biomarkers Prev; 2011; 20, 1928. 
8. Davis SN; Diefenbach MA; Valdimarsdottir H et al. Pros and Cons of Prostate Cancer Screening: Associations With Screening Knowledge and Attitudes Among Urban African American Men // JNMA; 2010; 102(3): 174-82

9. Brown JM, Vessella RL, Kostenuik PJ, et al. Serum Osteoprotegerin Levels Are Increased in Patients with Advanced Prostate Cancer // Clin Cancer Res; 2001; 7:2977-2983

10. Kudahetti S, Fisher G, Ambroisine L et al. p53 immunochemistry is an independent prognostic marker for outcome in conservatively treated prostate cancer // BJU Internat; 2009; 104(1): $20-24$

11. Karami S, Young HA, Henson DE. Earlier age at diagnosis: Another dimension in cancer disparity? // Cancer Detection and Prevention 31 (2007) 29-34

12. Smith RA, Cokkinides V, Brooks D, et al. Cancer Screening in the United States, 2010: A Review of Current American Cancer Society Guidelines and Issues in Cancer Screening // CA Cancer J Clin 2010;60;99-119

13. Holen I and Shipman CM. Role of osteoprotegerin (OPG) in cancer // Clinical Science (2006) 110, 279-291

14. Chen G, Sircar K, Aprikian A, et al. Expression of RANKL/RANK/OPG in Primary and Metastatic Human Prostate Cancer as Markers of Disease Stage and Functional Regulation // Cancer 2006;107( 2): $289-98$

15. Blair JM, Zhou H, Seibel MJ and Dunstan CR. Mechanisms of Disease: roles of OPG, RANKL and RANK in the pathophysiology of skeletal metastasis // Nature Clinical Practice Oncology; 2006; $3(1): 41$

16. Lan YT, Chang S-C, Li AF-Y, et al. p53 protein accumulation as a prognostic marker in sporadic colorectal cancer // International Journal of Colorectal Disease; 2007; 22(5); 499-506

17. Lim LY, Vidnovic N, Ellisen LW, et al. Mutant p53 mediates survival of breast cancer cells // British Journal of Cancer (2009) 101, 1606-1612

18. Sleddens, H. F., Oostra, B. A., Brinkmann, A. O., and Trapman, J. (1992) Trinucleotide repeat polymorphism in the androgen receptor gene (AR). Nucleic Acids Res 20, 1427.

19. Sartor O, Zheng Q, Eastham JA. Androgen receptor gene CAG repeat length varies in a race-specific fashion in men without prostate cancer. Urology [1999, 53(2):378-380]

20. Zumoff B, Strain GW, Miller LK, et al. Plasma Free and Non-Sex-Hormone-Binding-Globulin Bound Testosterone Are Decreased in Obese Men in Proportion to Their Degree of Obesity. The Journal of Clinical Endocrinology \& Metabolism;1990; 71(4): 929-931

21. Feldman BJ, Feldman D. The development of androgen-independent prostate cancer. Nature Reviews Cancer 2001; 1: 34-45

\section{Appendices}

1. IRB approval

2. SRC approval

3. Specific aims of the submitted R03

4. Specific aims and summary statement of the R21

5. BRCA cancers poster

6. Prostate AAM poster

7. HNF1B poster

8. Ovarian transport poster

9. AR CAG repeats poster

10. HNF1B manuscript (submitted to Cancer Prevention Research)

11. $B R C A$ manuscript (submitted to British Journal of Cancer)

12. Ovarian transport paper (PLOS One)

13. Moffitt postdoctoral evaluation 2011-2012

14. Moffitt postdoctoral evaluation 2012-2013

15. Merged data dictionary 
16. No cost extension approval (06/2013-05/2014)

17. Specific aims of the funded R21 and the letter of award

18. Ovarian transport paper - revisions email

19. AACR abstract: prostate tumors and the email of the travel award 


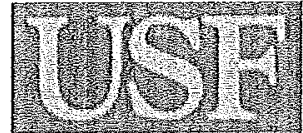

UNIVERSITY OF

SOUTH FLORIDA
DIVISION OF RESEARGH INTEORITI AND COMPLLANCE

Institutional Review Boards, FWA No.00001669

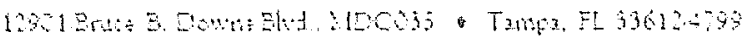

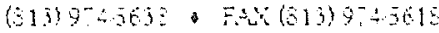

$7 / 21 / 2011$

Ganna Chornokur

H Lee Moffitt Cancer Center

12902 Magnolia Dr.

RE: Exempt Certification for IRBH: Pro00004885

Title: Comprehensive Population-Specific Marker Panel for Early Prostate Cancer

Diagnostics and Risk Assessment

Dear Dr. Chornokur:

On $7 / 21 / 2011$, the Institutional Review Board (IRB) determined that your research meets USF requirements and Federal Exemption criteria as outlined in the federal regulations at 45CFR46.101(b):

(4) Research involving the collection or study of existing data, documents, records, pathological specimens, or diagnostic specimens, if these sources are publicly available or if the information is recorded by the investigator in such a manner that subjects cannot be identified, directly or through identifiers linked to the subjects.

As the principal investigator for this study, it is your responsibility to ensure that this research is conducted as outlined in your application and consistent with the ethical principles outlined in the Belmont Report and with USF IRB policies and procedures. Please note that changes to this protocol may disqualify it from exempt status. Please note that you are responsible for notifying the IRB prior to implementing any changes to the currently approved protocol.

The Institutional Review Board will maintain your exemption application for a period of five years from the date of this letter or for three years after a Final Progress Report is received, whichever is longer. If you wish to continue this protocol beyond five years, you will need to submit a continuing review application at least 60 days prior to the exemption expiration date. Should you complete this study prior to the end of the five-year period, you must submit a request to close the study.

We appreciate your dedication to the ethical conduct of human subject research at the University of South Florida and your continued commitment to human research protections. If you have any questions regarding this matter, please call 813-974-5638. 
Sincerely,

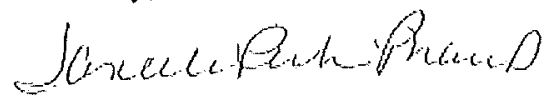

Janelle Perkins, PharmD, Chairperson

USF Institutional Review Board 
August 24, 2011

Ganna Chornokur, PhD

H. Lee Moffitt Cancer Center \& Research Institute

University of South Florida

12902 Magnolia Drive

Tampa, FL 33612

Dear Dr. Chornokur:

The Scientific Review Committee (SRC) has reviewed your response to its critique of amendment version dated $07 / 05 / 2011$ to your research protocol entitled, "Comprehensive Population-Specific Marker Panel for Early Prostate Cancer Diagnostics and Risk Assessment" (MCC 16701). The revised amendment version dated 08/15/2011 is approved as written for use at the Moffitt Cancer Center pending approval of the Institutional Review Board (IRB).

The use of tissue and data for research purposes is essential to advancing the scientific field; however because of safety, privacy, and security reasons, such research use is highly regulated by the federal government. Accordingly, the use of such tissue must be in accordance with the applicable Institutional Review Board (IRB) policy. Any changes or deviations that you wish to carry out on your approved study must be reported to the SRC Coordinator for determination of whether additional Scientific Review Committee (SRC) and IRB approvals are needed. This approval does not guarantee access to tissue samples.

It is your responsibility to ensure that all Moffitt staff (pathology, tissue core, data management, etc.) are informed and aware of the details of the project. The committee encourages the use of in-services for those projects that are complex or require special attention.

All changes made to protocols approved by the SRC must be submitted to the Protocol Review and Monitoring System office. Changes made to the protocol document require SRC review and approval. Minor changes (i.e. changes to personnel, non-scientific changes, changes that do not affect patient participation) will be expedited through the SRC review process. 
If this project is not being managed by the Clinical Trials Office or Clinical Research Unit, then it is your responsibility to follow through with all requirements for submission to the IRB. All IRB approvals are required to be documented in Oncore, and all associated regulatory documentation (signed applications, IRB approval letters and IRB approved consent forms, etc.) are to be saved in the appropriate study folder in the e-binders directory at J:lebinders.

Oncore is the Cancer Center's mechanism for submission and review of materials requiring Scientific Review (SRC) and Protocol Monitoring (PMC). If you need access to Oncore, please contact Jeryl Madden, Oncore Administrator, at 745-6964 for assistance.

Sincerely,

Simm Siegl

Erin Siegel, $\mathrm{PhD}, \mathrm{MPH}$

Chair, Scientific Review Committee 


\section{SPECIFIC AIMS:}

The American Cancer Society estimates that about 240,890 new cases of prostate cancer (PCa) occurred in the US during 2011 and 33,720 men died due to this disease. While PCa remains the most common type of solid malignancy, and the second-leading cause of all cancer death in men, African American men (AAM) have 1.6 times the incidence, and more than twice the mortality rate of PCa, compared to European American men (EAM) [1]. Although the reason(s) for this striking racial disparity are not well understood, recent research have identified the overactive survival mechanisms, that may predispose AAM to a more biologically aggressive disease. Despite advances in the screening, early detection and treatment of $\mathrm{PCa}$, the mortality and morbidity burden in AAM from the disease remains high. With the current uncertainty and complexity with regard to timing and frequency of screening for high risk populations, there is a pressing need for PCa control beyond early screening and detection. It is well recognized that the most promising approach to cancer control is a national commitment to prevention. Notably, PCa constitutes an ideal chemopreventive target due to existence of well defined premalignant lesions, as well as a generally long period of tumor dormancy in the localized stage $[2 ; 3]$.

Epidemiological and laboratory studies have demonstrated that several plant-derived botanicals influence multiple biochemical and molecular cascades that inhibit mutagenesis, proliferation, induce apoptosis and suppress the formation and growth of human cancers, modulate genetic and epigenetic pathways, thus targeting several hallmarks of carcinogenesis. Among these promising agents, curcumin (diferuloylmethane, an Indian dietary spice) was found to delay initiation and slow down PCa progression in the epidemiological and molecular studies [4-6], and animal models [7;8]. Curcumin exerts its multitargeted anticancer activity on myriad of cellular pathways that are essentially antiproliferative and proapoptotic [9-10]. Curcumin has been shown to inhibit proliferation in several prostate cancer cell lines, such as LNCaP, DU-145, and PC3 [9;11]. Curcumin has also been shown to induce cell cycle arrest in G1/S [12] and G2/M [13] phases in LNCaP and PC3. Additionally, curcumin induces apoptosis in LNCaP, DU145 and PC3 [12;14]. Curcumin inhibits NFKB activity in LNCaP and DU145 [14]. Lastly, curcumin inhibited invasiveness and reduced the MMP2 and MMP9 expression in DU145 [7]. Interestingly, AA-derived PCa tumors were found to have over expressed signaling receptors (including AR and EGFR) [15-16] and significantly greater proliferation rates can be observed in AAderived prostate tumors relative to EA-derived tumors. Similarly, key anti-apoptotic protein BCL-2 is upregulated [17-18], NFKB pathway is more active [19] in AAM-derived PCa tumors, whereas elevated expression of MMP9 has also been observed, increasing their invasive capacity [20]. These characteristics observed in AA-derived prostate cancer cell lines compared to EA-derived cell lines suggest that AAM and EAM PCa tumors treated with curcumin may exhibit different proliferation rates, demonstrate different cell cycle profiles, apoptosis rates, NFkB activities, and invasion capacities. Since curcumin specifically targets these molecular processes critical to prostate carcinogensis, at the public health level, these data provide first clues that AAM may have even better response to curcumin in terms of $\mathrm{PCa}$ chemoprevention. However at present, the effect(s) tumor biological differences exert on the chemoprevention of PCa with curcumin in AAM are unknown. Given the increased burden of $\mathrm{PCa}$ in $\mathrm{AAM}$ and potentially high effectiveness of $\mathrm{PCa}$ chemoprevention in reducing the disease burden, there is a dire need to establish and compare the effectiveness of $\mathrm{PCa}$ chemoprevention with curcumin in AAM and EAM, in order to inform the design of future chemopreventive trials in this exceptionally high risk population. With the availability of several commercially standardized formulations of curcumin and excellent safety profile, curcumin is an attractive compound to be tested for PCa chemoprevention. Our long term goal is to optimize the effectiveness of chemopreventive intervention against PCa in AAM and EAM. The objective of the proposed work is to determine whether chemopreventive effects of curcumin differ in AAM and EAM PCa cell lines. Our central hypothesis is that chemopreventive effects of curcumin, as measured by the changes in the main carcinogenic events - cell proliferation, cell cycle/ apoptosis and invasion/ metastasis - differ in AAM and EAM due to the underlying differences in tumor biology. We propose the following specific aim to test our hypothesis.

Specific aim 1 :To compare the chemopreventive effects of curcumin, as measured by the changes in the main carcinogenic events - cell proliferation, cell cycle/ apoptosis and invasion/ metastasis, in the wellcharacterized PCa cell lines, derived from AAM and EAM prostate tumors. Our successfully completed project is expected to contribute to evidence-based, clearly documented chemopreventive effects of curcumin in AAM and EAM derived PCa cell lines, as measured by the markers of cell proliferation, cell cycle/ apoptosis and invasion/metastasis. These mechanistic data are of a critical importance for designing a chemopreventive clinical trial of curcumin in men with PCa. Because AAM consistently carry increased burden of PCa, evidence based, specifically tailored chemopreventive intervention would offer tremendous public health benefit not only to that particular racial group, but to racially and ethnically diverse U.S. population as a whole. 


\section{$A p p \cdot 4$}

SPECIFIC AIMS. Both obesity (Body Mass Index (BMI) $\geq 30$ ) and prostate cancer (PCa) constitute significant public health problems, for which the disparities between African American men (AAM) and Non-Hispanic European men (EAM) are evident. AAM are 10\% more likely to be obese [1], $60 \%$ more likely to be diagnosed with, and $145 \%$ - to die from [2], PCa compared to their EAM counterparts. While obesity is an established risk factor for $\mathrm{PCa}$ biochemical recurrence and/or post treatment progression [3], the specific role of obesity in PCa risk is under investigation. Obesity as a physiological state is characterized by significant alterations in the individual's hormonal profile [4]. Since PCa is a hormonal disease, it appears biologically plausible that obesity affects PCa risk, possibly through the altered tumor growth enabled by the hormonal imbalances [5]. This effect may be even more pronounced in AAM since their PCa tumors tend to demonstrate more aggressive biological behavior at baseline [6-12]. Epidemiological studies have linked obesity to a slight decrease in the incidence of a low-grade (non-lethal) PCa and an increase in the incidence of an aggressive (lethal) disease [13-14]. A few studies [15-16] have linked obesity to more aggressive PCa in AAM specifically, suggesting involvement of obesity in PCa disparity. However, to date, the mechanistic biology studies aimed to elucidate the effects of obesity on PCa risk in AAM and EAM are lacking.

Our recent observation comparing AAM and EAM with and without PCa indicates that obese AAM (odds ratio (OR) 1.06; $p=0.022$ ) but not EAM (OR $0.98 ; p=0.332$ ) have slightly elevated overall PCa risk [Chornokur et al, appendices 1]. We further observed that AAM homozygous for the minor allele of the single nucleotide polymorphism (SNP) rs7501939 in the HNF1B gene have increased PCa risk (OR 2.14; $p=0.0103$ ) over 2-fold. Interestingly, the excessive risk is not observed in the non-obese AAM (OR 1.09; $p=0.763$ ) or EAM of any BMI ( $p>0.05)$. HNF1B encodes a member of a transcription factor superfamily that is expressed in the kidneys, pancreas and prostate. As such, it modulates key cellular processes, such as proliferation. Genetic variation in the HNF1B was previously associated with PCa [17-18] and type II diabetes [18], however the underlying mechanistic pathway(s) remain elusive. Taken together, these data suggest that obesity may be a $\mathrm{PCa}$ risk factor in AAM, and the extent of risk is determined by the individual's genetic variation. The goal of our project is to understand the joint impact of germline genetic variations and obesity on prostate tumor biology and PCa risk in AAM and EAM. We hypothesize that select genetic variation, when combined with the environment of obesity, influences PCa risk by impacting key cellular processes relevant to the tumor biology. We propose the following specific aims to lest our hypothesis:

1. To elucidate the effects of obesity on the gene expression profiles in AAM and EAM PCa tumors.

Approach. PCa tumors derived from obese and non-obese AAM and EAM, matched for age and Gleason grade will be profiled for expression of select genes using the NanoString Gene expression assays.

2. To test the functional significance of the selected genes in vitro and in vivo.

Approach. A. AAM and EAM derived PCa cell lines will be grown with and without the environment of obesity (sera from mice with diet-induced obesity). The genes of interest will be knocked down and the effects of the knock-down on the growth will be studied. $\underline{B}$. Cell lines with the most promising genes from the sub-aim A will be injected into nude mice (normal weight and obese) to monitor the effect of the knock-down on the tumor growth in vivo.

3. To link obtained data to $P C a$ risk through variation in the germline genome.

Approach. We will genotype the genes of interest using germline DNA from AAM and EAM cases and controls. We will use statistical approaches to determine whether genetic variation correlates with PCa risk.

Significance. Although AAM consistently carry increased PCa burden, the etiology of the disparity is unclear. AAM are also more likely to be obese, compared to their EAM counterparts. Thus, understanding the specific role of obesity in $\mathrm{PCa}$ risk is crucial for efficient development of individualized $\mathrm{PCa}$ risk estimation in $\mathrm{AAM}$ and EAM; selection of the most appropriate treatment modalities; estimating the risk of progression; advancing knowledge of the tumor biology in AAM and EAM; and developing targeted risk reduction interventions and informing the policies on healthy lifestyle and PCa prevention in diverse populations. Innovation. Our work is innovative, comprehensive and contemporary in that we will examine, within a single integrative approach, how obesity alters gene expression in PCa tumors of AAM and EAM; how these alterations affect PCa growth in $A A M$ and EAM; and whether germline genetic variation in those genes affects PCa risk in AAM and EAM. Unlike the non-candidate driven studies (such as GWAS) that cannot, on its own, elucidate the functional significance, we propose functionally relevant genetic variation to be incorporated in the risk prediction. Future directions. Guided by our findings, we plan to launch a clinical preventive study aimed to validate the results in a larger cohort of AAM and EAM, improve the proposed approach, and test the chemopreventive and/or lifestyle interventions targeted towards specific tumor and genetic features in AAM and EAM. In addition, our proposed model can be applied to study gene-environmental interactions in virtually any other malignancy. 


\section{App. $4 a$}

SUMMARY STATEMENT

PROGRAM CONTACT:

(Privileged Communication)

Release Date: $\quad 04 / 03 / 2013$

Rina Das

$301-496.8589$

dasr2@mail.nih.gov

Principal Investigator

Application Number: 1 R21 CA179659-01

CHORNOKUR, GANNA

Applicant Organization: H. LEE MOFFITT CANCER CTR \& RES INST

Review Group: ZRG' OBT.M (55)

Center for Sclentific Review Special Emphasis Panel

PAR Panel: Cancer Health Disparities/Diversity in Basic Cancer Research

Meeting Date: $03 / 18 / 2013$

Council: MAY 2013

Requested Start: 07/01/2013

$\begin{aligned} \text { RFA/PA: } & \text { PAR12-094 } \\ \text { PCC: } & \text { F3CD }\end{aligned}$

Project Title: Obesity and prostate cancer risk in Black and White men: a functional approach

SRG Action: Impact Score: 39 Percentile: 30 \#

Next Steps: Visit http://grants.nih.gov/grants/next_steps.htm

Human Subjects: E4-Human subjects involved - Exemption \#4 designated

Animal Subjects: 30 -Vertebrate animals involved - no SRG concerns noted

\begin{tabular}{ccr}
$\begin{array}{c}\text { Project } \\
\text { Year }\end{array}$ & $\begin{array}{c}\text { Direct Costs } \\
\text { Requested }\end{array}$ & $\begin{array}{r}\text { Estimated } \\
\text { Total Cost } \\
2\end{array}$ \\
& 150,000 & 252,750 \\
TOTAL & 125,000 & 210,625 \\
\cline { 2 - 3 } & 275,000 & 463,375
\end{tabular}

ADMINISTRATIVE BUDGET NOTE: The budget shown is the requested budget and has not been adjusted to reflect any recommendations made by reviewers. If an award is planned, the costs will be calculated by Institute grants management staff based on the recommendations outlined below in the COMMITTEE BUDGET RECOMMENDATIONS section. 


\section{R21CA179659-01 CHORNOKUR, GANNA}

RESUME AND SUMMARY OF DISCUSSION: The purpose of this study is to further understand the role obesity plays in prostate cancer ( $\mathrm{PCa}$ ) aggressiveness in African American men (AAM) compared to European American men (EAM), by exploring gene expression profiles of obese and non-obese men from each race and testing functional significance of the identified genes. The study is pertinent to cancer health disparities. Strengths are: biological relevant concept under consideration; state of the art technology; access to a good pool of human samples already collected; potential translational relevance; the cumulative expertise of the investigative team. Weaknesses that dampened enthusiasm include: selection of chemokines may not be relevant to $\mathrm{PCa}$; ambitious nature of the experimental design for a two year time frame; completion of Aims $2 \& 3$ is dependent of success of Aim 1; and normal adjacent tissue will not be compared to tumors. Several reviewers expressed concern with the minimum percent effort from senior collaborators and uncertain that the applicant has enough experience to drive the project. Most members of the study section agreed that these weaknesses diminish the impact of the proposal to the PCa and cancer health disparities fields and were score driving. However, few were more enthusiastic because of the proposal's translational potential.

DESCRIPTION (provided by applicant): Both obesity (Body Mass Index (BMI) e30) and prostate cancer $(\mathrm{PCa})$ constitute significant public health problems, for which there are persistent disparities between African American men (AAM) and Non-Hispanic European men (EAM). Obesity as a physiological state is characterized by significant alterations in the individual's hormonal profile. Since $\mathrm{PCa}$ is a hormonal disease, it appears biologically plausible that obesity affects PCa risk, possibly through the altered tumor growth enabled by the hormonal imbalances. This effect may be even more pronounced in AAM since their PCa tumors tend to demonstrate more aggressive biological behavior at baseline. Indeed, a few studies have linked obesity to more aggressive PCa in AAM specifically, suggesting involvement of obesity in PCa disparity. However, to date, the mechanistic biology studies aimed to elucidate the effects of obesity on PCa risk in AAM and EAM are lacking. In concordance with the published literature, our recent preliminary data suggest that obesity may be a PCa risk factor in $A A M$, and the extent of risk is determined by the individual's genetic variation. The goal of our project is to understand the joint impact of germline genetic variations and obesity on prostate tumor biology and $P C a$ risk in AAM and EAM. We hypothesize that select genetic variation, when combined with the environment of obesity, influences PCa risk by impacting key cellular processes relevant to the tumor biology. To test this hypothesis, a functional integrated approach is proposed, that utilizes prostate tumor biology as a starting point. In the Aim 1, we will investigate whether there are differences in the gene expression profiles of obese and non-obese men in each race. In the Aim 2, we will test the functional significance of the identified genes in vivo (cell lines) and in vitro (mice). Finally, in the Aim 3 we propose to link obtained data to PCa risk through variation in the germline genome. Significance. Understanding the specific role of obesity in PCa risk is crucial for efficient development of individualized PCa risk estimation in AAM and EAM; selection of the most appropriate treatment modalities; estimating the risk of progression; advancing knowledge of the tumor biology in AAM and EAM; and developing targeted risk reduction interventions. Innovation. Our work is innovative, comprehensive and contemporary in that we propose functionally relevant genetic variation to be incorporated in the risk prediction. Future directions. Guided by our findings, we plan to launch a clinical preventive study aimed to validate the results in a larger cohort of AAM and EAM, improve the proposed approach, and test the chemopreventive and/or lifestyle interventions targeted towards specific tumor and genetic features in AAM and EAM. In addition, our proposed model can be applied to study gene-environmental interactions in virtually any other malignancy.

PUBLIC HEALTH RELEVANCE: The proposed research is relevant to public health because its overarching goal is to reduce the prostate cancer burden on society, by understanding the role of obesity and germline genetic variation in prostate cancer risk in men of African and European descent. 
Thus, the proposed research is relevant to the NCl's mission of supporting research with respect to the prevention of cancer.

\section{CRITIQUE 1:}

Significance: 2

Investigator(s): 2

Innovation: 3

Approach: 5

Environment: 2

Overall Impact:

The relationship between obesity and predisposition of other diseases is becoming more relevant as the number of investigations increase. This proposal seeks to study the relationship between obesity, prostate cancer ( $\mathrm{PCa}$ ) and genetic variation. The investigators will use in vitro and in vivo approaches to explore gene expression and translate these findings back to human germline variations to determine risk prediction in African-American and European-American men. This proposal is highly significant and innovative partly justifying the level of enthusiasm.

\section{Significance:}

Strengths

- Obesity is a significant public health problem. The relationship between obesity and PCa is significant and highly relevant.

\section{Weaknesses}

- No major weaknesses noted.

\section{Investigator(s):}

Strengths

- Dr. Chornokur has put together a highly qualified Research team.

- Inclusion of biostatistician and the needed expertise is supported.

Weaknesses

- No major weaknesses noted.

\section{Innovation:}

\section{Strengths}

- A true translational approach to in vitro and in vivo gene expression exploration and the correlating these findings back to human germline variations to determine risk prediction in African-American and European-American men.

- The inclusion of a "gene-environment" analysis with in vitro, in vivo and risk determination.

\section{Weaknesses}

- General SNP profiling of AAM versus EAM men, not novel.

\section{Approach:}

\section{Strengths}

- Candidate-driven approach following gene expression analysis, then determination of functional relevance in vitro and vivo is novel.

\section{Weaknesses}

- The use of genomics to explore general African-American versus European American is not novel. Exploration of those genes selected or re-sequencing of those genes selected would give increased value to SNP selection and profiling. 
- Obesity induces inflammation; the modulation of inflammatory proteins in human cell lines may not be relevant in a rodent xenograft model.

\section{Environment:}

Strengths

- The environment is sufficient and adequate to sustain the completion of proposed goals.

Weaknesses

- No major weaknesses noted.

Protections for Human Subjects:

Acceptable Risks and/or Adequate Protections

- Falls under exempted study.

Data and Safety Monitoring Plan (Applicable for Clinical Trials Only):

- Not Applicable

Inclusion of Women, Minorities and Children:

G3A - Only Men, Acceptable

Vertebrate Animals:

Acceptable

- The five points well addressed.

\section{Biohazards:}

Not Applicable

Applications from Foreign Organizations:

Not Applicable (No Foreign Organizations)

\section{Select Agents:}

Not Applicable (No Select Agents)

Resource Sharing Plans:

Acceptable

\section{Budget and Period of Support:}

Recommend as Requested

\section{CRITIQUE 2:}

\section{Significance: 4}

Investigator(s): 4

Innovation: 3

Approach: 5

Environment: 4

\section{Overall Impact:}

The applicant proposes to evaluate the joint impact of genetic variation and obesity on prostate cancer tumor biology and prostate cancer risk in African American and European American men. The application might lead to improved predication of prostate cancer risk as well as clinical and lifestyle interventions to reduce the risk of prostate cancer. The application is high risk and novel - and if successful, can establish a new paradigm for conducting research on gene-environment interactions. 
The primary project seeks to accomplish broad goals, but lacks a methodical approach that can lay the groundwork for future research, reducing its impact.

\section{Significance:}

Strengths

- The role of obesity in prostate cancer risk is unknown; African American men have a higher risk of both; hormone imbalances represent a plausible mechanism by which obesity may impact prostate cancer risk.

- Preliminary data show possible interaction between genes and environment, thus there is a need for further examination of this topic.

- The applicant proposes to focus on functionally relevant genetic variation to ultimately improve risk prediction and direct clinical and lifestyle interventions.

- Data collected from this study can be used to conduct individualized prostate cancer risk assessments for African American and European American men, and to advance the knowledge of prostate cancer tumor biology.

\section{Weaknesses}

- Sample sizes are too small to draw solid conclusions; thus even if aims are achieved, the findings will need to be confirmed in larger, more controlled, studies.

\section{Investigator(s):}

\section{Strengths}

- Dr. Chornokur is a post-doctoral scientist at Moffitt Cancer Center and will contribute significant effort $(75 \%)$ to the project.

- The investigator is developing a track record of research in prostate cancer and her research has been recognized at AACR Health Disparities conferences.

\section{Weaknesses}

- An important concern is the low percent effort contributed by the senior investigators, most of who will participate in project meetings, deliver presentations, and prepare manuscripts.

- An additional weakness is the lack of expertise across the broad range needed for the diverse aspects of the study - more expertise in population sciences, less in animal models.

\section{Innovation:}

\section{Strengths}

- The project is highly innovative - the approach relies on the use of tumor biology as a starting point for identifying candidate genes responsible for prostate cancer risk. The applicant plans to apply what is learned from humans to animal models.

\section{Weaknesses}

- The project is perhaps overly ambitious- as it is unclear whether the findings from humans can be applied to animal models. Alternative approaches are not fully considered.

\section{Approach: \\ Strengths}

- The approach involves a combination of human and animal studies.

\section{Weaknesses}

- The project is ambitious and may not be readily accomplished in the allotted timeframe. It is preferable to limit the scope of this project, in a more rigorously controlled manner, than to conduct a broader less rigorous study, as proposed.

- The relatively small sample size, limited phenotype data, and somewhat simplified analysis plan means that the strategy proposed may be unable to detect true associations that may exist.

\section{Environment:}




\section{Strengths}

- Moffitt Cancer Center has sufficient resources and facilities to conduct the proposed study.

- The study will use retrospectively collected samples from African American and European American men.

Weaknesses

- It is unclear how much dedicated laboratory space the applicant has, and the commitment of Moffitt Cancer Center to provide her with space, as the applicant has served as a post-doctoral scientist for 4 years.

Protections for Human Subjects:

Acceptable Risks and/or Adequate Protections Data and Safety

- Anonymous samples already collected- Exemption \#4

Monitoring Plan (Applicable for Clinical Trials Only):

Not Applicable (No Clinical Trials)

Inclusion of Women, Minorities and Children:

G3A - Only Men, Acceptable

M1A - Minority and Non-minority, Acceptable

C3A - No Children Included, Acceptable

Vertebrate Animals:

Acceptable

Biohazards:

Not Applicable (No Biohazards)

Applications from Foreign Organizations:

Not Applicable (No Foreign Organizations)

\section{Select Agents:}

Not Applicable (No Select Agents)

Resource Sharing Plans:

Acceptable

Budget and Period of Support:

Recommend as Requested

\section{CRITIQUE 3:}

Significance: 1

Investigator(s): 1

Innovation: 2

Approach: 3

Environment: 1

\section{Overall Impact:}

This proposal seeks to determine whether genomic anomalies, including differentially expressed genes and genetic susceptibilities, coupled with obesity may help explain disparities in prostate cancer among African-Americans. They are also interested in understanding how differential expression of "obesity" genes may influence prostate cancer development using African-American and European prostate cancer cell lines. Their hypothesis, suggest that "obesity" genes combined with obesity may explain 
prostate cancer onset, progression, and more importantly health disparities. This goal is well supported by published reports and preliminary data and is consistent with NIH's provocative question regarding the link between obesity and cancer. There is some accumulating data suggesting that obesity may be related to prostate cancer risk, especially aggressive prostate cancer. The American Cancer Society and the National Institute of health are particularly interested in the link between obesity and cancer, which makes the proposed project a timely one. Adding the genomic and disparity elements make it particularly intriguing and novel, conceptually. This proposal offers a paradigm shift away from GWAS studies which sought to understand the genetic architecture of various cancers, leaving us with the identification of targets without any information about their biological importance. Instead, expression analysis of obese versus non-obese genes in AAM and EAM are used to guide functional assays in vitro as well as genetic susceptibilities within a human population study. The applicant 31 st authorships and 4 co-publications, and has assembled a stellar multi-disciplinary research team with documented evidence of collaborations. The statistician and oncologist are highly productive. This well written proposal has a high likelihood of helping to refocus basic scientist, epidemiologist, and biosystems biologists in terms of understanding genetics and obesity in relation to prostate cancer and other malignancies. If successful, it will help to make better recommendations in terms of readily modifiable risk factors. Human tissue specimens and germ-line DNA will be used in the proposed project, but a biohazard safety protocol was not addressed in the proposal.

\section{Significance:}

Strengths

- In the population where 3.5 out of 10 adults are overweight or chronically overweight and 1 and 6 men are diagnosed with prostate cancer, understanding the role of obesity in PCA risk is crucial for efficient control of this disease.

- This proposal will inform future obesity-genetic studies in virtually all malignancies.

- Improve our understanding on the role of the obesity-genetic axis on prostate cancer health disparities.

- Data will be useful to eventually provide medical and public health value to aid with prostate cancer risk assessment as well as intervention strategies.

- Future studies by the research team will use the results to inform future policies on healthy

\section{Weaknesses} lifestyle and prostate cancer prevention in diverse populations.

- None noted

\section{Investigator(s):}

Strengths

- The applicant is a Post-doc fellow at Moffitt Cancer Center and Research Institute.

- He has 7 publications of which 3 are 1 st authorships and 2 submitted manuscripts.

- The applicant is member of a multidisciplinary team with 4 co-publications.

- Dr. Kumar is an expert in cancer chemoprevention and obesity, clinical trials, translational research and cancer health disparities, particularly PCa disparity.

- Dr. Jong Park is an expert in molecular and genetic epidemiology focusing on PCa. He is actively involved in $\mathrm{PCa}$ tumor biology research, as well as characterization of genetic and epigenetic risks in $\mathrm{PCa}$. Dr. Park is building a model to predict metastatic progression of $\mathrm{PCa}$, including the influence of obesity.

- Dr. Catherine Phelan is an expert in molecular genetics. Dr. Phelan's research interests include cancer health disparities in African American men with PCa and Latin American women with breast cancer.

- Dr. Hul-Yi Lin is an expert in genetic and biomedical statistics who will provide help with the data Weaknesses analysis. Documented collaboration with Dr. Jong Park. 
- None noted.

3. Innovation:

Strengths

- Looking at the link between prostate cancer and obesity is novel, especially as it relates to prostate cancer health disparity research.

- Suggest a paradigm shift away from GWAS and back to a candidate gene approach.

Weaknesses

- Overall methods are pretty common.

\section{Approach:}

Strengths

- Tumor expression profiles from pre-clinical studies in Aim 2 will be saved for future studies.

- Availability of survival data among the cases will permit future exploratory studies.

- Seeks to use a state-of the art genomic approach that is suitable for archival tissue.

- State of the art equipment for gene expression analysis.

\section{Weaknesses}

- Not clear how race/ethnic-specific genes will be selected in Aims 1-3.

- For Aim 2, no justification for focusing on the top 5 genes selected in Aim 2. How will the selected genes be prioritized?

- Pathway analysis tools are ignored in Aim 1. This seems like a missed opportunity to find racespecific genes/pathways responsible for obesity induced prostate cancer.

- Seems like a missed opportunity to ignore gene-gene interaction effects in Aim 3.

- Aim 1, Not sure what percent of subjects would have a BMI 25-29.9. Would these individuals be placed in the "high" or "low" risk group?

- Aim 1, analysis gene expression separately for each racial/ethnic group is fine but it seems like using AAMs to select for high-risk genes should be considered as well. In this regard, genes that are over- or under-expressed relative to EAM may serve as high-risk markers.

- Aim 2, budget limitations are acknowledged and understood. However, failure to tease out the cancer related genes from the surrounding "normal" tissue may dilute the capacity to finding meaningful relationships.

- Aim 1, not clear what \% change in means between "obese vs. non-obese" or "AAM vs. EAM" are needed for the results to be meaningful. Of course for the racial ethnic comparisons, one would have to "subtract out" or adjust for normal tissue expression profiles.

- $\operatorname{Aim} 3$, not clear what strategy if any will be used to prioritize and select 205 SNPs.

\section{Environment:}

\section{Strengths}

- Outstanding research environment. All resources for the proposed project are readily available.

\section{Weaknesses}

- None noted.

Protections for Human Subjects:

Acceptable Risks and/or Adequate Protections

- adequately addressed

Data and Safety Monitoring Plan (Applicable for Clinical Trials Only): Not Applicable (No Clinical Trials)

Inclusion of Women, Minorities and Children: G3A - Only Men, Acceptable 
1R21 CA179659-01 
Vertebrate Animals:

Acceptable

- Adequately addressed

Biohazards:

Unacceptable

- Human tissue specimens will be analyzed; however, no biohazard safety methods were noted.

Applications from Foreign Organizations:

Not Applicable (No Foreign Organizations)

Select Agents:

Not Applicable (No Select Agents)

Resource Sharing Plans:

Acceptable

- Adequately addressed.

Budget and Period of Support:

Recommend as Requested

THE FOLLOWING RESUME SECTIONS WERE PREPARED BY THE SCIENTIFIC REVIEW OFFICER TO SUMMARIZE THE OUTCOME OF DISCUSSIONS OF THE REVIEW COMMITTEE ON THE FOLLOWING ISSUES:

PROTECTION OF HUMAN SUBJECTS (Resume): ACCEPTABLE. Use of anonymous and retrospectively collected for another study, their use is justified. Exemption 4 is applicable.

VERTEBRATE ANIMAL (Resume): ACCEPTABLE. The applicant has adequately described the use of mice in the proposed studies. Both the number and experimental details are well justified and clearly presented.

COMMITTEE BUDGET RECOMMENDATIONS: The budget was recommended as requested.

\section{\# Ad hoc or special section application percentiled against "Total CSR" base.}

NIH has modified its policy regarding the receipt of resubmissions (amended applications). See Guide Notice NOT-OD-10-080 at

http://grants.nih.gov/grants/guide/notice-files/NOT-OD-10-080.html.

The impact/priority score is calculated after discussion of an application by averaging the overall scores (1-9) given by all voting reviewers on the committee and multiplying by 10 . The criterion scores are submitted prior to the meeting by the individual reviewers assigned to an application, and are not discussed specifically at the review meeting or calculated into the overall impact score. Some applications also receive a percentile ranking. For details on the review process, see http://grants.nih.gov/grants/peer_review_process.htm\#scoring. 


\section{MEETING ROSTER}

\section{Center for Scientific Review Special Emphasis Panel \\ CENTER FOR SCIENTIFIC REVIEW \\ PAR Panel: Cancer Health Disparities/Diversity in Basic Cancer Research \\ ZRG1 OBT-M (55) R}

March 18, 2013 - March 19, 2013

\author{
CHAIRPERSON \\ FLYNN, DANIEL, PHD \\ ASSOCIATE DEAN OF RESEARCH \\ UNIDEL PROFESSOR OF HEALTH SCIENCES \\ ASSOCIATE DEAN FOR RESEARCH \\ UNIVERSITY OF DELEWARE \\ COLLEGE OF HEALTH SCIENCES \\ NEWARK, DE 19716

\section{MEMBERS} \\ BENSON, CHARLESE GARNETT, PHD \\ ASSISTANT PROFESSOR \\ DEPARTMENT OF BIOLOGY \\ GEORGIA STATE UNIVERSITY \\ ATLANTA, GA 30302 \\ BRYANT-FRIEDRICH, AMANDA C, PHD \\ ASSOCIATE PROFESSOR \\ DEPARTMENT OF MEDICINAL AND \\ BIOLOGICAL CHEMISTRY \\ UNIVERSITY OF TOLEDO COLLEGE OF PHARMACY \\ TOLEDO, OH 43606 \\ CHAUHAN, SUBHASH C, PHD, PHD \\ ASSOCIATE PROFESSOR \\ CANCER BIOLOGY RESEARCH CENTER \\ SANFORD RESEARCH/USD \\ SIOUX FALLS, SD 57105 \\ CHEN, HONGWU, DVM, PHD \\ PROFESSOR \\ DEPARMENT OF BIOCHEMISTRY \\ AND MOLECULAR MEDICINE \\ UC DAVIS CANCER CENTER \\ UNIVERSITY OF CALIFORNIA AT DAVIS \\ SACARAMENTO, CA 95817 \\ CORONADO, GLORIA D, PHD \\ MITCH GREENLICK ENDORSED SENIOR INVESTIGATOR \\ IN HEALTH DISPARITIES RESEARCH \\ KAISER PERMANENTE CHR \\ PORTLAND, OR 97227 \\ DEL CARMEN, MARCELA G \\ ASSOCIATE PROFESSOR \\ DEPARTMENT OF OBSTETRICS, GYNECOLOGY \\ AND REPRODUCTIVE BIOLOGY \\ HARVARD MEDICAL SCHOOL \\ BOSTON, MA 02114 \\ GANAPATHI, RAM N., PHD \\ CHAIR, CANCER PHARMACOLOGY \\ LEVINE CANCER INSTITUTE \\ CAROLINAS HEALTHCARE SYSTEM \\ CHARLOTTE, NC 28204
}

GU, XINBIN, MD, PHD

PROFESSOR, ASSOCIATE DEAN FOR RESEARCH

DEPARTMENT OF ORAL PATHOLOGY

HOWARD UNIVERSITY COLLEGE OF DENTISTRY

WASHINGTON, DC 20059

HU, JENNIFER J, PHD

PROFESSOR, DEPARTMENT OF EPIDEMIOLOGY AND

PUBLIC HEALTH

ASSOCIATE DIRECTOR, DIVISION OF CANCER

PREVENTION

AND CONTROL

SYLVESTER COMPREHENSIVE CANCER CENTER

UNIVERSITY OF MIAMI MILLIER SCHOOL OF MEDICINE MIAMI, FL 33136

KAUSHIK-BASU, NEERJA, PHD

ASSOCIATE PROFESSOR

DEPARTMENT OF BIOCHEMISTRY AND MOLECULAR

BIOLOGY

UMDNJ-NEW JERSEY MEDICAL SCHOOL

NEWARK, NJ 07103

KELLEY, MARKR., PHD

BETTY AND EARI. HERR CHAIR IN PEDIATRIC

ONCOLOGY RESEARCH AND PROFESSOR,

DEPARTMENTS OF BIOCHEMISTRY AND MOLECULAR

BIOLOGY \& PHARMACOLOGY AND TOXICOLOGY

INDIANA UNIVERSITY SCHOOL OF MEDICINE

INDIANAPOLIS, IN 46202

KIDD, LA CREIS RENEE, PHD

ASSOCIATE PROFESSOR

ENDOWED CHAIR IN CANCER RESEARCH

DEPARTMENT OF PHARMACOLOGY AND TOXICOLOGY UNIVERSITY OF LOUISVILLE

LOUISVILLE, KY 40202

KIMBRO, KEVIN SEAN, PHD

ASSOCIATE PROFESSOR

DIRECTOR, BIOMEDICAL/BIOTECHNOLOGY

RESEARCH INSTITUTE

NORTH CAROLINA CENTRAL UNIVERSITY

DURHAM, NC 27713

KUMAR, DEEPAK, PHD

ASSOCIATE PROFESSOR AND CHAIR

DEPARTMENT OF BIOLOGY

UNIVERSITY OF THE DISTRICT OF COLUMBIA

WASHINGTON, DC 20008

LIESVELD, JANE L, MD

PROFESSOR

DEPARTMENT OF MEDICINE

JAMES P. WILMOT CANCER CENTER

UNIVERSITY OF ROCHESTER SCHOOL OF MEDICINE ROCHESTER, NY 14642 
LOKESHWAR, BAL L., PHD

PROFESSOR

DEPARTMENT OF UROLOGY AND RADIATION

ONCOLOGY

UNIVERSITY OF MIAMI MILLER SCHOOL OF MEDICINE

MIAMI, FL 33136

MATTA, JAIME L PHD

PROFESSOR OF PHARMACOLOGY AND TOXICOLOY, RESEARCH PROFESSOR OF SURGERY

PONCE SCHOOL OF MEDICINE AND HEALTH SCIENCES PONCE, PR 007327004

MUGANDA, PERPETUA M, PHD

PROFESSOR

DEPARTMENT OF BIOLOGY

COLLEGE OF ARTS AND SCIENCES

NORTH CAROLINA A\&T STATE UNIVERSITY

GREENSBORO, NC 27411

RAY, RATNA B., PHD

PROFESSOR

DEPARTMENT OF PATHOLOGY

EDWARD A DOISY RESEARCH CENTER

SAINT LOUIS UNIVERSITY

ST. LOUIS, MO 63104

SLACK-DAVIS, JILL, PHD

ASSISTANT PROFESSOR

DEPARTMENT OF MICROBIOLOGY, IMMUNOLOGY

AND CANCER BIOLOGY

UNIVERSITY OF VIRGINIA

CHARLOTTESVILLE, VA 22908

TAIOLI, EMANUELA, MD, PHD

PROFESSOR/CHIEF

DEPARTMENT OF EPIDEMIOLOGY

HOFSTRA SCHOOL OF MEDICINE

MANHASSET, NY 11021

WEBSTER-CYRIAQUE, JENNIFER Y, DDS, PHD

ASSOCIATE PROFESSOR

DEPARTMENT OF DENTAL ECOLOGY AND DENTAL

RESEARCH

SCHOOL OF DENTISTRY

DEPT OF MICROBIOLOGY SCHOOL OF MEDICINE

UNIVERSITY OF NORTH CAROLINA CHAPEL HILL

CHAPEL HILL, NC 27599

YAMAMOTO, MASATO, MD, PHD

CO-DIRECTOR PROFESSOR

DIVISION OF BASIC AND TRANSLATION RESEARCH

DEPARTMENT OF SURGERY

UNIVERSITY OF MINNESOTA

MINNEAPOLIS, MN 55455

YULL, FIONAE, PHD

ASSOCIATE PROFESSOR

DEPARTMENT OF CANCER BIOLOGY

INGRAM CANCER CENTER

VANDERBILT UNIVERSITY

NASHVILLE, TN 37232
MAIL REVIEWER(S)

CRISTINI, VITTORIO, PHD

PROFESSOR

DEPARTMENT OF PATHOLOGY

UNIVERSITY OF NEW MEXICO

ALBUQUERQUE, NM 87131

TRICHE, TIMOTHY J., MD, PHD

PATHOLOGIST-IN-CHIEF/CHAIRMAN/PROFESSOR DEPARTMENT OF PATHOLOGY AND LABORATORY MEDICINE

CHILDREN'S HOSPITAL OF LOS ANGELES

UNIVERSITY OF SOUTHERN CALIFORNIA

LOS ANGELES, CA 90027

WEBB, TONYA J., PHD

ASSISTANT PROFESSOR

DEPARTMENT OF MICROBIOLOGY AND IMMUNOLOGY

UNIVERSITY OF MARYLAND SCHOOL OF MEDICINE

BALTIMORE, MD 21201

SCIENTIFIC REVIEW ADMINISTRATOR

SIERRA-RIVERA, ELAINE, PHD

SCIENTIFIC REVIEW OFFICER

CENTER FOR SCIENTIFIC REVIEW

NATIONAL INSTITUTES OF HEALTH

BETHESDA, MD 20892

\section{GRANTS TECHNICAL ASSISTANT}

MORRIS, DONTE

EXTRAMURAL SUPPORT ASSISTANT

CENTER FOR SCIENTIFIC REVIEW

NATIONAL INSTITUTE OF HEALTH

BETHESDA, MD 20892

Consultants are required to absent themselves from the room during the review of any application If their presence would constitute or appear to constitute a conflict of interest. 


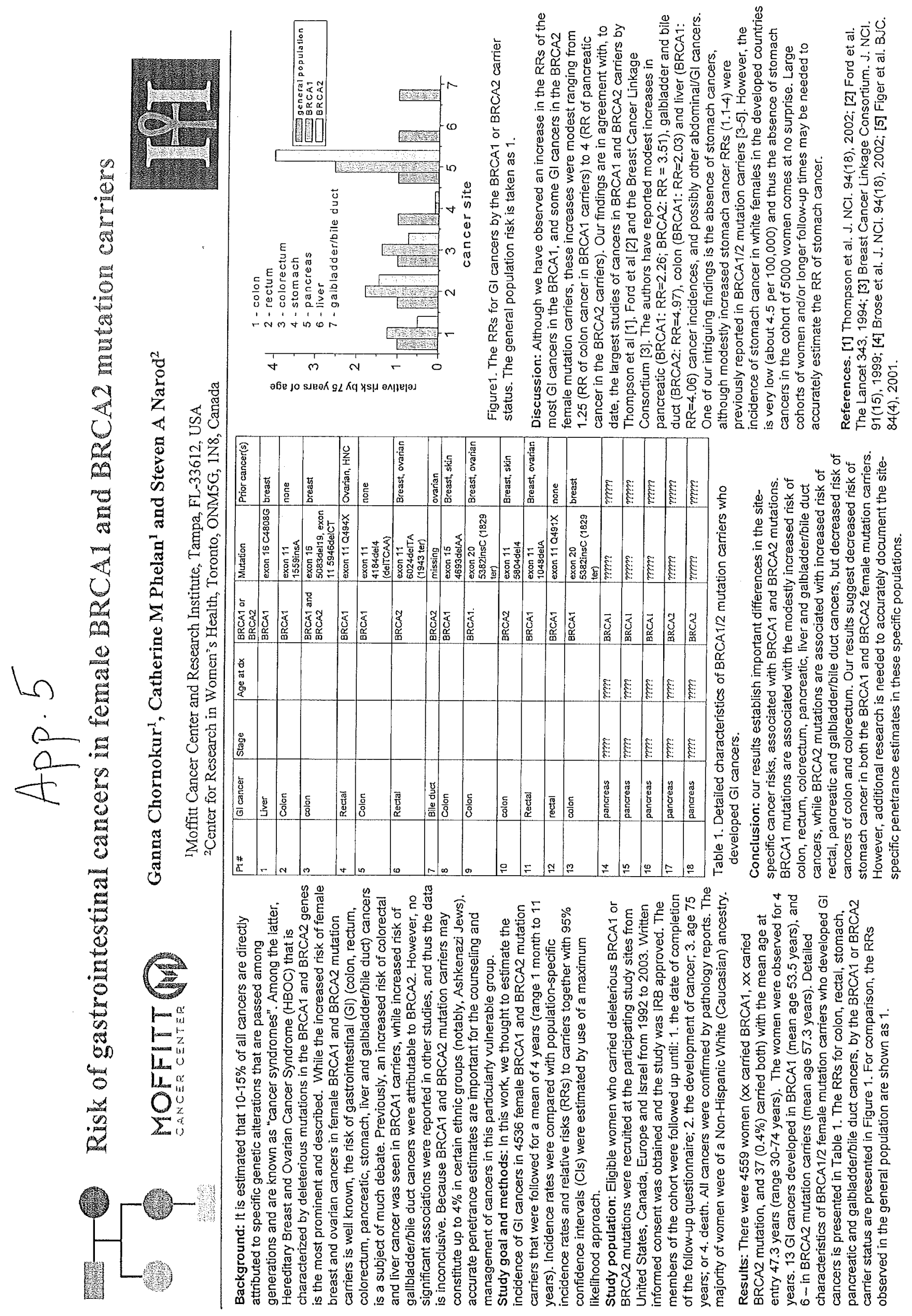



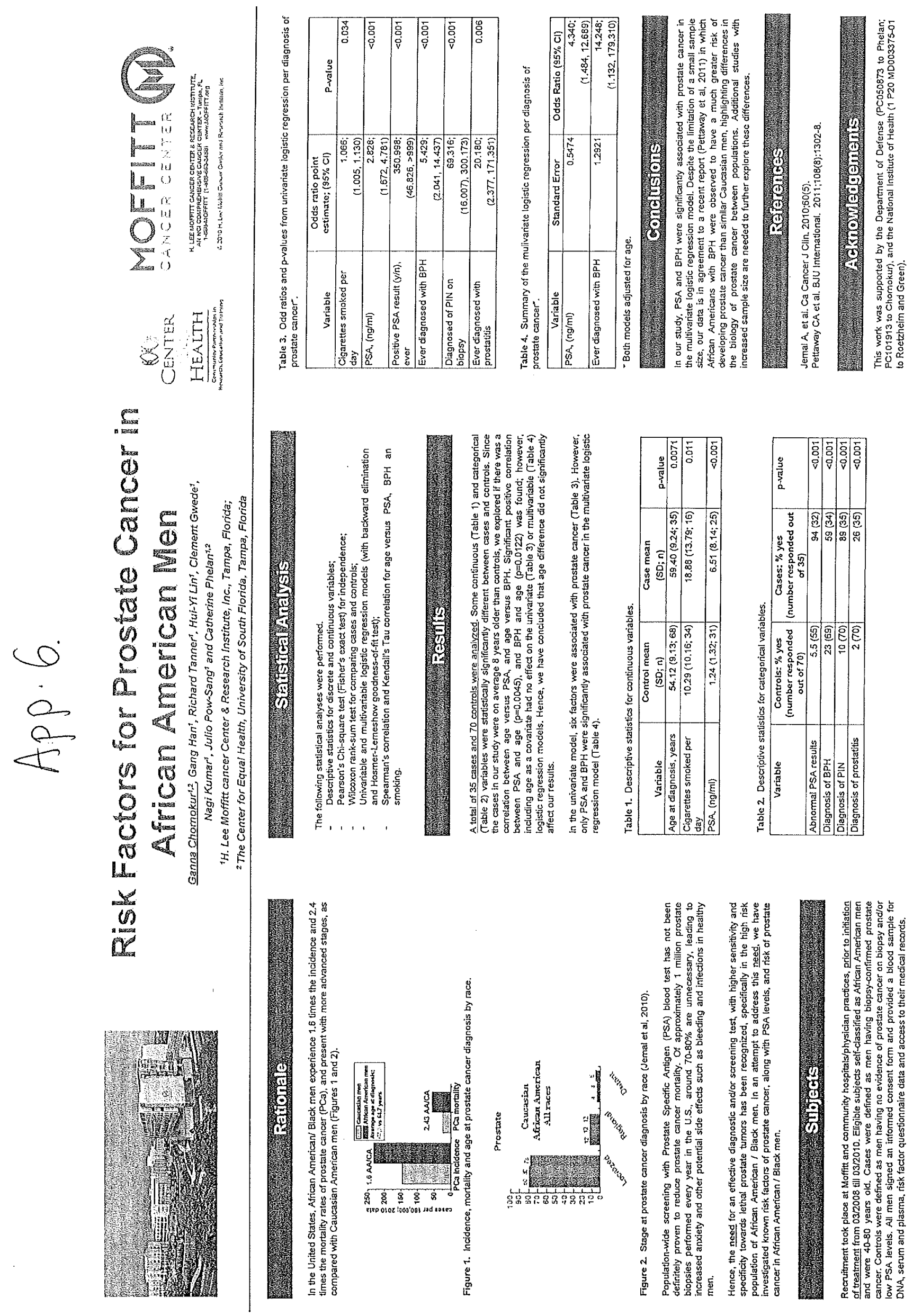


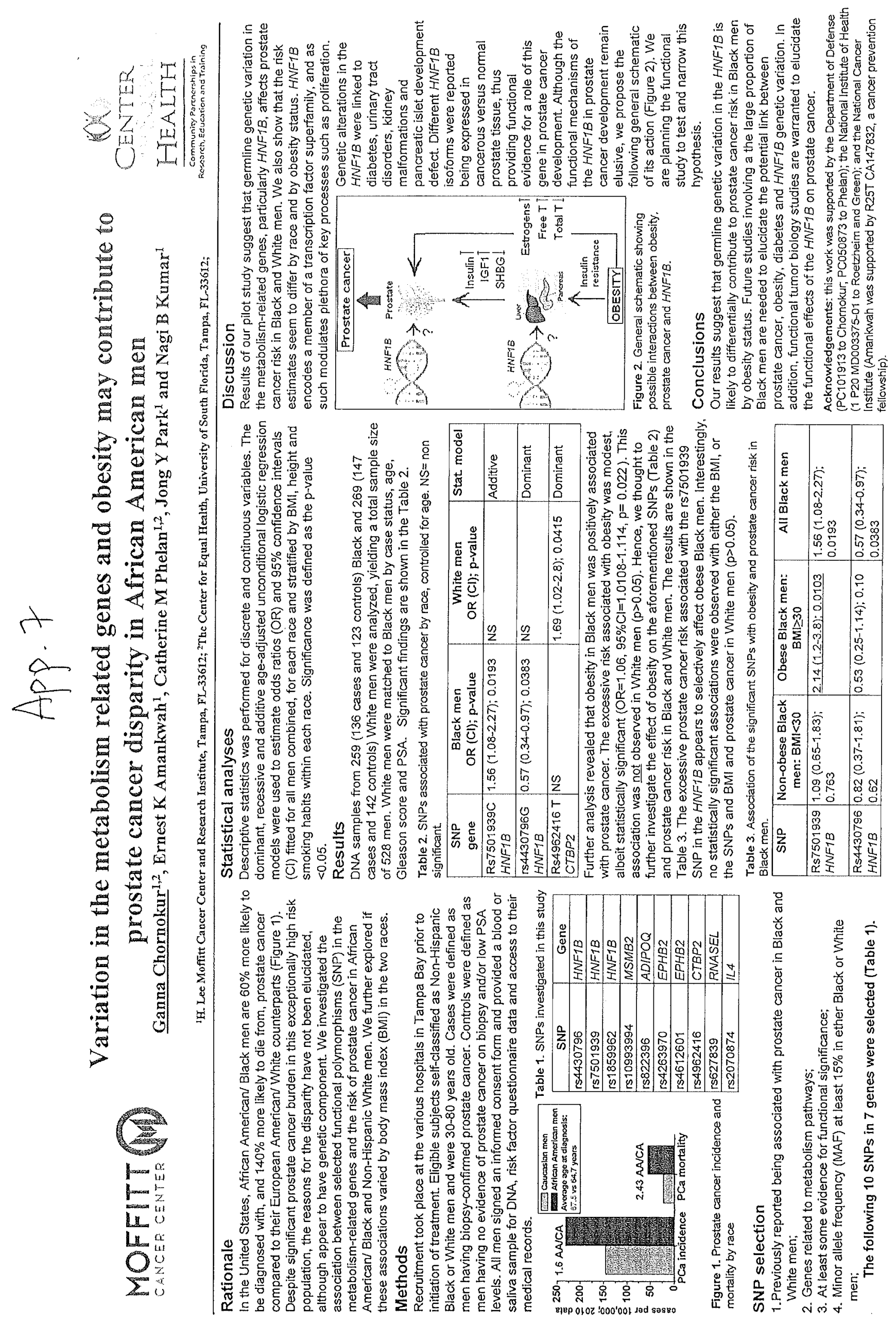




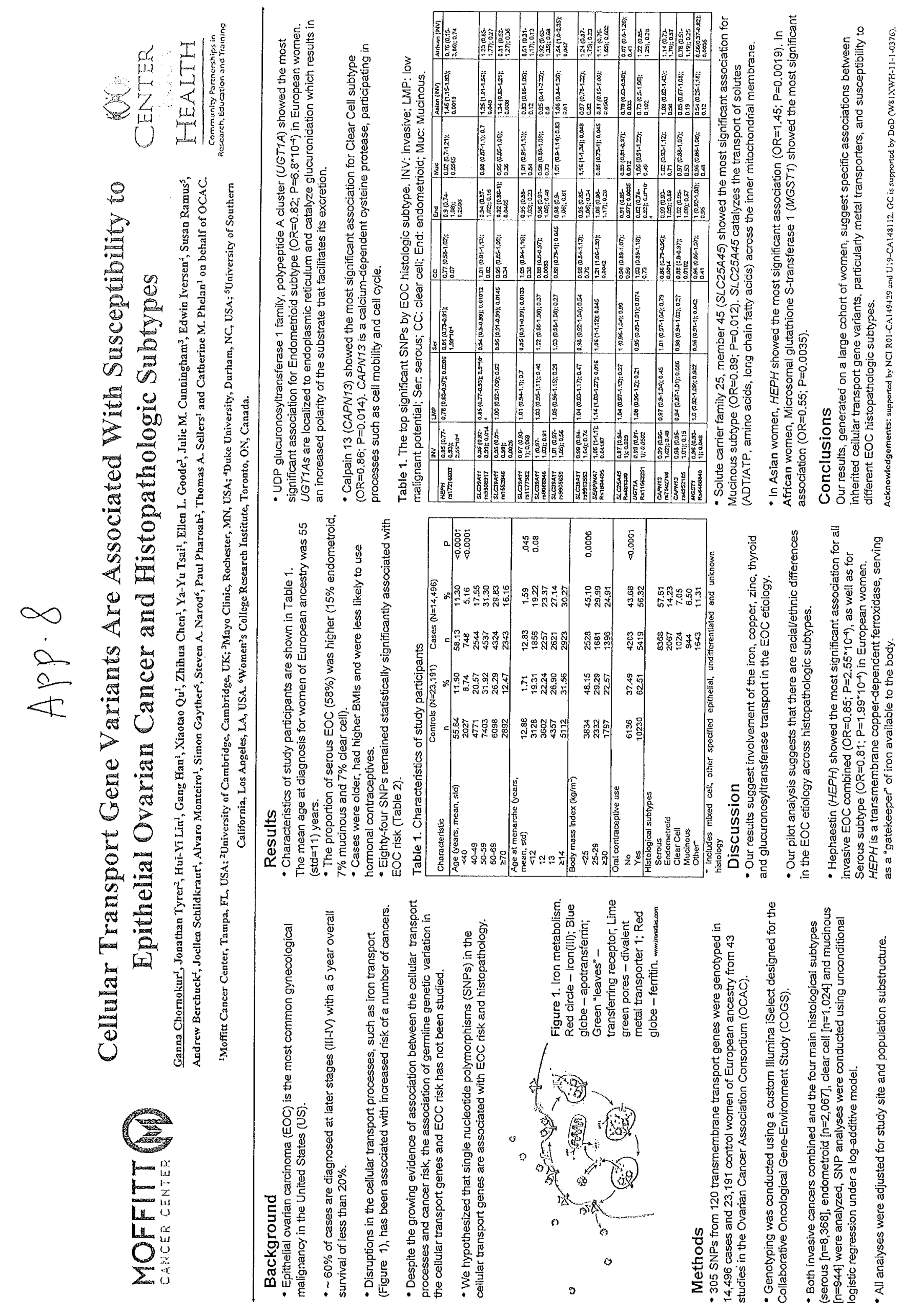




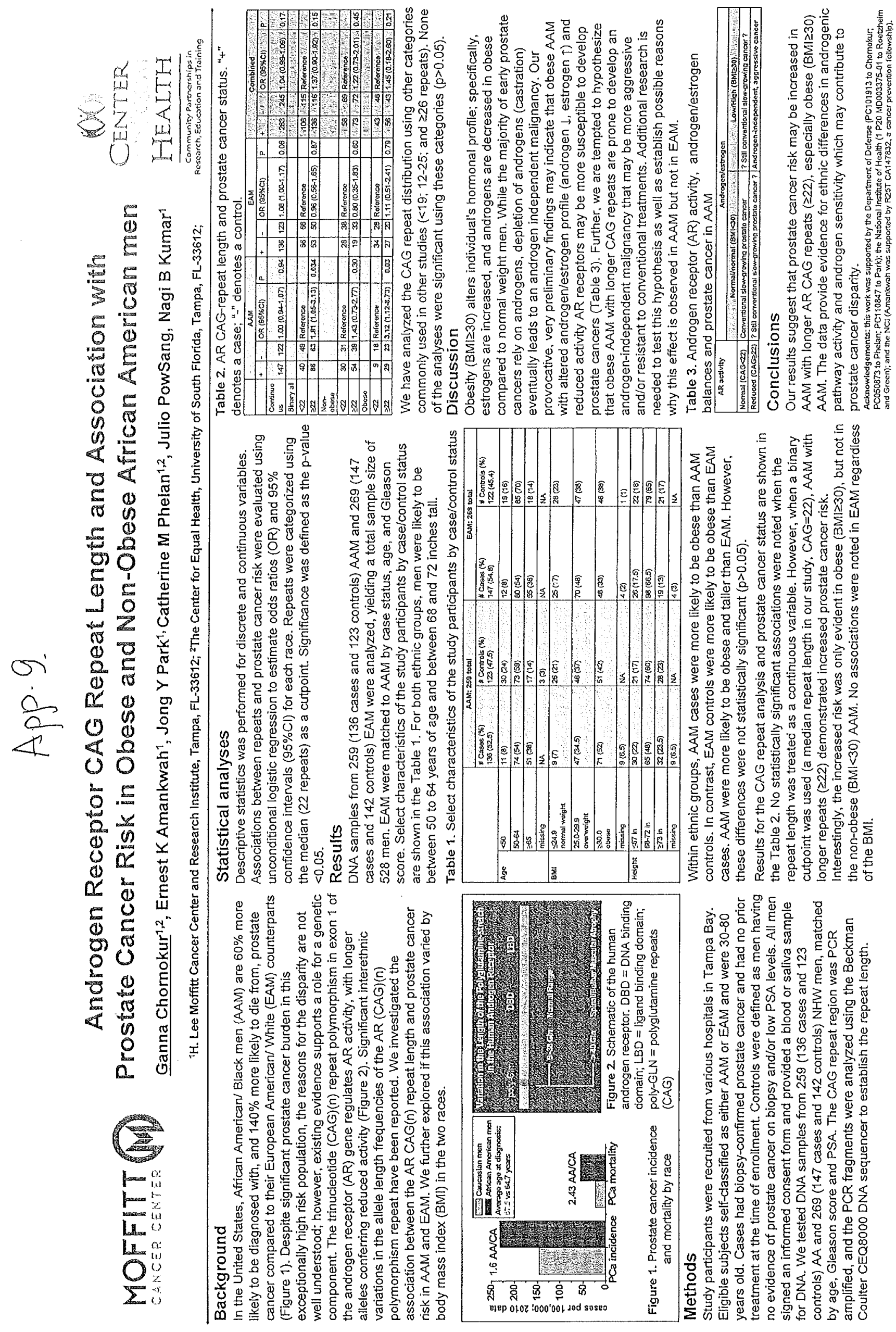




\section{App. 10}

Variation in HNF1B and obesity may influence prostate cancer risk in African American men: a pilot study

Ganna Chornokur ${ }^{1,4 *}$, Ernest K Amankwah ${ }^{1}$, Stacy N Davis ${ }^{2}$, Catherine M Phelan ${ }^{1,4}$, Jong $Y$ Park', Julio Pow-Sang ${ }^{3}$ and Nagi B Kumar ${ }^{1,4}$

${ }^{1}$ Department of Cancer Epidemiology, Moffitt Cancer Center, Tampa, FL33612

${ }^{2}$ Department of Health Outcomes and Behavior, Moffitt Cancer Center, Tampa, FL33612

${ }^{3}$ Department of Genitourinary Oncology, Moffitt Cancer Center, Tampa, FL33612

${ }^{4}$ The Center for Equal Health, Tampa, FL33612

*To whom correspondence should be addressed:

Ganna Chornokur, PhD,

Postdoctoral Scientist,

Department of Cancer Epidemiology,

Moffitt Cancer Center,

Tampa, FL33612.

Ph: 813-745-6531

Fax: 813-745-6525

E-mail: ganna.chornokur@moffitt.org 


\section{Abstract}

Background. Prostate cancer ( $\mathrm{PCa}$ ) racial disparity is multifactorial, involving biological, as well as socio-cultural and lifestyle determinants. We investigated the association between selected potentially functional polymorphisms and PCa risk in African American/Black (AAM) and NonHispanic White (EAM) men. We further explored if these associations varied by the body mass index (BMI) and height in each race.

Methods. Age-matched DNA samples from 259 (136 cases and 123 controls) AAM and 269 (147 cases and 142 controls) EAM, were genotyped for 10 candidate single nucleotide polymorphisms (SNPs) in 7 genes using the TaqMan allelic differentiation analysis. The dominant, recessive and additive age-adjusted unconditional logistic regression models were fitted for all men combined, for each race and stratified by BMl and height within each race. Results. Three SNPS showed statistically significant associations with PCa risk. In AAM: HNF1B rs7501939 $(\mathrm{OR}=2.42,95 \% \mathrm{Cl}=1.31-4.47, \mathrm{P}=0.0046)$ and $\mathrm{rs} 4430796(\mathrm{OR}=0.57$, $95 \% \mathrm{Cl}=0.34-0.97, \mathrm{P}=0.0383$ ), which were both previously associated with the risk for type II diabetes. In EAM: CTBP2 rs4962416 (OR=1.52, 95\% $\mathrm{Cl}=1.02-2.26, \mathrm{P}=0.0384)$. In addition, high BMI in AAM (OR=1.06, 95\% $\mathrm{Cl}=1.01-1.114, \mathrm{P}=0.022)$, and height in $E A M(O R=0.92$, $95 \% \mathrm{Cl}=0.85-0.99, \mathrm{P}=0.0434$ ) showed significant associations. Interestingly, HNF1B rs7501939 was associated with $P C a$ exclusively in obese $A A M(O R=2.14,95 \% C l=1.2-3.8, P=0.0103)$. Conclusion. Our results suggest that variation in the HNF1B may influence PCa risk in obese AAM. 


\section{Introduction}

Prostate cancer ( $\mathrm{PCa}$ ) remains the most common type of solid malignancy, and the second-leading cause of all cancer death in U.S. men [1]. However, the burden of PCa is not the same across all racial and ethnic groups, as African American / Black men (AAM) consistently demonstrate 1.6 times higher incidence, and 2-3 times higher mortality rates of PCa, compared to their Non-Hispanic White (EAM) counterparts [2]. In addition, AAM are more likely to be diagnosed at an earlier age, have more aggressive tumors and higher recurrence rates following definite treatments [2-3]. The etiology of racial disparity in PCa is thought to be multifactorial, involving biological, as well as socio-cultural and lifestyle determinants [4]. Although genome-wide association studies (GWAS) have identified more than a dozen PCa risk loci [5], elucidating the biological basis for these associations is challenging [6]. The post-GWAS studies are increasingly suggestive of the interaction between genetic variants and environmental risk factors [7] for which our understanding is still largely inadequate [8].

Established risk factors for $\mathrm{PCa}$ are increasing age, race and a family history of the disease [2-4]. Obesity (which affects $35 \%$ of all U.S, adults [9] and is more prevalent in African American population [10]) is linked to plethora of diseases including cardio-vascular problems, type II diabetes, gallbladder disease, osteoarthritis [11] and an array of human cancers such as breast, uterine, and pancreas [11-13]. Furthermore, obesity alters the individual's biochemical and hormonal profile [14], which may facilitate cancer growth [15]. However, obesity has been inconsistently associated with PCa risk [16], and the inconsistency may be due to an interaction with genetic variants [17-18]. In an attempt to elucidate the connection between PCa health disparity, genetic variation and obesity, we hypothesized that genetic variation differentially alters the PCa risk in obese and non-obese AAM and EAM. Given the extremely high burden of $\mathrm{PCa}$ and staggering rates of obesity, elucidating the links between the individual's genetic variation, race, PCa risk and obesity is likely to have a major positive impact on the public health 
of the US population. Thus, our hypothesis-generating study may open new venues for tackling the PCa disparity from a new perspective.

\section{Methods}

\section{Study participants}

Study participants were recruited from various clinics in the Tampa Bay area in Florida, including the Moffitt Cancer Center, Tampa Bay Radiation Oncology centers, Moffitt Cancer Center affiliated-Lifetime Cancer Screening \& Prevention Center, James A. Haley Veteran Affairs (VA), and the $30^{\text {th }}$ Street Medical Associates (a community clinic). All recruitment protocols were approved by the University of South Florida Institutional Review Board (IRB), while the VA protocol was approved by the VA IRB. The study population comprised of AAM and EAM aged 30-85 years and enrolled between 2006 and 2012. The cases and controls were recruited during the initial PCa screening of all consecutive, unselected patients. Cases were histologically -confirmed PCa patients and controls were men with low PSA and/or no evidence of PCa on biopsy. The AAM or EAM ancestry was self-reported. Men were excluded if they did not self-identify as either AAM or EAM, were outside of the 30-85 year old range, were in poor physical or mental health, were diagnosed with other cancers (excluding non-melanoma skin cancer), or did not speak English well enough to read and understand the informed consent. The response rates in all studies were high, at or above $90 \%$.

\section{Single nucleotide polymorphism (SNP) selection and genotyping}

Literature search using Pubmed and Google scholar databases was performed to identify potential SNPs of interest. The following criteria were set to guide the SNP search (all inclusive): 1. Confer increased PCa risk in AAM; 2. Confer increased PCa risk in EAM; 3. Demonstrate potential for functional significance (that is, located in or close to a gene with a known function); 4. Reported Minor allele frequency (MAF) $\geq 15 \%$ in AAM and EAM. Based on these criteria, 10 SNPs in the 7 genes were selected: rs4430796; rs7501939; rs 1859962 in HNF1B; rs10993994 in MSMB; rs822396 in ADIPOQ; rs4263970; rs4612601 in EPHB2; 
rs4962416 in CTBP2; rs627839 in RNASEL; rs2070874 in IL4. DNA was extracted from blood or buccal cell samples using commercially available extraction kits and TaqMan genotyping was conducted at the Moffitt Cancer Center on the DNA samples from 259 (136 cases and 123 controls) AAM and 269 (147 cases and 142 controls) EAM, matched on age at diagnosis.

\section{Statistical Analyses}

Descriptive statistics were used to summarize participants' demographic and clinical characteristics. Genotypes among participants were used to estimate allele frequencies and departure from Hardy-Weinberg equilibrium (HWE) was assessed among control subjects using Chi-squared test. The association between each SNP and PCa risk was estimated with odds ratios $(O R)$ and $95 \%$ confidence intervals $(\mathrm{Cl})$ using unconditional logistic regression adjusted for age at diagnosis. Three inheritance genetic models (log-additive, dominant and recessive) were tested for each SNP and the model with the minimum $P$-value was considered as the best fitting model. Separate analyses were performed for each race and all men combined. We conducted exploratory subgroup analyses for different strata based on BMI and height within each race. Statistical tests were two-sided with an alpha level $<0.05$ considered statistically significant. All statistical analyses were performed with SAS/Genetics version 9.2 (SAS Institute, NC).

\section{Results}

Selected characteristics of the study participants by case/control status are shown in the Table 1. For both ethnic groups, men were likely to be between 50 to 64 years of age and between 68 and 72 inches tall. AAM were more likely to be obese than EAM (47\% and $35.5 \%$ obese men in each group, respectively). AAM were also more likely to be taller. Within each ethnic group, cases were more likely to be older, although there was no significant difference in the age of cases and controls between races. In addition, AAM cases were more likely to be obese than AAM controls. In contrast, EAM controls were more likely to be obese than EAM cases. 
The results for association analyses between SNP and risk are shown in the Table 2. The MAF of the SNPs ranged from 0.15-0.49 and none of the SNPs deviated from HWE (all P > 0.05). In AAM, we observed an increased PCa risk at HNF1B rs7501939 (Recessive model: $\mathrm{OR}=2.42,95 \% \mathrm{Cl}=1.31-4.47, P=0.0046 ;$ Additive model: $\mathrm{OR}=1.56,95 \% \mathrm{Cl}=1.08-2.27, P=0.0193$ ) and a decreased PCa risk at HNF1B rs 4430796 (Dominant model: $\mathrm{OR}=0.57,95 \% \mathrm{Cl}=0.34-0.97$, $\mathrm{P}=0.0383 ;$ Additive model: $\mathrm{OR}=0.67,95 \% \mathrm{Cl}=0.46-0.99, \mathrm{P}=0.0431)$. These SNPs were not significantly associated with PCa risk in EAM. In EAM, we observed an increased PCa risk at the CTBP2 rs4962416 (Dominant model: $O R=1.69,95 \% \mathrm{Cl}=1.02-2.80, P=0.0415$; Additive model: $\mathrm{OR}=1.52,95 \% \mathrm{Cl}=1.02-2.26, \mathrm{P}=0.0384)$. This association was not confirmed in AAM.

Age-adjusted association between select anthropometric variables and PCa are shown in the Table 3. We observed an increased PCa risk in obese, compared to non-obese AAM $(\mathrm{OR}=1.06,95 \% \mathrm{Cl}=1.01-1.11, \mathrm{P}=0.022)$, and decreased $\mathrm{PCa}$ risk in the tallest group of $\mathrm{EAM}$ compared to all other EAM (OR=0.92, $C l=0.85-0.99, P=0.0434)$. Since our results indicated that BMI might be positively associated with PCa in AAM, we decided to examine the SNPassociations stratified by obesity for SNPs that were significant for AAM: rs7501939 and rs4430796.

Results for SNP-associations stratified by obesity in AAM are shown in Table 4. Interestingly, when stratified by obesity status, rs7501939 at HNF1B only increased PCa risk in obese AAM $(O R=2.14,95 \% C l=1.2-3.8, P=0.01)$, but not in the non-obese AAM $(P=0.76)$, or EAM of any $B M I(P=0.3$ in obese, and $p=0.8$ in non-obese $E A M)$. No differential association by obesity status was observed at $r \$ 4430796$ in AAM $(P=0.18$ in obese and $P=0.51$ in the nonobese AAM). There were no significant associations with PCa risk at these SNP in EAM regardless of obesity status ( $p>0.05)$.

Finally, we used the SNP Annotation and Proxy Search (SNAP) software (Broad Institute) to elucidate whether there are other SNPS in Linkage Disequilibrium (LD) with our significant SNPS. The results are shown in the Table 5. There are no SNPs in the LD $\left(r^{2} \geq 0.8\right)$ 
with either of the HNF1B SNPS significant in AAM. While there are several SNPS in weak LD $\left(r^{2} \geq 0.5\right)$ with $r 57501939$, they were not found to be associated with PCa or any other disease. In EAM, while a number of SNPs are reported being in LD with the CTBP2 rs4962416, only one of those SNPS (rs12769019) was linked to a marginally increased PCa risk in EAM (OR=1.1,95\% Cl, 0.99-1.25) [19].

Table 1. Select characteristics of the study participants by case/control status.

\begin{tabular}{|c|c|c|c|c|c|c|c|}
\hline & \multicolumn{2}{|c|}{ AAM: 259 total } & \multicolumn{2}{|c|}{ EAM: 269 total } & \multicolumn{2}{|c|}{$\begin{array}{c}\text { Total sample } \\
\text { combined }\end{array}$} \\
\hline & & $\begin{array}{l}\# \text { Cases } \\
(\%) \\
136 \\
(52.5)\end{array}$ & $\begin{array}{l}\# \text { Controls } \\
(\%) \\
123(47.5)\end{array}$ & $\begin{array}{l}\# \text { Cases } \\
(\%) \\
147 \\
(54.6)\end{array}$ & $\begin{array}{l}\# \text { Controls } \\
(\%) \\
122(45.4)\end{array}$ & $\begin{array}{l}\# \text { Cases } \\
(\%) \\
283 \\
(53.6)\end{array}$ & $\begin{array}{l}\text { \# Controls } \\
(\%) \\
245(46.4)\end{array}$ \\
\hline \multirow[t]{4}{*}{ Age } & $<50$ & $11(8)$ & $12(8)$ & $19(16)$ & $30(24)$ & $30(12)$ & $42(16)$ \\
\hline & $50-64$ & $74(54)$ & $80(54)$ & $85(70)$ & $73(59)$ & $159(62)$ & $153(56.5)$ \\
\hline & $\geq 65$ & $51(38)$ & $55(38)$ & $18(14)$ & $17(14)$ & $69(26)$ & $72(26)$ \\
\hline & missing & NA & NA & NA & $3(3)$ & NA & $3(1.5)$ \\
\hline \multirow[t]{4}{*}{ BMI } & $\begin{array}{l}\leq 24.9 \\
\text { normal } \\
\text { weight }\end{array}$ & $9(7)$ & $25(17)$ & $28(23)$ & $26(21)$ & $37(15)$ & $51(19)$ \\
\hline & $\begin{array}{l}25.0-29.9 \\
\text { overweight }\end{array}$ & $47(34.5)$ & $70(48)$ & $47(38)$ & $46(37)$ & $94(36)$ & $116(42.5)$ \\
\hline & $\begin{array}{l}\geq 30.0 \\
\text { obese }\end{array}$ & $71(52)$ & $48(33)$ & $46(38)$ & $51(42)$ & $58.5(45)$ & $49.5(37.5)$ \\
\hline & missing & $9(6.5)$ & $4(2)$ & $1(1)$ & NA & $10(3.5)$ & $4(1)$ \\
\hline \multirow[t]{4}{*}{ Height } & $\leq 67$ & $30(22)$ & $26(17.5)$ & $22(18)$ & $21(17)$ & $52(20)$ & $47(17)$ \\
\hline & $68-72$ & $65(48)$ & $98(66.5)$ & $79(65)$ & $74(60)$ & $\begin{array}{l}144 \\
(56.5)\end{array}$ & $172(63)$ \\
\hline & 273 & $32(23.5)$ & $19(13)$ & $21(17)$ & $28(23)$ & $53(20)$ & $47(18)$ \\
\hline & missing & $9(6.5)$ & $4(3)$ & $\mathrm{NA}$ & NA & $9(3)$ & $4(1.5)$ \\
\hline
\end{tabular}

Table 2. Age-adjusted odds ratios (OR) and $95 \%$ confidence intervals $(95 \% \mathrm{Cl})$ for PCa in AAM and EAM and combined.

\begin{tabular}{|l|l|l|l|}
\hline $\begin{array}{l}\text { Rs\# and gene; minor allele } \\
\text { and its frequency }\end{array}$ & $\begin{array}{l}\text { Dominant Model } \\
\text { OR }(C l) ; p \text {-value }\end{array}$ & $\begin{array}{l}\text { Recessive Model } \\
\text { OR(Cl); } p \text {-value }\end{array}$ & $\begin{array}{l}\text { Additive Model } \\
\text { OR(Cl); p-value }\end{array}$ \\
\hline rs4612601; EPHB2 & AAM: $1.09(0.63-1.9) ; 0.749$ & $0.86(0.46-1.61) ; 0.638$ & $0.99(0.69-1.41) ; 0.951$ \\
\cline { 2 - 4 } AA: $0.49(\mathrm{G})$ & EAM: $1.18(0.67-2.10) ; 0.564$ & $0.9(0.52-1.56) ; 0.709$ & $1.02(0.73-1.43) ; 0.912$ \\
\cline { 2 - 5 } EA: $0.45(\mathrm{~A})$ & All: $1.13(0.76-1.69) ; 0.537$ & $0.89(0.59-1.34) ; 0.565$ & $1.00(0.79-1.28) ; 0.969$ \\
\hline rs4263970; EPHB2 & AAM: $0.98(0.57-1.68) ; 0.932$ & $0.88(0.44-1.75) ; 0.711$ & $0.95(0.66-1.38) ; 0.797$ \\
\cline { 2 - 5 } AA: $0.47(\mathrm{~T})$ & EAM: $1.08(0.61-1.9) ; 0.795$ & $0.76(0.44-1.33) ; 0.334$ & $0.93(0.66-1.30) ; 0.665$ \\
\cline { 2 - 5 } EA: $0.45(\mathrm{C})$ & All: $1.02(0.69-1.5) ; 0.918$ & $0.81(0.53-1.25) ; 0.343$ & $0.94(0.73-1.21) ; 0.630$ \\
\hline rs822396; ADIPOQ & AAM: $0.89(0.52-1.52) ; 0.671$ & $1.64(0.37-7.21) ; 0.511$ & $0.96(0.6-1.54) ; 0.878$ \\
\cline { 2 - 5 } AA: $0.2(\mathrm{G})$ & EAM: $0.75(0.44-1.27) ; 0.288$ & $1.1(0.29-4.09) ; 0.094$ & $0.82(0.53-1.29) ; 0.392$ \\
\cline { 2 - 5 } EA: $0.15(\mathrm{G})$ & All: $0.82(0.56-1.19) ; 0.285$ & $1.29(0.49-3.48) ; 0.601$ & $0.88(0.64-1.22) ; 0.456$ \\
\hline
\end{tabular}




\begin{tabular}{|l|l|l|l|}
\hline rs10993994; MSMB & AAM: $0.82(0.48-1.4) ; 0.472$ & $1.04(0.51-2.10) ; 0.919$ & $0.92(0.63-1.33) ; 0.657$ \\
\cline { 2 - 5 } AA: $0.2(\mathrm{C})$ & EAM: $1.04(0.54-2.00) ; 0.899$ & $0.61(0.36-1.05) ; 0.077$ & $0.81(0.56-1.17) ; 0.258$ \\
\cline { 2 - 5 } EA: $0.34(\mathrm{~T})$ & All: $0.9(0.6-1.35) ; 0.611$ & $0.75(0.49-1.14) ; 0.177$ & $0.87(0.67-1.11) ; 0.261$ \\
\hline rs1859962; HNF1B & AAM: $1.03(0.61-1.74) ; 0.905$ & $1.23(0.54-2.81) ; 0.626$ & $1.06(0.72-1.56) ; 0.752$ \\
\cline { 2 - 5 } AA: $0.49(\mathrm{G})$ & EAM: $1.38(0.77-2.45) ; 0.278$ & $1.00(0.57-1.76) ; 0.997$ & $1.13(0.79-1.6) ; 0.508$ \\
\cline { 2 - 5 } EA: $0.2(\mathrm{G})$ & All: $1.16(0.8-1.69) ; 0.431$ & $1.06(0.67-1.69) ; 0.790$ & $1.09(0.85-1.4) ; 0.503$ \\
\hline rs7501939; HNF1B & AAM: $1.34(0.73-2.47) ; 0.343$ & $2.42(1.31-4.47) ; 0.0046$ & $1.56(1.08-2.27) ; 0.0193$ \\
\cline { 2 - 5 } AA: $0.48(\mathrm{C})$ & EAM: $0.82(0.5-1.35) ; 0.439$ & $1.13(0.54-2.38) ; 0.742$ & $0.93(0.65-1.33) ; 0.692$ \\
\cline { 2 - 5 } EA: $0.49(\mathrm{~T})$ & All: $0.99(0.68-1.45) ; 0.981$ & $1.76(1.11-2.79) ; 0.0167$ & $1.18(0.92-1.52) ; 0.187$ \\
\hline rs4430796; HNF1B & AAM: $0.57(0.34-0.97) ; 0.0383$ & $0.64(0.29-1.42) ; 0.272$ & $0.67(0.46-0.99) ; 0.0431$ \\
\cline { 2 - 5 } AA: $0.34(\mathrm{~A})$ & EAM: $1.27(0.7-2.3) ; 0.439$ & $0.98(0.57-1.68) ; 0.946$ & $1.07(0.76-1.51) ; 0.689$ \\
\cline { 2 - 5 } EA: $0.47(\mathrm{~A})$ & All: $0.81(0.55-1.18) ; 0.273$ & $0.86(0.59-1.33) ; 0.500$ & $0.87(0.69-1.12) ; 0.279$ \\
\hline rs2070874; IL4 & AAM: $0.94(0.54-1.64) ; 0.824$ & $1.45(0.7-3.0) ; 0.314$ & $1.08(0.73-1.59) ; 0.700$ \\
\cline { 2 - 5 } AA: $0.45(T)$ & EAM: $0.65(0.38-1.11) ; 0.115$ & $0.92(0.22-3.93) ; 0.916$ & $0.72(0.45-1.14) ; 0.161$ \\
\cline { 2 - 5 } EA: $0.2(\mathrm{~T})$ & All: $0.82(0.57-1.17) ; 0.275$ & $1.32(0.7-2.49) ; 0.386$ & $0.94(0.71-1.24) ; 0.649$ \\
\hline rs627839; RNASEL & AAM: $1.2(0.7-2.06) ; 0.511$ & $1.63(0.78-3.42) ; 0.192$ & $1.24(0.85-1.83) ; 0.252$ \\
\cline { 2 - 5 } AA: $0.46(T)$ & EAM:0.86(0.5-1.47);0.571 & $0.99(0.55-1.8) ; 0.986$ & $0.94(0.67-1.32) ; 0.710$ \\
\cline { 2 - 5 } EA: $0.45(T)$ & All: $1.01(0.69-1.48) ; 0.952$ & $1.21(0.76-1.91) ; 0.427$ & $1.06(0.83-1.37) ; 0.632$ \\
\hline rs4962416; CTBP2 & AAM: $0.9(0.5-1.59) ; 0.709$ & $5.65(0.62-51.7) ; 0.125$ & $1.05(0.63-1.74) ; 0.861$ \\
AA: $0.23(\mathrm{C})$ & EAM: $1.69(1.02-2.8) ; 0.0415$ & $1.72(0.68-4.31) ; 0.251$ & $1.52(1.02-2.26) ; 0.0384$ \\
EA: $0.23(\mathrm{C})$ & All: $1.28(0.88-1.85) ; 0.198$ & $2.12(0.92-4.9) ; 0.0784$ & $1.31(0.97-1.78) ; 0.083$ \\
\hline
\end{tabular}

Table 3. Age-adjusted association between select anthropometric variables and PCa in men stratifying by race and combined. Bold denotes statistically significant associations.

\begin{tabular}{|l|l|l|l|}
\hline & \multicolumn{1}{|c|}{ AAM } & \multicolumn{1}{c|}{ EAM } & \multicolumn{1}{c|}{ All } \\
\cline { 2 - 5 } & \multicolumn{1}{|c|}{ OR $(95 \% \mathrm{Cl}) ; \mathrm{p}$-value } & \multicolumn{1}{c|}{ OR $(95 \% \mathrm{Cl}) ; p$-value } & \multicolumn{1}{c|}{ OR $(95 \% \mathrm{Cl}) ; \mathrm{p}$-value } \\
\hline Height (inches) & $0.98(0.9-1.05) ; 0.54$ & $0.92(0.85-0.99) ; 0.0434$ & $0.95(0.89-1.01) ; 0.0549$ \\
\hline BMI (kg/m2) & $1.06(1.01-1.11) ; 0.022$ & $0.98(0.93-1.023) ; 0.33$ & $1.02(0.98-1.05) ; 0.374$ \\
$<30$ (Non-obese) & 1.0 & 1.0 & 1.0 \\
$\geq 30$ (Obese) & $2.07(1.21-3.55) ; 0.008$ & $0.90(0.54-1.51) ; 0.69$ & $1.32(0.97-1.77) ; 0.09$ \\
\hline
\end{tabular}

Table 4. rs7501939 and rs4430796 as PCa risk factors in AAM stratified by BMI. Statistically significant associations are shown in bold.

\begin{tabular}{|l|l|l|l|}
\hline & Non-obese AAM & Obese AAM & All AAM \\
\hline rs7501939 & $1.09(0.65-1.83) ; 0.75$ & $2.13(1.20-3.81) ; 0.01$ & $1.56(1.08-2.27) ; P=0.019$ \\
\hline rs4430796 & $0.84(0.49-1.43) ; 0.52$ & $0.67(0.37-1.20) ; 0.18$ & $0.67(0.46-0.99) ; 0.043$ \\
\hline
\end{tabular}

Table 5. SNPs reported being in LD regions with our SNPs of interest.

\begin{tabular}{|c|c|c|c|}
\hline SNP of interest & $r^{2} \geq 0.8$ & $r^{2} \geq 0.5$ & Disease and comments \\
\hline rs7501939 in AAM & none & $\begin{array}{l}r s 11657964\left(r^{2}=0.61\right) \\
r s 8064454\left(r^{2}=0.549\right)\end{array}$ & $\begin{array}{l}\text { None reported being } \\
\text { associated with prostate } \\
\text { cancer or any other disease. }\end{array}$ \\
\hline rs4430796 in AAM & none & none & NA \\
\hline rs4962416 in EAM & $\begin{array}{l}r s 4962720\left(r^{2}=1.00\right) \\
r s 4962419\left(r^{2}=1.00\right) \\
r s 12771627\left(r^{2}=1.00\right) \\
r s 12769019\left(r^{2}=0.92\right) \\
r s 11598549\left(r^{2}=0.92\right) \\
r s 12782469\left(r^{2}=0.83\right)\end{array}$ & 14 additional SNPS & $\begin{array}{l}\text { rs12769019: slightly increased } \\
\text { risk for prostate cancer in EAM } \\
\text { (OR=1.1) [19]; }\end{array}$ \\
\hline
\end{tabular}




\section{Discussion}

We observe that the HNF1B SNPs (rs7501939 and rs4430796) identified in PCa GWAS [20-21] are associated with PCa risk in AAM, and that the CTBP2 SNP rs4962416, also identified in PCa GWAS [20], is associated with PCa risk in EAM. Our novel finding is that the association of rs7501939 with PCa risk in AAM may be modified by obesity.

Gudmundsson et al [21] reported that HNF1B SNPs were associated with PCa in the Non-Hispanic White men (largely living in Europe) on the genome-wide significance level (rs7501939: $O R=1.19, P=4.7^{*} 10^{-9} ; \quad r s 4430796: \quad O R=1.22, P=1.4^{*} 10^{-11}$ ). The authors also reported that the same SNPS were inversely associated with the type II diabetes (rs7501939: $\left.O R=0.91, p=9.2^{*} 10^{-7} ; r s 4430796: O R=0.91, p=2.7^{*} 10^{-7}\right)$. Liu et al [22] conducted a metaanalysis of all PCa-related GWA studies combined, and stratified by ethnicity. The authors have found that in a combined analysis both HNF1B SNPs were significantly associated with PCa (rs7501939: $O R=1.19, P<0.001 ; r s 4430796: O R=0.75, P<0.001)$. However, neither of the two SNPS attained statistical significance when analysis was restricted to AAM $(P>0.05)$. Stevens et al [23] reported that the two HNF1B SNPs of interest were significantly inversely associated with $\mathrm{PCa}$ risk in their cohorts of EAM (rs7501939: $\mathrm{OR}=0.87, \mathrm{Cl}=0.80-0.94 ;$ rs4430796: $\mathrm{OR}=0.85$, $\mathrm{Cl}=0.79-0.92)$. However, unlike Gudmundsson et al [21], the authors did not observe a statistically significant association with diabetes. Sun et al [24] analyzed a diverse cohort of men (2139 EAM and 717 AAM) and reported associations with PCa risk and both SNPs in EAM(rs7501939: $\left.O R=1.31, P=1.8^{*} 10^{-4} ; r s 4430796: O R=1.28, P=5.1^{*} 10^{-4}\right)$. However, in an analysis restricted to AAM, only rs4430796 retained statistical significance (rs75001939: $P>0,05 ; r s 4430796: O R=1.26, P=0.04)$. The authors used reversed risk alleles ( $T$ for rs4430796 and $G$ for rs75001939) which is opposite to our study and to other cited studies. Ahn et al. [25] reported that rs4430796 was not associated with risk for metastatic prostate cancer and recurrence. Although none of the aforementioned studies controlled for BMI, Lindstrom et al [26] 
have reported that BMI had no modifying effects on the SNP-PCa associations in EAM. No similar analysis was performed in AAM.

While the aforementioned studies involved mostly EAM participants, Chang et al. [27] could not validate the association of either of the two HNF1B SNPs with PCa in their large cohort of 4,040 AAM PCa cases and 3,748 healthy AAM controls ( $r$ 7501939: OR=0.97, $P=0.65 ;$ rs4430796: $O R=1.08, P=0.053$ ). Haiman et al [28] reported no association in their large cohort of 3,621 AAM PCa cases and 3,652 controls (rs7501939: OR=1.03, P=0.44; rs4430796: $O R=1.02, P=0.52$ ). Hooker et al. [29] have attempted to replicate the PCa SNPs identified in the GWAS studies, in their cohort of 755 unrelated AAM. The authors reported that HNF1B rs 7501939 was not significant $(O R=0.94, P=0.20)$, and $r s 4430796$ conferred increased $P C a$ risk $(\mathrm{OR}=1.48, P=0.008)$.

As can be concluded from the referenced studies, there is significant discordance between the published studies on the effects of the two aforementioned HNF1B SNPs on PCa risk. While the authors presented high-quality studies with large sample sizes, the majority did not report controlling for the environmental confounders, including BMI. To our knowledge, we are the first group to report that the association of the HNF1B SNPs with PCa risk may be modified by the level of adiposity and racial/ethnic background. Importantly, BMI was associated with $P C a$ risk in our sample of $A A M$ independently of genetic variation $(O R=1.06, P=0.022)$ (Table 3). Our hypothesis-generating data may be even more intriguing in light of the ongoing debate surrounding the relationship between obesity and PCa risk. At present, there appears to be a consensus that obese men experience slightly reduced overall PCa incidence, at the expense of an increase in aggressive, "clinically significant" disease. The overall decrease, therefore, is mainly due to reduction in the "clinically insignificant", potentially indolent PCa [14]. While several hypotheses aimed to explain this observation have been proposed [30], neither has been widely accepted by scientific or medical communities. Additionally, because the data were obtained in EAM, the effect of obesity on PCa risk in AAM remains unknown. Our pilot 
study helps to close this knowledge gap and serve as a basis for future sufficiently powered studies involving larger numbers of AA participants, as well as more extensive epidemiological data analysis.

Mutations in the HNF1B cause MODY5 (Maturity-Onset of Diabetes, Type 5) that may be accompanied by urinary tract disorders, including renal disease and/or undeveloped/malformed kidneys, and atrophic pancreas [31-32]. Some men with the HNF1B mutations have malformations in the reproductive tract including epididymal cysts, agenesis of the vas deferens, or infertility due to abnormal spermatozoa [33]. More recently, genetic variants in the HNF1B were implicated in the prostate [34-35] and endometrial [36-37] cancer risks. It was reported [38] that different HNF1B isoforms were expressed in prostate tumors versus normal prostate tissue, thus providing functional evidence for a potential role of this gene in PCa. However, the functional studies to examine whether HNF1B variants influence PCa risk and/or prognosis are lacking. HNF1B variants were implicated in a slightly reduced risk of type II diabetes mellitus in AAM and EAM [21]. Interestingly, PCa risk seems to be attenuated in men with diabetes [39], although the latter was only reported in people of EA descent and the biological basis for this association remains to be elucidated. At this time, the relationship between obesity, diabetes and PCa is poorly understood, and so is the contribution of the HNF1B variants to the risk. However, since obesity as a risk factor for breast cancer differs in $A A$ and EA women [40-41], it is plausible that a similar effect may be observed with obesity and PCa in AAM and EAM. Additionally, our data suggests that HNF1B variants may be implicated in the risk. Future epidemiological, genetic and functional tumor biology studies are required to address this provocative hypothesis.

In EAM, our results replicate a previously reported finding that the CTBP2 rs 4962416 confers increased PCa risk: $O R=1.69, p=0.0415$ in our study vs. the overall GWAS data: $O R=1.25, p=0.004$ [22]. CTBP2 encodes a transcriptional co-repressor that is activated under stress condition and can mediate stress-induced migration of tumor cells [42]. CTBP2 
expression is detected in the prostate, and has been linked to decreased PTEN expression and activation of the phosphatidylinositol 3-kinase pathway [43] which may support or promote PCa growth. rs4962416 was not previously implicated in PCa risk in AAM [22] which is also in agreement with our data.

The main strength of our study is inclusion of equal proportions of age-matched $A A$ and EA men with high rates of obese men in both populations, allowing us to tease out the interaction of obesity with genetic variants. Our results should be interpreted in light of limitations of a small sample size and inability to access relevant information such as diabetes history. However, given the increased PCa burden in AAM, alarming obesity rates, and limited number of studies that involve AAM, our results are novel, timely and as such, deserve dissemination.

In summary, our results suggest that germline genetic variation in HNF1B and CTBP2 differentially contribute to $\mathrm{PCa}$ risk in men of different races and adiposities. Future sufficiently powered studies involving the large proportion of AAM are needed to elucidate the potential connection between the race, $\mathrm{PCa}$, obesity, diabetes and HNF1B. In addition, functional tumor biology studies are warranted to elucidate the effects of obesity on PCa in carriers and noncarriers of different races and ethnicities.

\section{Conflict of Interest}

All authors declare that they have no conflict of interest.

Acknowledgements. This research is supported by the Department of Defense, Prostate Cancer Research Program (DoD PCRP): W81XWH-11-1-0376 (GC); W81XWH-06-1-0034 (CP); W81XWH-12-1-0113 (JP). The National Institute of Health (NIH): P20 MD003375-01 (CP, NK); 5R25 CA090314 (SD). And by the National Cancer Institute (NCI): R25T CA147832 (EA); R01CA128813 (JP). The sponsors had no role in the conception, execution, data analysis or reporting of these results. 
Authors' contributions

Conception and design: GC; NK; CP; JYP

Data collection and analysis: GC; EA; SD

Writing and editing of the manuscript: GC; EA; SD

Study supervision: JPS; NK

\section{References.}

[1] American Cancer Society. Cancer Facts \& Figures for African Americans 2011-2012. Atlanta: American Cancer Society, 2011

[2] Chornokur G, Dalton K, Borysova ME, Kumar NB. Disparities at presentation, diagnosis, treatment, and survival in African American men, affected by prostate cancer. The Prostate 2011; 71(9): 985-997.

[3] Powell IJ. Epidemiology and pathophysiology of prostate cancer in African-American men. $J$ Urol 2007; 177(2): 444-449.

[4] Crawford ED. Epidemiology of prostate cancer. Urol 2003; 22(6) S1: 3-12.

[5] Kote-Jarai Z, Al Olama AA, Giles GG, et al. Seven prostate cancer susceptibility loci identified by a multi-stage genome-wide association study. Nature Genetics 2011; 43: 785-791.

[6] Freedman ML, Monteiro AN, Gayther SA, et al. Principles for the post-GWAS functional characterization of cancer risk loci. Nat Genet 2011; 43(6): 513-518.

[7] Kooperberg C, LeBlanc M, Dai JY, Rajapakse I. Structures and Assumptions: Strategies to Harness Gene $\times$ Gene and Gene x Environment Interactions in GWAS. Stat Sci 2009; 24(4): 472-488.

[8] Cornelis MC, Agrawal A, Cole JW, et al. The gene, environment association studies consortium (GENEVA): maximizing the knowledge obtained from GWAS by collaboration across studies of multiple conditions. Genetic Epidemiology 2010; 34(4):364-372.

[9] Michaud DS, Augustsson K, Rimm EB, Stampfer MJ, Willett WC, Giovannucci E. A prospective study on intake of animal products and risk of prostate cancer. Cancer Causes Control 2001; 12(6): 557-567.

[10] Sinha R, Park Y, Graubard BI, Leitzmann MF, Hollenbeck A, Schatzkin A, Cross AJ. Meat and Meat-related Compounds and Risk of Prostate Cancer in a Large Prospective Cohort Study in the United States. Am J Epidemiol 2009; 170(9): 1165-1177.

[11] Giovannucci EL, Liu Y, Leitzmann MF, Stampfer MJ, Willett WC. A Prospective Study of Physical Activity and Incident and Fatal Prostate Cancer. Arch Intern Med 2005;165(9):10051010.

[12] Friedenreich $C M$, Thune I. A review of physical activity and prostate cancer risk. Cancer Causes Control 2001; 12(5): 461-475

[13] Friedenreich CM, McGregor SE, Courneya KS, Angyalfi SJ, Elliott FG. Case-Control Study of Lifetime Total Physical Activity and Prostate Cancer Risk. Am J Epidemiol 2004; 159(8): 740749.

[14] Freedland SJ, Platz EA. Obesity and Prostate Cancer: Making Sense out of Apparently Conflicting Data. Epidemiol Rev 2007; 29: 88-97

[15] Ogden CL, Carroll MD, Kit BK, Flegal KM. Prevalence of obesity in the United States, 20092010. NCHS Data Brief 2012; 82:1-8.

[16] CDC, 2012. Health United States, 2011. Table 74. Available from: http://www.cdc.gov/nchs/data/hus/hus 11.pdf 
[17] Kirechner MA, Ertel N, Schneider G. Obesity, Hormones, and Cancer. Cancer Res 1981; 41: 371-377.

[18] Renehan AG, Tyson M, Egger M, Heller RF, Zwahlen M. Body-mass index and incidence of cancer: a systematic review and meta-analysis of prospective observational studies. Lancet $2008 ; 371 ; 569-578$.

[19] Waters KM, Le Marchand L, Kolonel LN, Monroe KR, Stram DO, Henderson BE, Haiman CA. Generalizability of Associations from Prostate Cancer Genome-Wide Association Studies in Multiple Populations. Cancer Epidemiol Biomarkers Prev 2009; 18: 1285.

[20] Eeles RA, Kote-Jarai Z, Giles GG, et al. Multiple newly identified loci associated with prostate cancer susceptibility. Nat Gen 2008; 40(3): 316-21.

[21] Gudmundsson J, Sulem $P$, Steinthorsdottir V, et al. Two variants on chromosome 17 confer prostate cancer risk, and the one in TCF2 protects against type 2 diabetes. Nat Genet 2007; 39(8): 977-83.

[22] Liu H, Wang B, Han C. Meta-Analysis of Genome-Wide and Replication Association Studies on Prostate Cancer. The Prostate 2011; 71: 209-224.

[23] Stevens VL, Ahn J, Sun J, et al. HNF1B and JAZF1 Genes, Diabetes, and Prostate Cancer Risk. Prostate 2010; 70(6): 601-607.

[24] Sun J, Purcell L, Gao Z, et al. Association of variants at two 17q loci with prostate cancer risk in European and African Americans. Prostate 2008; 68(7): 691-697.

[25] Ahn J, Kibel AS, Park JY, Rebbeck TR, Rennert H, Stanford JL, Ostrander EA, Chanock S, Wang $\mathrm{M}-\mathrm{H}$, Mittal RD, Isaacs WB, Platz EA, Hayes RB. Prostate Cancer Predisposition Loci and Risk of Metastatic Disease and Prostate Cancer Recurrence. Clin Cancer Res 2011; 17(5); 1075-1081.

[26] Lindstrom S, Schumacher F, Siddiq A, et al. Characterizing Associations and SNP. Environment Interactions for GWAS-Identified Prostate Cancer Risk Markers-Results from BPC3. PLOS One 2011; 6(2): e17142.

[27] Chang B-L, Spangler E, Gallagher S, et al. Validation of Genome-Wide Prostate Cancer Associations in Men of African Descent. Cancer Epidemiol Biomarkers Prev 2011; 20(1): 23-32. [28] Haiman CA, Chen GK, Blot WJ, et al. Characterizing Genetic Risk at Known Prostate Cancer Susceptibility Loci in African Americans. PLOS Genetics 2011; 7(5): e1001387. [29] Hooker S, Hernandez W, Chen H, et al. Replication of Prostate Cancer Risk Loci on $8 q 24,11 q 13,17 q 12,19 q 33$, and Xp11 in African Americans. The Prostate 2010; 70: 270-275. [30] Hsing AW, Sakoda LC, Chua Jr. SC. Obesity, metabolic syndrome, and prostate cancer. Am J Clin Nutr 2007; 86(suppl): 843S-57S.

[31] Bingham C, Hattersley AT. Renal cysts and diabetes syndrome resulting from mutations in hepatocyte nuclear factor-1 $\beta$. Nephrol Dial Transplant 2004; 19(11): 2703-2708.

[32] Haldorsen IS, Vesterhus M, Ræder H, et al. Lack of pancreatic body and tail in HNF1B mutation carriers. Diabetic Medicine 2008; 25(7): 782-787.

[33] Nakayama M, Nozu K, Goto Y, et al. HNF1B alterations associated with congenital anomalies of the kidney and urinary tract. Pediatric Nephrology 2010; 25(6):1073-1079. [34] Berndt SI, Sampson J, Yeager M, et al. Large-scale fine mapping of the HNF1B locus and prostate cancer risk. Hum Mol Genet 2011; 20(16): 3322-3329.

[35] Sun J, Zheng SL, Wiklund $F$, et al. Evidence for two independent prostate cancer risk associated loci in the HNF1B gene at 17q12. Nat Genet 2008; 40(10): 1153-1155.

[36] Setiawan VW, Haessler J, Schumacher F, et al. HNF1B and endometrial cancer risk: results from the PAGE study. PLoS One 2012; 7(1): e30390.

[37] Spurdle AB, Thompson DJ, Ahmed S, et al. Genome-wide association study identifies a common variant associated with risk of endometrial cancer. Nat Genet 2011; 43: 451-454.

[38] Harries LW, Perry JRB, McCullagh P, et et al. Alterations in the LMTK2, MSMB and HNF1B gene expression are associated with the development of prostate cancer. BMC Cancer 2010; 10: 315 . 
[39] Weiderpass $E, Y e W$, Vainio $H$, et al. Reduced risk of prostate cancer among patients with diabetes mellitus. Int J Cancer 2002; 102; 258-261.

[40] Berstad P, Coates RJ, Bernstein L, et al. A Case-Control Study of Body Mass Index and Breast Cancer Risk in White and African-American Women. Cancer Epidemiol Biomarkers Prev 2010; 19(6): 1532-1544.

[41] Sarkissyan M, Wu Y, Vadgama JV. Obesity Is Associated With Breast Cancer in AfricanAmerican Women But Not Hispanic Women in South Los Angeles. Cancer 2011; 117: 38143823.

[42] Paliwal S, Kovi RC, Nath B, et al. The Alternative Reading Frame Tumor Suppressor Antagonizes Hypoxia-Induced Cancer Cell Migration via Interaction with the COOH-Terminal Binding Protein Corepressor, Cancer Res 2007; 67(19): 9322-9329.

[43] Thomas $G$, Jacobs KB, Yeager M, et al. Multiple loci identified in a genome-wide association study of prostate cancer. Nat Genet 2008; 40: 310-315. 


\section{App. II}

Incidence of colorectal cancer in $B R C A 1$ and $B R C A 2$ mutation carriers: Results from a follow-up study.

Catherine M. Phelan, ${ }^{1}$ Javaid Iqbal, ${ }^{2}$ Henry T. Lynch, ${ }^{3}$ Jan Lubinski, ${ }^{4}$ Jacek Gronwald, ${ }^{4}$

Pal Moller, ${ }^{5}$ Parviz Ghadirian, ${ }^{6}$ William D. Foulkes, ${ }^{7}$ Susan Armel, ${ }^{8}$ Susan L. Neuhausen, ${ }^{10}$

Leigha Senter, ${ }^{11}$ Christian F Singer, ${ }^{12}$ Charmaine Kim-Sing, ${ }^{14}$ Nadine Tung, ${ }^{15}$ Marcia

Llacuachaqui, ${ }^{2}$ Ganna Chornokur, ${ }^{1}$ Sun Ping, ${ }^{2}$ Steven A. Narod ${ }^{2 *}$ and the Hereditary Breast

Cancer Study Group

\section{Affiliations;}

${ }^{1}$ Moffitt Cancer Center, Department of Cancer Epidemiology, 12902 Magnolia Drive, Tampa, Florida 33647, USA

${ }^{2}$ Women's College Research Institute, Familial Breast Cancer Research, 790 Bay Street, Toronto, Ontario, M5G 1N8 Canada

${ }^{3}$ Department of Preventive Medicine and Public Health, Creighton University School of Medicine, 2500 California Plaza, Omaha, NE, 68178 USA

${ }^{4}$ International Hereditary Cancer Center, Pomeranian Medical University, Al. Powstancow WIpk. 72, 70-111 Szczecin, Poland

${ }^{5}$ Norwegian Radium Hospital, N-0310, Oslo, Norway

${ }^{6}$ Epidemiology Research Unit, Research Centre of the University of Montreal Hospital Centre (CRCHUM), 3850 St. Urbain, Montreal, QC, H2W 1 T8 Canada

${ }^{7}$ Program in Cancer Genetics, Department of Oncology, McGill University, 1650 Cedar Avenue, Montreal, QC, H3G 1A4, Canada 
${ }^{8}$ Department of Obstetrics and Gynecology, University of Toronto and Gynecologic Oncology, Princess Margaret Hospital, Toronto, Ontario, M5G 2M9, Canada

${ }^{9}$ Sunnybrook Regional Cancer Centre, Toronto, Ontario, M4N 3M5 Canada

${ }^{10}$ Department of Population Sciences, City of Hope, Duarte, CA, 91010, USA

${ }^{11}$ Division of Human Genetics, The Ohio State University Medical Center, Comprehensive

Cancer Center, Columbus, Ohio, 43210, USA

${ }^{12}$ Department of Obstetrics and Gynecology and Comprehensive Cancer Center, Medical

University of Vienna, Spitalgasse 23, 1090, Vienna, Austria

${ }^{13}$ London Regional Cancer Program, London, Ontario, N6A 4L6 Canada

${ }^{14}$ BC Cancer Agency, 675 West 10th Avenue Vancouver; BC, V5Z 1L3, Canada

${ }^{15}$ Beth Israel Deaconess Medical Center, Cancer Risk and Prevention Program, 330 Brookline AvenueBoston, MA, $02215 U \mathrm{USA}$

\section{Running title: Colorectal cancer in BRCA Mutation Carriers}




\section{Other members of the Hereditary Breast Cancer Clinical Study Group:}

Ophira Ginsburg, Lovise Maehle, Kevin Sweet, Dawna Gilchrist, Olufunmilayo I. Olopade, Fergus Couch, Claudine Isaacs, Beth Karlan, Charis Eng, Jeffrey N. Weitzel, Mary B. Daly, Judy

E. Garber, Dana Zakalik, Carey A. Cullinane, Dominique Stoppa-Lyonnet, Howard Saal, Wendy Meschino, Wendy McKinnon, Marie Wood, Taya Fallen, Raluca Kurz, Siranoush Manoukian, Barry Rosen, Rochelle Demsky, Edmond Lemire, Jane McLennan, Seema Panchal Albert E. Chudley, Susan T. Vadaparampil, Tuya Pal, Daniel Rayson, Adriana Valentini, Susan Friedman (on behalf of FORCE) Cezary Cybulski, Tomasz Byrski, Tomasz Huzarski

\section{${ }^{*}$ Corresponding Author:}

Steven A. Narod

Women's College Research Institute

Familial Breast Cancer Research

790 Bay Street, $7^{\text {th }}$ floor

Toronto, ON, Canada M5G 1N8

Email: steven.narod@wchospital.ca

Phone: +1 4163513765

Fax: +1 4163513767 


\section{ABSTRACT}

Background: The BRCA1 and $B R C A 2$ genes confer increased susceptibility to breast and ovarian cancer and to cancer types. There is controversy regarding the risk of colorectal cancer conferred by germline mutations in these two genes. We estimated the incidence of colorectal cancer in a cohort of female carriers of $B R C A 1$ and $B R C A 2$ mutation carriers from the six countries.

Methods: We followed 7,015 women with a BRCA mutation for new cases of colorectal cancer. Incidence rates in carriers were compared with population-specific incidence rates, and relative risks (SIRs) were estimated. The expected numbers of cancers were computed by multiplying person-years at risk by the appropriate age-, sex-and country-specific incidence rates from the six countries.

Results: Twenty-two incident colorectal cancer cases were observed among all mutation carriers, compared to 23.6 cases expected. The SIR for BRCAI carriers was 0.97 (95\%CI, 0.58 $1.53, \mathrm{p}=0.9)$ and for $B R C A 2$ carriers was $0.82(95 \% \mathrm{CI}, 0.30-1.81, \mathrm{p}=0.7)$. The SIR for colon cancer was 3.81 (95\% CI 1.77 to 7.23 ) for women below the age of 50 (both genes combined) and was $0.65(95 \% \mathrm{Cl} 0.37-1.06)$ for women aged 50 and above.

Conclusions: The risk of colorectal cancer is increased in female carriers of $B R C A 1$ and $B R C A 2$ mutations below the age of 50 , but not in older women. 


\section{Background}

The $B R C A 1$ and $B R C A 2$ genes confer increased susceptibility to breast and ovarian cancer (1-5) and to a spectrum of other cancers (6-10). However, the risk for colorectal cancers associated with $B R C A 1$ and $B R C A 2$ mutations remains unclear. Previous studies which were designed to estimate the risk of colon cancer among mutation carries were based on cross-sectional reviews of family histories of women with mutations and were susceptible to both selection bias and misclassification. The diagnoses of colorectal cancer were based on information provided by a family member and this approach may not always be accurate. Further, in previous studies, the mutation status of the colorectal cancer cases was unknown. We conducted a prospective study of the incidence of colorectal cancer in a cohort of BRCAI and the BRCA2 mutation carriers. We followed 7,105 women with a $B R C A 1$ or $B R C A 2$ mutation for a mean of 5.5 years. The knowledge of colorectal cancer incidence rates has important implications for genetic counselors and their patients and for developing appropriate screening policies.

\section{METHODS}

\section{Study Population}

Eligible study participants were women at one of 50 centers in six countries from Canada, the United States or Europe who carry a deleterious BRCAl or BRCA2 mutation. In most cases, genetic testing was offered initially to women who were affected either by breast or ovarian cancer. When a mutation in either $B R C A I$ or $B R C A 2$ was found in a proband or in her relative, testing was offered to other at-risk women in her family, both affected and unaffected. In some cases, mutation testing was offered directly to unaffected women when no affected family 
member was available for testing. The criteria for genetic testing varied from center to center, but all participating facilities offered testing to both affected and unaffected women. Mutation detection was performed using a range of techniques, but all abnormal nucleotide sequences were confirmed by the direct Sanger sequencing. A woman was eligible for the study when the molecular analysis established that she was a mutation carrier. She was then asked to participate in this prospective study and to complete a baseline questionnaire. Participants were enrolled in the study from 1992 to 2010 . The majority of participants completed the baseline questionnaire at the time of genetic testing or within one year of receiving their result. This is a dynamic cohort with ongoing accrual, and therefore, the lengths of follow-up varied from individual to individual. Participants completed a baseline questionnaire and at least one follow- up questionnaire, a minimum of two years following the baseline questionnaire. The baseline and follow-up questionnaires requested information regarding reproductive history, surgical history (including preventive oophorectomy and mastectomy) and all new diagnoses of cancers. All participants provided written informed consent for genetic testing and for participating in the prospective study. The ethics committees of all participating centers have approved the study. The 7,021 carriers were from 3878 different families. Of 7,021 women, 6 women had data missing on key variables (e.g. date of birth, date of questionnaires, gene mutation) and were excluded, leaving 7,015 women in final analysis. An attempt was made to retrieve the pathology report for each of the incident cases of colorectal cancer.

\section{Statistical analysis}

Women who had a history of breast cancer were eligible for follow-up but women with a history of ovarian cancer were considered ineligible. Women were followed from the date at the 
baseline until the date of last questionnaire, the diagnosis of colorectal cancer, diagnosis of ovarian cancer or death from another cause. The risk of colorectal cancer in the $B R C A I$ and BRCA2 mutation carriers, relative to the general population was estimated with standardized incidence ratios (SIRs). The SIR was obtained by calculating the ratio of observed to expected number of new colorectal cancer cases, for all women combined and then separately for $B R C A I$ and the $B R C A 2$ carriers. To do so, the observed and expected numbers of colorectal cancers were derived separately for carriers from each of six countries (Canada, United States, Poland, France, Italy, Norway). First, the annual age-standardized incidence rates of colorectal cancer were calculated with the count (numerator) and person-year at risk (denominator). The person-years at risk were calculated using the total number of $B R C A 1$ and $B R C A 2$ carriers multiplied with the average follow-up time in years. The person-years were subcategorized according to different countries and different age groups. The age-standardized incidence rates for each participating country were obtained from GLOBOCAN 2008 (Ferlay et al. 2010). The expected number of colorectal cancers was calculated by multiplying each age-standardized incidence rate of the country-specific general population by the observed person-years in our BRCA cohort and divided by 100,000 to get the expected numbers of colorectal cancers (indirect standardization method). The SIRs were also estimated for age subgroups $<50$ years and $\geq 50$ years.

\section{RESULTS}

7,015 women in our database of $B R C A 1$ and $B R C A 2$ carriers were followed for a mean of 5.5

years. The mean age of the cohort at study entry was 47.3 years (range, 30-74 years). 5,481 participants $(78.13 \%)$ carried a $B R C A 1$ mutation, 1,474 (21,01\%) carried a BRCA2 mutation, and 
60 participants $(0.8 \%)$ carried both a $B R C A 1$ and $B R C A 2$ mutation. 2829 women $(40 \%)$ had a past history of breast cancer.

We identified 22 new colorectal cancer cases among the $B R C A I$ and $B R C A 2$ carriers versus 23.6 colorectal cancers expected ( $\mathrm{SIR}=0.93, \mathrm{p}=0.7$ ). Of the 22 colorectal cancer cases, 17 cases occurred in $B R C A 1$ carriers, versus 17.37 colorectal cancers expected $(\mathrm{SIR}=0.97, \mathrm{p}=0.9)$ and 5 cases occurred in BRCA2 carriers versus 6.1 colorectal cancers expected ( $\operatorname{SIR}=0.82, \mathrm{p}=$ 0.7)(table 1). The characteristics of the 15 colorectal cases for whom a pathology report was retrieved are presented in Table 2 .

The mean age of diagnosis for the cases of colon cancer was 56.3 years $(53.5$ years for the $B R C A 1$ mutation carriers and 57.3 years for the $B R C A 2$ mutation carriers). For women above the age of 50, the annual incidence rate was 52 per 100,000 per year for $B R C A l$ carriers and was 87 per 100,000 per year for $B R C A 2$ carriers (Table 3). For women below the age of 50 , the anmual incidence rate was 62 per 100,000 per year for BRCA1 carriers and was 40 per 100,000 per year for $B R C A 2$ carriers. The risk of colon cancer was four times greater than expected for young women (aged 30-49) $(\mathrm{SIR}=3.81 ; 95 \% \mathrm{CI} 1.77-7.23)$. The risk of early onset colon cancer was significantly elevated only for BRCA1 carriers. There were eight colorectal cancers in $B R C A 1$ carriers before age 50, the youngest occurred at age 32 and the others at ages 38,41 , $43,46,47,48$ and 49 years. There was no evidence of an increase in the risk of colorectal cancer for women aged above 50 years ( 14 cancers observed, 21.5 cancers expected). 
In addition to the 22 new cases of colorectal cancer, there were single cases of cancer of the gallbladder and bile duct. Because of the small numbers of these cases, SIRs were not estimated. No case of stomach cancers was reported in the follow-up period. 


\section{Discussion}

We have estimated the risks for cancer of the colon, rectum, gallbladder, bile duct and stomach among women with a $B R C A 1$ or $B R C A 2$ mutation. There were only single cases of cancers of the gallbladder and bile duct (and no case of stomach cancer) and therefore it was not possible to do a formal analy'sis for these. In contrast, there were 22 cases of colorectal cancer, but the incidence was not in excess of what we would have expected by chance, based on population rates for the five countries. However, the risk of early-onset colon cancer was significantly increased for young BRCAl carriers.

Our findings are consistent with the studies of cancers the Breast Cancer Linkage Consortium [13] wherein the authors reported modest but significant increases in colorectal cancer risk in family members of families with a $B R C A 1$ or $B R C A 2$ mutation. The relative risk associated with a $B R C A l$ mutation was $2.03(\mathrm{RR}=2.03,95 \% \mathrm{CI} 1.45$ to $2.85, \mathrm{P}<.001)(2)$. Easton et al, performed a comprehensive assessment of the cancer risks to $B R C A 2$ mutation carriers in these families. Significantly increased risks in carriers were observed for cancers of the stomach (RR $=2.59 ; 95 \% \mathrm{Cl} 41.46-4.61 ; \mathrm{P} .012)$ and gallbladder and bile ducts $(\mathrm{RR}=4.97 ; 95 \% \mathrm{Cl} 41.50$ $16.52 ; \mathrm{P}=.03)$ but not for colon cancer $(\mathrm{RR}=1.43 ; 95 \% \mathrm{CI} 0.79-2.58)$ and rectal cancer $(\mathrm{RR}=$ $1.11 ; 95 \%$ Cl $0.48-2.60)$.

Lim et al, 1999 investigated 42 patients with colorectal cancer from 32 hereditary breast cancer kindreds and a general population colorectal cancer cohort was composed of 755 patients from a tumor registry. They found the mean age of onset for patients with colorectal cancer was 60 years $(+/-2$ years) for hereditary breast cancer kindreds compared with 67 years $(+/-0.4$ years) 
for the general population ( $\mathrm{P}=0,0004)$. A greater number of Stage I and fewer Stage IV cancers were seen in subjects with hereditary breast cancer compared with the general population $(\mathrm{P}=$ 0.01). Overall BRCA-associated colorectal cancer had an earlier age of onset, lower tumor stage, and better survival rate than the general population.

In a recent study, 2,398 unselected patients with colorectal cancer and 4,570 controls from Poland were screened for three BRCA1 founder mutations. A BRCA1 mutation was present in $0.42 \%$ of unselected cases of colorectal cancer and in $0.48 \%$ of controls $(\mathrm{OR}=0.8 ; \mathrm{P}=0.8)$. In keeping with our findings, BRCA1 mutations were more common than this $(0.82 \%)$ in 851 cases who were diagnosed with colorectal cancer at age 60 or earlier (OR $=1.7)$ but this was not significant $(P=0.3)$. In a similar study conducted in Ashkenazi Jews, Niell et al 2004 identified a founder mutation in BRCA1 or BRCA2 in 24 of 1422 colon cancer cases and 20 of 1566 controls $(\mathrm{OR}=1.24,95 \%$ confidence interval $[\mathrm{CI}]=0.68$ to 2.26$)$.

In a population-based series of 649 unselected incident cases of ovarian cancer, Risch et al identified 60 mutations among 515 women with invasive ovarian cancers, 39 in BRCA1 and 21 in BRCA2. The risk of colorectal cancer was increased 3-fold for relatives of cases carrying a BRCA2 mutation. The risk of stomach cancer was increased 6-fold among first-degree relatives of cases carrying a BRCA1 mutation, compared with relatives of non-carriers. We reported no incident case of stomach cancer in our cohort. Jakubowska et al [1] observed a strong association between co-occurrence of ovarian cancer and stomach cancer in a family and the presence of a BRCA2 mutation in Poland. The increased risk of stomach cancer in BRCA2 carriers was observed predominantly in males. Bermejo et al [5] conducted a large retrospective 
population study in Swedish families eligible for BRCA1/2 testing. A 2-fold increased incidence of stomach cancer was observed; most individuals diagnosed with stomach cancer were men. The authors suggest an association of BRCA1 mutation carrier status in men with stomach cancer.

Our study provides the strongest evidence to date for an increased risk of colon cancer in young women with a BRCA1 or BRCA2 mutation. The primary strength of our study is that this is a large-scale prospective study in women confirmed to carry a BRCA1 or BRCA2 mutation. Many previous studies used a historical cohort design whereby genetic testing took place after the diagnoses of the incident cancers. Historical cohort studies are subject to bias because women who experience the endpoint of interest (colon, rectal and stomach cancer) may be more (or less) likely to undergo testing than healthy women because of local genetic testing criteria or high mortality. Our study has a number of limitations pertaining to both the estimation of the incidence and overall survival, Our cohort study includes only women and therefore, we cannot estimate the incidence of colorectal cancer in males. The number of incidence cases was relatively small $(n=22)$ and this limits the precision of the risk estimates, especially for subgroups. We were able to retrieve a pathology report or medical record on 18 of the cases $(82 \%)$ and the remainder were based on personal reporting.

The U.S. Preventive Services Task Force (USPSTF) recommends general population screening for colorectal cancer using high-sensitivity fecal occult blood testing, sigmoidoscopy, or colonoscopy beginning at age 50 years and continuing until age 75 years (11). However, they recommend that people at higher risk of developing colorectal cancer should begin screening at a younger age, and may need to be tested more frequently. Based on the results reported here, we 
recommend screening for colon cancer for women with a BRCA1 mutation be initiated at age 40 . There are insufficient data to make a recommendation for BRCA2 carriers that is different from that of the general population. 


\section{References}

1. Wooster R, Bignell G, Lancaster J, Swift S, Seal S, Mangion J, Collins N, Gregory S, Gumbs C, Micklem G. Identification of the breast cancer susceptibility gene BRCA2. Nature 1995;378:789-92.

2. Ford D, Easton DF, Stratton M, Narod S, Goldgar D, Devilee P, Bishop DT, Weber B, Lenoir G, Chang-Claude J, Sobol H, Teare MD, Struewing J, Arason A, Scherneck S, Peto J, Rebbeck TR, Tonin P, Neuhausen S, Barkardottir R, Eyfjord J, Lynch H, Ponder BA, Gayther SA, Zelada-Hedman M, and the Breast Cancer Linkage Consortium. Genetic heterogeneity and penetrance analysis of the BRCA1 and BRCA2 genes in breast cancer families. The Breast Cancer Linkage Consortium. Am J Hum Genet 1998;62:67689.

3. Thompson D, Easton D. Breast Cancer Linkage Consortium. Variation in cancer risks, by mutation position, in BRCA2 mutation carriers. Am J Hum Genet 2001;68:410-19.

4. Satagopan JM, Offit K, Foulkes W, Robson ME, Wacholder S, Eng CM, Karp SE, Begg $\mathrm{CB}$. The lifetime risks of breast cancer in Ashkenazi Jewish carriers of BRCA1 and BRCA2 mutations. Cancer Epidemiol Biomarkers Prev 2001;10:467-73.

5. Antoniou A, Pharoah PD, Narod S, Risch HA, Eyfjord JE, Hopper JL, Loman N, Olsson H, Johannsson O, Borg A, Pasini B, Radice P, Manoukian S, Eccles DM, Tang N, Olah E, Anton-Culver H, Warner E, Lubinski J, Gronwald J, Gorski B, Tulinius H, Thorlacius S, Eerola H, Nevanlinna H, Syrjakoski K, Kallioniemi OP, Thompson D, Evans C, Peto J, Lalloo F, Evans DG, Easton DF. Average risks of breast and ovarian cancer associated with BRCA1 or BRCA2 mutations detected in case Series unselected for family history: a combined analysis of 22 studies. Am J Hum Genet 2003;72:1117-30. 
6. King MC, Marks JH, Mandell JB, New York Breast Cancer Study Group. Breast and ovarian cancer risks due to inherited mutations in BRCA1 and BRCA2, Science $2003 ; 302: 643-6$.

7. Struewing JP, Hartge P, Wacholder S, Baker SM, Berlin M, McAdams M, Timmerman MM, Brody LC, Tucker MA. The risk of cancer associated with specific mutations of BRCA1 and BRCA2 among Ashkenazi Jews. N Engl J Med 1997;336:1401-8.

8. Breast Cancer Linkage Consortium. Cancer risks in BRCA2 mutation carriers. J Natl Cancer Inst 1999;91:1310-16.

9. Thompson D, Easton DF. Cancer incidence in BRCA1 mutation carriers. J Natl Cancer Inst 2002;94:1358-65.

10. Brose MS, Rebbeck TR, Calzone KA, Stopfer JE, Nathanson KL, Weber BL. Cancer Risk estimates for BRCA1 mutation carriers identified in a risk evaluation program. $J$ Natl Cancer Inst 2002;94:1365-72.

11. Gayther SA, Mangion J, Russell P, Seal S, Barfoot R, Ponder BA, Stratton MR, Easton D. Variation of risks of breast and ovarian cancer associated with different germline mutations of the BRCA2 gene. Nat Genet 1997;15:103-5.

12. Begg CB. On the use of familial aggregation in population-based case probands for calculating penetrance. J Natl Cancer Inst 2002;94:1221-6.

13. Gruber SB, Petersen GM. Cancer risks in BRCA1 carriers: time for the next generation of studies. J Natl Cancer Inst 2002;94:1344-5.

14. Anonymous. Statement of the American Society of Clinical Oncology: genetic testing for cancer susceptibility. J Clin Oncol 1996;14:1730-6. 
15. World Health Organisation (WHO). International Classification of Diseases: manual of the international statistical classification of diseases, injuries and causes of death, vol I. Geneva: WHO, 1997;(Switzerland).

16. Breslow NE, Day NE. Statistical methods in cancer research, vol I \&II: the design and analysis of case-control and cohort studies, IARC science publication no.32. Lyon: International Agency for Research on Cancer, 1987.

17. Visser O, Coebergh JWW, Schouten LJ, van Dijck JAAM. Incidence of cancer in the Netherlands. Utrecht, Comprehensive Cancer Centers, 2001.

18. In: Coebergh JWW, van der Heijden LH, Janssen-Heijnen MLG, eds. Cancer incidence and survival in the Southeast of the Netherlands 1955-1994. The Netherlands: Eindhoven, 1995.

19. Parkin DM, Whelan SL, Gao YT, Ferlay J, Raymond L, Young J, eds. Cancer Incidence in five continents, vol VII. IARC science publication no.143. Lyon: International Agency for Research on Cancer, 1997.

20. Tulinius H, Olafsdottir GH, Sigvaldason H, Arason A, Barkardottir RB, Egilsson V, Ogmundsdottir HM, Tryggvadottir L, Gudlaugsdottir S, Eyfjord JE. The effect of a single BRCA2 mutation on cancer in Iceland. J Med Genet. 2002;39:457-62.

21. Meijers-Heijboer EJ, Brohet RM, van Asperen CJ, van 't Veer LJ, Rookus MA, van Leeuwen FE, HEBON working group. Risks of cancer sites other than breast and ovary among BRCA1 mutation carriers. Familial Cancer 2004;3:153.

22. Offit K, Levran O, Mullaney B, Mah K, Nafa K, Batish SD, Diotti R, Schneider H, Deffenbaugh A, Scholl T, Proud VK, Robson M, Norton L, Ellis N, Hanenberg H, 
Auerbach AD. Shared genetic susceptibility to breast cancer, brain tumors, and Fanconi anemia. J Natl Cancer Inst 2003;95:1548-51.

23. Risch HA, McLaughlin JR, Cole DE, Rosen B, Bradley L, Kwan E, Jack E, Vesprini DJ, Kuperstein G, Abrahamson JL, Fan I, Wong B, Narod SA. Prevalence and penetrance of germline BRCA1 and BRCA2 mutations in a population series of 649 women with ovarian cancer. Am J Hum Genet 2001;68:700-10.

24. Kirchhoff T, Satagopan JM, Kauff ND, Huang H, Kolachana P, Palmer C, Rapaport H, Nafa K, Ellis NA, Offit K. Frequency of BRCA1 and BRCA2 mutations in unselected Ashkenazi Jewish patients with colorectal cancer. J Natl Cancer Inst 2004;96:68-70.

25. Niell BL, Rennert G, Bonner JD, Almog R, Tomsho LP, Gruber SB. BRCA1 and BRCA2 founder mutations and the risk of colorectal cancer. J Natl Cancer Inst 2004;96:15-21.

26. Easton DF, Steele L, Fields P, Ormiston W, Averill D, Daly PA, McManus R, Neuhausen SL, Ford D, Wooster R, Cannon-Albright LA, Stratton MR, Goldgar DE. Cancer risks in two large breast cancer families linked to BRCA2 on chromosome 13q12-13. Am J Hum Genet 1997;61:120-8. 
Table 1: Observed and expected number of colorectal cancer in BRCA1 and BRCA2 carriers according to the contributing country.

\begin{tabular}{|c|c|c|c|c|c|c|c|c|}
\hline Country & $\begin{array}{l}B R C A \\
\text { status }\end{array}$ & $N$ & $\begin{array}{l}\text { Person- } \\
\text { year's }\end{array}$ & $\begin{array}{c}\text { Rate } \\
\text { Per } \\
100,000 \\
\end{array}$ & $\begin{array}{l}\text { Observed } \\
\text { cancers }\end{array}$ & $\begin{array}{l}\text { Expected } \\
\text { cancers }\end{array}$ & SIR $(95 \% \mathrm{CI})$ & $\begin{array}{c}\text { p-value } \\
\text { (two-tailed) }\end{array}$ \\
\hline \multirow{3}{*}{ Canada } & All & 1760 & 10494 & 72.23 & 8 & 9.16 & $0.87(0.40-1.65)$ & 0.7 \\
\hline & $B R C A I$ & 1012 & 6172 & 97.21 & 6 & 5.13 & $1.17(0.47-2.43)$ & 0.6 \\
\hline & BRCA2 & 725 & 4222 & 47.37 & 2 & 3.96 & $0.50(0.08-1.67)$ & 0.3 \\
\hline \multirow{3}{*}{ USA } & All & 1853 & 10071 & 69.50 & 7 & 6.64 & $0.95(0.49-1.6)$ & 1 \\
\hline & $B R C A 1$ & 1253 & 7027 & 71.15 & 5 & 4.47 & $1.12(0.41-2.4)$ & 0.7 \\
\hline & $B R C A 2$ & 577 & 2934 & 68.16 & 2 & 2.1 & $0.95(0.16-3.1)$ & 1 \\
\hline \multirow{3}{*}{ Austria } & All & 141 & 704 & 142.04 & 1 & 0.26 & $3.85(0.19-19)$ & 0.2 \\
\hline & $B R C A 1$ & 107 & 548 & - & 0 & 0.18 & - & - \\
\hline & $B R C A 2$ & 20 & 118 & 847.45 & 1 & 0.07 & $14.29(0.71-70.4)$ & 0.07 \\
\hline \multirow{3}{*}{ Poland } & All & 2475 & 11718 & 34.13 & 4 & 4.28 & $0.93(0.29-2.2)$ & 0.9 \\
\hline & $B R C A I$ & 2468 & 11596 & 34.49 & 4 & 4.23 & $0.94(0.30-2.3)$ & 0.9 \\
\hline & $B R C A 2$ & 7 & 22 & - & 0 & 0.01 & - & - \\
\hline \multirow{3}{*}{ Norway } & All & 682 & 5160 & 38.76 & 2 & 4.53 & $0.44(0.07-1.60)$ & 0.2 \\
\hline & $B R C A 1$ & 556 & 4392 & 45.54 & 2 & 3.76 & $0.53(0.09-1.75)$ & 0.3 \\
\hline & $B R C A 2$ & 126 & 803 & - & 0 & 0.81 & - & - \\
\hline \multirow{3}{*}{$\begin{array}{c}\text { All } \\
\text { countries }\end{array}$} & All & 7015 & 38646 & 56.93 & 22 & 23.6 & $0.93(0.59-1.38)$ & 0.7 \\
\hline & $B R C A I$ & 5481 & 30191 & 56.31 & 17 & 17.37 & $0.97(0.58-1.53)$ & 0.9 \\
\hline & $B R C A 2$ & 1474 & 8208 & 60.96 & 5 & 6.1 & $0.82(0.30-1.81)$ & 0.7 \\
\hline
\end{tabular}

Abbreviations: SIR, standardized-incidence ratio; CI, confidence interval 
Table 2: Characteristics of the incidence cases of colorectal cancer in BRCA mutation carriers

\begin{tabular}{|l|l|l|l|l|l|l|}
\hline $\begin{array}{l}\text { Pedigree } \\
\text { number }\end{array}$ & Age & $\begin{array}{l}\text { BRCA } \\
\text { status }\end{array}$ & Tumor site & Tumor pathology & $\begin{array}{l}\text { Tumor } \\
\text { Grade }\end{array}$ & $\begin{array}{l}\text { Duke's } \\
\text { stage }\end{array}$ \\
\hline CR1973 & 46 & BRCA1 & Anal canal & Squamous cell carcinoma & Grade 2 & Unk \\
\hline UU2802 & 51 & BRCA1 & Unknown & Adenocarcinoma & Unk & Unk \\
\hline BCW141 & 57 & BRCA1 & Right colon & Adenocarcinoma & Grade 2 & Duke B \\
\hline BC169 & 48 & BRCA1 & Right colon & Adenocarcinoma & Grade 3 & Duke C \\
\hline CI1407 & 73 & BRCA1 & Metastatic, PSU & Adenocarcinoma & Unk & Unk \\
\hline NR1575 & 32 & BRCA1 & Left colon & Adenocarcinoma & Grade 2 & Duke C \\
\hline NR1353 & 55 & BRCA1 & Transverse colon & Adenocarcinoma & Grade 3 & Duke C \\
\hline PD121177 & 61 & BRCA1 & Unknown & Adenocarcinoma & Grade 2 & Unk \\
\hline PD56009 & 44 & BRCA1 & Anal canal & Squamous cell carcinoma & Unk & Unk \\
\hline ED37623 & 65 & BRCA1 & Rectum & Adenocarcinoma & Grade 1 & Duke C \\
\hline HM1030 & 56 & BRCA1 & Anal canal & Squamous cell carcinoma & Grade 3 & Unk \\
\hline AUF089 & 62 & BRCA2 & Sigmoid colon & Adenocarcinoma & Grade 2 & Duke B \\
\hline SB42233 & 65 & BRCA2 & Transverse colon & Adenocarcinoma & Grade 2 & Duke B \\
\hline CLC018 & 77 & BRCA2 & Sigmoid colon & Adenocarcinoma & Grade 2 & Duke A \\
\hline VT9729 & 55 & BRCA2 & Anal canal & Squamous cell carcinoma & Grade 1 & Duke A \\
\hline
\end{tabular}

Abbreviations: PSU, primary site unknown; Unk, unknown 
Table 3: Observed and expected number of colorectal cancer in $B R C A 1$ and $B R C A 2$ carriers according to age groups.

\begin{tabular}{|c|c|c|c|c|c|c|c|c|}
\hline $\begin{array}{c}\text { BRCA } \\
\text { status }\end{array}$ & $\begin{array}{c}\text { Age } \\
\text { (years) }\end{array}$ & $\mathrm{N}$ & $\begin{array}{c}\text { Person } \\
\text {-years }\end{array}$ & $\begin{array}{c}\text { Rate } \\
\text { per } \\
100,000\end{array}$ & $\begin{array}{c}\text { Observed } \\
\text { Cancers }\end{array}$ & $\begin{array}{c}\text { Expected } \\
\text { cancers }\end{array}$ & SIR (95\% CI) & $\begin{array}{c}\text { p-value } \\
\text { (two-tailed) }\end{array}$ \\
\hline \multirow{2}{*}{ All } & $30-49$ & 3194 & 15466 & 51.73 & 8 & 2.10 & $3.81(1.77-7.23)$ & 0.001 \\
\cline { 2 - 9 } & $50-74$ & 3821 & 23180 & 60.40 & 14 & 21.50 & $0.65(0.37-1.06)$ & 0.09 \\
\hline \multirow{2}{*}{$B R C A 1$} & $30-49$ & 2638 & 12848 & 62.27 & 8 & 1.68 & $4.76(2.21-9.04)$ & $<0.001$ \\
\cline { 2 - 9 } & $50-74$ & 2843 & 17342 & 51.90 & 9 & 15.68 & $0.57(0.28-1.05)$ & 0.07 \\
\hline \multirow{2}{*}{$B R C A 2$} & $30-49$ & 554 & 2486 & - & 0 & 0.39 & - & - \\
\cline { 2 - 9 } & $50-74$ & 980 & 5722 & 87.38 & 5 & 5.70 & $0.87(0.32-1.94)$ & 0.8 \\
\hline
\end{tabular}

Abbreviations: SIR, standardized-incidence ratio; $\mathrm{Cl}$, confidence interval 


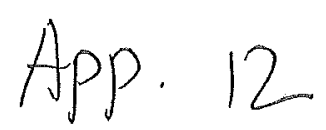

Cellular Transport Gene Variants Are Associated With Susceptibility to Epithelial Ovarian Cancer Risk and Histopathologic Subtypes

Ganna Chornokur ${ }^{1}$, Jonathan Tyrer, Hui-Yi Lin, , Ya-Yu Tsai ${ }^{1}$, Emest K. Amankwah ${ }^{1}$, Ellen L. Goode ${ }^{2}$, Julie M.

Cunningham $^{3}$, Brooke L. Fridley ................... OCAC ...................................Edward Iversen" ${ }^{4}$, David Fenstermacher, Susan Ramus, Andrew Berchuck, Joellen Schildkraut ${ }^{5}$, Alvaro Monteiro, Simon Gayther, Thomas A. Sellers', Paul Pharoah and Catherine M. Phelan ${ }^{1}$ on behalf of OCAC.

1. Division of Cancer Prevention and Control, H. Lee Moffitt Cancer Center and Research Institute, 12902 Magnolia Drive, Tampa, Florida 33612, USA.

2. Department of Health Sciences Research, Mayo Clinic College of Medicine, 200 First Street SW, Rochester, MN 55905, USA.

3. Department of Laboratory Medicine and Pathology Mayo Clinic College of Medicine, 200 First Street SW, Rochester, MN 55905, USA.

4. Department of Statistical Science, Duke University, Durham, NC, USA

5. Division of Preventive Medicine, The Duke Comprehensive Cancer Center, Durham, NC 27710, USA.

Running Title: Cellular transport gene variants and ovarian cancer risk

Tables: 4

Figures: 1

Supplementary Tables: 3

*To whom correspondence should be addressed

Catherine M. Phelan,

Department of Cancer Epidemiology,

Moffitt Cancer Center,

12902 Magnolia Drive,

Tampa, FL 33612,

USA.

Ph: 813-745-4971

e-mail: Catherine,phelan@moffitt.org 


\section{Abstract}

Background. Epithelial Ovarian Cancer (EOC) is a lethal gynecologic malignancy and the fifth cause of cancer mortality in the U.S. females. Recently, cellular transport processes were implicated in the pathogenesis of EOC. We hypothesized that variation in cellular transport genes is associated with the EOC risk.

Methods. In a discovery set of 7931 EOC cases and 9206 controls, we investigated 4200 SNPs in ??? genes, 472 of which showed associations up to the significance level of $p<0.05$. In a replication set we genotyped 305 of the most significant SNPS in 10,243 EOC cases an 16,932 controls so the combined dataset consisted of 18,736 EOC cases and 23,448 controls (of European ancestry). The 305 SNPs, from 120 genes were genotyped using an Illumina Infinium iSelect BeadChip as part of the Collaborative Oncological Geneenvironment Study (COGS). Both invasive cancers combined and the four main histological subtypes (serous $[n=8,372]$, endometroid $[n=2,068]$, clear cell $[n=1,025]$ and mucinous $[n=943]$ were analyzed. SNP analyses were conducted using unconditional logistic regression under a log-additive model. All analyses were adjusted for study site and population substructure.

Results. The strongest evidence of an association for invasive cancers combined (INV) was observed for SNP rs 17216603 in the iron transporter HEPH $\left(\mathrm{OR}=0.85,95 \% \mathrm{Cl}=0.77-0.93, \mathrm{P}=2.55^{*} 10^{-4}\right)$, which was also the most significant SNP associated with the serous subtype $\left(P=1.99^{*} 10^{-4}\right)$, and associated with the borderline/low malignant potential (LMP) tumors $(P=0.0206)$. The most significant association for endometroid EOC was rs11563251 near the UGT1A gene cluster $\left(O R=0.82,95 \% C l=0.73-0.92, P=6.59^{*} 10^{-4}\right)$. The most significant associations for mucinous subtype was rs681309 near the $S L C 25 A 45$ (OR=0.89, 95\%Cl=0.81-0.97, $\mathrm{P}=0.012)$. This SNP was also associated with the endometrioid subtype $(P=0.0035)$ and INV EOC $(P=0.0294)$. The most significant association with clear cell carcinoma was rs7562766 located near CAPN13 (OR=0.86, $95 \% \mathrm{Cl}=0.79-0.95, P=0.0014)$. One more SNP in CAPN13 was significant in the clear cell subtype only. Association with the rs9908917 in the intron of SLC39A11 was observed in LMP (OR=0.85, 95\% Cl=0.77-0.93, $\left.P=3.9^{*} 10^{-4}\right)$. This SNP was also associated with the serous subtype $(P=0.0123)$ and INV EOC $(P=0.0144)$. Five additional SNPS in the SLC39A11 were significant across different histologic subtypes. Interestingly, rs1804495 in SERPINA7 was associated with serous, mucinous, clear cell, INV and LMP subgroups $(P<0.05)$. Conclusion. Our results, generated on a large cohort of women, suggest specific associations between inherited cellular transport gene variants and risk of different EOC histologic subtypes. 


\section{Introduction}

Epithelial ovarian carcinoma (EOC) is the most common gynecological malignancy and the leading cause of gynecological cancer-related mortality in the United States (US) and other developed nations [1]. Early stage EOC is accompanied by vague, non-specific symptoms and is difficult to detect. Importantly, there are no EOC screening or early detection strategies that have been proven useful [2]. As a consequence, approximately $60 \%$ of cases are diagnosed at later stages (III-IV) with a 5 year overall survival of less than $20 \%$ [3]. Typical management of advanced ovarian cancer involves surgical cytoreduction followed by platinum-based chemotherapy [4]. Initially the majority of patients respond to the chemotherapy but at least half of all patients recur within 4 years [5]. Given these grim statistics, improved understanding of the disease etiology is critical to reduce the morbidity and mortality associated with ovarian cancer.

A major deterrent in the detection and treatment of ovarian cancer is our poor understanding of the genetic and biological basis for this disease. Disruptions in the cellular transport processes, such as metal ion transport through the cellular membranes, has been associated with increased risk of a number of cancers including breast [6-8], prostate [9], liver [10], colorectal [11], thyroid [12] and neuroblastoma [13]. Iron is essential for erythropoiesis [14] and the respiratory chain functioning where it plays a key role in electron transport, in the form of iron-sulphur clusters or in haem centers [15]. However, excess iron and copper may promote the formation of reactive oxygen radicals possibly leading to organ damage and supporting cancer growth [16]. Partially reduced oxygen species (PROS) formed as a byproduct in the mitochondrial respiratory chain, are rendered innocuous by the enzyme superoxide dismutase and converted to oxygen and hydrogen peroxide. Hydrogen peroxide is in itself stable but can react with iron or copper and form hydroxyl radicals which are extremely reactive and damaging to living tissues [17]. In concordance with these data, transport of the three most abundant transition metals in the human organism - iron, zinc and copper - was linked to the etiology of liver [10, 18], prostate [19-20] and lymphoma [21] cancers, although the biological basis for this assoaiation is poorly understood.

Despite the growing evidence of association between the cellular transport processes and cancer risk, the association of germline genetic variation in the cellular transport genes and EOC risk has not been studied. We hypothesized that single nucleotide polymorphisms (SNPs) in the cellular transport genes are associated with EOC risk and histopathology. In a discovery set of 7931 EOC cases and 9206 controls, we investigated 4200 SNPs in 100 genes, 305 of which showed associations up to the significance level of $p<0.05$. This study describes the replication of these findings and we present the results of statistically significant associations with EOC risk with 305 SNPs in 120 genes in the large combined dataset of 18,736 EOC cases and 23,448 controls. 


\section{Materials and Methods}

\section{Discovery Set Study Populations}

The Discovery set consisted of 7931 EOC cases and 9205 controls in total. We combined the results from two ovarian cancer GWAS from North America and the UK. Details of these studies have been previously published [22]. Briefly, the North American study comprised four case control studies genotyped using the Illumina 610-quad Beadchip Array ${ }^{\mathrm{TM}}$ (1,815 cases and 1,900 controls) and a single case-control study genotyped on the Illumina $317 \mathrm{~K}$ and $370 \mathrm{~K}$ arrays (137 cases and 142 controls). The UK study comprised four case-only studies genotyped on the Illumina 610-quad and two common control sets genotyped on the Illumina $550 \mathrm{~K}$ array (1,817 cases and 2,354 controls). A second phase of the UK GWAS comprised an additional ten case-control studies (4,162 cases and 4,810 controls). The North American and UK studies were analysed separately and the results combined using standard fixed effects meta-analysis. SNPs were ranked according to the p-values for each of four analyses performed: North America study only (all histologies and serous histology), and combined GWAS meta-analysis (all histologies and serous histology). The minimal ranking for each SNP was obtained across the four sets of results. We acquired the design score for each SNP using the Illumina Assay Design Tool and removed SNPs that were redundant or predicted to perform poorly, In total, 322 SNPs were included on the COGS custom genotyping array and 307 passed QC.

\section{Replication/Combined Set Study populations}

The replication set included an additional 10,243 cases and 16,932 controls. The combined set consisted of a total of 47,517 samples from 44 sites in OCAC were genotyped of which 44,312 passed QC, including 18,174 (10,316 serous) cases and 26,138 controls [22]. HapMap/1000 Genomes Project samples for European (CEU, $n=60)$, African (YRI, n=53) and Asian (JPT+CHB, n=88) were also genotyped.

\section{SNP Selection}

A total of 120 cellular transport-related genes were identified through review of the published literature (www.pubmed.gov) and pathways described in the Cancer Genome Anatomy Project. There were over 4200 SNPS in these 120 genes in the Illumina $550 \mathrm{~K}$ and 610 quad chip, of which 427 were statistically significantly associated with EOC risk $(p<0.05)$ in the discovery set. The final selection of immunomodulatory -related SNPS for genotyping in COGS was informed by ranking of minimal p-values from the US GWAS and/or US/UK GWAS meta-analysis data. The top 305 SNPs in 120 genes were selected for genotyping in the replication set.

\section{SNP genotyping}

Genotyping was conducted using an Illumina Infinium iSelect BeadChip in two centers for OCAC - Genome Quebec $(n=25,782)$ and the Mayo Clinic Medical Genome Facility $(n=18,707)$. Each 96-well plate contained $750 \mathrm{ng}$ genomic DNA (or 1,500 ng whole-genome amplified DNA). Raw intensity data files for all consortia were sent to the COGS data co-ordination centre at the University of Cambridge for centralized genotype calling and QC. Genotypes were called using GenCall \{Kermani, 2008 \#10972\}. Initial calling used a cluster 
file generated using 270 samples from Hapmap2. These calls were used for ongoing QC checks during the genotyping. To generate the final calls used for the data analysis, we first selected a subset of 3,018 individuals, including samples from each of the genotyping centres, each of the participating consortia, and each major ethnicity. Only plates with a consistent high call rate in the initial calling were used. HapMap and 1000 Genomes Project samples, along with 160 samples that were known positive controls for rare variants on the array were used to generate a cluster file that was then applied to call the genotypes for the remaining samples using GenCall.

\section{Sample QC}

One thousand two hundred and seventy three OCAC samples were genotyped in duplicate. Genotypes were discordant for greater than 40 percent of SNPS for 22 pairs. For the remaining 1,251 pairs, concordance was greater than 99.6 percent. In addition we identified 245 pairs of samples that were unexpected genotypic duplicates. Of these, 137 were phenotypic duplicates and judged to be from the same individual. We used identity-by-state to identify 618 pairs of first-degree relatives. Samples were excluded according to the following criteria: 1) 1,171 samples with a conversion rate of less than 95 percent; 2) 169 samples with heterozygosity $>5$ standard deviations from the intercontinental ancestry specific mean heterozygosity; 3) 67 samples with ambiguous sex; 4) 294 samples with the lowest call rate from a first-degree relative pair 5) 1,604 samples that were either duplicate samples that were non-concordant for genotype or genotypic duplicates that were not concordant for phenotype. Thus, a total of 44,312 subjects including 18,174 cases and 26,138 controls were available for analysis.

\section{SNP QC}

Robust genotyping quality control guidelines were used to ensure accurate genotyping. SNPs were excluded according to the following criteria: (1) SNPs without a genotype call; (2) monomorphic SNPS; (3) SNPS with a call rate less than 95 percent and MAF $>0.05$ or call rate less than 99 percent with MAF $<0.05$; (4) SNPS showing evidence of deviation of genotype frequencies from Hardy-Weinberg equilibrium $\left(p<10^{-7}\right) ;(5)$ SNPS with greater than 2 percent discordance in duplicate pairs. Overall, 305 of the $320(95.3 \%)$ selected transport SNPs passed QC.

\section{Statistical methods}

Analysis of the combined COGS data set

We used the program LAMP \{Sankararaman, 2008 \#445\} to assign intercontinental ancestry based on the

genotype frequencies for these three populations. Subjects with greater than 90 percent European ancestry were defined as European $(n=39,944)$ and those with greater than 80 percent Asian and African ancestry were defined as being Asian ( $n=2,388)$ and African respectively $(n=387)$. All other subjects were defined as being of mixed ancestry $(n=1,770)$. A set of 37,000 unlinked markers was used to perform principal components 
analysis within each major population subgroup (using a programme available at http://ccge.medschl,cam.ac.uk/software/).

Unconditional logistic regression treating the number of alternate alleles carried as an ordinal variable (logadditive, co-dominant model) was used to evaluate the association between each SNP and ovarian cancer risk. A likelihood ratio test was used to test for association, and per-allele log odds ratios and 95 percent confidence limits were estimated. $\{$ Xing, 2012 \#10925\}. Separate analyses were carried out for each ancestry group. The model for European subjects was adjusted for study and population substructure by including study-specific indicators and the first five eigenvalues from the principal components analysis in the model. For analysis of the Asian and other ancestry groups, the first five ancestry-specific principal components were included in the model, and one principal component was included in the model for analysis of subjects of African ancestry. These cut-offs were based on the position of the inflexion of the principal components scree plot.

In order to assess the magnitude of confounding due to cryptic population substructure, we tested for association for the 147,722 SNPs included on the genotyping array that not been selected as candidates for ovarian cancer susceptibility. In analyses restricted to European subjects and adjusted only for study, there was a small inflation of the test statistic for $(\lambda=1.13$ equivalent to $\lambda=1.007$ for a study of 1000 cases and 1000 controls). This was reduced to $1.078\left(\lambda_{1000}=1.004\right)$ after adjusting for five principal components. Heterogeneity of odds ratios between studies was tested with Cochran's $Q$ statistic.

To maximize statistical power, the "combined" COGS dataset was used to perform SNP-specific analyses for all invasive EOC, the four main histological subtypes (serous, endometroid, clear cell and mucinous), tumors of low malignant potential (LMP) and for all the ethnicities. OR specific for each histological subtype was estimated by comparing cases of each subtype to all available controls as the reference. We also stratified the analysis for the top SNPs in all invasive EOC and serous histological subtype by risk factors for ovarian cancer including age at diagnosis/interview, age at menarche, parity, oral contraceptive use and family history. Linear trends for age at diagnosis/interview and menarche were determined.

\section{Results}

Table 1: Clinical characteristics of cases and controls.

Table 2: Statistically significant associations with EOC risk by tumor behavior and histologic subtype in European subjects

Table 3: Statistically significant associations with serous EOC risk in European, Asian and African American subjects

Table 4: GxE interactions in all invasive EOC combined in European women Supplementary Table 1: The Discovery set?

Supplementary Table 2: Statistically significant associations for the 85 SNPs which remained significant in the discovery, replication and combined datasets. 
We genotyped 305 SNPs from 120 cellular transport genes (Supplementary Table 2), in 18,736 EOC cases and 23,448 controls of European ancestry. Both invasive cancers combined and the four main histological subtypes (serous $[n=8,372]$, endometroid $[n=2,068]$, clear cell $[n=1,025]$ and mucinous $[n=943]$ were analyzed. The mean age at diagnosis/interview for women of European ancestry was 55 (std=11) years (Table 1). Distribution of risk factors (Table 1). As expected, the proportion of serous histological subtype (58\%) was higher than the other subtypes (15\% for endometroid, $7 \%$ for mucinous and $7 \%$ for clear cell) (Table 1).

Eighty-four SNPs remained statistically significantly associated with EOC risk on replication and in the combined dataset (Supplementary Table 2).

The strongest evidence of an association for invasive cancers combined (INV) was observed for SNP rs 17216603 in the iron transporter $\mathrm{HEPH}\left(\mathrm{OR}=0.85,95 \% \mathrm{Cl}=0.77-0.93, \mathrm{P}=2.55^{*} 10^{-4}\right)$, which was also the most significant SNP associated with the serous subtype $\left(P=1.99^{*} 10^{-4}\right)$, and associated with the borderline/low malignant potential (LMP) tumors $(P=0.0206)$. The most significant association for endometroid EOC was rs11563251 near the UGT1A gene cluster $\left(O R=0.82,95 \% \mathrm{Cl}=0.73-0.92, \mathrm{P}=6.59^{*} 10^{-4}\right)$. The most significant associations for mucinous subtype was rs681309 near the $S L C 25 A 45(O R=0.89,95 \% C l=0.81-0.97, P=0.012)$. This SNP was also associated with the endometrioid subtype $(P=0.0035)$ and INV EOC $(P=0.0294)$. The most significant association with clear cell carcinoma was rs7562766 located near CAPN13 (OR=0.86, $95 \% \mathrm{Cl}=0.79-0.95, \mathrm{P}=0.0014)$. One more SNP in CAPN13 was significant in the clear cell subtype only. Association with the rs9908917 in the intron of SLC39A11 was observed in LMP (OR=0.85, 95\%Cl=0.77-0.93, $\left.P=3.9^{*} 10^{-4}\right)$. This SNP was also associated with the serous subtype $(P=0.0123)$ and INV EOC $(P=0.0144)$. Five additional SNPS in the SLC39A11 were significant across different histologic subtypes. Interestingly, rs1804495 in SERPINA7 was associated with serous, mucinous, clear cell, INV and LMP subgroups $(P<0.05)$.

We have conducted exploratory analyses for other ethnicities and serous EOC. 14 SNPs showed significant associations in Asian and African women, each (compared to 16 significant associations in women of European descent). Six of the SNPS in Asian women were also significant in European women compared to two of the 14 SNPs in African women. The two top SNPs in women of Asian ancestry (rs17216603 in HEPH and rs1552846 in SLC39A11) were shared with the NHW women. The SLC25A45 rs681309 was also shared. SERPINA7 rs 1804495 was borderline significant ( $P=0.0503$ ) likely due to a small sample size. The most significant association in women of African ancestry was noted at the SNP rs6488840 in the Microsomal glutathione S-transferase 1 (MGST1) gene. In our study, MGST1 rs6488840 was associated with statistically significantly reduced INV EOC risk in women of African ancestry $(O R=0.55 ; P=0.0035)$. This SNP was also borderline significant in women of European ( $O R=0.95 ; P=0.042)$, but not Asian, ethnicity. However, the power to detect associations in Africans and Asians was low due to the small sample sizes of these populations. 


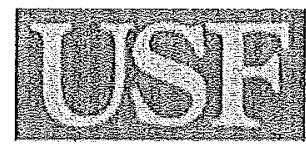

UNIVERSITY OF

SOUTH FLORIDA
DWTION OF RESEARCH INTEORITI'AND CONPLLNCE

In:titutional Review Boards, EWA No, 000 1669

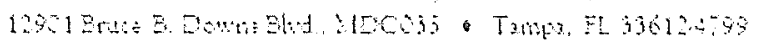

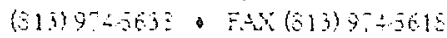

$7 / 21 / 2011$

Ganna Chornokur

H Lee Moffitt Cancer Center

12902 Magnolia Dr.

RE: Exempt Certification for IRBH: Pro00004885

Title: Comprehensive Population-Specific Marker Panel for Early Prostate Cancer

Diagnostics and Risk Assessment

Dear Dr. Chornokur:

On $7 / 21 / 2011$, the Institutional Review Board (IRB) determined that your research meets USF requirements and Federal Exemption criteria as outlined in the federal regulations at 45CFR46.101(b):

(4) Research involving the collection or study of existing data, documents, records, pathological specimens, or diagnostic specimens, if these sources are publicly available or if the information is recorded by the investigator in such a manner that subjects cannot be identified, directly or through identifiers linked to the subjects.

As the principal investigator for this study, it is your responsibility to ensure that this research is conducted as outlined in your application and consistent with the ethical principles outlined in the Belmont Report and with USF IRB policies and procedures. Please note that changes to this protocol may disqualify it from exempt status. Please note that you are responsible for notifying the IRB prior to implementing any changes to the currently approved protocol.

The Institutional Review Board will maintain your exemption application for a period of five years from the date of this letter or for three years after a Final Progress Report is received, whichever is longer. If you wish to continue this protocol beyond five years, you will need to submit a continuing review application at least 60 days prior to the exemption expiration date. Should you complete this study prior to the end of the five-year period, you must submit a request to close the study.

We appreciate your dedication to the ethical conduct of human subject research at the University of South Florida and your continued commitment to human research protections. If you have any questions regarding this matter, please call 813-974-5638. 
Sincerely,

$\left.\int(x) \cos \theta x-8\right)$

Janelle Perkins, PharmD, Chairperson

USF Institutional Review Board 
in the small intestine and the colon, its expression has also been detected in the lung, kidney, stomach, skin, nervous system, pancreas, placenta and other tissues [24, 28-29]; however, its role in these tissues is not clear. Similarly, the role of iron homeostasis in cancer progression is yet to be deciphered. It was reported that depletion of the iron storages in the cells causes cell cycle arrest and apoptosis, limits the rate of DNA synthesis, and down-regulates expression of various carcinogenic kinases such as cyclin-dependent kinases (CDKs) and the cyclins itself [30]. Additionally, iron is known to facilitate generation of reactive oxygen species (ROS) that have a direct connection to cancer [31]. Thus, it is biologically plausible that iron homeostasis may modulate cancer progression via disruptions in the cell cycle and/or generation of ROS. Specifically, depleted iron stores may lead to decreased rates of cancer growth. In concordance with this intriguing hypothesis, our bioinformatics simulated data indicated that rs17216603 may lead to a reduction or loss of the HEPH function, thus potentially altering (diminishing) systemic iron adsorption. Hence, it is tempting to suggest that women who carry at least one A-allele in the rs17216603 have decreased serous EOC risk due to diminished iron stores in the ovarian epithelium and/or the circulation, compared to women who are homozygous for the major G-allele. It is also possible that HEPH has other carcinogenic role(s) in the ovarian epithelium (unrelated to iron metabolism), such as kinase signaling, although at present there is no data to support or reject this hypothesis. Additionally, studies show that copper deficient mice have dramatically reduced levels of $\mathrm{HEPH}$ expression, diminished ferroxidase activity and shortened half life, indicating that copper is required for proper $\mathrm{HEPH}$ synthesis and/or function [32-33]. However, the relevance of this observation to our reported finding is unknown. Although intriguing and novel, verification of the aforementioned hypotheses will require extensive functional and epidemiological work.

Solute carrier family 39, member 11 (SLC39A11) belongs to a family of metal ion transporters. It is integrated in the cellular membrane and may act as a zinc-influx transporter (by similarity to other members with established zinc-transport activity such as $A 1$ and $A 10$ ), although the exact functions of the member A11 are yet to be experimentally established [34]. Members of the SLC39 family may also transport other metal ions, such as iron, copper, cadmium and manganese [35]. There is some experimental evidence that SLC39A7 (Zip7) releases zinc from the endoplasmic reticulum and might be required for tyrosine kinase activation [36]. There are multiple reports of different SLC39 members being involved in cancer. For example, SLC39A1 was reported [37] to act as a tumor suppressor gene in the prostate tumor cells by allowing zinc ions to accumulate in the prostate epithelium. The authors concluded that silencing the Zip1 (a protein product of the SLC39A1) leads to decreased intracellular concentration of zinc, loss of the tumor suppression and increased prostate cancer growth. SLC39A4 (Zip4) was reported [38] to be significantly overexpressed in pancreatinc cancer cells, which leads to the 2-fold increased proliferation and increased zinc uptake in vitro. Consequently, in vivo animal models with forcefully enhanced Zip4 expression demonstrated over 7-fold increased tumor weight, peritoneal dissemination and ascites incidence. These data suggest that Zip4 may facilitate pancreatic cancer proliferation. SLC39A10 (Zip10) was involved in the invasive behavior of breast cancer cells suggesting that zinc and ZIP10 play an essential role in the migratory activity of highly metastatic breast cancer cells, and 
suggest ZIP10 as a possible marker for the metastatic phenotype of breast cancer and a promising target of novel treatment strategies [39]. In the present study, rs9908917 in SLC39A11 conferred modestly, albeit statistically significant decreased risk for serous, LMP and INV EOC. Importantly, five additional SNPs in the SLC39A11 (rs1552846, rs1177982, rs8068946, rs9905659 and rs9913553) were significant across different histologic subtypes. Importantly, A11 is one of the most understudied SLC39 members and we could not find any information on its specific function(s) in cancer. Given our results obtained using a very large cohort of women, such studies are highly warranted.

Serpin peptidase inhibitor, clade A (alpha-1 antiproteinase, antitrypsin), member 7 (SERPINA7), also known as thyroxine-binding globulin (TBG), is a protein that binds thyroid hormones thyroxin (T4) and 3,5,3'triiodothyronine (T3) in circulation [40]. Numerous mutations in SERPINA7 have been identified [41-43] leading to partially or completely absent TBG production. Although the hallmark of TBG deficiency is abnormally low T3 and T4 combined with normal thyroid stimulating hormone (TSH) values, the affected carriers are clinically asymptomatic [41]. This is because the amount of the unbound (active) thyroid hormone is not affected by the impaired TBG production enough to cause an overt thyroid dysfunction. The specific role of SERPINA7 in cancer etiology has not been established; however, thyroid hormones may support cancer growth [44]. Thus, it is conceivable that impaired (diminished) TBG production in the minor allele rs1804495 carriers may lead to a slight elevation in the free T3 and/or T4 which, while clinically insignificant, may promote EOC growth if persists for many years. We note that in our study, rs1804495 confers statistically significantly increased risk for LMP, INV, serous and clear cell, but decreased risk for mucinous EOC. This observation is consistent with the previously published studies that emphasize on the differences between the mucinous disease and other EOCs [45-46]. In summary, our results suggest involvement of the thyroid hormone metabolism in EOC etiology across different histological subtypes and calls for additional studies on this topic.

Solute carrier family 25 (mitochondrial carrier; adenine nucleotide translocator), member 45 $(S L C 25 A 45)$ belongs to the family of nuclear-encoded membrane-embedded proteins that catalyze the transport of solutes across the inner mitochondrial membrane [47]. While substrates for the SLC25 family carriers include ADP/ATP, amino acids (glutamate, aspartate, lysine, histidine, and arginine), malate, ornithine, and citruline [48], the predominant substrate(s) for the A45 specifically remain to be experimentally established [49]. Although specific functions of the SLC25A45 are unknown, it was reported that A45 is closely related to another SLC25 member, A29 [48]. SLC25A29 together with SLC25A20 are known to be responsible for transport of long-chain fatty acids such as palmitoylcarnitine and acylcarnitine [50]. It is thus possible that SLC25A4 is also involved in the transport of long-chain fatty acids. SLC25A45 is known to be expressed in the skeletal muscle, intestine, brain, and testis [49]. In our study, rs681309 in the SLC25A4 conferred modest although statistically significantly decreased risk for mucinous, endometrioid and all INV EOC combined. Thus, our results warrant additional studies on the role of SLC25A4 in particular, as well as mitochondria in general, in the EOC etiology. 
UDP glucuronosyltransferase 1 family, polypeptide A cluster (UGT1A) represents a complex locus that encodes nine human UDP-glucuronosyltransferases. The locus includes thirteen unique alternate first exons followed by four common exons. Four of the alternate first exons are considered pseudogenes. Each of the remaining nine $5^{\prime}$ exons may be spliced to the four common exons, resulting in nine proteins with different $\mathrm{N}$ termini and identical C-termini. Each first exon encodes the substrate binding site, and is regulated by its own promoter [51]. UDP-glucuronosyltransferase (UGT) enzymes are localized to endoplasmic reticulum (ER) and catalyze glucuronidation, which represents a major phase II conjugation pathway in humans and is involved in the metabolism and excretion of endogenous and exogenous compounds. The process results in an increased polarity of the substrate that facilitates its excretion from the body through bile and urine [52]. This metabolic process is involved in the elimination of bilirubin, steroids, bile acids, toxic dietary components, and several drugs, including morphine, and irinotecan [53]. UDP-glucuronosyltransferase expression is primarily localized to the liver and bile ducts, but has also been detected in other organs such as stomach, colon, intestines, mammary glands, prostate and the lung [52]. Genetic variations in a sole member of the UGT1A family, UGT1A1, are involved in the inherited disorders of the bilirubin metabolism named such as Crigler-Najjar syndrome, which is manifested in the complete absence (type 1) or diminished (types 2-3) bilirubin glucuronidation and resulting impaired bilirubin excretion. While type 1 is a lethal disease in the absence of immediate liver transplantation, type 2 is treatable by prolonged induction therapy, while type 3 usually does not require medical intervention [52]. UGT1A locus was previously implicated in tumorigenesis. Strassburg et al [55] reported that the UGT $1 A 7^{\star 3} 3$ allele exhibited a highly significant association with colorectal cancer $(O R=2.39 ; P=0.02)$, possibly due to diminished activity of the enzyme in the UGT1A7*3 carriers towards all tested substrates. Same group [56] later reported that pancreatic cancer was associated with the low detoxification activity UGT1A7*3 allele $(\mathrm{OR}=1.98 ; P=0.003)$. The association of UGT1A7*3 was especially strong in smokers with pancreatic carcinoma who were younger than 55 years $(O R=4.7 ; P=0.0009)$. They also suggested [57] that differential down-regulation of the UGT1A locus may be an early event in hepatocarcinogenesis. Giuliani et al [58] determined that while abundant UGT1A expression was detected in the normal urinary bladder and intestinal epithelia, it was virtually absent in the corresponding tumor tissues. The authors hypothesized that UGTs constitutive expression in the normal mucosa could protect these organs from carcinogens released in the bladder or introduced directly with the diet in the colon. Araki et al [59] suggested that the presence of UGT1A7 polymorphisms was associated with lung cancer. Homozygous UGT1A7*3 is a possible risk factor for lung cancer, at least in the Japanese population. The most relevant finding to our study was reported by Duguay et al [54], who reported that lower expression of UGT1A1 decreases the risk of endometrial cancer by reducing the excretion of 2-hydroxyestradiol, the antiproliferative metabolite of estradiol, in the endometrium. Interestingly, in our study, rs11563251 near the UGT1A cluster was associated with a statistically significantly decreased endometrioid EOC risk. No other EOC subtypes showed significant associations with this SNP. Since UGT1A genes are known to be expressed in the endometrial cancer, as well as different EOC subtypes [60], and due to their resemblance to the endometrial 
tissue, we suggest that further evaluation of the role of the UGT1A member in the endometrioid EOC is highly warranted.

Calpain 13 (CAPN13) is a protein in the family of well-conserved, calcium-dependent, non-lysosomal cysteine proteases (proteolytic enzymes) expressed ubiquitously in mammals and many other organisms [61]. Although the physiological role of calpains is still poorly understood, they have been shown to be active participants in processes such as cell mobility and cell cycle progression, as well as cell-type specific functions such as long-term potentiation in neurons and cell fusion in myoblasts [62]. Under these physiological conditions, a transient and localized influx of calcium into the cell activates a small local population of calpains (for example, those close to $\mathrm{Ca}^{2+}$ channels), which then advance the signal transduction pathway by catalyzing the controlled proteolysis of its target proteins. Other reported roles of calpains are in cell function, helping to regulate clotting and the diameter of blood vessels, and playing a role in memory. Calpains have been implicated in apoptotic cell death, and appear to be an essential component of necrosis [63]. Calpains are also involved in cancer. Mamoune et al [64] reported that pharmacological and molecular inhibitors of calpain-2 significantly reduce the motility and invasiveness of DU145 human prostate carcinoma cells both in vitro and in Vivo, despite the fact that the overall tumor growth was not affected. In our study, rs7562766 near the CAPN13 was associated with a statistically significantly decreased clear cell EOC risk. One more SNP in CAPN13 (rs4952185) was significant in the clear cell subtype only. No other EOC subtypes showed significant associations with any of the CAPN13 SNPS.

\section{Results in women of Asian ancestry}

Due to the limited sample size, we only analyzed the INV EOCs combined in women of Asian ancestry. The two top SNPs in this ethnic group (rs17216603 in HEPH and rs1552846 in SLC39A11) were shared with the NHW women. The SLC25A45 rs681309 was also shared. SERPINA7 rs 1804495 was borderline significant $(P=0.0503)$ likely due to a small sample size. Overall, the INV EOC results observed in Asian women were highly concordant with the INV EOC results obtained in European women. We are tempted to hypothesize that the high level of concordance reflects similar genetic and biological disease etiology in Asian and European women; however, this provocative hypothesis remains to be tested.

\section{Results in women of African ancestry}

Due to the limited sample size, we only analyzed the INV EOCs combined in women of African ancestry. The most significant SNP rs6488840 was in the Microsomal glutathione S-transferase 1 (MGST1) gene, which encodes a protein that catalyzes the conjugation of glutathione to electrophiles and the reduction of lipid hydroperoxides. This protein is localized to the endoplasmic reticulum and outer mitochondrial membrane where it is thought to protect these membranes from oxidative stress. The product of this gene is involved in the cellular defense against toxic, carcinogenic, and pharmacologically active electrophilic compounds [65]. MGST1 overexpression has been demonstrated in various cancers (e.g., prostate cancer and lung cancer) and has been associated with high metastatic potential and chemoresistance. It has been 
suggested to be an early marker of disease in colorectal and lung cancer [66], In a study [65] MGST1 was abundantly expressed in different EOC primary tumors, distant metastases and effusions. The authors hypothesized that oxidative response pathways are involved in the EOC etiology. In our study, MGST1 rs6488840 was associated with statistically significantly reduced INV EOC risk in women of African ancestry $(P=0.0035)$; while this SNP was also associated with the INV and serous EOC in European women, the $P$ values were close to the limit of significance ( $P=0.048$ INV and $P=0.042$ serous), possibly indicating weaker association. Other significant SNPs in women of African descent included various members of the SLC39 family: SLC39A11 (rs9905659 and rs16977431, both shared with European women) and SLC39A8(rs233807). Although the results were similar to the ones obtained for European and Asian women, overall the degree of concordance seemed weaker than the one observed for women of European and Asian descent. Whether this observation is an artifact of a small sample size in women of African descent, or a true finding reflecting biological and genetic differences in cancer etiology, remains to be established.

\section{Gene-Environment Interactions for INV EOC in European Women}

We analyzed the Gene-Environment Interactions (GxE) for 28 significant INV SNPs in European women (Table 4). The following $E$ were included: overweight (OW); obesity $(\mathrm{OB})$; hormonal contraceptives use $(\mathrm{OC})$; the number of full birth (FB); age at menarche (mage); hormonal replacement therapy use (HRT); personal history of endometriosis (end); and family history of breast and/or ovarian cancer (FH). Overall, statistically significant GXE were found for 13 SNPs in 8 genes. 5 of 13 significant SNPs were in the SLC35F3 gene, and three of the 13 SNPs demonstrated significant association with two Es. No significant GxE were noted for being overweight (OW).

Solute carrier 35 member F3 (SLC35F3) gene encodes a putative transmembrane transporter which exact role has not been experimentally established [67]. SLC35 is an extended diverse family of nucleotide-sugar transporters consisting of 6 distinct sub-families (A-F), each of which has up to five discovered members. Families $E$ and $F$ were discovered recently and are the most understudied subfamilies; thus, their exact substrates and functions in the transport are unknown [68]. The highest expression level of SLC35F3 mRNA has been found in the adult cerebellum and brain, and - to lesser extent - in other tissues, including ovary [67]. In our study, SLC35F3 SNPs were associated with OC use (rs10910292: OR=1.38; $p=0.027$ ), HRT use (rs936411, rs10910354, rs10910358: ORs=1.12; $p=0.039$ ), and $F H(r s 936411: O R=0.9 ; p=0.045 ; r s 10910360$ : $O R=0.89 ; p=0.39$ ). Of those, rs936411 was associated with both the HRT and $F H$, although with disparate risk directions. These data suggest that SLC35F3 might be involved in hormonal metabolism and transport. Although the role of SLC35F3 in cancer has not been established, our data provides first evidence supporting the importance of future research on this topic.

Microsomal glutathione S-transferase 1 (MGST1) gene encodes a protein that catalyzes the conjugation of glutathione to electrophiles and the reduction of lipid hydroperoxides. Two SNPs in MGST were associated 
with FH ( $r s 4149186$ and $r s 6488840: O R s=1.15 ; p=0.036)$, and one with HRT (rs6488840: OR=1.14; $p=0.017$ ) in our study. Of note, rs6488840 was associated with both the HRT and FH with identical risk profiles.

Solute liquid carrier family 30 member A8 (SLC30A8) is a transmembrane zinc transporter linked to insulin secretion [69]. Certain alleles of this gene may increase the risk for developing type 2 diabetes [70]. In our study, SLC30A8 rs10282940 was associated with the number of full bith (OR=1.06; $p=0.014$ ) and personal history of endometriosis (OR=0.77; $p=0.045)$.

SLC30A1 and SLC39A11 both act as zinc influx transporters [71]. In our study, SLC30A1 rs12727395 $(O R=1.14 ; p=0.0033)$ and SLC39A11 rs1552846 (OR=1.09; $p=0.039)$ were associated with MAGE and OC use, respectively.

SERPINA7, a thyroid hormone transporter [40], was associated with $\mathrm{FH}(\mathrm{OR}=0.82 ; p=0.023)$.

Long-chain-fatty-acid-CoA ligase 1 (ACSL1) encodes an isozyme of the long-chain fatty-acid-coenzyme A ligase family. Although differing in substrate specificity, subcellular localization, and tissue distribution, all isozymes of this family convert free long-chain fatty acids into fatty acyl-CoA esters, and thereby play a key role in lipid biosynthesis and fatty acid degradation [72]. In our study, ACSL1 rs10024579 was associated with end $(O R=0.84 ; p=0.037)$.

Tumor necrosis factor receptor superfamily member 21 (TNFRSF21, also called DR6) is a member of the TNFreceptor superfamily. This receptor has been shown to activate NF-KB and MAPK8/JNK, and induce cell apoptosis. It is abundantly expressed in heart, brain, placenta, pancreas, thymus, lymph node and several nonlymphoid cancer cell lines [73]. Knockout studies in mice suggested that this gene plays a role in $T$ helper cell activation, and may be involved in inflammation and immune regulation. In addition to its roles in regulating immune responses, DR6 may also be involved in tumor cell survival and immune evasion [74]. In our study, TNFRSF21 rs7751646 was associated with HRT (OR=0.89; $p=0.027)$.

We note that GXE interactions are challenging to study and/or interpret due to their complexity and out insufficient understanding of the nature of those interactions. The authors are currently planning a study focused specifically on the GXE aspects of EOC.

The main strength of our study is a large sample size that allowed us to reach sufficient power to detect smaller associations typically observed on the SNP level. The weaknesses included the lack of the functional studies to establish and/or confirm the biological significance of the observed associations and/or the HEPH gene in general in the EOC etiology. The functional work is being planned by authors in the nearest future. Another weakness is a small sample size in each racial/ethnic category other than the Non Hispanic Whites. It is currently not clear whether genetic and/or biological differences between the racial groups contribute to the EOC etiology. However, because ovarian cancer health disparities are observed along the whole continuum of 
the disease globally and in the U.S. [75], this topic is without a doubt important and deserves its own dedicated studies.

In summary, we report that genetic variation in the transmembrane transport genes contribute to the serous EOC risk across different histologic subtypes (Table $X$ ). This novel hypothesis-generating evidence suggests that disruptions in the metal ion (primarily iron, zinc) and calcium transport, as well as mitochondriarelated transport, thyroid hormones and glucuronidation may play a role in the EOC etiology across different histopatologic subtypes. Functional studies are warranted to establish biological significance of these findings.

Table X: the top significant SNPs in the transport pathway. INV: all invasive EOC combined; LMP: low malignant potential / borderline tumors; Ser: serous; CC: clear cell; End: endometrioid; Muc: mucinous.

\begin{tabular}{|c|c|c|c|c|c|c|c|c|}
\hline & INV & LMP & Ser & $\mathrm{CC}$ & End & Muc & $\begin{array}{l}\text { Asian } \\
\text { (INV) }\end{array}$ & $\begin{array}{l}\text { African } \\
\text { (INV) }\end{array}$ \\
\hline $\begin{array}{l}\text { HEPH } \\
\text { rs17216603 }\end{array}$ & $\begin{array}{l}0.85(0.77- \\
0.93) \\
2.55^{\star} 10^{-4}\end{array}$ & $\begin{array}{l}0.78(0.63= \\
0.97) \\
0.0206\end{array}$ & $\begin{array}{l}0.81(0.73- \\
0.91) ; \\
1.99 * 10^{-4}\end{array}$ & $\begin{array}{l}0.77(0.58- \\
1.02) ; 0.07\end{array}$ & $\begin{array}{l}0.9(0.74- \\
1.08) ; \\
0.2596\end{array}$ & $\begin{array}{l}0.92(0.7- \\
1.21) \\
0.5565\end{array}$ & $\begin{array}{l}1.45(1.15- \\
1.83) ; \\
0.0019\end{array}$ & $\begin{array}{l}0.76(0.15- \\
3.86) ; 0.74\end{array}$ \\
\hline $\begin{array}{l}\text { SLC39A11 } \\
\text { rs9908917 }\end{array}$ & $\begin{array}{l}0.95(0.92 \\
0.99) \\
0.014\end{array}$ & $\begin{array}{l}0.85(0.77- \\
0.93) ; \\
3.9^{*} 10^{-4}\end{array}$ & $\begin{array}{l}0.94(0.9- \\
0.99) ; \\
0.01012\end{array}$ & $\begin{array}{l}1.01(0.91 \\
1.13) ; 0.82\end{array}$ & $\begin{array}{l}0.94(0.87- \\
1.02) ; 0.16\end{array}$ & $\begin{array}{l}0.98(0.87 \\
1.1) ; 0.7\end{array}$ & $\begin{array}{l}1.25(1.01- \\
1.56) ; \\
0.049\end{array}$ & $\begin{array}{l}1.23(0.85- \\
1.77) ; 0.27\end{array}$ \\
\hline $\begin{array}{l}\text { SLC39A11 } \\
\text { rs1552846 }\end{array}$ & $\begin{array}{l}0.95(0.91- \\
0.98) ; \\
0.0026\end{array}$ & $\begin{array}{l}1.00(0.92- \\
1.09) ; 0.92\end{array}$ & $\begin{array}{l}0.95(0.91- \\
0.99) ; \\
0.0145\end{array}$ & $\begin{array}{l}0.95(0.85- \\
1.06) ; 0.34\end{array}$ & $\begin{array}{l}0.92(0.86- \\
1) ; 0.0465\end{array}$ & $\begin{array}{l}0.95(0.85- \\
1.06) ; 0.36\end{array}$ & $\begin{array}{l}1.34(0.83- \\
1.21) ; \\
0.008\end{array}$ & $\begin{array}{l}0.81(0.52- \\
1.27) ; 0.36\end{array}$ \\
\hline $\begin{array}{l}\text { SLC39A11 } \\
\text { rs1177982 }\end{array}$ & $\begin{array}{l}0.97(0.93-1) ; \\
0.069\end{array}$ & $\begin{array}{l}1.01(0.94- \\
1.1) ; 0.7\end{array}$ & $\begin{array}{l}0.95(0.91- \\
0.99) ; \\
0.0133\end{array}$ & $\begin{array}{l}.05(0.94- \\
1.16) ; 0.38\end{array}$ & $\begin{array}{l}0.95(0.88 \\
1.03) ; 0.23\end{array}$ & $\begin{array}{l}1.01(0.91- \\
1.13) ; 0.84\end{array}$ & $\begin{array}{l}0.83(0.66- \\
1.05) ; 0.12\end{array}$ & $\begin{array}{l}0.61\langle 0.31- \\
1.17) ; 0.13\end{array}$ \\
\hline $\begin{array}{l}\text { SLC39A11 } \\
\text { rs8068946 }\end{array}$ & $\begin{array}{l}1(0.97-1.03) ; \\
0.91\end{array}$ & $\begin{array}{l}1.03(0.95 \\
1.11) ; 0.46\end{array}$ & $\begin{array}{l}1.02(0.98- \\
1.06) ; 0.37\end{array}$ & $\begin{array}{l}0.88(0.8- \\
0.97) \\
0.0083\end{array}$ & $\begin{array}{l}0.98(0.91- \\
1.05) ; 0.48\end{array}$ & $\begin{array}{l}0.98(0.89- \\
1.09) ; 0.73\end{array}$ & $\begin{array}{l}0.95(0.41- \\
2.22) ; 0.9\end{array}$ & $\begin{array}{l}0.92(0.63- \\
1.35) ; 0.68\end{array}$ \\
\hline $\begin{array}{l}\text { SLC39A11 } \\
\text { rs9905659 }\end{array}$ & $\begin{array}{l}1.01(0.97- \\
1.05) ; 0.56\end{array}$ & $\begin{array}{l}1.05(0.96- \\
1.15) ; 0.29\end{array}$ & $\begin{array}{l}1.03(0.98- \\
1.08) ; 0.27\end{array}$ & $\begin{array}{l}0.88(0.79- \\
1) ; 0.045\end{array}$ & $\begin{array}{l}0.98(0.9- \\
1.06) ; 0.61\end{array}$ & $\begin{array}{l}1.01(0.9- \\
1.14) ; 0.83\end{array}$ & $\begin{array}{l}1.06(0.84- \\
1.36) ; 0.61\end{array}$ & $\begin{array}{l}1.54(1.0- \\
2.35) ; \\
0.047\end{array}$ \\
\hline $\begin{array}{l}\text { SLC39A11 } \\
\text { rs9913553 }\end{array}$ & $\begin{array}{l}0.99(0.94- \\
1.04) ; 0.74\end{array}$ & $\begin{array}{l}1.04(0.93 \\
1.17): 0.47\end{array}$ & $\begin{array}{l}0.98(0.92- \\
1.04) ; 0.54\end{array}$ & $\begin{array}{l}0.98(0.84- \\
1.13) ; 0.76\end{array}$ & $\begin{array}{l}0.95(0.85- \\
1.06) ; 0.34\end{array}$ & $\begin{array}{l}1.16(1- \\
1.34) ; \\
0.048\end{array}$ & $\begin{array}{l}0.97(0.78- \\
1.22) ; 0.82\end{array}$ & $\begin{array}{l}1.24(0.87- \\
1.75) ; 0.23\end{array}$ \\
\hline SERPINA7 & $\begin{array}{l}1.05(1- \\
1.1) ;\end{array}$ & $\begin{array}{l}1.14(1.03- \\
1.27) ;\end{array}$ & $\begin{array}{l}1.06(1- \\
1.12) ;\end{array}$ & $\begin{array}{l}1.21(1.06- \\
1.39) ;\end{array}$ & $1.06(0.96-$ & $0.85(0.73-$ & $\begin{array}{l}0.81(0.65- \\
1.00) ;\end{array}$ & $1.11(0.75-$ \\
\hline
\end{tabular}




\begin{tabular}{|c|c|c|c|c|c|c|c|c|}
\hline Rs1804495 & 0.04187 & 0.016 & 0.045 & 0.0042 & $1.17) ; 0.28$ & 1); 0.045 & 0.0503 & $1.65) ; 0.602$ \\
\hline $\begin{array}{l}\text { SLC25A45 } \\
\text { Rs681309 }\end{array}$ & $\begin{array}{l}0.97(0.94 \\
\text { 1); } 0.029\end{array}$ & $\begin{array}{l}1.04(0.97- \\
1.12) ; 0.27\end{array}$ & $\begin{array}{l}1(0.96-1.04) i \\
0.99\end{array}$ & $\begin{array}{l}0.98(0.89- \\
1.07) ; 0.59\end{array}$ & $\begin{array}{l}0.91(0.85- \\
0.97) ; \\
0.0035\end{array}$ & $\begin{array}{l}0.89(0.81- \\
0.97) ; \\
0.012\end{array}$ & $\begin{array}{l}0.78(0.63- \\
0.98) \\
0.033\end{array}$ & $\begin{array}{l}0.87(0.6- \\
1.26) ; 0.41\end{array}$ \\
\hline $\begin{array}{l}\text { UGT1A } \\
\text { Rs11563251 }\end{array}$ & $\begin{array}{l}0.95(0.91- \\
1) ; 0.0502\end{array}$ & $\begin{array}{l}1.08(0.96- \\
1.2) ; 0.21\end{array}$ & $\begin{array}{l}0.95(0.89- \\
1.01) ; 0.074\end{array}$ & $\begin{array}{l}1.03(0.89- \\
1.18) ; 0.73\end{array}$ & $\begin{array}{l}0.82(0.74- \\
0.92) ; \\
6.8 * 10^{-4}\end{array}$ & $\begin{array}{l}1.06(0.91- \\
1.22) ; 0.49\end{array}$ & $\begin{array}{l}0.73(0.5- \\
1.06) ; 0.102\end{array}$ & $\begin{array}{l}1.22(0.85- \\
1.25) ; 0.28\end{array}$ \\
\hline $\begin{array}{l}\text { CAPN13 } \\
\text { rs7562766 }\end{array}$ & $\begin{array}{l}0.99(0.96- \\
1.02) ; 0.49\end{array}$ & $\begin{array}{l}0.97(0.9- \\
1.04) ; 0.45\end{array}$ & $\begin{array}{l}1.01(0.97- \\
1.04) ; 0.79\end{array}$ & $\begin{array}{l}0.86(0.79 \\
0.95) ; \\
0.0014\end{array}$ & $\begin{array}{l}0.99(0.93- \\
1.05) ; 0.69\end{array}$ & $\begin{array}{l}1.02(0.93- \\
1.12) ; 0.71\end{array}$ & $\begin{array}{l}1.08(0.82- \\
1.43) ; 0.56\end{array}$ & $\begin{array}{l}1.14(0.73- \\
1.79) ; 0.57\end{array}$ \\
\hline $\begin{array}{l}\text { CAPN13 } \\
\text { rs4952185 }\end{array}$ & $\begin{array}{l}0.98(0.95- \\
1.01) ; 0.15\end{array}$ & $\begin{array}{l}0.94(0.87- \\
1.01) ; 0.086\end{array}$ & $\begin{array}{l}0.98(0.94- \\
1.02) ; 0.27\end{array}$ & $\begin{array}{l}0.88(0.8- \\
0.97) ; \\
0.0102\end{array}$ & $\begin{array}{l}1.02(0.05- \\
1.09) ; 0.67\end{array}$ & $\begin{array}{l}0.97(0.88- \\
1.07) ; 0.53\end{array}$ & $\begin{array}{l}0.85(0.67- \\
1.08) ; 0.19\end{array}$ & $\begin{array}{l}0.78(0.51- \\
1.19) ; 0.25\end{array}$ \\
\hline $\begin{array}{l}\text { MGST1 } \\
\text { Rs6488840 }\end{array}$ & $\begin{array}{l}0.96(0.93- \\
1) ; 0.048\end{array}$ & $\begin{array}{l}1.0(0.92- \\
1.09) ; 0.902\end{array}$ & $\begin{array}{l}0.95(0.91- \\
1) ; 0.042\end{array}$ & $\begin{array}{l}0.96(0.86- \\
1.07) ; 0.41\end{array}$ & $\begin{array}{l}1(0.92-1.08) ; \\
0.95\end{array}$ & $\begin{array}{l}0.96(0.86- \\
1.08) ; 0.48\end{array}$ & $\begin{array}{l}0.54(0.25- \\
1.18) ; 0.12\end{array}$ & $\begin{array}{l}0.55(0.37- \\
0.82) \\
0.0035\end{array}$ \\
\hline
\end{tabular}

Acknowledgements. This work is supported by the National Institute of Health (NIH) R01..., U19..., and the Department of Defense (DoD) W81XWH-11-1-0376. The manuscript contents are solely the responsibility of the authors and do not necessarily represent the official views of the NIH or the DoD.

\section{References}

1. Parkin M, Bray F, Ferlay J, Pisani P. Global Cancer Statistics, 2002. CA Cancer J Clin 2002; 55:74-108

2. Saundra S. Buys, MD; Edward Partridge, MD; Amanda Black et al. Effect of Screening on Ovarian Cancer MortalityThe Prostate, Lung, Colorectal and Ovarian (PLCO) Cancer Screening Randomized Controlled Trial. JAMA. 2011;305(22):2295-2303. doi:10.1001/jama.2011.766

3. Kosary C (2007) Cancer of the ovary. In: Ries LAG, Young JL, Keel GE, Eisner MP, Lin YD, et al., (ed) SEER survival monograph: cancer survival among adults: US SEER Program, 1988-2001, patient and tumor characteristics. Bethesda (Maryland): National Cancer Institute, SEER Program

4. Zeimet AG, Reimer D, Concin N, Braun S, Marth C. Primary chemotherapy and maintenance therapy in epithelial ovarian cancer. MEMO 2008;1:99-102

5. Danijela Jelovac $\mathrm{MD}^{1}$, Deborah $\mathrm{K}$. Armstrong. Recent progress in the diagnosis and treatment of ovarian cancer. CA CANCER J CLIN 2011;61:183-203

6. Maria L. Macheda, Suzanne Rogers, James D. Best. Molecular and cellular regulation of glucose transporter (GLUT) proteins in cancer. Journal of Cellular Physiology Volume 202, Issue 3, pages 654-662, March 2005

7. Arnaud Guilbert ${ }^{1}$, , Mathieu Gautier ${ }^{1},{ }^{*}$, Isabelle Dhennin-Duthille ${ }^{1}$, Nathalie Haren ${ }^{1}$, Henri Sevestre ${ }^{1}{ }^{2}$, and Halima Ouadid-Ahidouch. Evidence that TRPM7 is required for breast cancer cell proliferation. Evidence that TRPM7 is required for breast cancer cell proliferation. Am J Physiol Cell Physiol 297: C493-C502, 2009. 
8. Céline Pinheiro1,2, Bárbara Sousa3, André Albergaria1,3, Joana Paredes3, Rozany Dufloth4, Daniella Vieira5, Fernando Schmitt3,6 and Fátima Baltazar. GLUT1 and CAIX expression profiles in breast cancer correlate with adverse prognostic factors and MCT1 overexpression. Histol Histopathol (2011) 26: 1279-1286

9. Nelma Pértega-Gomes ${ }^{1,2}$, José R Vizcaíno ${ }^{3}$, Vera Miranda-Gonçalves ${ }^{1,2}$, Céline Pinheiro ${ }^{1,2}$, Joana Silva ${ }^{1,2}$, Helena Pereira ${ }^{4}$, Pedro Monteiro ${ }^{5}$, Rui M Henrique ${ }^{6}$, Rui M Reis ${ }^{1,2,7}$, Carlos Lopes ${ }^{3}$ and Fátima Baltazar. Monocarboxylate transporter 4 (MCT4) and CD147 overexpression is associated with poor prognosis in prostate cancer. BMC Cancer $2011,11: 312$

10. Juxing Chen and Maja Chloupková. Abnormal iron uptake and liver cancer. Cancer Biology \& Therapy 8:18, 1699-1708; 15 September 2009

11. Amanda J. Cross1, Rashmi Sinha1, Richard J. Wood3, Xiaonan Xue4, Wen-Yi Huang1, Meredith Yeager2, Richard B. Hayes5, and Marc J. Gunter4, Iron Homeostasis and Distal Colorectal Adenoma Risk in the Prostate, Lung, Colorectal, and Ovarian Cancer Screening Trial. Cancer Prev Res September 2011 4; 1465

12. Sebastiano Filetti, Jean-Michel Bidart2, Franco Arturi, Bernard Caillou3, Diego Russo1 and Martin Schlumberger. Sodium/iodide symporter: a key transport system in thyroid cancer cell metabolism. European Journal of Endocrinology (1999) 141 443-457

13. Takaya Ishiharał1, Jun Inoueł, Ken-ichi Kozakił§, Issei Imotoł, and Johji Inazawa. HECT-type Ubiquitin Ligase ITCH Targets Lysosomal-associated Proteln Multispanning Transmembrane 5 (LAPTM5) and Prevents LAPTM5mediated Cell Death. THE JOURNAL OF BIOLOGICAL CHEMISTRY VOL. 286, NO. 51, pp. 44086-44094, December 23,2011

14. 14. Nemeth E. Iron regulation and erythropoiesis. Curr Opin Hematol 2008; 15(3): 169-75.

15. 15. Giorgio Lenaz ${ }^{a}$, Alessandra Baracca ${ }^{a}$, Giovanna Barbero ${ }^{a}$, et al. Mitochondrial respiratory chain supercomplex I-III in physiology and pathology. Biochimica et Biophysica Acta (BBA) - Bioenergetics Volume 1797, Issues 6-7, June-July 2010, Pages 633-640

16. Susan P. Foy ${ }^{a}$, Vinod Labhasetwar. Oh the irony: Iron as a cancer cause or cure? Biomaterials Volume 32 , Issue 35, December 2011, Pages 9155-9158

17. Iron atlas: www.ironatlas.com

18. Shinsuke Wada MD, Tsuyoshi Noguchi MD, PhD, Shinsuke Takeno MD, PhD, Katsunobu Kawahara MD, PhD . PIK3CA and TFRC Located in 3q Are New Prognostic Factors in Esophageal Squamous Cell Carcinoma. Annals of Surgical Oncology July 2006, Volume 13, Issue 7, pp 961-966

19. Hogstrand ${ }^{1}$, P. Kille ${ }^{2}$, R.I. Nicholson ${ }^{3}$, K.M. Taylor. Zinc transporters and cancer: a potential role for ZIP7 as a hub for tyrosine kinase activation. Trends in molecular medicine Volume 15, Issue 3, March 2009, Pages 101-111

20. Shu-fei Lin, Hua Wei, Dennis Maeder, Renty B. Franklin, Pei Feng. Profiling of zinc-altered gene expression in human prostate normal vs, cancer cells: a time course study. The Journal of Nutritional Biochemistry Volume 20, Issue 12, December 2009, Pages 1000-1012

21. Amanda P. Liggins ${ }^{1}$, Christopher D. O. Cooper ${ }^{1}$, Charles H. Lawrie ${ }^{2}$, Philip J. Brown ${ }^{1}$, Graham P. Collins ${ }^{2}$, Chris S. Hatton ${ }^{3}$, Karen Pulford', Alison H. Banham. MORC4, a novel member of the MORC family, is highly expressed in a subset of diffuse large B-cell lymphomas. British Journal of Haematology. Volume 138, issue 4, pages 479-486, August 2007

22. Pharoah et al, Nat Gen 2013

23. Robert E. Fleming and William S. Sly. The iron gatekeeper: keys to the front and back doors. BLOOD 2003, 102(5), 1567

24. Christopher D. Vulpe1,2, Yien-Ming Kuo2, Therese L. Murphy3, Lex Cowley3, Candice Askwith4, Natasha Libina2, Jane Gitschier1,2 \& Gregory J. Anderson. Hephaestin, a ceruloplasmin homologue implicated in intestinal iron transport, is defective in the sla mouse, nature genetics - volume $21 \cdot$ february $1999,195-9$

25. Llangtao LI*, Chris D. VULPE† and Jerry KAPLAN. Functional studies of hephaestin in yeast: evidence for multicopper oxidase activity in the endocytic pathway. Biochem. J. (2003) 375, 793-798

26. Giada Sebastiani and Kostas Pantopoulos. Iron Metabolism and Disease (Chapter 13). In: Cellular and molecular biology of metals, 2010 by Taylor and Francis Group, LLC, 351-368

27. KWO-YIH YEH, ${ }^{*}, \S$ $\ddagger$ MARY YEH, $\S$ and JONATHAN GLASS. Interactions Between Ferroportin and Hephaestin in Rat Enterocytes Are Reduced After Iron Ingestion. GASTROENTEROLOGY 2011;141:292-299

28. David M. Hudson, 1,2* Susan B. Curtis, 1,2* Valerie C. Smith, 1,2 Tanya A. M. Griffiths,1,2 Ann Y. K. Wong, 1,2 Charles H. Scudamore, 3 Alison M. J. Buchan,4 and Ross T. A. MacGillivray. Human hephaestin expression is not limited to enterocytes of the gastrointestinal tract but is also found in the antrum, the enteric nervous system, and pancreatic _cells. Am J Physiol Gastrointest Liver Physiol 298: G425-G432, 2010.

29. DAVID M. FRAZER,1 CHRISTOPHER D. VULPE,2 ANDREW T. MCKIE,3 SARAH J. WILKINS, 1 DEBORAH TRINDER,4 GEOFFREY J. CLEGHORN,5 AND GREGORY J. ANDERSOn. Cloning and gastrointestinal expression of 
rat hephaestin: relationship to other iron transport proteins. Am J Physiol Gastrointest Liver Physiol 281: G931-G939, 2001.

30. Angelica M. Merlot, Danuta S. Kalinowski, and Des R. Richardson. Novel Chelators for Cancer Treatment: Where Are We Now? Antioxid. Redox Signal. 00, 000-000. 2012

31. Galaris D, Pantopoulos K. Oxidative stress and iron homeostasis: mechanistic and health aspects. Crit Rev Clin Lab Sci, 2008;45(1):1-23.

32. Huijun Chen, ${ }^{*}$ Gang Huang, ${ }^{*}$ Trent Su, ${ }^{*}$ Hua Gao, ${ }^{*}$ Zouhair K. Attieh, ${ }^{*} y$ Andrew T. McKie, ${ }^{* *}$ Gregory J. Anderson,z and Chris D. Vulpe. Decreased Hephaestin Activity in the Intestine of Copper-Deficient Mice Causes Systemic Iron Deficiency. J. Nutr. 136: 1236-1241, 2006.

33. Kwo-yih Yeh, 1,2,3 Mary Yeh,3 Laura Mims,3 and Jonathan Glass. Iron feeding induces ferroportin 1 and hephaestin migration and interaction in rat duodenal epithelium. Am J Physiol Gastrointest Liver Physiol 296: G55-G65, 2009 .

34. David J. Eide. The SLC39 family of metal ion transporters. Pflugers Arch - Eur J Physiol (2004) 447:796-800

35. Taylor KM, Morgan HE, Smart K, Zahari NM, Pumford S, Ellis IO, Robertson JF, Nicholson RI. The emerging role of the LIV-1 subfamily of zinc transporters in breast cancer. Mol Med. 2007 Jul-Aug;13(7-8):396-406.

36. C. Hogstrand ${ }^{1}$, P. Kille ${ }^{2}$, R.I. Nicholson ${ }^{3}$, K.M. Taylor. Zinc transporters and cancer: a potential role for ZIP7 as a hub for tyrosine kinase activation. Trends in molecular medicine Volume 15, Issue 3, March 2009, Pages 101-111

37. Costello LC, Franklin RB. The clinical relevance of the metabolism of prostate cancer; zinc and tumor suppression: connecting the dots. Mol Cancer. 2006 May 15;5:17.

38. Min Li, Yuqing Zhang, Zijuan Liu et al. Aberrant expression of zinc transporter ZIP4 (SLC39A4) significantly contributes to human pancreatic cancer pathogenesis and progression. PNAS November 20, 2007 vol. 104 no. 47 1863618641

39. Naofumi Kagara, Natsumi Tanaka, Shinzaburo Noguchi, Toshio Hirano. Zinc and its transporter ZIP10 are involved in invasive behavior of breast cancer cells. Cancer Science Volume 98, Issue 5, pages 692-697, May 2007

40. An overview of the serpin superfamily. Ruby HP Law*, Qingwei Zhang* $\dagger$, Sheena McGowan* $+\neq$, Ashley M Buckle* + , Gary A Silverman $\S$, Wilson Wong ${ }^{*}$, Carlos J Rosado* $\neq$, Chris G Langendorf* $\neq$, Rob N Pike*, Philip I Bird* and James C WhisstockGenome Biology 2006, 7:216 (doi:10.1186/gb-2006-7-5-216)

41. Rita Domingues, Paula Font, Luís Sobrinho, Maria Joăo Bugalho. A novel variant in Serpina7 gene in a family with thyroxine-binding globulin deficiency. Endocrine August 2009, Volume 36, Issue 1, pp 83-86

42. Katarzyna Lacka, Teresa Nizankowska, Agnieszka Ogrodowicz, and Jan K. Lacki. A Novel Mutation (del 1711 G) in the TBG Gene as a Cause of Complete TBG Deficiency Thyroid. November 2007, 17(11): 1143-1146. doi:10.1089/thy.2007.0023.

43. HIROAKI KOBAYASHI, AKIHIRO SAKURAI, MIYUKI KATAI, and KIYOSHI HASHIZUME. Autosomally Transmitted Low Concentration of Thyroxine-Binding Globulin Thyroid. February 1999, 9(2): 159-163. doi: 10.1089/thy. 1999.9.159.

44. Massimo Cristofanilli, Yuko Yamamura, Shu-Wan Kau et al. Thyroid Hormone and Breast Carcinoma. CANCER March 15, 2005 / Volume 103 / Number 6, p. 1122-8

45. Michael Frumovitz, Kathleen M. Schmeler ${ }^{a}$, Anais Malpica ${ }^{a}$, , Anil K. Sood ${ }^{a}$, David M. Gershenson ${ }^{a}$. Unmasking the complexities of mucinous ovarian carcinoma. Gynecologic Oncology Volume 117, Issue 3, June 2010, Pages 491496

46. Muneaki Shimada', Junzo Kigawa, Yoshihiro Ohishi et al. Clinicopathological characteristics of mucinous adenocarcinoma of the ovary. Gynecologic Oncology Volume 113, Issue 3, June 2009, Pages 331-334

47. Palmieri F. The mitochondrial transporter family (SLC25): physiological and pathological implications. Pflügers Archiv February 2004, Volume 447, Issue 5, pp 689-709

48. Tatjana Haitina, Jonas Lindblom, Thomas Renström, Robert Fredriksson. Fourteen novel human members of mitochondrial solute carrier family 25 (SLC25) widely expressed in the central nervous system. Genomics Volume 88, Issue December 2006, Pages 779-790

49. Palmieri F. The mitochondrial transporter family SLC25: Identification, properties and physiopathology. Molecular Aspects of Medicine 2012, in press

50. V. lacobazzi et al.Molecular and functional analysis of SLC25A20 mutations causing carnitine-acylcarnitine translocase deficiency Hum. Mutat., 24 (2004), pp. 312-320

51. NCBI database: UGT1A UDP glucuronosyltransferase 1 family, polypeptide A complex locus [ Homo sapiens ]. Available from: http://www. ncbi.nlm.nih.gov/gene?Db=gene\&Cmd=ShowDetailView\&TermToSearch=7361

52. Tukey RH, Strassburg CP. Human UDP-glucuronosyltransferases: metabolism, expression, and disease. Annu Rev Pharmacol Toxicol. 2000;40:581-616. 
53. Eric Lévesque, Hugo Girard, Kim Journault et al. Regulation of the UGT1A1 bilirubin-conjugating pathway: Role of a new splicing event at the UGT1A locus. Hepatology Volume 45, Issue 1, pages 128-138, January 2007

54. Yannick Duguay, Monica McGrath, Johanie Lépine, et al. The Functional UGT1A1 Promoter Polymorphism Decreases Endometrial Cancer Risk. Cancer Res 2004;64:1202-1207.

55. C C P Strassburg, ${ }^{1}$ A Vogel, ${ }^{1}$ S Kneip, ${ }^{1}$ R H Tukey, ${ }^{2}$ and M P Manns. Polymorphisms of the human UDP. glucuronosyltransferase (UGT) 1 A7 gene in colorectal cancer. Gut. 2002 June; 50(6): 851-856.

56. Johann Ockenga ${ }^{* 1,2,3}$, Arndt Vogel ${ }^{*}{ }^{1,3}$, Niels Teich ${ }^{\ddagger}{ }^{3}$, et al. UDP glucuronosyltransferase (UGT1A7) gene polymorphisms increase the risk of chronic pancreatitis and pancreatic cancer. Gastroenterology Volume 124, Issue 7, June 2003, Pages 1802-1808

57. Christian P. Strassburg, Michael P. Manns, and Robert H. Tukey. Differential Down-Regulation of the UDPGlucuronosyltransferase 1A Locus Is an Early Event in Human Liver and Biliary Cancer ${ }^{1}$. Cancer Res 1997;57:29792985.

58. Giuliani L, Ciotti M, Stoppacciaro A, et al. UDP-glucuronosyltransferases $1 \mathrm{~A}$ expression in human urinary bladder and colon cancer by immunohistochemistry. Oncology Reports [2005, 13(2):185-191]

59. Jun Araki ${ }^{a}$, Yoshinao Kobayash' Motoh Iwasa ${ }^{a}$, et al. Polymorphism of UDP-glucuronosyltransferase 1A7 gene: A possible new risk factor for lung cancer. European Journal of Cancer Volume 41, Issue 15, October 2005, Pages 23602365

60. Kristin K. Zorn, Tomas Bonome, Lisa Gangi, et al, Clear Cell Subtypes of Ovarian and Endometrial Cancer Gene Expression Profiles of Serous, Endometrioid, and Endometrial cancer. Clin Cancer Res 2005;11:6422-6430.

61. DARREL E. GOLL, VALERY F. THOMPSON, HONGQI LI, et al. The Calpain System. Physiol Rev July 1, 2003 vol. 83 no. $3731-801$

62. Neil O Carragher, Margaret C Frame ${ }^{\mathrm{b}}$. Calpain; a role in cell transformation and migration. The International Journal of Biochemistry \& Cell Biology. Volume 34, Issue 12, December 2002, Pages 1539-1543

63. Wood DE, Thomas A, Devi LA, et al. Bax cleavage is mediated by calpain during drug-induced apoptosis. Oncogene [1998, 17(9): 1069-1078]

64. [CANCER RESEARCH 63, 4632-4640, August 1, 2003] Calpain-2 as a Target for Limiting Prostate Cancer Invasion1 Asmaa Mamoune, Jian-Hua Luo, Douglas A. Lauffenburger, and Alan Wells2 Department of Pathology, University of Pittsburgh, Pittsburgh, Pennsylvania 15261 [A. M., J-H. L., A. W.]; Pittsburgh R.

65. R. Morgenstern, J. Zhang, K. Johansson. Microsomal glutathione transferase 1: mechanism and functional roles Drug Metab Rev, 43 (2011), pp. 300-306

66. Thea Eline Hetland ${ }^{\mathrm{a}}$, Dag Andre Nymoen ${ }^{\mathrm{b}}$, Elisabeth Emilsen et al. MGST1 expression in serous ovarian carcinoma differs at various anatomic sites, but is unrelated to chemoresistance or survival. Gynecologic oncology Volume 126, Issue 3, September 2012, Pages 460-465

67. Masuhiro NISHIMURA1, Satoshi SUZUKI2, Tetsuo SATOH2 and Shinsaku NAITO. Tissue-Specific mRNA Expression Profiles of Human Solute Carrier 35 Transporters. Drug Metab. Pharmacokinet. 24 (1): 91-99 (2009).

68. Zhiwei Song. Roles of the nucleotide sugar transporters (SLC35 family) in health and disease. Molecular Aspects of Medicine Volume 34, Issues 2-3, April-June 2013, Pages 590-600

69. Fabrice Chimienti, Alain Favier, Michel Seve. ZnT-8, A Pancreatic Beta-Cell-Specific Zinc Transporter. Biometals August 2005, Volume 18, Issue 4, pp 313-317

70. Sladek $R$, Rocheleau $G$, Rung $J$ et al. A genome-wide association study identifies novel risk loci for type 2 diabetes. Nature. 2007 Feb 22;445(7130):881-5. Epub 2007 Feb 11.

71. Robert J. Cousins ${ }^{1}$, Juan P. Liuzzi and Louis A. Lichten. Mammalian Zinc Transport, Trafficking, and Signals. August 25, 2006 The Journal of Biological Chemistry, 281, 24085-24089.

72. Lei O. Li, Douglas G. Mashek, Jie An et al. OVEREXPRESSION OF RAT LONG CHAIN ACYL-COA SYNTHETASE 1 ALTERS FATTY ACID METABOLISM IN RAT PRIMARY HEPATOCYTES. December 1, 2006 The Journal of Biological Chemistry, 281, 37246-37255.

73. Guohua Pan ${ }^{\mathrm{a}}$ 离, Johannes H Bauer ${ }^{\mathrm{a}}$, Valsala Haridas et al. Identification and functional characterization of DR6, a novel death domain-containing TNF receptor. FEBS Letters Volume 431, Issue 3, 24 July 1998, Pages 351-356

74. Robert Benschop, Tao Wei, Songqing Na. Tumor Necrosis Factor Receptor Superfamily Member 21: TNFRRelated Death Receptor-6, DR6. Therapeutic Targets of the TNF superfamily, edited by I.S. Grewal. 2009 landes Bioscience + Business media

75. Chornokur $\mathrm{G}$ et al. Global ovarian cancer health disparities. J Gyn Oncol 2013 

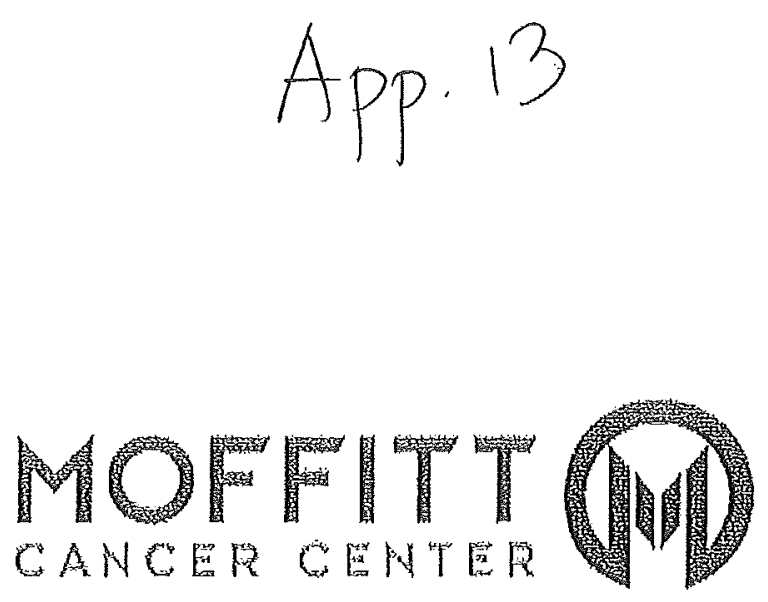

\section{Post Doc \\ Anniversary Evaluation - 2011/12}

\section{Employee Identification}

\author{
Name: Ganna Chornokur \\ Title/Rank: POST DOC FELLOW
}

Department \#: 25609

Emp status: 50
Employee ID: 4459845

Hire Date: $12 / 30 / 2009$

Department: Cancer Epidemlology

\section{PART I: BEHAVIORAL CRITERIA}

DO NOT ADJUST SECTION WEIGHT.

SECTION WEIGHT MUST REMAIN 50\%

Behavioral Criteria

Score: $4.1 / 5.0(50 \%)$

Customer Focus: Commitment to Providing Outstanding Score: $3.6 / 5.0$ (0\%) Customer Service

Conveys a positive image of Moffitt to customers. Is dedlcated to superior customer service and satisfaction. Develops and maintains positive relationshlps with both internal and external customers. Demonstrates dignity and respect to internal and external customers.
4.6-5.0: Far Exceeds
(7) $3.6-4.5:$ Surpasses
2.5-3.5: Successfully Meets
1.0-2.4: Does Not Meet 
Teamwork: Work, as Part of a Group, to Achieve Results Score: 4.6 / 5.0 (0\%)

Shares equally in the department's success and fallures, Works effectively and constructively to find mutually beneficial solutions for all concerned partles. Shares knowledge and expertise with others to ensure the success of team and individual efforts. Supports co-workers by maintaining attendance requirements. When appropriate, works in partnership with staff, faculty and/or patient and family advisors to improve processes or care.

(-) 4.6-5.0: Far Exceeds

3.6-4.5: Surpasses

2.5-3.5: Successfully Meets

1.0-2.4: Does Not Meet

\section{Comments:}

Adaptability: Demonstration of Creativity, Innovation, Flexibility \& Willing Acceptance of Challenge

Score: $4.6 / 5.0(0 \%)$

Demonstrates willingness to adapt to changing indlvidual and institutional roles, needs and environment. Exhlbits a problem solving attitude; constantly seeks ways to improve processes, increase efflciency, find solutions to current situations or to develop new methods and procedures.
(c) $4,6-5.0:$ Far Exceeds
O $3.6-4.5:$ Surpasses
2.5-3.5: Successfully Meets
O $1.0-2.4:$ Does Not Meet

Accepts accountability for actlons, cholces and outcomes; assumes nothing; answers for own conduct and obligations.
4,6 - 5,0: Far Exceeds
(7.6-4.5: Surpasses
2.5-3.5: Successfully Meets
1.0-2.4: Does Not Meet 
Consistently provides quality product/services, Commits to the princlple of continuous improvement in the workplace. Projects pride in their work as exhibited in day-to-day interactions with staff, co-workers, patlents and all those they come in contact with. commits to the princlples of patlent and famlly-centered care: dignity \& respect, information sharing, particlpation and collaboration.
O 4.6 - 5.0: Far Exceeds
(1) $3.6-4.5:$ Surpasses
2.5-3.5: Successfully Meets
1.0-2,4: Does Not Meet

\section{Comments:}

Culture of Safety: Promotion of safety \& prevention of injury must be the first consideration

Malntains awareness and follows safety policles and procedures applicable to assigned duties. Commits to the princlple of continuous improvement in the workplace, Uses sound judgment including reasonable awareness of potential hazards before acting. Promptly reports errors and/or events and/or situations of actual or potentlal harm.
4.6- 5.0: Far Exceeds
(C) $3.6-4.5:$ Surpasses
(2.5-3.5: Successfully Meets
1.0-2.4: Does Not Meet

Comments:

\section{PART II: ACCOMPLISHMENTS/PROGRESS WITHIN THE PAST YEAR:}

POST DOC: In the areas below, describe your commpllshments relative to the specific area.

\section{Work Accomplished toward goals}

Work

State the project title, broad project goals and the speciflc progress made in the last year. If multiple projects are underway, evaluate progress with each project, identify the 

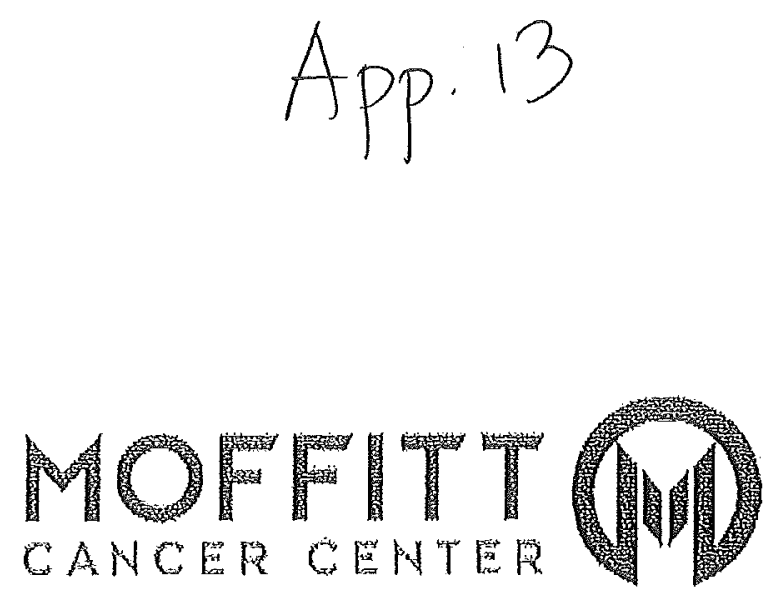

Post Doc

Anniversary Evaluation - 2011/12

\section{Employee Identification}

Name: Ganna Chornokur

Title/Rank: POST DOC FELLOW

Department \#: 25609

Emp status: 50
Employee ID: 4459845

Hire Date: 12/30/2009

Department: Cancer Epldemlology

\section{PART I: BEHAVIORAL CRITERIA}

DO NOT ADJUST SECTION WEIGHT. SECTION WEIGHT MUST REMAIN 50\%

\section{Behavioral Criteria}

Customer Focus: Commitment to Providing Outstanding Score: $3.6 / 5.0$ (0\%) Customer Service

Conveys a positive image of Moffltt to customers. Is dedlcated to superlor customer service and satisfaction. Develops and maintains positive relatlonships with both internal and external customers. Demonstrates dignity and respect to internal and external customers.

4.6-5.0: Far Exceeds

(6) $3.6-4.5:$ Surpasses

2.5-3.5: Successfully Meets

(1.0-2.4: Does Not Meet 
Shares equally in the department's success and fallures. Works effectlvely and constructively to find mutually beneficlal solutions for all concerned parties. Shares knowledge and expertise with others to ensure the success of team and Individual efforts. Supports co-workers by maintaining attendance requirements. When appropriate, works in partnership with staff, faculty and/or patient and family advisors to Improve processes or care.

(3) 4.6-5.0: Far Exceeds

O $3.6-4.5:$ surpasses

2.5-3.5: Successfully Meets

1.0-2.4: Does Not Meet

\section{Comments:}

Adaptability: Demonstration of Creativity, Innovation, Score: $4.6 / 5.0$ (0\%) Flexibility \& Willing Acceptance of Challenge

Demonstrates willingness to adapt to changing individual and institutional roles, needs and environment. Exhibits a problem solving attitude; constantly seeks ways to Improve processes, increase efficlency, find solutions to current situations or to develop new methods and procedures.

(0) 4,6-5.0: Far Exceeds

( $3.6-4.5:$ surpasses

2.5-3.5: Successfully Meets

1.0-2.4: Does Not Meet

\section{Responsibility: Acting Responsibly in All Matters}

Accepts accountabllity for actions, cholces and outcomes; assumes nothing; answers for own conduct and obligations.

4 4.6 - 5.0: Far Exceeds

(7) $3,6-4,5:$ Surpasses

2.5 - 3.5: Successfully Meets

1.0 - 2.4: Does Not Meet 
Commitment to Excellence: Striving to do the Best

score: $3.6 / 5.0(0 \%)$ Every Day

Consistently provides quality product/servlces, Commits to the principle of continuous improvement in the workplace, Projects pride in their work as exhiblted in day-tomday interactions with staff, co-workers, patients and all those they come in contact with. commits to the principles of patient and famlly-centered care: dignity \& respect, information sharing, particlpation and collaboration.

4.6-5.0: Far Exceeds

(6) $3.6-4.5 ;$ Surpasses

2.5-3.5: Successfully Meets

1.0-2.4: Does Not Meet

\section{Comments:}

Culture of Safety: Promotion of safety \& prevention of Score: $4.6 / 5.0(0 \%)$ injury must be the first consideration

Maintains awareness and follows safety policles and procedures applicable to assigned duties, Commits to the principle of continuous improvement in the workplace. Uses sound judgment including reasonable awareness of potentlal hazards before acting. Promptly reports errors and/or events and/or situations of actual or potential harm.

(0) 4.6-5.0: Far Exceeds

O $3.6-4.5$ : Surpasses

( $2.5-3.5$ : Successfully Meets

O 1.0-2.4: Does Not Meet

Comments:

\section{PART II: ACCOMPLISHMENTS/PROGRESS WITHTN THE PAST:YEAR:}

POST DOC: In the areas below, describe your commplishments relative to the specific area.

\section{Work Accomplished toward goals}

\section{Work}

State the project title, broad project goals and the speciflc progress made in the last year. If multiple projects are underway, evaluate progress with each project, identify the 
relevant obstacles and include a timeline for completion.

1. MCC16701. We hypothesize, that a combination panel (DETECT) of genetic, blochemical, socio-cultural and llfestyle population-specific blomarkers and factors will provide a valuable PCa screening and risk assessment tool. The goal of this study is to evaluate a feaslbility of using DETECT as a reliable approach to estimate the risk and/or detect PCa early in AAM ultimately elimlnating the disparity in PCa morbldity and mortality.

speciflc progress to date,

- SRC and IRB approvals were obtained. This was actually the hardest, the longest, and the most painful process so far.

- Since active recruitment was associated with great financial, time, organizational and particlpation barrlers, we have substituted the prospectlve sample collection with retrospectlvely collected samples in the Drs. Phelan and Park studles. The strength of this approach is that I will analyze 600 samples in total (300 African Amerlcan). Thus, much greater statistical power could be achleved, compared with Just 120 samples in total. In addition, Caucaslan samples will also be analyzed, allowing for an interraclal comparison between biomarkers.

- The data dictionary to combine the epidemlological data for the two studles has been completed.

- Sample selection and supply ordering have been completed.

- The nearest future plans: genotyping.

- The timeline for completion of the project: 09/2013, as speclified by the grant.

2. MCC14648. We hypothesized that select clinical and/or blo-behavloral risk factors are assoclated with prostate cancer in Afrlcan American men, 105 African American men aged 34-80 (35 cases and 70 controls) were recruited. Univariable and multivarlable logistic regression models were bullt to test the marginal and jolnt effects of the varlables when predlcting the cancer status, specific progress,

- The data collected during the accrual time of this protocol was analyzed and the most relevant varlables were chosen for analysis.

- Statistical analysis was performed by blostatistician;

- Significant varlables were identified and discussed;

- An abstract, based on the findings of this research, was submitted to the AACR 2012 meeting.

- A manuscript, based on the findings of this research, is in progress.

- Future plans: planning of a bigger study Involving more African Amerlcan men with prostate cancer and healthy controls.

- Timeline for completion: this secondary analysis of collected data is already compelted. However, the manuscrlpt will take another 3-6 months to be submitted.

3. MCC16112. We hypothesised that varlation in the mitochondrial genome and nuclear genome-wide variation plays a role in ovarlan cancer. The GOAL of this study is to more comprehenslvely investigate the contribution of mitochondrial genome variation to ovarlan cancer risk.

Speciflc progress.

- The list of genes related to the pathways of cellular senescence, hormonal pathways, and chromatin remodelling have been assembled. This llst ylelded over 400 genes total. 
- The list of SNPs related to the genes, identifled within the mentioned above pathways, was assembled.

- The selectlon of over 8000 of SNPS was analysed in the subset of ovarian cancer cases and controls, Several signiflcant SNPS $(p<0.05)$ In different genes have been Identifled.

- Future plans: writing a manuscript and/or an abstract to disseminate our findings.

Timeline for completion: this speclfic part - within one year. The project however will not end untll another 4 years.

\section{Research}

\section{1}

Human Subjects (list grants number, title and IRB \# In which you particlpated):

1. PC101913 and MCC16701: "Comprehensive Populatlon-Specific Marker Panel for Early Prostate Cancer Dlagnostics and Risk Assessment". Funding Agency: Department of the U.S. Army (DoD) Prostate Cancer Research Program; Chornokur PI.

2. W81XWH-06-1-0034 and MCC14648: "Prostate Cancer in African American Men: Serum Blomarkers for Early Detection Using Nanopartlcles". Funding Agency: Department of the U.S. Army (DoD) Prostate Cancer Research Program; Phelan PI.

3, 1R01 CA149429-01 and MCC16112: "The Mitochondrial Genome and Ovarlan Cancer RIsk". Funding agency: NIH: Phelan PI.

\section{2}

Vertebrate Animals (list grants number, title and IACUC \# in which you partlcipated):

N/A

\section{Training}

1

Meetings attended ( $w / 0$ presentation):

1. 10/10: ASCO-NCI-EORTC Annual Meeting on Molecular Markers in Cancer, Florlda

2. Center for Equal Health/ P20 Strategic Planning Retreat Meeting; date: 09/29/2011 
Workshops/Tralning completed in the last year (Research, Ethlcs, Human Subjects, Biosaefty, Vertebrate Annimals use-include date completed):

IRB and Bloethlcs completed $\sim 2$ years ago

Mandatory Education test: $05 / 2011$

3

Optional Workshop/Tralning completed in last year (Communication Skills, Clinical Trlals, Grant/Scientific Writing, technical Workshops, Engllsh as a Second Language):

EndNote training at USF library: approx date 12/2010;

Clinical trials Grant/Sclentlflc Writing completed $\sim 2$ years ago:

4

Other Training:

Cancer Epldemlology course: In progress;

Cancer Health Disparitles course: In progress;

Blostats 101 lecture serles: 10-112011 (Certificate of Completion Awarded);

01/11: 11-hour educational course, entitled "Cultural and Linguistic

Competency: A 21.st Century Response to Historlcal \& Unending Inequities"

(Certificate of Completion Awarded);

09/23/2011: "Feed your future", 3-hour lecture serles in recognitlon of Infant

Mortallty Month at USF

\section{Publications/Presentations}

1

Peer-revlewed publications:

1. Shahnjayla Connors, Ganna Chornokur, Nagi Kumar. New Insights to the Mechanisms of Green Tea Catechins in the Chemoprevention of Prostate Cancer. Accepted to the International Journal of Nutrition and Cancer, 2011

2. G. Chornokur, Kyle Dalton, M. Borysova, and N. Kumar. Disparitles at Presentatlon, Dlagnosis, Treatment and Survival in African American Men, Affected by Prostate Cancer, "The Prostate", 71(9), 985-97, 2011

3. G. Chornokur, S. Arya, C. Phelan, R. Tanner and S. Bhansali. Impedancebased Minlaturized Blosensor for Ultrasensitlve and Fast Prostate Speciflc Antigen Detection. Hindawl "Journal of Sensors", vol 2011, Article ID 983752, 7 pages

4. Manju Venugopal, Sunil K. Arya, Ganna Chornokur, Shekhar Bhansall. A Realtime and Continuous Assessment of Cortisol in ISF Using Electrochemical 
Impedance Spectroscopy // Sensors and Actuators A, 2011

5. Sunil K. Arya, Ganna Chornokur, Manju Venugopal and Shekhar Bhansali, Antibody functionalized Interdigitated -electrode (ID E) based Impedimetric cortlsol blosensor // Analyst, 2010, 135, 1941 - 1946

6. S. Arya; G. Chornokur, M. Venugopal; and S. Bhansall. Dithlobis(succlnimidyl proplonate) Modified Gold Micro Array Electrode Based Electrochemical Immunosensor for Ultrasensitive Detection of Cortisol // Blosensors and Bloelectronles 2010 25(10),2296-2301

2

other (non peer-reviewed) publications:

$N / A$

3

Manuscripts that are in preparation or under review:

1. Ganna Chornokur and Catherine M Phelan. Global ovarlan cancer disparitles a revlew.

2. Catherine M. Phelan, Robert Royer, Shlyu Zhang, Song LI, Kelly Metcalfe, Aletta Poll, PIng Sun, Ganna Chornokur, Steven A. Narod. Risks of gastrointestinal cancers in female BRCA1 and BRCA2 mutation carrlers.

3. Ganna Chornokur, Gang Han, RIchard Tanner, Jullo Pow-Sang, and Catherine Phelan. Biomarkers of prostate cancer in African American men. 4. Meghan E. Borysova, Ganna Chornokur, Kyle J. Dalton, and Dawood H Sultan. Prostate Cancer Health Disparitles throughout the Cancer Control Continuum.

4

Abstracts/Posters/Talks presented (Indicate authors, title, date, venue):

06/2011, Orlando, FL: Joining FORCEs Against Hereditary Cancer Conference presenter. The poster presentation entitled "RIsk of Gastrointestinal Cancers in Female BRCA1 and BRCA2 Mutation Carriers".

03/2011, Tampa, FL: The Moffitt Research Institute Scientiflc Retreat Conference - presenter. The poster presentation entitled "Comprehensive Population-Speciflc Blo-Behavloral Marker Panel for Early Prostate Cancer Dlagnostics and Risk Assessment: a DETECT study".

10/2010, Mlaml, FL: 3rd AACR conference "The Science of Health Disparitles" presenter. The poster presentation entitled "Comprehensive Population-Speclflc Mrker Panel for Prostate Cancer Screening",

Abstract submitted for poster presentation (acceptance status is yet unknown): 
Submission date 11/2011. Conference: Chicago, IL 03/2012: Annual AACR meeting - presenter. The abstract entltled "Risk Factors of Prostate Cancer in African Amerlcan Men".

\section{Honors and Awards}

1

Open Comment:

$N / A$

\section{Grants/Proposals}

Include PI, Agency, Date, Total Cost

1

Proposals funded:

11/2010: The reclplent (Principal Investlgator) of the 2-year Health Disparity
Training Award: "Comprehensive Population-Specific Marker Panel for Early
Prostate Cancer Dlagnostics and RIsk Assessment". Fundling Agency:
Department of the U.S. Army (DOD) Prostate Cancer Research Program; Start
Date: $08 / 2011$.
Total cost: $\sim 115,000$

2

Proposals submltted:

$N / A$

3

Proposals in preparation/planning:

Chemopreventive Effects of Curcumin In Prostate Cancer Cell Lines, Derived from African American and European Amerlcan Men: R03 proposal in preparation

\section{Teaching (if applicable)}


1

List teaching responsibilitles. Include individuals mentored: student name, program, dates:

I am currently mentoring a USF PhD student, Edikan Archibong. Edikan's
primary department is Blomedical and Chemical Engineering and she's
pursuing research in biosensors in cancer. As she has just started in August
2011, her final topic is still in preparation. However, she is learning cancer
blology in general and methods (including ELISA) in particular, and I am her
Immedlate mentor in this process. Edikan will be conducting research in Dr.
Phelan/Alvaro's labs at Moffitt, as well as at the Engineering department at
USF.

\section{Service and Administration (if applicable)}

1

National level:

N/A

2

Local (Moffitt/USF) level:

N/A

3

Research group or lab level:

N/A

\section{Career Progress}

1

Career goals:

My long-term career goal is to contribute to the resolution of cancer-related health disparities by conducting innovative, high-impact research as an independent investigator with competitive, peer-reviewed funding.

This broad, long-term goal is being achieved through methodologically 
organized series of the following structured activities:

1. Structured mentoring program coordlnated by the mentoring team. This includes weekly meetings with Dr. Phelan; bi-weekly meetings with Dr. Kumar; meetings with Dr. Park and biostatisticlans on as-needed basis.

2. Become Famillar with the Major Studies and Findlngs in the Area of cancer disparity. Thls is achieved by regular attendance of relevant Moffitt ground rounds and USF lecture serles; systematic revlew of the cutting edge literature In cancer health disparitles field; and attendance of relevant conferences, seminars and classes.

3. Gain Expertise in Methodologles Needed to Conduct Transdiscipllnary cancer disparlty research. Thls is achleved by galning experience in the cutting edge laboratory (i.e. genotyping) as well as blo-behavioral (i.e. community particlpatory research) techniques.

4. Be Able to Critically Review and Evaluate Research in Cancer disparity. This is achleved through attendance of journal clubs, as well as through discussions with my Mentoring team and writing my own review manuscripts that were published and are getting ready for submisslon to high impact peer-revlewed journals.

5. Gain an Understanding of Fundamental Issues Regarding the Ethical Conduct of Research, and responsible conduct of human research. This was achleved through attending Bloethlcs for researchers class (certlficate awarded), as well as IRB certification (certiflcate awarded), and by discussions with my Mentors who are engaged in clinlcal trials and other human subjects' research. 6. Attend and present at relevant research and educational meetings. Please see the prevlous sections for detalls on the meetings and presentations. 7. Sclentific writing and research dissemination. Please see the prevlous sections for detalls on the published manuscripts and manuscripts in preparation.

8. Applying for peer-revlewed research funding. A training grant was funded by the DOD; in addition, an R03 submission is in preparation. Please see the details in the prevlous sectlons.

9. Contrlbute to ralsing a new generation of students interested in cancer research. This Is achleved by mentoring a $\mathrm{PhD}$ student. Please see detalls in the prevlous section.

\section{2}

How are you making necessary connections:

1. Regular attendance of Moffltt ground rounds, including designated meeting with the speaker (only in case of the most relevant topics / simllar research interests);

2. Regular attendance of relevant semInars and lectures given at USF, including meeting with the speaker (only in case of the most relevant toplcs / similar research interests);

3. Attending and presenting at the high impact conferences, Including the AACR and ASCO meetings;

4. Being introduced to the Moffitt sclentists/members by my Mentor(s); 5. Actlve collaboration with several Moffitt cores, Including biostatistics and survey cores. 
3

List jobs applied to or interviews which have taken place (Optional):

N/A.

I have started the execution of my funded 2-year proposal just a few months ago. I consider successful completion of this proposal to be an important step in my career, and since Moffitt is an Ideal environment for this purpose, I am NOT looking for other jobs at this time.

4

Other career oriented accomplishments/concerns:

$N / A$

\section{PART III: NUMERICAL EVALUATION}

EVALUATOR: Assign a score to each area (see rating scale below). Weights on areas may be adjusted but must be whole numbers only. Weights of 8 areas must add up to $50 \%$

\section{Rating Scale}

4.6 - 5.0: Far Exceeds- Outstanding performance that always exceeds expectations and is demonstrated for an extended period of time.

$3.6-4.5$ : Surpasses - Very strong performance that exceeds expectations in most situations and meets expectations in all others.

2.5 - 3.5: Successfully Meets- Consistently meets performance expectations.

1.0 - 2.4: Does Not Meet - Indicates inconslstent performance, meeting some, but not all skill requirements. Immediate and substantial improvements must be made.

Work Accomplished towards goals

Score 1-5. If not applicable, change weight to zero

Training

Score 1-5. If not applicable, change weight to zero
Score: $4.6 / 5.0(7 \%)$

Score: $4.6 / 5.0(0 \%)$
Score: $4.5 / 5.0(7 \%)$

Score: $4.5 / 5.0(0 \%)$ 


\section{Publications}

Score: $4.6 / 5.0(6 \%)$

Score 1-5. If not applicable, change weight to zero

Honors and Awards

Score 1-5. If not applicable, change weight to zero
Score $4.0 / 5.0(6 \%)$

Score: $4.0 / 5.0(0 \%)$
Score $4.5 \% 5.0(6 \%)$ Score: $4.5 / 5 \times 0(0 \%)$

Score 1-5. If not applicable, change weight to zero

Score: $4,0 \% 5.0(6 \%)$

Teaching

(if applicable)

Score 1-5. If not applícable, change weight to zero

Score: $4.0 / 5.0(0 \%)$

Service and

Administration

(if applicable)

Score 1-5. If not applicable, change weight to zero

Career Progress

Score $1-5$. If not applicable, change weight to zero
Score: $3.6 / 5.0(6 \%)$

Score: $3.6 / 5.0(0 \%)$
Score: $4.6 / 5 \times 0(6 \%)$

Score: $4.6 / 5.0(0 \%)$ 
Summary of Numerical Evaluation area. Area weight should equal $50 \%$

\section{Numerical Evaluation Comments}

Evaluator comments related to the numerical evaluation:

OVERALL SCORE (FINAL SCORE) Score $4.2: 5.0(100 \%)$

The Overall Score Is made up of the Numerical Evaluation and Behavloral Competencies areas

\section{PART IV: NEW GOALS}

POST DOC: Propose goals and expectations for the next year. Identify potential obstacles and propose solutions.

EVALUATOR: Populate the Approved Goals areas as appllcable, using the Proposed Goals as a gulde.

\section{Post Doc's Proposed Goals: Research/Scholarship}

Main focus: Continue the execution of MCC16701. (DoD DETECT training grant); aim 1 should be completed and analysed and alm 2 should be initiated.

Also, continue the MCC16112 and MCC14648 as it related to data analysis and research dissemination.

\section{Approved Goals: Research/Scholarship}

Main focus: Continue the execution of MCC16701 (DOD DETECT training grant); aim 1 should be completed and analysed and alm 2 should be initiated.

Also, continue the MCC16112 and MCC14648 as it related to data analysls and research dlssemination.

\section{Post Doc's Proposed Goals: Training}

- Continue regular attendance of relevant workshops, Moffitt Ground rounds and USF lectures; 
- Audit the following classes: Cancer blology III; tentative: health disparities (subject to avallability); - Clinical: shadow rese

- Tentatlve: phlebotomy course;

- Tentative: grant writing workshop(s) (subect physlcian (subject to avallabllity).

- Tentative: shadow an MCC prostate

\section{Approved Goals: Training}

- Continue regular attendance of relevant workshops, Moffitt Ground rounds and USF lectures;

- Audlt the following classes: Cancer blology III; tentative: health disparities (subject to avallabllity);

- Clinical: shadow research coordinators from Dr, Kumar's group as they recrult patients into the clinical trials;

- Tentative: phlebotomy course;

- Tentative: grant writing workshop(s) (suncer physician (subject to avallabllity).

\section{Post Doc's Proposed Goals: Publications/Pre}

Publications: at least two 1-author publications in the relevant peer-revlew journals accepted for publication.

Presentations: at least two poster and/or oral presentations at the high-impact sclentiflc meetings / conferences. Possible meetings may Include AACR meeting 03/2012 (abstract meetings / conferences, Possith dlsparity meeting $09-10 / 2012$, relevant in 2012.
submitted), AACR Cancer health
meetings and/or other high Impact health disparity meetings to be held

\section{Approved Goals: Publications/Presentation}

Publlcations: at least two 1-author publications in the relevant peer-review journals accepted for publlcation.

Presentations: at least two poster and/or oral presentations at the high-impact scientlfic meetings / conferences, Posslble meetings may Include AACR meeting 03/2012 (abstract submitted), AACR Cancer health disparty mealth dlsparlty meetings to be held in 2012 .

Post Doc's Proposed Goals: Honors and Awards 
AACR Scholar-In-Tralning Awards: Avallable to early-career sclentists presenting a meritorious proffered paper at the AACR Annual Meeting.

I have applied for this award at the time of abstract submission.

\section{Approved Goals: Honors and Awards}

AACR Scholar-in-Training Awards: Avallable to early-career scientists presenting a meritorlous proffered paper at the AACR Annual Meeting.

I have applled for thls award at the time of abstract submlssion

\section{Post Doc's Proposed Goals: Grants/Proposals}

At least one NIH RO3 proposal submitted and/or at least one DoD proposal submitted (other than the training grant), Focus: prostate cancer health disparities

\section{Approved Goals: Grants/Proposals}

At least one NIH RO3 proposal submitted and/or at least one DOD proposal submitted (other than the training grant)

Focus: prostate cancer health disparities

\section{Post Doc's Proposed Goals: Teaching} Continue mentoring Edlkan Archibong,
Tentative: mentoring other students, Including Summer Interns like SPARK/LINK,

\section{Approved Goals: Teaching}

Continue mentoring Edikan Archibong. Tentative: mentoring other students, including Summer interns like SPARK/LINK. 


\section{Post Doc's Proposed Goals: Service and Administration}

At this point, I don't have any goals in this area.

\section{Approved Goals: Service and Administration}

At this point, I don't have any goals in this area.

\section{Post Doc's Proposed Goals: Career}

To continue my transition to an independent researcher by the means of:

1. Enhancing my research skills:

a. Molecular methods

b. Biobehavloral components

c. Learning about Cancer disparities

d. Writing publications

e. Presenting my research

2. Gaining career development skills:

a. Grant submissions (R03, DoD idea development)

b. Forming research collaborations

c. Management of the 1 mited funds, avallable through the DOD training grant, and budgeting

\section{Approved Goals: Career}

To continue my transition to an independent researcher by the means of:

1. Enhancing my research skills:

a. Molecular methods

b. Blobehavioral components

c. Learning about Cancer disparities

d. Writing publications

e. Presenting my research

2. Galning career development skills:

a. Grant submissions (RO3, DOD Idea development)

b. Forming research collaborations

c. Management of the limlted funds, avallable through the DoD training grant, and 
budgeting

New Goals Overall Comments (Optional):

Evaluator may use this area to make comments related to new goals:

Overall, Ganna is doing very well. We need to start Ganna's entrance into service and administration and increase her teaching.

Post Doc Final comments (optional)

Evaluator Final Comments (optional): 
Employee:

Ganna Chornokur G.C. (electronic signature for the evaluation of Ganna Chornokur')

Date:

01/03/2012 09:15 AM 
Manager:

Catherine Phelan C,P. (electronic signature for the evaluation of Ganna Chornokur)

Date:

01/03/2012 10:08 AM 
App. 14

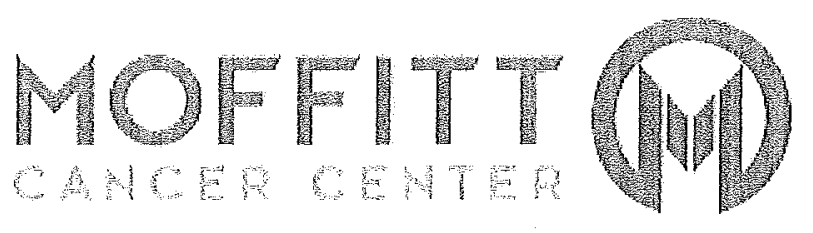

Post Doc

Anniversary Evaluation - 2012/13

\title{
Emplovee Identification
}

Name: Ganna Chornokur

Title/Rank: POST DOC FELLOW

Department \#: 25609

Emp Status: 50
Employee ID: 4459845

Hire Date: 12/30/2009

Department: Cancer Epidemiology

\section{Instructions}

The Post Doc will start off the evaulation by completing Parts II and IV only. The evaluator will then complete the remaining sections.

\section{PART I: BEHAVIORAL CRITERIA}

DO NOT ADJUST SECTION WEIGHT,

SECTION WEIGHT MUST REMAIN $50 \%$

\section{Behavioral Criteria}

\author{
Score: $4.6 / 5.0$
}

$(50 \%)$

\section{Customer Focus: Commitment to Providing Outstanding Score: $4.6 / 5.0(0 \%)$ Customer Service}

Conveys a positive image of Moffitt to customers. Is dedicated to superior customer service and satisfaction. Develops and maintains positive relationships with both internal and external customers. Demonstrates dignity and respect to internal and external customers.
(6) 4.6 - 5.0: Far Exceeds
3.6-4.5: Surpasses
2.5 - 3.5: Successfully Meets 


\section{Comments:}

Teamwork: Work, as Part of a Group, to Achieve Results Score: $4.6 / 5.0(0 \%)$

Shares equally in the department's success and failures. Works effectively and constructively to find mutually beneficial solutions for all concerned parties. Shares knowledge and expertise with others to ensure the success of team and individual efforts. Supports co-workers by maintaining attendance requirements. When appropriate, works in partnership with staff, faculty and/or patient and family advisors to improve processes or care.
(9) 4.6 - 5.0: Far Exceeds
3.6 - 4.5: Surpasses
2.5 - 3.5: Successfully Meets
1.0 - 2.4: Does Not Meet

\section{Comments:}

\section{Adaptability: Demonstration of Creativity, Innovation, Score: $\mathbf{4 . 6 / 5 . 0 ( 0 \% )}$ Flexibility \& Willing Acceptance of Challenge}

Demonstrates willingness to adapt to changing individual and institutional roles, needs and environment. Exhibits a problem solving attitude; constantly seeks ways to improve processes, increase efficiency, find solutions to current situations or to develop new methods and procedures.
(9) 4.6-5.0: Far Exceeds
3.6- 4.5: Surpasses
2.5-3.5: Successfully Meets
1.0 - 2.4: Does Not Meet

\section{Comments:}

Responsibility: Acting Responsibly in All Matters

Accepts accountability for actions, choices and outcomes; assumes nothing; answers for own conduct and obligations.
(- 4.6 - 5.0: Far Exceeds
3.6-4.5: Surpasses
2.5-3.5: Successfully Meets
0 
Comments:

Commitment to Excellence: Striving to do the Best Every Day

Score: $4.6 / 5.0(0 \%)$

Consistently provides quality product/services. Commits to the principle of continuous improvement in the workplace. Projects pride in their work as exhibited in day-to-day interactions with staff, co-workers, patients and all those they come in contact with. Commits to the principles of patient and family-centered care: dignity \& respect, information sharing, participation and collaboration.

(6) 4.6 - 5.0: Far Exceeds

$3.6-4.5:$ Surpasses

2.5 - 3.5: Successfully Meets

1.0-2.4: Does Not Meet

\section{Comments:}

Culture of Safety: Promotion of safety \& prevention of injury must be the first consideration

Score: $4.6 / 5.0(0 \%)$

Maintains awareness and follows safety policies and procedures applicable to assigned duties. Commits to the principle of continuous improvement in the workplace. Uses sound judgment including reasonable awareness of potential hazards before acting. Promptly reports errors and/or events and/or situations of actual or potential harm.

(9) 4.6 - 5.0: Far Exceeds

3.6-4.5: Surpasses

2.5 - 3.5: Successfully Meets

1.0 - 2.4: Does Not Meet

\section{Comments:}

\section{PART IT: ACCOMPLISHMENTS/PROGRESS WITHIN THE PAST YEAR}

POST DOC: In the areas below, describe your accomplishments relative to the specific subject.

If you do not see any goals from last year listed in the sections below and you participated in last year's evaluation process, please reference last year's appraisal saved in the "My Performance" section of your dashboard in Halogen.

If you are a new Post Doc, you will not have any pre-defined Goals. 


\section{Work Accomplished toward goals}

\section{Work}

State the project title, broad project goals and the specific progress made in the last year. If multiple projects are underway, evaluate progress with each project, identify the relevant obstacles and include a timeline for completion.

1. MCC16701: We hypothesize, that a combination panel (DETECT) of genetic, biochemical, socio-cultural and lifestyle population-specific biomarkers and factors will provide a valuable PCa screening and risk assessment tool.

Specific progress made in the last year.

1. Genotyping for the select SNPs of interest have been successfully completed in Black and White DNA samples.

2. Statistical analysis have been completed.

3. We have found that in African American (but not European American) men there is interaction between prostate cancer risk, obesity and select germline SNPS.

4. These data were presented as a poster at the AACR health disparities conference and will be presented at the NIH health disparities summit in December 2012.

5. The manuscript is in preparation.

6. Using these data as preliminary, an R21 have been submitted in November 2012, entitled "Obesity and prostate cancer risk in Black and White men: a functional approach".

7. An annual DoD report was completed and accepted by the DoD as written.

8. My Mentoring team and I have decided to proceed with genotyping the CAG repeat region in the $A R$ gene in the same germline samples.

9. Genotyping has now been completed and data analysis is in progress.

2. MCC14648: We hypothesized that select clinical and/or bio-behavioral risk factors are associated with prostate cancer in African American men. 105 African American men aged 34-80 (35 cases and 70 controls) were recruited. Univariable and multivariable logistic regression models were built to test the marginal and joint effects of the variables when predicting the cancer status. Specific progress within the last year:

1. Data analysis was completed.

2. A poster presentation, entitled "Risk factors for prostate cancer in African American men" was presented by me at the Annual AACR meeting 2012.

3. The manuscript entitled "High Grade Prostate Intraepithelial Neoplasia (PIN)

is a PSA-independent risk factor for prostate cancer in African American men: a pilot study" by Ganna Chornokur; Gang Han; Richard Tanner; Hui-Yi Lin; Lee B Green, Julio Pow-Sang; Catherine M Phelan was completed and submitted to "Cancer Letters".

4. The Journal was potentially interested in publication, but some edits were requested. Hence, a revised version was submitted 11/2012. Given favorable peer-review, we expect that the manuscript will be accepted.

5. Using these data as preliminary, a grant project entitled "Prostatic Intraepithelial Neoplasia and prostate cancer in African American men" was submitted to the DoD 08/2012. Dr. Catherine Phelan is a PI and I am a co-I on this project. 
3. MCC16112: We hypothesized that variation in the mitochondrial genome and nuclear genome-wide variation plays a role in ovarian cancer. The goal of this study is to more comprehensively investigate the contribution of mitochondrial genome variation to ovarian cancer risk.

Specific progress made in the last year:

1. Genotyping have been completed. Eight key cancer-relevant pathways were selected. I am responsible for analysis of the transmembrane and metabolism pathway that includes 305 SNPs from 120 genes.

2. Usign these data, an abstract entitled "Variation in the cellular transport genes influence epithelial ovarian cancer risk and histopathologic subtype" was submitted to the AACR Annual Meeting 2013. I am a presenter and Dr Phelan is a senior author.

3. A manuscript entitled "Variation in the cellular transport genes influence epithelial ovarian cancer risk and histopathologic subtype" is in progress.

4. A review manuscript entitled "Global ovarian cancer health disparities" has been submitted to Gynecologic Oncology Journal. The manuscript was accepted pending minor revisions. A revised version is expected to be submitted to the journal next week. Prompt approval is anticipated.

\section{Existing Research Goals}

Main focus: Continue the execution of MCC16701 (DoD DETECT training grant); aim 1 should be completed and analysed and aim 2 should be initiated.

Also, continue the MCC16112 and MCC14648 as it related to data analysis and research dissemination.

\section{Research}

1

Human Subjects (list grants number, title and IRB \# in which you participated):

1. MCC 14648: Nanoscale Detection of Plasma Prostate Cancer Cells in African American Men; IRB\#: Pro00001823 (Phelan PI)

2. MCC 16701: Comprehensive Population-Specific Marker Panel for Early Prostate Cancer Diagnostics and Risk Assessment; IRB\#: Pro00004885 (Chornokur PI)

3. MCC 16112: The Mitochondrial Genome and Ovarian Cancer Risk; IRB\#: Pro00000249 (Phelan PI)

Vertebrate Animals (list grants number, title and IACUC \# in which you participated): 
N/A

\section{Existing Training Goals}

- Continue regular attendance of relevant workshops, Moffitt Ground rounds and USF lectures;

- Audit the following classes: Cancer biology III; tentative: health disparities (subject to availability);

- Clinical: shadow research coordinators from Dr. Kumar's group as they recruit patients into the clinical trials;

- Tentative: phlebotomy course;

- Tentative: grant writing workshop(s) (subject to availability).

- Tentative: shadow an MCC prostate cancer physician (subject to availability).

\section{Training}

1

Meetings attended (w/o presentation):

$\mathrm{N} / \mathrm{A}$

2

Workshops/Training completed in the last year (Research, Ethics, Human Subjects, Biosaefty, Vertebrate Annimals use-include date completed):

1. Moffitt Annual Mandatory Continuing Education Test: 05/2012

2. IRB bi-annual test: $04 / 2012$

3. Biosafety annual continuing education module: $04 / 2012$

3

Optional Workshop/Training completed in last year (Communication Skills, Clinical Trials, Grant/Scientific Writing, technical Workshops, English as a Second Language):

1. Interactive NIH Grant Writing workshop held during the Annual AACR Meeting: 03/2012

4

Other Training:

1. Moffitt Office of Technology and Commercialization (OTMC) internship:

10/2012 - 08/2013 (in progress).

2. USF postdoctoral training workshop, entitled "Negotiate offers for faculty positions": 09/2012. 


\section{Existing Publication/Presentation Goals}

Publications: at least two 1-author publications in the relevant peer-review journals accepted for publication.

Presentations: at least two poster and/or oral presentations at the high-impact scientific meetings / conferences. Possible meetings may include AACR meeting 03/2012 (abstract submitted), AACR Cancer health disparity meeting 09-10/2012, relevant prostate cancer meetings and/or other high impact health disparity meetings to be held in 2012 .

\section{Publications/Presentations}

\section{1}

Peer-reviewed publications:

1. Kryshtab TG, Borkovska LV, Kolomys O, Korsunska NO, Strelchuk VV, Germash LP, Pechers'ka KYu, Chornokur G, Ostapenko SS, Phelan CM, Stroyuk $\mathrm{OL}$. The effect of bio-conjugation on aging of the photoluminescence in CdSeTeZnS core-shell quantum dots. Superlattice Microst. 2012:51:353-62. DOI: $10.1016 / j . s p m i .2011 .12 .005$

2. Kumar NB, Crocker T, Smith T, Pow-Sang J, Spiess PE, Connors SK, Chornokur G, Dickinson IS, Williams CR, Salup R, Bai W. Prostate Cancer Chemoprevention targeting High Risk Populations: Model for trial design and outcome measures. J Cancer Sci Ther. 2012 ; 2011(S3). PMID: 22422102

3. Connors S, Chornokur G, Kumar N. New Insights to the Mechanisms of Green Tea Catechins in the Chemoprevention of Prostate Cancer. Nutr Cancer. 2012:64(1): 4-22. PMID: 22098273

2

Other (non peer-reviewed) publications:

N/A

3

Manuscripts that are in preparation or under review:

1. Chornokur G, Amankwah E, Schildkraut JM, Phelan CM. Global ovarian cancer health disparities. Submitted to Gynecologic Oncology [accepted pending minor revisions]

2. Chornokur G and Kumar NB. Evidence-based strategies for prostate cancer chemoprevention in men of African descent. Submitted to Cancer Causes and Control [major revision requested] 
3. Chornokur G; Han G; Tanner R; Lin H-Y; Green LB, Pow-Sang J; Phelan CM. High Grade Prostate Intraepithelial Neoplasia (PIN) is a PSA-independent risk factor for prostate cancer in African American men. Submitted to Cancer Letters [accepted pending revisions]

4. Chornokur G, Amankwah E, Phelan CM, Park JY, Pow-Sang J, Kumar NB. Variation in the metabolism related genes and obesity may contribute to prostate cancer disparity in African American men. In preparation

5. Ganna Chornokur, Jonathan Tyrer, Hui-Yi Lin, Gang Han, Xiaotao Qu, Zhihua Chen, Ya-Yu Tsai, Ellen L. Goode, Julie M. Cunningham, Edwin Iversen, Susan Ramus, Andrew Berchuck, Joellen Schildkraut, Alvaro Monteiro, Simon Gayther, Steven A. Narod, Paul Pharoah, Thomas A. Sellers and Catherine M. Phelan. Variation in the cellular transport genes influence epithelial ovarian cancer risk and histopathologic subtype. In preparation.

6. Kumar NB, Chornokur G, Dalton $\mathrm{K}$ et al. Comparing the watchful waiting and radical prostatectomy cohorts in a comprehensive NIH-designated cancer center with uniform assignment criteria. In preparation.

4

Abstracts/Posters/Talks presented (Indicate authors, title, date, venue):

1. AACR Annual Meeting $(03-04,2012)$ : Risk Factors of Prostate Cancer in African American Men (poster presentation): presenter

2. AACR "The Science of Health Disparities" Conference $(10,2012)$ :

Polymorphisms in the metabolism related genes and obesity may explain prostate cancer disparity in African American men (poster presentation): presenter

3. NIH Summitt to Reduce Health Disparities (12, 2012): Polymorphisms in the metabolism related genes and obesity may explain prostate cancer disparity in African American men (poster presentation): presenter

4. AACR Annual Meeting $(04,2013)$ : Variation in the cellular transport genes influence epithelial ovarian cancer risk and histopathologic subtype (abstract submitted, presenter)

\section{Existing Horors and Awards}

AACR Scholar-in-Training Awards: Available to early-career scientists presenting a meritorious proffered paper at the AACR Annual Meeting.

I have applied for this award at the time of abstract submission.

\section{Honors and Awards}


Open Comment:

1. Center for Equal Health (CEH) travel award to attend and present at the 2012 Annual AACR meeting (Chicago, IL), 04, 2012 [\$500]

2. Scholar-in-training Award to attend the Fifth AACR Conference on The Science of Cancer Health Disparities in Racial/Ethnic Minorities and the Medically Underserved, 10, 2012 [\$1250]

\section{Existing Grants/Proposals}

At least one NIH R03 proposal submitted and/or

at least one DoD proposal submitted (other than the training grant).

Focus: prostate cancer health disparities

\section{Grants/Proposals}

include PI, Agency, Date, Total Cost

1

Proposals funded:

1. Department of the U.S. Army (DoD) Prostate Cancer Research Program, Health Disparity Training Award: Comprehensive Population-Specific Marker Panel for Early Prostate Cancer Diagnostics and Risk Assessment, 08/2011 $07 / 2013$ [funded and active]

\section{2}

Proposals submitted:

1. Department of the U.S. Army (DoD) Prostate Cancer Research Program, Hypothesis Development Award: Comparative race-specific chemopreventive effects of curcumin in prostate cancer, 06/2012 [undergoing peer-review]

2. National Institute of Health (NIH) Exploratory/Developmental Grants Program for Basic Cancer Research in Cancer Health Disparities (R21): Obesity, tumor biology, genetics and prostate cancer risk in men of African and European descent, 11/2012 [undergoing peer-review]

3. National Institute of Health (NIH) Cancer Prevention Research Small Grant Program (R03): Comparative race-specific chemopreventive effects of curcumin in prostate cancer, 02/2012

[not funded] 
Proposals in preparation/planning:

1. Department of the U.S. Army (DoD) Prostate Cancer Research Program, Health Disparity Research Award. Due date 08/2013. Proposal is in the planning stage, final topic dependent on the results of my current experimental work (genotyping and analysis of the CAG repeat in the AR gene in Black and White men with prostate cancer and controls).

\section{Existing Teaching Goals (if applicable)}

Continue mentoring Edikan Archibong.

Tentative: mentoring other students, including Summer interns like SPARK/LINK.

\section{Teaching (if applicable)}

1 List teaching responsibilities. Include individuals mentored: student name, program,
dates:

Edikan Archibong has changed her research direction. However, I helped Dr Phelan supervise an INSPIRE (Interest, Need, Stimulate, Persevere, Ideas, Relevance and Excellence) Undergraduate Summer Student (Jennifer Diaz), 0609/ 2012.

- Project entitled "Breast Cancer in Latin America"

\section{Existing Service and Administration Goals (if applicable)}

At this point, I don't have any goals in this area.

Service and Administracion (if applicable)

1

National level:

N/A

2

Local (Moffitt/USF) level: 
N/A

\section{3}

Research group or lab level:

N/A

\section{Exhs"ing Careen Progress Goals}

To continue my transition to an independent researcher by the means of:

1. Enhancing my research skills:

a. Molecular methods

b. Biobehavioral components

c. Learning about Cancer disparities

d. Writing publications

e. Presenting my research

2. Gaining career development skills:

a. Grant submissions (R03, DoD idea development)

b. Forming research collaborations

c. Management of the limited funds, available through the DoD training grant, and budgeting

\section{Career Progress}

1

Career goals:

1. Grant submissions: at least one new submission and/or re-submission as a P.I. However, my goal is at least two submissions a year (including new submissions and revisions). I have completed 3 new grant submissions during the last year.

2. Peer-reviewed publications: at least two relevant peer-reviewed publications accepted a year, preferably at least one of them 1st author. While I had 3 peerreviewed publications last year, none of them is 1st author. However, at present I have 3 1st author publications favorably peer-reviewed. It is expected that at least 2 of them will be promptly accepted following minor revisions.

3. Presentations: at least two relevant presentations at the high-impact scientific meetings. Last year, I had three conference poster presentations and was awarded two travel grants to attend the conferences. The goal for the next year is to continue this schedule, with an emphasis on oral presentations.

4. Training: I am continuously attending the relevant scientific ground rounds 
and seminars at Moffitt and USF at the average of 1 per week. I am keeping my IRB, Biosafety and other mandatory trainings and certifications up to date. In addition, I am doing an internship at the OTMC. Although not directly relevant to my current work, this is a great opportunity to broaden my horizons and provide me with an advance in the job search.

5. Job search: I am currently on the road to independence, and looking for suitable academic faculty positions. So far, I have applied to one highly relevant position at the MD Anderson. I have several other open job positions in mind which I may apply later on. In addition, I am continuously looking for new job opportunities via a variety of sources, including Internet, conferences, networking etc.

6. Networking. I am using the conferences as main networking opportunities. In addition, I am attending the "Expert lunches" with the Invited Ground Rounds speakers (where possible).

\section{2}

How are you making necessary connections:

Not sure what this means exactly, but I am utilizing all the steps specified in the previous bullet (1. Career goals) to achieve career progress.

\section{3}

List jobs applied to or interviews which have taken place (Optional):

1. Duncan Family Institute Mentored Junior Faculty Fellowship in Cancer

Prevention at the MD Anderson Cancer Center: applied 11/2012.

\section{4}

Other career oriented accomplishments/concerns:

If possible, I would like to get involved into service and administration at any level.

\section{PART TII: NUMERICAL EVALUATION}

Assign a score to each area (see rating scale below).

Weights on areas may be adjusted but must be in whole numbers only.

Weights of 8 areas must add up to $50 \%$

\section{Rating Scale}

4.6 - 5.0: Far Exceeds- Outstanding performance that always exceeds expectations and is demonstrated for an extended period of time.

3.6 - 4.5: Surpasses - Very strong performance that exceeds expectations in most situations and meets expectations in all others. 
2.5 - 3.5: Successfully Meets- Consistently meets performance expectations.

1.0 - 2.4: Does Not Meet - Indicates inconsistent performance, meeting some, but not all skill requirements. Immediate and substantial improvements must be made.

Work Accomplished Towards goals

Score 1-5. If not applicable, change weight to zero

Training

Score 1-5. If not applicable, change weight to zero

Publications

Score 1-5. If not applicable, change weight to zero

Honors and Awards

Score 1-5. If not applicable, change weight to zero

Grants/Proposals

Score 1-5. If not applicable, change weight to zero

Teaching

(if applicable)
Score: $4.5 / 5.0$

$(7 \%)$

Score: $4.5 / 5.0(0 \%)$

Score: $4.5 / 5.0$

$(7 \%)$

Score: $4.5 / 5.0(0 \%)$

Score: $4.3 / 5.0$

$(6 \%)$

Score: $4.3 / 5.0(0 \%)$

Score: $4.0 / 5.0$

$(6 \%)$

Score: $4.0 / 5.0(0 \%)$

Score: $4.0 / 5.0$ $(6 \%)$

Score: $4.0 / 5.0(0 \%)$ 
Score 1-5. If not applicable, change weight to zero

Score: $4.3 / 5.0(0 \%)$

Service and Administration

(în applicable)

Scone: $4.3 / 5.0$

$(6 \%)$

Score 1-5 If not applicable, change weight to zero

Score: $4.3 / 5.0(0 \%)$

Carean Progress

Score: $4.0 / 5.0$

$(6 \%)$

Score 1-5. If not applicable, change weight to zero

Score: $4.0 / 5.0(0 \%)$

Summary score

Score: $4.2 / 5.0(50 \%)$

Summary of Numerical Evaluation area. Area weight should equal $50 \%$

Numerical Evaluation Comments

Evaluator comments related to the numerical evaluation:

OVERALL SCORE (FINAL SCORE)

Score: $4.4 / 5.0(100 \%)$

The Overall Score is made up of the Numerical Evaluation and Behavioral Competencies areas

\section{PART TV: NEW GOALS}

POST DOC: Propose goals and expectations for the next year. Identify potential obstacles and propose solutions.

EVALUATOR: Populate the Approved Goals areas as applicable, using the Proposed Goals as a guide.

\section{Post Doc's Proposed Goals: Research/Scholarship}

1. Continue and finish the Aim 2 of the DoD training award. Successfully complete the grant, write the final evaluation etc.

2. Continue working on the ovarian mitochondrial genome project. Conduct some 
functional work to elucidate the biological significance of the identified SNPs and genes on ovarian carcinogenesis.

\section{Aprovad Goals: Research/Scholarship}

1. Continue and finish the Aim 2 of the DoD training award. Successfully complete the grant, write the final evaluation etc.

2. Continue working on the ovarian mitochondrial genome project. Conduct some functional work to elucidate the biological significance of the identified SNPS and genes on ovarian carcinogenesis.

\section{Post Doc's Proposed Goals: Training}

1. Finish the OTMC internship

2. Audit the Cancer genetics course (Dr Alvaro Monteiro)

3. Continuous attending of the relevant scientific ground rounds, seminars, talks etc at Moffitt and/or USF

\section{Approved Goals: Training}

1. Finish the OTMC internship

2. Audit the Cancer genetics course (Dr Alvaro Monteiro)

3. Continuous attending of the relevant scientific ground rounds, seminars, talks etc at Moffitt and/or USF

\section{Post Doc's Proposed Goals: Publications/Presentation}

At least two relevant peer-reviewed publication accepted in reputable scientific journals. At least one of which is the 1st author.

Ideally, two 1st author plus at least one non-1st author.

\section{Approved Goals: Publications/Presentation}

At least two relevant peer-reviewed publication accepted in reputable scientific journals. At least one of which is the 1st author.

Ideally, two 1st author plus at least one non-1st author.

\section{Post Doc's Proposed Goals: Honors and Awards}


Travel awards where applicable.

Approved Goals: Honors and Awards

Travel awards where applicable.

Post Doc's Proposed Goals: Grath/Proposals

At least one new submission and/or re-submission as a P.I. However, my goal is at least two submissions a year (including new submissions and revisions).

\section{Approved Goals: Granks/Proposals}

At least one new submission and/or re-submission as a P.I. However, my goal is at least two submissions a year (including new submissions and revisions).

\section{Post Doc's Proposed Goals: Teaching}

Mentor undergraduate or graduate students such as SPARK / LINK.

\section{Approved Goals: Teaching}

Mentor undergraduate or graduate students such as SPARK / LINK.

\section{Post Doc's Proposed Goals: Service and Administration}

Not sure at this time, but would like to get involved.

\section{Approved Goals: Service and Administration}

Not sure at this time, but would like to get involved. 
Post Doc's Proposed Goals: Career

At least two relevant job applications a year.

Approved Goals: Career

At least two relevant job applications a year.

New Goals Overall Comments (Optional):

Evaluator may use this area to make comments related to new goals:

post Doc Final Comments (optional):

\section{N/A}

\section{Evaluator Final Comments (optional):}

Ganna is a bright, hardworking post doctoral candidate with a focussed interest in prostate cancer disparity. She has garnered outstanding skill sets and is a versatile researcher. 
Employee:

Date:
Ganna Chornokur G.C. (electronic signature for the evaluation of Ganna Chornokur)

$12 / 11 / 201208: 51$ AM 


\begin{tabular}{|c|c|c|}
\hline Variable & Dr Phelan's study & Dr Park's study \\
\hline Case & $\begin{array}{l}\text { Part 7, \#1: Yes, table, row "prostate } \\
\text { cancer" }\end{array}$ & Part III, A: Yes - prostate \\
\hline Control & Part 7, \#1: No & Part III, A: No \\
\hline Age & 2012 - Part $1, \# 4$ year only & $\begin{array}{l}2012 \text { - the DOB year only (top of the } 1^{\text {st }} \\
\text { page) }\end{array}$ \\
\hline $\begin{array}{l}\text { Age at diagnosis } \\
\text { (cases only) }\end{array}$ & $\begin{array}{l}\text { Part } 7, \# 1 \text { table, column "What was your } \\
\text { age when you were told you have this type } \\
\text { of cancer", row "prostate cancer". }\end{array}$ & $\begin{array}{l}\text { Top of the } 1^{\text {st }} \text { page: } \\
\text { [date of current diagnosis, year] }-[D O B \text {, } \\
\text { year] }\end{array}$ \\
\hline \multirow{2}{*}{$\begin{array}{l}\text { Race/ethnicity: } \\
\text { - Black/Non-Hispanic or African } \\
\text { American } \\
\text { - White/Non-Hispanic or Caucasian }\end{array}$} & $\begin{array}{l}\text { Part 1, \#1: No; and } \\
\text { Part 1, \#2: Black or African American }\end{array}$ & $\begin{array}{l}\text { Part I, C: No; and } \\
\text { Part I, D: Black or African American }\end{array}$ \\
\hline & $\begin{array}{l}\text { Part 1, \#1: No; and } \\
\text { Part 1, \#2: White }\end{array}$ & $\begin{array}{l}\text { Part I, C: No; and } \\
\text { Part I, D: White }\end{array}$ \\
\hline \multirow{5}{*}{$\begin{array}{l}\text { Education: } \\
\text { - Some High school } \\
\text { - High school graduate } \\
\text {-Some college } \\
\text { - College graduate } \\
\text { - Postgraduate }\end{array}$} & $\begin{array}{l}\text { Part } 1 \text {, \#6: less than } 6^{\text {th }} \text { grade; } 6^{\text {th }}-8^{\text {th }} \\
\text { grade; } 9^{\text {th }}-10^{\text {th }} \text { grade; }\end{array}$ & $\begin{array}{l}\text { Part I, E: grade school/junior high school; } \\
\text { some high school }\end{array}$ \\
\hline & $\begin{array}{l}\text { Part } 1, \# 6: 11^{\text {th }}-12^{\text {th }} \text { grade; GED or } \\
\text { equivalent; }\end{array}$ & Part I, E: high school graduate \\
\hline & Part 1, \#6: some college; vocational school & $\begin{array}{l}\text { Part I, E: some college/ technical/ } \\
\text { vocational school certificate }\end{array}$ \\
\hline & Part 1, \#6: graduate college & Part I, E: college graduate \\
\hline & $\begin{array}{l}\text { Part 1, \#6: postgraduate or professional } \\
\text { school }\end{array}$ & Part I, E: post-graduate degree \\
\hline \multirow{3}{*}{$\begin{array}{l}\text { Relationship status: } \\
\text { - Married/living with a partner } \\
\text { - Widowed/ divorced/separated/single } \\
\text { - Refuse to answer }\end{array}$} & $\begin{array}{l}\text { Part 1, \#5: cohabitating/living together; } \\
\text { married }\end{array}$ & Part I, A: married/living with partner \\
\hline & $\begin{array}{l}\text { Part 1, \#5: Widowed; divorced/separated; } \\
\text { single }\end{array}$ & $\begin{array}{l}\text { Part I, A: widowed; divorced; separated; } \\
\text { single }\end{array}$ \\
\hline & Part 1, \#5: Refuse to answer & Not an option \\
\hline \multirow[t]{2}{*}{$\begin{array}{l}\text { Personal history of cancers (other than } \\
\text { prostate cancer): } \\
\text { - Yes }\end{array}$} & $\begin{array}{l}\text { Part 7, \#1: Yes, table, all rows besides } \\
\text { prostate cancer. Please specify the cancer } \\
\text { type }\end{array}$ & $\begin{array}{l}\text { Part III, A: Yes - a. If yes, what area of the } \\
\text { body and what was the diagnosis? Please } \\
\text { specify the cancer type }\end{array}$ \\
\hline & Part 7, \#1: No & Part III, A: No \\
\hline $\begin{array}{l}\text { If yes to Personal history of cancers, } \\
\text { please specify the age at diagnosis }\end{array}$ & $\begin{array}{l}\text { Part 7, \#1: table, column "what was your } \\
\text { age when you were told that you had this } \\
\text { type of cancer?" }\end{array}$ & $\begin{array}{l}\text { Part III, } A, b \text {. In what year was your } \\
\text { diagnosis and how old were you? }\end{array}$ \\
\hline \multirow{2}{*}{$\begin{array}{l}\text { Family history of cancers } \\
\text { - Yes } \\
\text { - No/Don't know }\end{array}$} & Part 8, \#6: Yes & Part III, C: table is filled \\
\hline & Part 8, \#6: No; don't know & Part III, C: table is empty \\
\hline $\begin{array}{l}\text { If yes to family history of cancers, what } \\
\text { was the cancer site/type? }\end{array}$ & $\begin{array}{l}\text { Part } 8, \# 6, \text { table - yes to the "type of } \\
\text { cancer" column; AND/OR } \\
\text { Part } 8, \# 7 \text {, table - yes to the "type of } \\
\text { cancer" column. } \\
\text { Please specify the type(s). }\end{array}$ & $\begin{array}{l}\text { Part III, C: table, column "type (site) of } \\
\text { cancer". Please specify the cancer type(s). }\end{array}$ \\
\hline $\begin{array}{l}\text { If yes to family history of cancers, what } \\
\text { blood relative(s) got it? }\end{array}$ & $\begin{array}{l}\text { Part } 8, \# 6 \text {, table - column "please indicate } \\
\text { who has had this type of cancer"; } \\
\text { AND/OR } \\
\text { Part } 8, \# 7 \text {, table - column "please indicate } \\
\text { who has had this type of cancer" } \\
\text { Please specify the relative(s). } \\
\end{array}$ & $\begin{array}{l}\text { Part III, C: table, column containing the } \\
\text { relatives (mother, father, sister, brother, } \\
\text { grandmother, grandfather). } \\
\text { Please specify the relative(s). }\end{array}$ \\
\hline $\begin{array}{c}\text { What of these conditions do you have? } \\
\text { - Depression } \\
\text { - Heart disease } \\
\text { - } \quad \text { High blood pressure } \\
\text { - High cholesterol } \\
\text { - Thyroid issues } \\
\text { - Diabetes } \\
\text { None of the above }\end{array}$ & $\begin{array}{l}\text { Part 3, \# 3: "yes" marked for one or more } \\
\text { of the following: antidepressants, } \\
\text { medication for heart condition, cholesterol } \\
\text { lowering medication, thyroid medication, } \\
\text { treatment of adult onset diabetes. Please } \\
\text { document which of the above. } \\
\text { Part 3, \# 3: "yes" marked for one or more }\end{array}$ & $\begin{array}{l}\text { Part II, table: column "yes" checked for } \\
\text { one or more of the following: diabetes, } \\
\text { heart disease, thyroid problems, high } \\
\text { blood pressure, depression. Please } \\
\text { document which of the above. } \\
\text { Part II, table: column "yes" checked for }\end{array}$ \\
\hline
\end{tabular}




\begin{tabular}{|c|c|c|}
\hline & $\begin{array}{l}\text { of the following: osteoporosis prevention; } \\
\text { chemoprevention treatment; none of the } \\
\text { above }\end{array}$ & $\begin{array}{l}\text { chronic bronchitis, asthma, asbestosis, } \\
\text { epilepsy, stroke, osteoarthritis, rheumatoid } \\
\text { arthritis; AND/OR the column "no" } \\
\text { checked for everything (else). }\end{array}$ \\
\hline $\begin{array}{l}\text { Were you born in the US? } \\
-\quad \text { Yes } \\
\text { No }\end{array}$ & $\begin{array}{l}\text { Part 1, \#3: the box "United States" is } \\
\text { checked } \\
\text { Part 1, \#3: the box "other" is checked }\end{array}$ & $\begin{array}{l}\text { Part I, F: yes } \\
\text { Part I, F: no }\end{array}$ \\
\hline $\begin{array}{l}\text { If No to "Were you born in the US", } \\
\text { specify the country. }\end{array}$ & $\begin{array}{l}\text { Part 1, \#3: the box "other" is checked. } \\
\text { Please list the specified country. }\end{array}$ & $\begin{array}{l}\text { Part I, F: a. "If no, in what country were } \\
\text { you born?" Please list the country. }\end{array}$ \\
\hline $\begin{array}{l}\text { If No to "Were you born in the US", how } \\
\text { many years have you lived in the US? }\end{array}$ & $\begin{array}{l}\text { Part } 1 \text {, \#3: "In you were born in another } \\
\text { country, how many years have you lived in } \\
\text { the United States?" Please list the number. }\end{array}$ & $\begin{array}{l}\text { Part I, F: b. "In what year did you come to } \\
\text { live in the United States?" } \\
\text { Please list the following: } 2010 \text { - [the \# in } \\
\text { the Part I, F: b.]. }\end{array}$ \\
\hline $\begin{array}{l}\text { Occupation } \\
\text { - Refuse to answer }\end{array}$ & $\begin{array}{l}\text { Part } 1, \# 7 \text {; what is your occupation, } \\
\text { current or former? Please list the } \\
\text { occupation provided. } \\
\text { Part } 1, \# 7 \text {; "refuse to answer" box is } \\
\text { checked }\end{array}$ & $\begin{array}{l}\text { Part VIII, A: "what occupation or job have } \\
\text { you worked at the longest?" Please list the } \\
\text { occupation provided. } \\
\text { Not an option }\end{array}$ \\
\hline Height & Part 1, \#8.1.: "how tall are you". & Part IV, C: "how tall are you" \\
\hline Weight at diagnosis & $\begin{array}{l}\text { Part } 1, \# 8.2 .: \text { "how much do you currently } \\
\text { weigh" }\end{array}$ & Part IV, B: "your current weight" \\
\hline BMI & \multicolumn{2}{|c|}{ BMI $=(\text { weight, pounds })^{*} 703 /$ height $^{\text {inches }}{ }^{2}$} \\
\hline $\begin{array}{l}\text { Physical activity during the last year, hrs } \\
\text { per week: } \\
\text { - Vigorous } \\
\text { - Moderate } \\
\text { - Walking } \\
\text { No physical activity }\end{array}$ & $\begin{array}{l}\text { Part 9, \#1 [days per week] * Part 9, \#2 } \\
\text { [hour's and minutes per day] } \\
\text { Part 9, \#3 [days per week] * Part 9, \#4 } \\
\text { [hours and minutes per day] } \\
\text { Part 9, \#5 [days per week] * Part 9, \#6 } \\
\text { [hours and minutes per day] } \\
\text { Part 9, \#1-6, options "no activities" and/or } \\
\text { "don't know/not sure" checked. }\end{array}$ & $\begin{array}{l}\text { Part IV, H: table, rows jogging or running, } \\
\text { swimming, bicycling, aerobics, column } \\
\text { "hours per week" } \\
\text { Part IV, H: table, rows racket sports, team } \\
\text { sports, dancing, column "hours per week" } \\
\text { Part IV, H: table, row walking, column } \\
\text { "hours per week" } \\
\text { Part IV, H: table - no activities checked }\end{array}$ \\
\hline $\begin{array}{l}\text { NSADs on a regular basis } \\
\text { - Aspirin } \\
\text { - Ibuprofen } \\
\text { - No Aspirin } \\
\text { - No Ibuprofen }\end{array}$ & $\begin{array}{l}\text { Part 3, \#1: } 1 \text { per week; } 2-5 \text { per week; } 6 \text { or } \\
\text { more per week; } 1-3 \text { per month are checked } \\
\text { Part 3, } \# 2: 1 \text { per week; } 2-5 \text { per week; } 6 \text { or } \\
\text { more per week; } 1-3 \text { per month are checked } \\
\text { Part 3, \#1: never is checked } \\
\text { Part 3, \#2: never is checked }\end{array}$ & $\begin{array}{l}\text { Part V, B: table, "Yes" by any of the } \\
\text { Aspirin products is checked } \\
\text { Part V, B: table, "Yes" by any of the } \\
\text { Ibuprofen products is checked } \\
\text { Part V, B: table, "No" by all of the Aspirin } \\
\text { products is checked } \\
\text { Part V, B: table, "No" by all of the } \\
\text { Ibuprofen products is checked }\end{array}$ \\
\hline $\begin{array}{l}\text { Have you ever smoked (chewed, snuffed } \\
\text { etc) tobacco products? } \\
\text { - Yes } \\
-\quad \text { No } \\
\end{array}$ & $\begin{array}{l}\text { Part 5, \#1(b): Yes } \\
\text { Part 5, \#1(b): No }\end{array}$ & $\begin{array}{l}\text { Part VI, A: Yes } \\
\text { Part VI, A: No }\end{array}$ \\
\hline $\begin{array}{l}\text { If yes, are you smolking (chewing, } \\
\text { snuffing etc) tobacco products now? } \\
\text { Yes }\end{array}$ & $\begin{array}{l}\text { Part 5, \#1(a): Yes } \\
\text { Part 5, \#1(a): No }\end{array}$ & $\begin{array}{l}\text { Part VI, A(1): table, raw "do you still } \\
\text { smoke (chew etc)?" - Yes to any or all } \\
\text { tobacco products } \\
\text { Part VI, A(1): table, raw "do you still } \\
\text { smoke (chew etc)?" - No to all tobacco } \\
\text { products }\end{array}$ \\
\hline $\begin{array}{l}\text { How old were you when you started } \\
\text { sinolking (chewing, snuffing etc) tobacco } \\
\text { products? }\end{array}$ & Part 5, \#1(c): note the age & $\begin{array}{l}\text { Part VI, A(1): table, raw "low old were } \\
\text { you when you started smoking (chewing) } \\
\text { regularly?" - note the age(s) for any or all } \\
\text { tobacco products }\end{array}$ \\
\hline $\begin{array}{l}\text { On average, how many cigarettes (cigars } \\
\text { etc) did you smoke (chew etc) per day? }\end{array}$ & Part $5, \# 1(\mathrm{e}):$ note the number & $\begin{array}{l}\text { Part VI, } A(1) \text { : table, raw "on average, how } \\
\text { many cigarettes did/do you smoke per }\end{array}$ \\
\hline
\end{tabular}




\begin{tabular}{|c|c|c|}
\hline & & $\begin{array}{l}\text { day?" - note the number for any or all } \\
\text { tobacco products }\end{array}$ \\
\hline Total years smoked in the lifetime & Part 5, \#1(d): note the number & $\begin{array}{l}\text { Part VI, A(1): table, raw "total years you } \\
\text { smoked" - note the number for any or all } \\
\text { tobacco products }\end{array}$ \\
\hline $\begin{array}{l}\text { Current alcohol consumption (within the } \\
\text { last year) } \\
\begin{array}{l}- \text { Yes } \\
-\quad \text { No }\end{array}\end{array}$ & $\begin{array}{l}\text { Part } 6, \# 1 \text { : there is a \# of days indicated } \\
\text { Part } 6 \text {, \#1: "no drinks in the past year" } \\
\text { option is checked }\end{array}$ & $\begin{array}{l}\text { Part VII, C: YES is checked } \\
\text { Part VII, C: NO is checked }\end{array}$ \\
\hline & & \\
\hline & & \\
\hline & & \\
\hline & & \\
\hline & & \\
\hline & & \\
\hline & & \\
\hline & & \\
\hline & & \\
\hline & & \\
\hline & & \\
\hline & & \\
\hline & & \\
\hline & & \\
\hline & & \\
\hline & & \\
\hline & & \\
\hline & & \\
\hline & & \\
\hline & & \\
\hline & & \\
\hline & & \\
\hline & & \\
\hline & & \\
\hline & & \\
\hline & & \\
\hline & & \\
\hline & & \\
\hline & & \\
\hline & & \\
\hline & & \\
\hline & & \\
\hline & & \\
\hline & & \\
\hline & & \\
\hline & & \\
\hline & & \\
\hline & & \\
\hline & & \\
\hline & & \\
\hline
\end{tabular}




\section{App. 16}

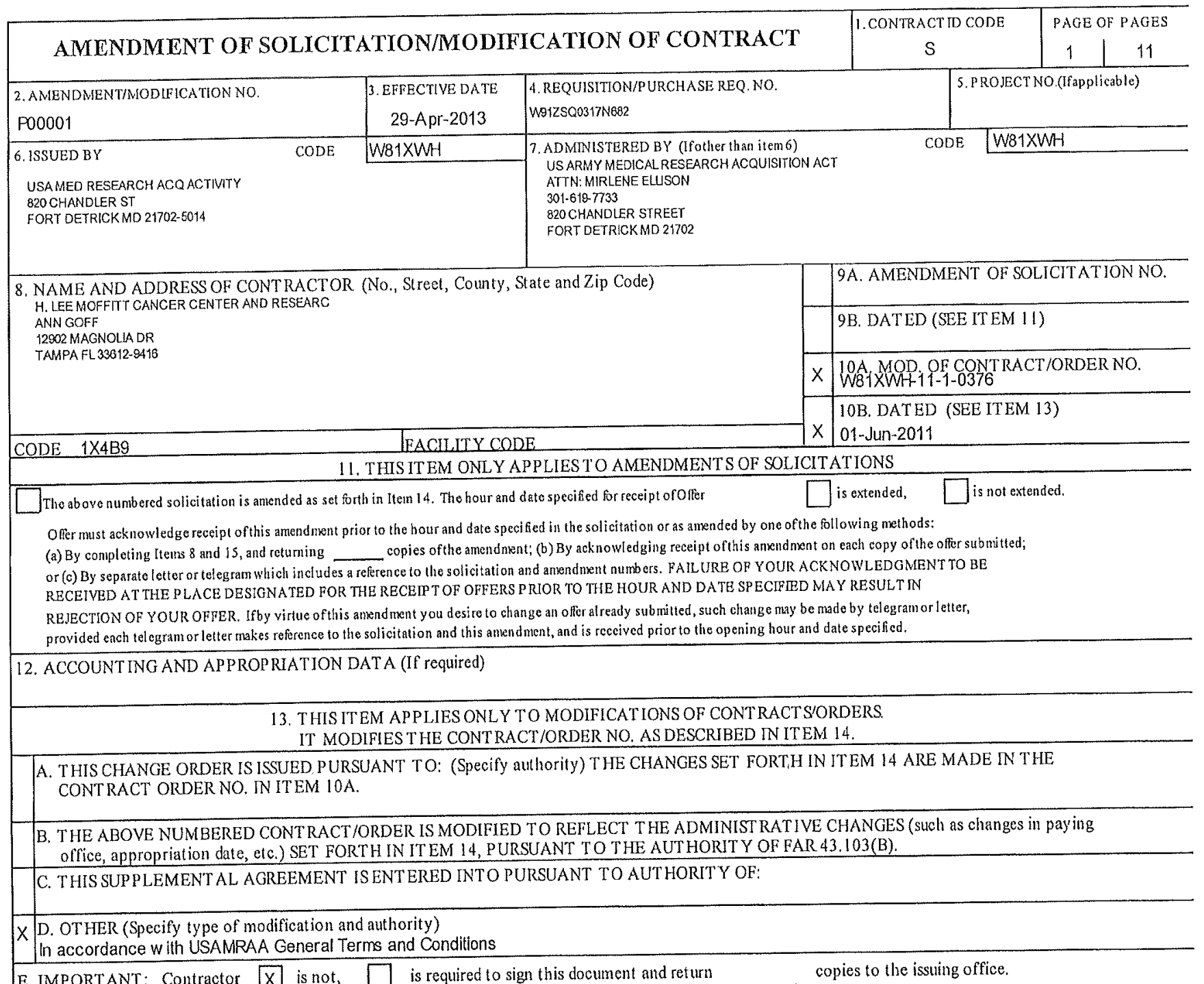

E. IMPORTANT: Contractor $[X]$ is not, $\square$ is required to sign this document and return _ copies to the issuing office.

14. DESCRIPTION OF AMENDMENT/MODIFICATION (Organized by UCF section headings, including solicitation/contract subject matter

where feasible.)

Modification Control Number: mellison 133532

The purpose of this modification is to:

1. Extend the period of performance end date from 30 June 2013 to 30 June 2014 (Research Ends 31 May 2014 ) at no cost to the

government in accordance $w$ th the reciplent's request dated 12 April 2013, and GOR approval dated 23 April 2013.

2. Incorporate a revised SOW dated 12 April 2013, and approved by the GOR on 23 April 2013.

3. An annual technical report $w$ ill be due on 30 June 2013.

4. The final technical report $w$ ill be due 30 June 2014.

All other terms and conditions remain unchanged

Except as provided herein, all terms and conditions of the document referenced in Item $9 \mathrm{~A}$ or $10 \mathrm{~A}$, ns herelofore clanged, remains unchanged and in full force and effect.

\begin{tabular}{l|l}
\hline 15A NAME AND TIT LE OF SIGNER (T ype or print) & 16A. NAME AND TITLE OF CONTRACTING OFFICER (Type or print)
\end{tabular}

JANET PKUHNS/CONTRACTING OFFICER

TEL: 301-619-2827 EMAlL: janet.p.hihns,clv@mail.mil

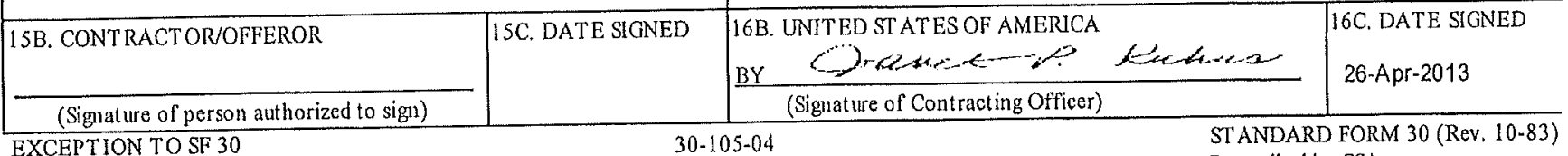

APPROVED BY OIRM 11-84

Prescribed by GSA

FAR (48 CFR) 53.243 
W81XWH-11-1-0376

$\mathrm{P} 00001$

Page 2 of 11

SECTION SF 30 BLOCK 14 CONTINUATION PAGE

\section{SUMNIARY OF CHANGES}

SECTION 00010 - SOLICITATION CONTRACT FORM

CLIN 0001

The CLIN extended description has changed from Prostate Cance 1 June 2011 - 30 June 2013 (Research Ends 31 Training Award - Postdoctoral - Ph.D or M.DPeriod of Performance: 1 June 2011 - 30 Jutdoctoral - Ph.D or

May 2013) to Prostate Cancer Research Program - 2014 (Research Ends 31 May 2014).

DELIVERIES AND PERFORMANCE

The following Delivery Schedule item for CLIN 0001 has been changed from:

$\begin{array}{llll}\text { DELIVERY DATE } & \text { QUANTITY } & \text { SHIP TO ADDRESS } & \text { UIC } \\ \text { POP 01-JUN-2011 TO } & \text { N/A } & \text { USA MED RESEARCH MAT CMD } & \text { W91ZSQ } \\ \text { 30-JUN-2013 } & & \text { 1077 PATCHEL STREET } \\ & \text { BLDG 1077 } & \\ & \text { FORT DETRICK MD 21702 } \\ & \text { FOB: Destination }\end{array}$

To:

$\begin{array}{llll}\text { DELIVERY DATE } & \text { QUANTITY } & \text { SHIP TO ADDRESS } & \text { UIC } \\ & & \text { W91ZSQ } \\ \text { POP 01-JUN-2011 TO } & \text { N/A } & \text { USA MED RESEARCH MAT CMD } & \text { 1077 PATCHEL STREET } \\ 30-J U N-2014 & & \text { BLDG 1077 } \\ & & \text { FORT DETRICK MD 21702 } \\ & \text { FOB: Destination }\end{array}$

SECTION 00800 - SPECIAL CONTRACT REQUIREMENTS

The following have been modified:

A. This award is made under the authority of 31 U.S.C. 6304 and 10 U.S.C. 2358 . The recipient's revised statement of work dated 12 April 2013, and the revised budget dated 11 May 2011 for this proposal submitted in response to 2010 (FY10) Department of Defense Prostate Cancer Research Program - Health Disparity Training (F. Ph.D or M.D Announcement, which closed May 26, 2010, are incorporated herein by Award - Postdoctoral - Ph,D or M.D Announcement, which closed Mative to this award is CFDA 12.420.
reference. The Catalog of Federal Domestic Assistance Number relative 
B. ACCEPTANCE OF AWARD: The recipient is not required to counter'sign this assistance award. In case of disagreement, the recipient shall notify the Grants Officel and not assess the award any costs until such disagreement(s) is resolved.

C. USAMRAA GENERAL TERMIS AND CONDITIONS: This assistance agreement is subject to the USAMRAA General Terms and Conditions and to any special considerations as contained in the below mentioned Section titled "Special Terms and Conditions". These USAMRAA General Terms and Conditions are incorporated by reference with the same force and effect as if they were given in full text. The full text of the USAMRAA General Terms and Conditions may be accessed electronically at http://www.usamraa.army.mil.

\section{SPECIAL TERMS AND CONDITIONS}

\section{TRAINING TECHNICAL REPORTING REQUIREMENTS (DEC 2008) (USAMRAA)}

\section{ANNUAL SUMMARY}

A 2-5 page annual summary in electronic format (PDF or Word file only), presenting a description of the training and research accomplishments to date, shall be submitted within 30 calendar days after the anniversary date of the award to https:/ers.amedd.army.mil.

\section{All reports shall have the following elements in this order:}

FRONT COVER: Sample front cover provided at htips:/mmcamedd.army.mil/rpindex.asp. The Accession Document (AD) Number should remain blank.

STANDARD FORM 298: Sample SF 298 provided at hllps:/mrmc.amedd.army.mil/ripindex.asp. The abstract in Block 13 must state the purpose, scope, major findings and be an up-to-date report of the progress in terms of results and significance. Subject terms are keywords that may have previously assigned to the proposal abstract or are keywords that may be significant to the training grant. The number of pages shall include all pages that have printed data (including the front cover, SF 298, table of contents, and all appendices). Please count pages carefully to ensure legibility and that there are no missing pages as this delays processing of reports. Page numbers should be typed: please do not hand number pages.

TABLE OF CONTENTS: Sample table of contents provided at hitps:/mrmc.amedd.army mil/mpindex.asp.

INTRODUCTION: Narrative that briefly (one paragraph) describes the subject, purpose and scope of the training grant.

BODY: The content of the report should address the training and research accomplishments associated with the tasks outlined in the approved Statement of Work. Any technical or unexpected difficulties encountered and/or any deviations from the original Statement of Work should be addressed. However, any changes to the original Statement of Work must be approved by the Army Grants Officer's Representative. This approval must be obtained prior to initiating any change to the original Statement of Work. Journal articles can be substituted for detailed descriptions of specific aspects of the research/training, but the original articles must be attached to the report as an appendix and appropriately referenced in the text.

KEY RESEARCH ACCOMPLISHMENTS: Bulleted list of key research accomplishments emanating from this training grant.

REPORTABLE OUTCOMES: Provide a list of reportable outcomes that have resulted from this training grant to include: 
W81XWH-11-1-0376

$\mathrm{P} 00001$

Page 4 of 11

manuscripts, abstracts, presentations; patents and licenses applied for and/or issued; degrees obtained that are supported by this award; development of cell lines, tissue or serum repositories; infomatics such as databases and animal models, etc,; funding applied for based on work supported by this award; employment or research opportunities applied for and/or' received based on experience/training supported by this award.

CONCLUSION: Summarize the results to include the importance and/or implications of the completed training grant and when necessary, recommend changes on future work to better address the problem. A "so what section" which evaluates the knowledge as a scientific or medical product shall also be included in the conclusion of the report.

REFERENCES: List all references pertinent to the report using a standard journal format (i.e. format used in Science, Military Medicine, etc.).

APPENDICES: Attach all appendices that contain information that supplements, clarifies or supports the text. Examples include original copies of journal articles, reprints of manuscripts and abstracts, a curriculum vitae, patent applications, study questionnaires, and surveys, etc.

Pages shall be consecutively numbered throughout the report. DO NOT RENUMBER PAGES IN THE APPENDICES,

Mark all pages of the report which contain proprietary or unpublished data that should be protected by the U.S. Government. Reports not properly marked for limitation will be distributed as Approved for Public Release. It is the responsibility of the Principal Investigator' to advise the U.S. Almy Medical Research and Materiel Command when restricted limitation assigned to a document can be downgraded to Approved for Public Release. DO NOT USE THE WORD "CONFIDENTIAL" WHEN MARKING DOCUMENTS.

\section{Manuscripts/Reprints, Abstrncts}

A copy of manuscripts or subsequent reprints resulting from the research shall be submitted to the USAMRMC. An extended abstract suitable for publication in the proceedings of the applicable research program is required in relation to a DOD meeting planned during the term of this award. The extended abstract shall (1) identify the accomplishments since award and (2) follow instructions to be prepared by the USAMRMC and promulgated at a later date. The extended abstract style will be dependent on the discipline.

\section{ADYANCE PAYMENTS AND FULL FUNDING (NOV 2000) (USAMRAA)}

a. Payments. Advance payments will be made to the recipient, Questions relative to payment issues involving Defense Finance and Accounting Service shall be directed to USAMRAA.GREEN.(A)AMEDD.ARMY.MIL.

b. Electronic Funds Transfer. All advance payments to the recipient will be made by electronic funds transfer (EFT). The recipient shall contact the Defense Finance and Accounting System (DFAS) named on the face page of this award to make arrangements for EFT. Failure to do so may result in nonpayment.

c. If the recipient fails to perform, the Grants Officer shall notify DFAS in writing to withhold payments.

d. Advance Payment Sohedule 
W81XWH-11-1-0376

$\mathrm{P} 00001$

Page 5 of 11

Year One $\$ 56.530 .00$

$\begin{array}{ll}\text { Amount } & \text { On or About } \\ \$ 14,132.50 & \text { Upon execution of this award } \\ \$ 14,132.50 & \text { 1 September 2011 } \\ \$ 14,132.50 & \text { 1 December 2011 } \\ \$ 14,132.50 & \text { 1 March 2012 }\end{array}$

Year Two $\$ \underline{61,222,00}$

$\begin{array}{ll}\text { Amount } & \text { On ol About } \\ \$ 15,305.50 & \text { 1 June 2012 } \\ \$ 15,305.50 & \text { 1 September 2012 } \\ \$ 15,305.50 & \text { 1 December 2012 } \\ \$ 15,305.50 & \text { 1 March 2013 }\end{array}$

e. Financial Reporting Requirements:

Federal Financial Report (SF 42.5): Quarterly and Final Reports (For reporting individual assistance agreements)

Reporting period end dates fall on the end of the calendar quarter for quarterly reports $(3 / 31,6 / 30,9 / 30,12 / 31)$ and the end date of the assistance agreement period of performance for the final report. Reports are due 30 days after the reporting period end date for quarterly reports and 90 days after the end date of the assistance agreement for the final report.

The SF425 and instructions for completion can be obtained from https://usamraa.army.mil. All SF425's shall be submitted electronically to USAMRAASF425@amedd.army.mil. The award number assigned by USAMRAA, XX shall be included in the subject line of the electronic submission. NOTE: The SF425 is a single form that consolidates and replaces the Federal Cash Transaction Report (SF272.SF272A) and the Financial Status Report (SF269/SF269A)

f. Interest Bearing Account. Unless exempted by applicable Treasury-State agreements in accordance with the Managent Improvement Act (CMIA) (31 U.S.C. 3335), the recipient shall deposit all advance payments in an inter'est bearing account. Interest over the amount of $\$ 250$ per year shall be remitted annually to the Department Services, Payment Management System, P.O. Box 6021, Rockville, MD 20852. A copy of the amount of interest remitted shall be sent to the U.S. Army Medical Research

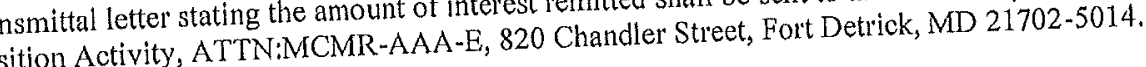

OF USE OF LABORATORY ANIMALS (JAN 2007) (USAMRAA)

\section{** PROHIBITION - READ FURTHER FOR DETAILS **}

Notwithstanding any other provisions contained in this award or incorporated by reference herein, the contractor is expressly forbidden to use or subcontract for the use of laboratory animals in any manner whatsoever without the express written approval of the US Army Medical Research and Materiel Command, Animal Care and Use Office (ACURO). The contractor will receive written approval to begin research under the applicable protocol proposed for this award from the US Army Medical Research and Materiel Com and Acquisition Activity for the official file. of this approval will be provided to the US Army Medic result in the termination of the award. Non-compliance with any provision of this clause may result in 


\section{PROHIBITION OF HUMAN RESEARCH (JAN 2007) (USAMRAA)}

\section{** PROHIBITION - READ FURTHER FOR DETAILS **}

Research under this award involving the use of human subjects, to include the use of human anatomical substances and/or human data, may not begin until the U.S. Army Medical Research and Materiel Command's Office of and/or human data, may not begin to begin Research Protections, for the use of human subjects under the applicable protocol proposed for this award will be issued from the US Army Medical Research and Materiel Command, HRPO, under separate letter to the contractor. A copy of this approval will be provided to the US Army Medical Research Acquisition Activity for the official file. Non-compliance with any provision of this clause may result in withholding of funds and or the termination of the award.

\section{PROHIBITION OF USE OF HUMAN CADAVERS (JAN 2007) (USAMRAA)}

\section{** PROHIBITION - READ FURTHER FOR DETAILS**}

Research under this award using human cadavers may not begin until the U.S. Army Medical Research and Materie Command's Office of Research Protections, Human Research Protections Office (HRPO) approves the protocol. Written approval to begin research or' subcontract for the use of human cadavers under the applicable protocol proposed for this award will be issued from the US Army Medical Research and Materiel Command, HRPO, under separate letter to the contractor. A copy of this approval will be provided to the US Army Medical Research Acquisition Activity for the official file. Non-compliance with any provision of this clause may result in withholding of funds and or the termination of the award.

\section{MAXIMUM OBLIGATION (SEP 2006) (USAMRAA)}

The maximum obligation for support of the project will not exceed the amount specified in the award, as amended. USAMRAA does not amend assistance agreements to provide additional funds for such purposes as reimbursement indirect costs resulting from the establishment of final negotiated rates or for increases in salaries, fringe benefits and other costs.

\section{SUPPORTING INFORMATION (APR 2008) (USAMRAA)}

Information such as subawards, consultant agreements, vendor quotes, and personnel work agreements may be required in order to support proposed costs or to determine the employment status of personnel under the assistance agreement. The Government's receipt of this information does not constitute approval or acceptance of any term or condition included therein. The terms and conditions of the assistance agreement take precedence over any term or condition included in supporting information. 


\section{CFR Part 170}

Requirements for Federal Funding Accountability and Transparency Act Implementation

$$
\text { Appendix A to Part 170-Award Term }
$$

\section{Reporting Subawards and Executive Compensation}

A. Reporting of first-tier subawards.

1. Applicability. Unless you are exempt as provided in paragraph D. of this award term, you must report each action that obligates $\$ 25,000$ or more in Federal funds that does not include Recovely funds (as defined in section 1512(a)(2) of the American Recovery and Reinvestment Act of 2009, Pub. L. 111-5) for a subaward to an entity (see definitions in paragraph e. of this award term).

\section{Where and when to report.}

i. You must report each obligating action described in paragraph a.1. of this award term to http://www, fsrs.gov.

ii. For subaward information, report no later than the end of the month following the month in which the obligation was made. (For example, if the obligation was made on November 7,2010 , the obligation must be reported by no later than December 31,2010 .)

3. What to report. You must report the information about each obligating action that the submission instructions posted at http://www, fsrs.gov specify. must report the information about each obligating action that the submission instructions posted at http://www. fsis.gov specify,

B. Reporting Total Compensation of Recipient Executives.

1. Applicability and what to report. You must report total compensation for each of your five most highly compensated executives for the preceding completed fiscal year, if--

i. the total Federal funding authorized to date under this award is $\$ 25,000$ or more;

ii. in the preceding fiscal year, you received--

(A) 80 percent or more of your annual gross revenues from Federal procurement contracts (and subcontracts) and Federal financial assistance subject to the Transparency Act, as defined at 2 CFR 170.320 (and subawards); and

(B) $\$ 25,000,000$ or more in annual gross revenues from Federal procurement contracts (and subcontracts) and Federal financial assistance subject to the Transparency Act, as defined at 2 CFR 170.320 (and subawards); and

iii. The public does not have access to information about the compensation of the executives through periodic reports filed under section 13(a) or 15(d) of the Securities Exchange Act of 1934 (15 U.S.C. $78 \mathrm{~m}(\mathrm{a}), 78 \mathrm{o}$ (d)) or section 6104 of the Internal Revenue Code of 1986. (To determine if the public has access to the compensation information, see the U.S. Security and Exchange Commission total compensation filings at http://www.sec.gov/answers/execomp.htm.)

2. Where and when to report. You must report executive total compensation described in paragraph $b .1$. of this award term:

annually thereafter.

i. As part of your registration profile at http://www.ccr.gov.

ii. By the end of the month following the month in which this award is made, and

\section{Reporting of Total Compensation of Subrecipient Executives.}

1. Applicability and what to report. Unless you are exempt as provided in paragraph d. of this award term, for each first-tier subrecipient under this award, you shall report the names and total compensation of each of the subrecipient's five most highly compensated executives for the subrecipient's preceding completed fiscal year, if-- 
i. $\quad$ in the subrecipient's preceding fiscal year, the subrecipient received--

(A) 80 percent or more of its annual gross revenues from Federal procurement contracts (and subcontracts) and Federal financial assistance subject to the Transparency Act, as defined at 2 CFR 170.320 (and subawards); and

(B) $\$ 25,000,000$ or mol'e in annual gross revenues fiom Federal procurement contracts (and subcontracts), and Federal financial assistance subject to the Transparency Act (and subawards); and

ii. The public does not have access to information about the compensation of the executives through periodic reports filed under section 13(a) or 15(d) of the Securities Exchange Act of 1934 (15 U.S.C. $78 \mathrm{~m}(\mathrm{a}), 78 \mathrm{o}$ (d)) or section 6104 of the Internal Revenue Code of 1986. (To determine if the public has access to the compensation information, see the U.S. Security and Exchange Commission total compensation filings at http://www.sec.gov/answers/execomp.htm.)

2. Where and when to report. You must report subrecipient executive total compensation described in paragraph c.1, of this award term:

i. To the recipient.

ii. By the end of the month following the month during which you make the subaward. For example, if a subaward is obligated on any date during the month of October of a given year (i.e., between October 1 and 31), you must report any required compensation information of the subrecipient by November 30 of that year.

D. Exemptions. If, in the previous tax year, you had gross income, from all sources, under $\$ 300,000$, you are exempt from the requirements to report:

subrecipient.

i. Subawards, and

ii. The total compensation of the five most highly compensated executives of any

E. Definitions, For purposes of this award term:

1. Entity means all of the following, as defined in 2 CFR part 25:

tribe;

i. A Governmental organization, which is a State, local government, or Indian

ii. A foreign public entity;

iii. A domestic or foreign nonprofit organization;

iv. A domestic or foreign for-profit organization;

v. A Federal agency, but only as a subrecipient under an award or subaward to a

non-Federal entity,

2. Executive means officers, managing partner's, or any other employees in management

positions.

\section{Subaward:}

i. $\quad$ This term means a legal instrument to provide support for the performance of any portion of the substantive project or program for which you received this award and that you as the recipient award to an eligible subrecipient.

ii. $\quad$ The term does not include your procurement of property and services needed to carty out the project or program (for further explanation, see Sec. -.... .210 of the attachment to OMB Circular A133, "Audits of States, Local Governments, and Non-Profit Organizations"),

iii. A subaward may be provided through any legal agreement, including an agreement that you or a subrecipient considers a contract. 
4. Subrecipient means an entity that:

i. Receives a subaward from you (the recipient) under this award; and

ii. Is accountable to you for the use of the Federal funds provided by the subaward.

5. Total compensation means the cash and noncash dollar value earned by the executive during the recipient's or subrecipient's preceding fiscal year and includes the following (for more information see 17 CFR 229.402(c)(2)):

i. Salary and bonus.

ii. Awards of stock, stock options, and stock appreciation rights. Use the dollar amount recognized for financial statement reporting purposes with respect to the fiscal year in accordance with the Statement of Financial Accounting Standards No. 123 (Revised 2004) (FAS 123R), Shared Based Payments.

iii. Earnings for services under non-equity incentive plans. This does not include group life, health, hospitalization or medical reimbursement plans that do not discriminate in favor of executives, and are available generally to all salaried employees.

and actuarial pension plans.

iv. Change in pension value. This is the change in present value of defined benefit

v. Above-market earnings on deferred compensation which is not tax- qualified.

vi. Other compensation, if the aggregate value of all such other compensation (e.g. severance, termination payments, value of life insurance paid on behalf of the employee, per'quisites or property) for the executive exceeds $\$ 10,000$. 


\section{App. 17}

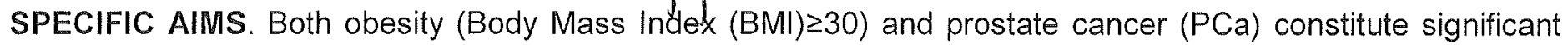
public health problems, for which the disparities between African American men (AAM) and Non-Hispanic European men (EAM) are evident. AAM are 10\% more likely to be obese ${ }^{1}, 60 \%$ more likely to be diagnosed with, and $145 \%$ - to die from ${ }^{2}$, PCa compared to their EAM counterparts. While obesity is an established risk factor for PCa biochemical recurrence and/or post treatment progression ${ }^{3}$, the specific role of obesity in $\mathrm{PCa}$ risk is under investigation. Obesity as a physiological state is characterized by significant alterations in the individual's hormonal profile ${ }^{4}$. Since $\mathrm{PCa}$ is a hormonal disease, it appears biologically plausible that obesity affects PCa risk, possibly through the altered tumor growth enabled by the hormonal imbalances ${ }^{5}$. This effect may be even more pronounced in AAM since their PCa tumors tend to demonstrate more aggressive biological behavior at baseline ${ }^{6-12}$. Epidemiological studies have linked obesity to a slight decrease in the incidence of a low-grade (non-lethal) PCa and an increase in the incidence of an aggressive (lethal) disease ${ }^{13-14}$. A few studies ${ }^{15-16}$ have linked obesity to more aggressive PCa in AAM specifically, suggesting involvement of obesity in PCa disparity. However, to date, the mechanistic biology studies aimed to elucidate the effects of obesity on $P C a$ risk in AAM and EAM are lacking.

Our recent observation comparing AAM and EAM with and without PCa indicates that obese AAM (odds ratio (OR) 1.06; $p=0.022$ ) but not EAM (OR 0.98; $p=0.332$ ) have slightly elevated overall PCa risk ${ }^{17}$. We further observed that AAM homozygous for the minor allele of the single nucleotide polymorphism (SNP) rs7501939 in the HNF1B gene have increased PCa risk (OR 2.14; $p=0.0103$ ) over 2-fold. Interestingly, the excessive risk is not observed in the non-obese AAM (OR 1.09; $p=0.763$ ) or EAM of any BMI ( $>0.05)$. HNF1B encodes a member of a transcription factor superfamily that is expressed in the kidneys, pancreas and prostate. As such, it modulates key cellular processes, such as proliferation. Genetic variation in the HNF1B was previously associated with $\mathrm{PCa}^{18-19}$ and type $\|$ diabetes ${ }^{19}$, however the underlying mechanistic pathway(s) remain elusive. Taken together, these data suggest that obesity may be a PCa risk factor in AAM, and the extent of risk is determined by the individual's genetic variation. The goal of our project is to understand the joint impact of germline genetic variations and obesity on prostate tumor biology and PCa risk in AAM and EAM. We hypothesize that select genetic variation, when combined with the environment of obesity, influences PCa risk by impacting key cellular processes relevant to the tumor biology. We propose the following specific aims to test our hypothesis:

1. To elucidate the effects of obesity on the gene expression profiles in AAM and EAM PCa tumors.

Approach. PCa tumors derived from obese and non-obese AAM and EAM, matched for age and Gleason grade will be profiled for expression of select genes using the NanoString Gene expression assays.

2. To test the functional significance of the selected genes.

Approach. AAM and EAM derived PCa cell lines will be grown with and without the environment of obesity (sera from mice with diet-induced obesity). The genes of interest will be knocked down, and the effects on the growth will be studied.

3. To link obtained data to PCa risk through variation in the germline genome.

Approach. We will genotype the genes of interest using germline DNA from AAM and EAM cases and controls. We will use statistical approaches to determine whether genetic variation correlates with PCa risk.

Significance. Although AAM consistently carry increased PCa burden, the etiology of the disparity is unclear. AAM are also more likely to be obese, compared to their EAM counterparts. Thus, understanding the specific role of obesity in PCa risk is crucial for efficient development of individualized PCa risk estimation in AAM and EAM; selection of the most appropriate treatment modalities; estimating the risk of progression; advancing knowledge of the tumor biology in AAM and EAM; and developing targeted risk reduction interventions and informing the policies on healthy lifestyle and PCa prevention in diverse populations. Innovation. Our work is innovative, comprehensive and contemporary in that we will examine, within a single integrative approach, how obesity alters gene expression in PCa tumors of AAM and EAM; how these alterations affect PCa growth in $A A M$ and EAM; and whether germline genetic variation in those genes affects PCa risk in AAM and EAM. Unlike the non-candidate driven studies (such as GWAS) that cannot, on its own, elucidate the functional significance, we propose functionally relevant genetic variation to be incorporated in the risk prediction. Future directions. Guided by our findings, we plan to launch a clinical preventive study aimed to validate the results in a larger cohort of AAM and EAM, improve the proposed approach, and test the chemopreventive and/or lifestyle interventions targeted towards specific tumor and genetic features in AAM and EAM. In addition, our proposed model can be applied to study gene-environmental interactions in virtually any other malignancy. 


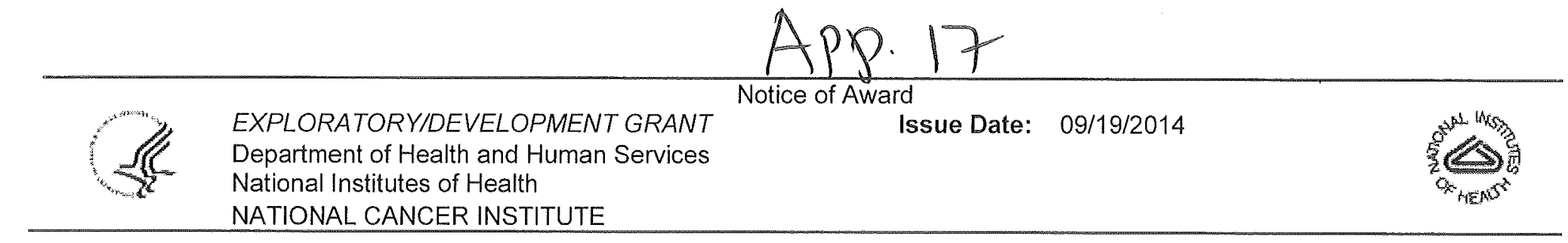

$\begin{array}{ll}\text { Grant Number: } & \text { 1R21CA179659-01A1 } \\ \text { FAIN: } & \text { R21CA179659 }\end{array}$

Principal Investigator(s):

Ganna Chornokur

Project Title: Obesity and prostate cancer risk in Black and White men: a functional approach

O'Connor, Jane

Director, Office of Sponsored Research

12902 Magnolia Drive

Tampa, FL 336129497

Award e-mailed to: awards@moffitt.org

Budget Period: 09/19/2014 - 08/31/2015

Project Period: 09/19/2014 - 08/31/2016

Dear Business Official:

The National Institutes of Health hereby awards a grant in the amount of $\$ 219,893$ (see "Award Calculation" in Section I and "Terms and Conditions" in Section III) to H. LEE MOFFITT CANCER CTR \& RES INST in support of the above referenced project. This award is pursuant to the authority of 42 USC 24142 CFR 52 and is subject to the requirements of this statute and regulation and of other referenced, incorporated or attached terms and conditions.

Acceptance of this award including the "Terms and Conditions" is acknowledged by the grantee when funds are drawn down or otherwise obtained from the grant payment system.

Each publication, press release, or other document about research supported by an NIH award must include an acknowledgment of NIH award support and a disclaimer such as "Research reported in this publication was supported by the National Cancer Institute of the National Institutes of Health under Award Number R21CA179659. The content is solely the responsibility of the authors and does not necessarily represent the official views of the National Institutes of Health." Prior to issuing a press release concerning the outcome of this research, please notify the NIH awarding IC in advance to allow for coordination.

Award recipients must promote objectivity in research by establishing standards that provide a reasonable expectation that the design, conduct and reporting of research funded under $\mathrm{NIH}$ awards will be free from bias resulting from an Investigator's Financial Conflict of Interest (FCOI), in accordance with the 2011 revised regulation at 42 CFR Part 50 Subpart F. The Institution shall submit all FCOI reports to the NIH through the eRA Commons FCOI Module. The regulation does not apply to Phase I Small Business Innovative Research (SBIR) and Small Business Technology Transfer (STTR) awards. Consult the NIH website http://grants.nih.gov/grants/policy/coi/for a link to the regulation and additional important information.

If you have any questions about this award, please contact the individual(s) referenced in Section IV.

Sincerely yours, 


\section{From:}

Sent:

To:

Subject:
Phelan, Catherine M.

Tuesday, July 22, 2014 7:28 AM

Chornokur, Ganna

FW: PLOS ONE Decision: Revise [PONE-D-14-22661] - [EMID:5b1c05b28578e2e9]

Positive result!

From: PLOS ONE [mailto:no-reply@editorialmanager.com]

Sent: Tuesday, July 22, 2014 05:32 AM Eastern Standard Time

To: Phelan, Catherine $M$.

Subject: PLOS ONE Decision: Revise [PONE-D-14-22661] - [EMID:5b1c05b28578e2e9]

PONE-D-14-22661

Common genetic variation in cellular transport genes and epithelial ovarian cancer risk

PLOS ONE

Dear Dr. Phelan,

Thank you for submitting your manuscript for review to PLOS ONE. After careful consideration, we feel that your manuscript will likely be suitable for publication if it is revised to address the points below. Therefore, my decision is "Minor Revision."

We invite you to submit a revised version of the manuscript that addresses the following points: Despite some weaknesses mentioned in the manuscript, the study is interesting and valuable. In your analysis you found that multiple SNPs in a set of genes are associated with ovarian cancer (OC) sub-types creating a mini-signature for each sub-type. It would be interesting to investigate whether these signatures are enriched in publicly available OC gene expression data sets using GSEA analysis. Please include this data if statistically significant enrichment is observed.

We encourage you to submit your revision within forty-five days of the date of this decision.

When your files are ready, please submit your revision by logging on to http://pone.edmgr.com/ and following the Submissions Needing Revision link. Do not submit a revised manuscript as a new submission. Before uploading, you should proofread your manuscript very closely for mistakes and grammatical errors. Should your manuscript be accepted for publication, you may not have another chance to make corrections as we do not offer pre-publication proofs.

If you would like to make changes to your financial disclosure, please include your updated statement in your cover letter.

In addition, when submitting your revision please include the following items:

- A rebuttal letter that responds to each point brought up by the academic editor and reviewer(s). This letter should be uploaded as a 'Response to Reviewers' file. 


$$
\text { App. } 19
$$

\title{
Differential gene expression profiles in prostate tumors of Black and White men
}

\author{
Ganna Chornokur, Hui-Yi Lin, Jong Y Park, Nagi B Kumar and Catherine M Phelan \\ Department of Cancer Epidemiology, Moffitt Cancer Center, Tampa, FL-33612
}

\begin{abstract}
Background. Prostate cancer affects men of African descent or Black men at disproportionately high rates. While the causality of this disparity is poorly understood, research continues to implicate biological tumor differences. Towards this venue, we investigated the gene expression profiles in prostate tumors of Black and White men.

Methods. Prostate tumors were collected from patients treated at the Moffitt Cancer Center or affiliated hospital network. Tumor RNA was extracted using the commercial kits, and gene expression was performed using the Affymetrix U133A human arrays. Descriptive statistics and paired t-tests were performed.

Results. A total of 220 tumors (200 White and 20 Black men) were profiled for expression of $\sim 1200$ genes implicated in carcinogenesis. Of those, a total of 15 genes showed statistically significant $(p<0.05)$ differences in expression. The top hit was PSPHP1 upregulated in Black men ( $F C=4.7 ; p=1.99 * 10-3)$ and associated with Falconi anemia. Other top hits all upregulated in White men included PDXDC2P ( $\left.F C=2.7 ; p=1.99^{*} 10-3\right), A C T N 2(F C=1.8 ; p=1.99 * 10-3)$ and PRN3P1 ( $F C=1.6 ; p=1.99^{*} 10-3$ ). The differentially expressed genes are mainly implicated in the invasion and migration and angiogenesis.

Conclusions. Prostate tumors derived from Black and White men demonstrate differential gene expression profiles. The genes appear to be implicated in the invasion and migration, and angiogenesis. Further research is needed to determine the impact of the observed differences on prostate cancer health disparity.
\end{abstract}


From:

Sent:

To:

Subject:
Kleiber, Meredith <meredith.kleiber@aacr.org>

Thursday, October 02, 2014 9:19 AM

Chornokur, Ganna

AACR Cancer Health Disparities Conference: Scholar-in-Training Award Notification

Dear Dr. Chornokur,

I am pleased to inform you that you have been selected to receive an AACR Scholar-in-Training Award supported by the Center to Reduce Cancer Health Disparities (CRCHD) of the National Cancer Institute in the amount of USD \$1,800 to support your attendance at the Seventh AACR Conference: The Science of Cancer Health Disparities in Ethnic Minorities and the Medically Underserved, being held November 9-12, 2014 in San Antonio, Texas. Congratulations on being selected for this award.

The funds are to be used to defray your travel, subsistence, and registration expenses to attend this conference. If you have not registered or made your travel and housing arrangements, we urge you to do so as soon as possible. Please note that your institution may not deduct any overhead expenses from the funds. These awards are competitive and funding is limited; therefore, by accepting this award, you agree to attend the entire conference and will not depart before it has completed. In addition, no further funds are available beyond those offered to you through the award.

Checks will be distributed on site at the AACR registration desk at the Grand Hyatt San Antonio. You must show photo identification, such as a passport or driver's license, to claim your check. If you are from outside of the U.S. or Canada, and prefer to have the funds bank-wired to you after the conference, please have the following information available for the on-site AACR staff: 1. Your bank account number, including the name on the account and address; 2 . Bank name, address, and Bank SWIFT Code ID. Bank-wire fees will apply and will be deducted from the amount of the award. If you would like to request a bank-wire transfer, please contact Meredith Kleiber at meredith.kleiber@aacr.org. Please note that we cannot provide cash on site for the awards. If you are unable to attend this conference, your award must be forfeited.

To confirm your acceptance of this award, you must download and return the Award Certification Form no later than Tuesday, October 7. Please download the form by clicking HERE, or by following the link at the end of this email. The form certifies your eligibility for the award and your intention to attend the entire conference. The Award Certification Form must be signed by the head of your department or, if you are a predoctoral student, by the registrar of your institution.

Please note that all awardees must download and submit the Travel Expense Reporting Form to the AACR, along with all original receipts totaling the amount of the award or greater, by December 3. Please click HERE to download the form, or follow the link at the end of this email. If AACR does not receive the Expense Reporting Form with all original receipts, the travel award will be treated as taxable income per IRS guidelines and we will send you a U.S. 1099-MISC income tax statement for the amount of the award in January 2015. It is the responsibility of the Awardee to determine the requirements to report this income when filing Year 2014 tax returns.

Awardees who are who are subject to U.S. income tax filing in 2014 must complete, sign, and return a W-9 form by October 7 so that we may issue payment and have your social security number on file for 1099 miscellaneous income reporting purposes, if applicable. Please download the W-9 Form (U.S. Residents only) by clicking HERE, or by following the link at the end of this email. Return the form via fax (267-765-1065) or email (meredith.kleiber@aacr.org) to Meredith Kleiber by Tuesday, October 7. 